\title{
Wechselwirkung zwischen Schwarzerlen und Erlenblattkäfer: Signaltransfer zwischen Bäumen und induzierte Resistenz
}

\author{
Dissertation \\ zur Erlangung des Doktorgrades (Dr. rer. nat.) \\ der Mathematisch-Naturwissenschaftlichen Fakultäten \\ der Georg-August-Universität zu Göttingen
}

vorgelegt von

Dipl. Biol. Sabine Thießen

aus

Wilhelmshaven

Göttingen 2001 
D7

Referent: Prof. Dr. Matthias Schaefer

Korreferent: Prof. Dr. Teja Tscharntke

Tag der mündlichen Prüfung: 01.11.2001 


\section{Inhaltsverzeichnis}

Abkürzungen

1 Einleitung .1

2 Grundlagen . .6

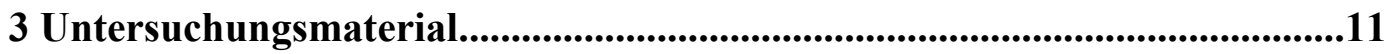

3.1 Die Schwarzerle (Alnus glutinosa (L.) (Gaertn.)) ........................................11

3.2 Der Blaue Erlenblattkäfer (Agelastica alni (L.)) ..........................................13

4 Material und Methoden ..............................................................................16

4.1 Anzucht von Alnus glutinosa-Pflanzen für Laborversuche.........................16

4.2 Haltung und Zucht von Agelastica alni im Labor.......................................17

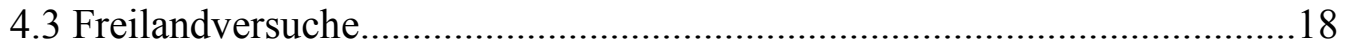

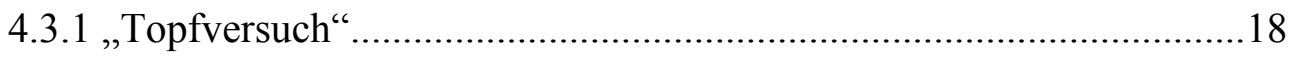

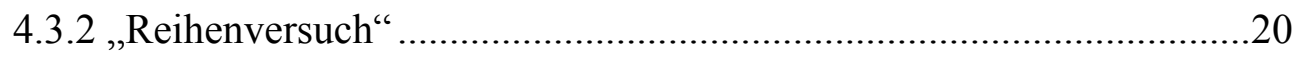

4.3.3 ,JA-Versuch“............................................................................22

4.3.4 Untersuchungen der Auswirkungen der simulierten Herbivorie

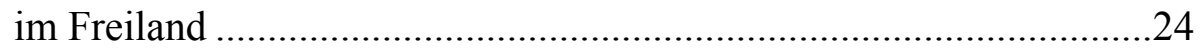

4.3.4.1 Relative Blattschädigung .......................................................26

4.3.4.2 Untersuchungen zur Ermittlung von physikalischen und chemischen Veränderungen ..................................................26

4.3.4.2.1 Prozentualer Blattwassergehalt .........................................26

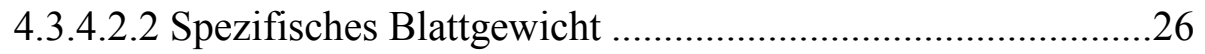

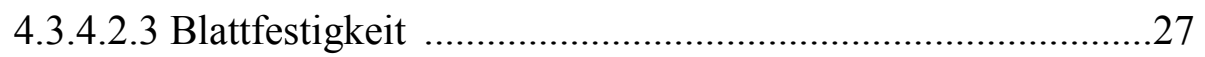

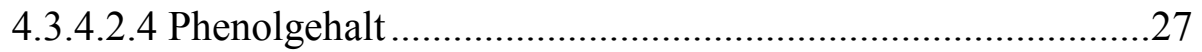

4.3.4.3 Fraßwahlverhalten des Herbivoren Agelastica alni ....................28

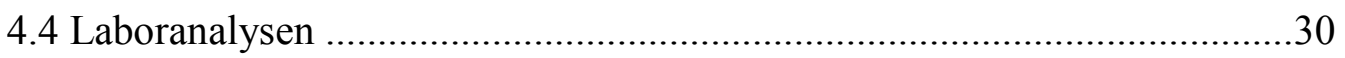

4.4.1 Physiologische Untersuchungen zu Veränderungen im Blattgewebe

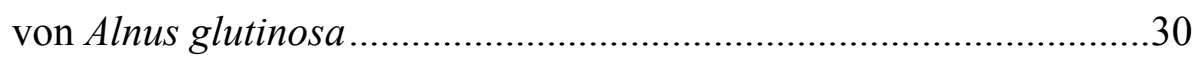

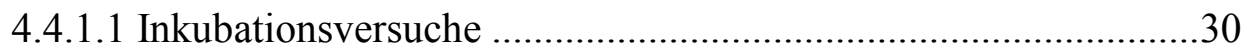

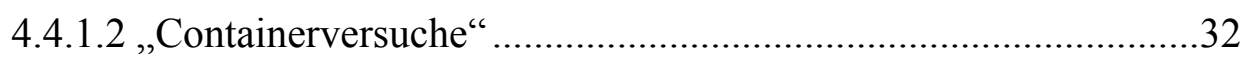

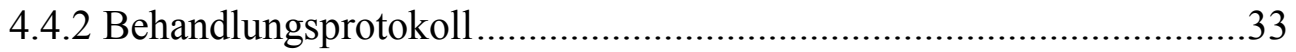

4.4.3 Durchführung der chemischen und physiologischen Analysen............36

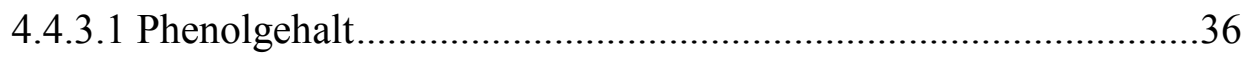

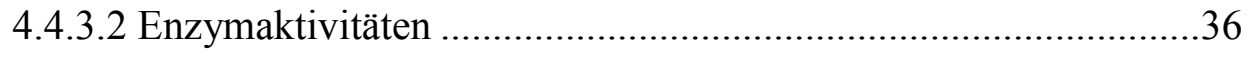

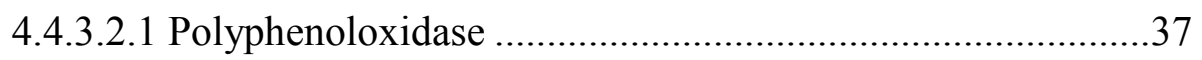




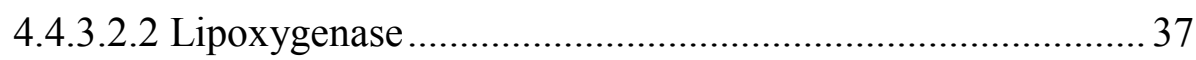

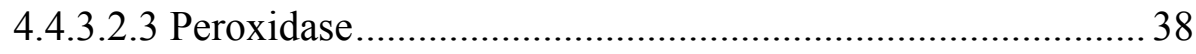

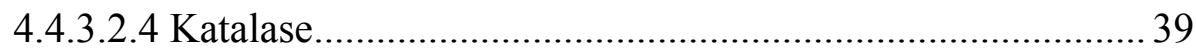

4.4.3.3 Bestimmung der Proteinaseinhibitoraktivitäten ........................ 39

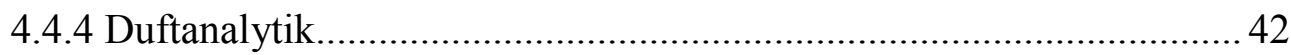

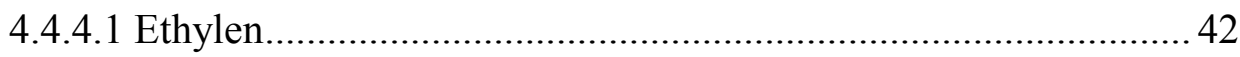

4.4.4.2 Flüchtige Blattinhaltsstoffe ................................................... 44

4.4.5 Quantifizierung von Jasmon- und Salicylsäure................................. 46

4.4.6 Charakterisierung des Regurgitats von Agelastica alni-Larven.......... 50

4.4.6.1 Chemische Untersuchungen .................................................. 50

4.4.6.2 Elektrophysiologische Untersuchungen ................................... 51

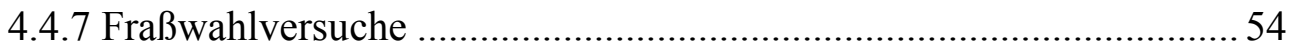

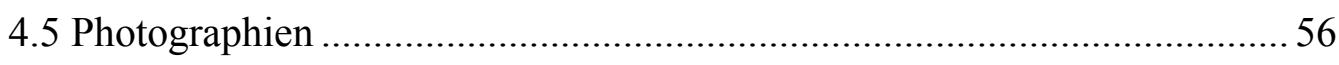

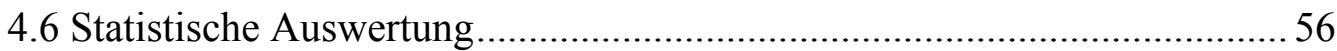

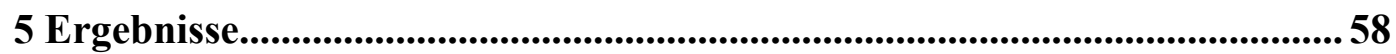

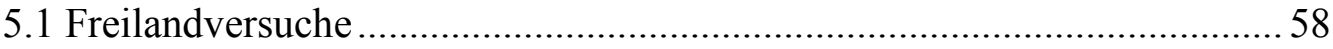

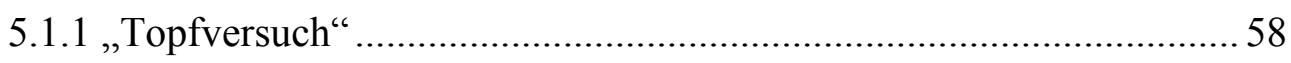

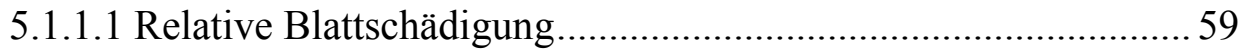

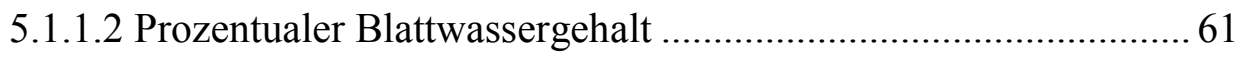

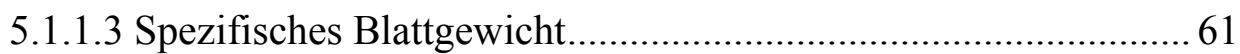

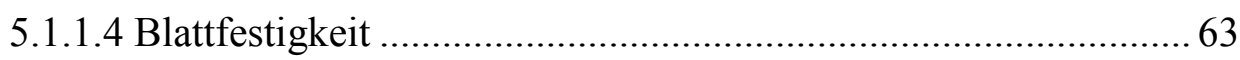

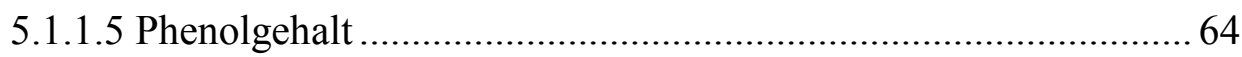

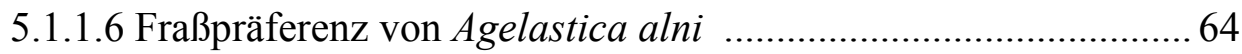

5.1.1.7 Zusammenfassung „Topfversuch“ ...........................................6 65

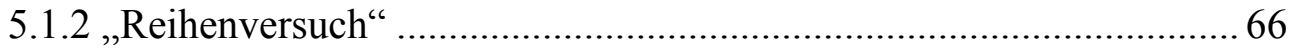

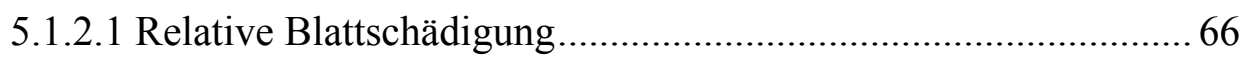

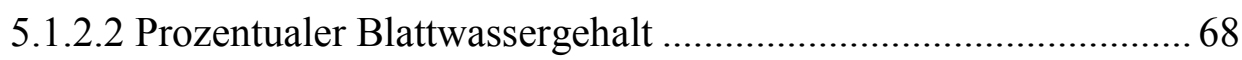

5.1.2.3 Spezifisches Blattgewicht..................................................... 70

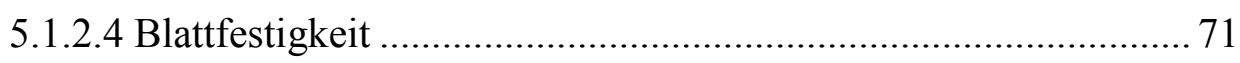

5.1.2.5 Fraßpräferenz von Agelastica alni .......................................... 71

5.1.2.6 Zusammenfassung „Reihenversuch““...................................... 72

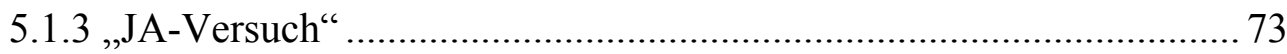

5.1.3.1 Relative Blattschädigung..................................................... 73

5.1.3.2 Prozentualer Blattwassergehalt ............................................ 74

5.1.3.3 Spezifisches Blattgewicht....................................................... 74

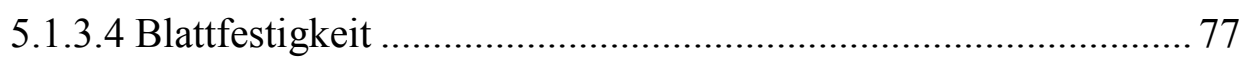

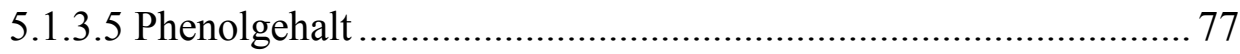

5.1.3.6 Fraßpräferenz von Agelastica alni ......................................... 77 
5.1.3.7 Zusammenfassung ,JA-Versuch“ “...........................................78

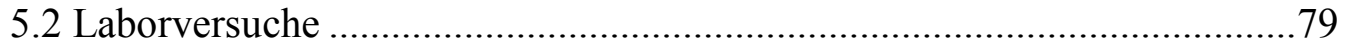

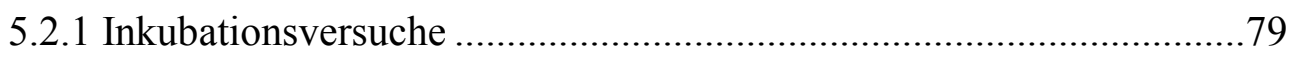

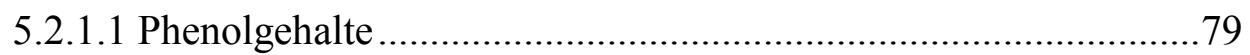

5.2.1.2 Enzymaktivitäten .................................................................. 81

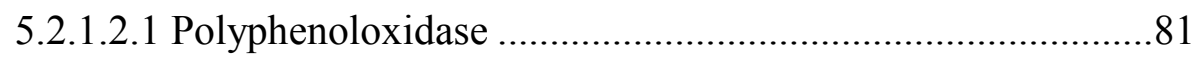

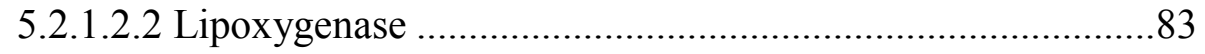

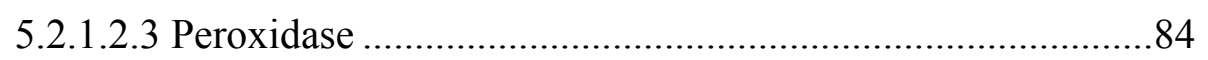

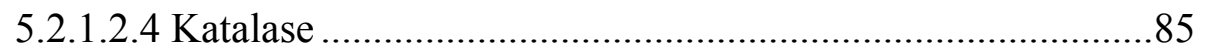

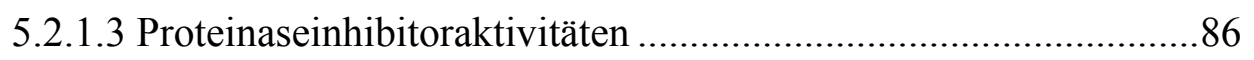

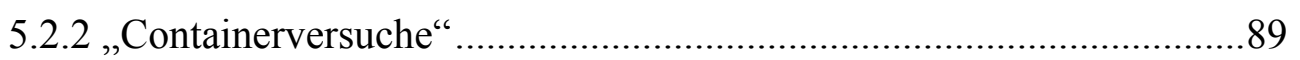

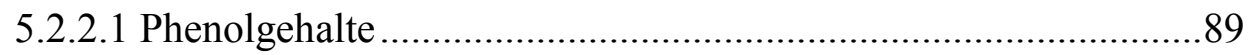

5.2.2.2 Enzymaktivitäten ............................................................. 91

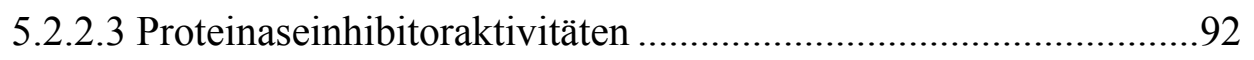

5.2.2.4 Zusammenfassung „Containerversuche“ ..................................93

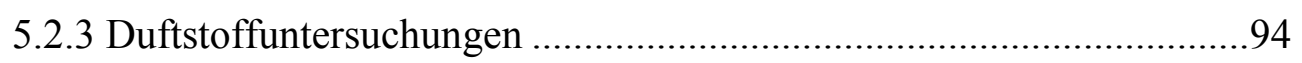

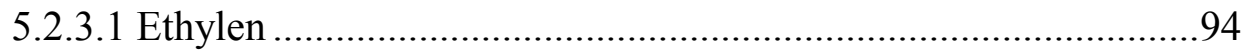

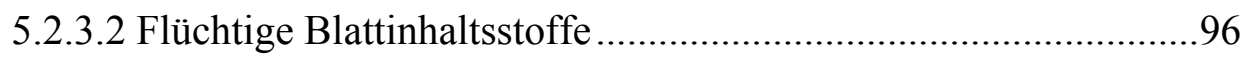

5.2.4 Quantifizierung von Jasmon- und Salicylsäure ................................100

5.2.5 Charakterisierung des Regurgitats von Agelastica alni-Larven .........102

5.2.5.1 Chemische Untersuchungen...................................................102

5.2.5.2 Elektrophysiologische Untersuchungen zur Membranaktivität 105

5.2.6 Fraßpräferenz von Agelastica alni................................................ 107

6 Diskussion ...............................................................................................113

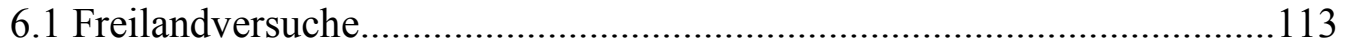

6.1.1 Auswirkungen einer experimentellen Schädigung auf benachbarte, ungeschädigte Erlenpflanzen:

„Reihenversuch“ und „Topfversuch“.....

6.1.2 Auswirkungen einer JA-Applikation auf benachbarte, ungeschädigte Erlenpflanzen: „JA-Versuch“.

6.2 Auswirkungen von Herbivorenfraß und Elicitierung auf die Physiologie von Alnus glutinosa

6.2.1 Durch Herbivorenfraß induzierte Veränderungen im Blattgewebe von Alnus glutinosa.

6.2.1.1 Beteiligung endogener Phytohormone.....

6.2.1.2 Chemische Zusammensetzung und Eigenschaften des Regurgitats von Agelastica alni-Larven. 
6.2.1.4 Enzymaktivitäten von Polyphenoloxidase, Lipoxygenase,

Peroxidase und Katalase ........................................................ 128

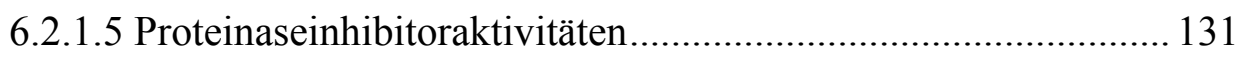

6.2.1.6 Emission von Duftstoffen..................................................... 132

6.2.2 Duftinduzierte Veränderungen im Blattgewebe von Alnus glutinosa 137

6.2.2.1 Auswirkungen von Ethylen, Methyljasmonat und

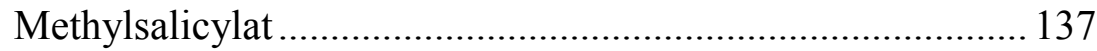

6.2.2.2 Auswirkungen fraßinduzierter Duftstoffe ............................... 139

6.2.3 Auswirkungen induzierter Veränderungen auf den Herbivoren

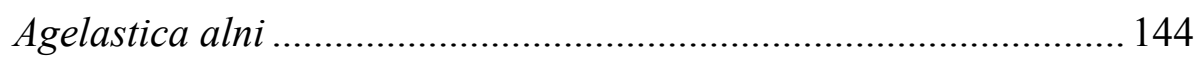

6.2.4 Bedeutung der Pflanze - Pflanze - Kommunikation für das System

Schwarzerle - Blauer Erlenblattkäfer ............................................ 146

6.2.6 Schlußbemerkung........................................................................ 148

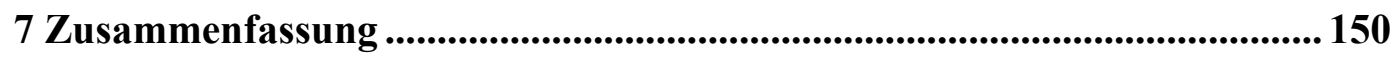

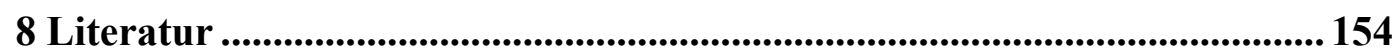

Anhang

Danksagung

Selbstständigkeitserklärung

Lebenslauf 


\section{Abkürzungen}

A. alni

Abb.

A. glutinosa

amu

APCI

CLS

DMNT

DW

EI

FW

$\mathrm{g}$

GC-MS

$\mathrm{h}$

HPLC

IS

JA

KAT

LC-MS

LOX

MeJA

MeSA

$\min$

$\mathrm{m} / \mathrm{z}$

PAS

PI

RT

SA

SAR

$\mathrm{t}$

Tab.

TMTT

POD

PPO
Agelastica alni

Abbildung

Alnus glutinosa

Masse (,Atomic mass unit”)

Atmospheric Pressure Chemical Ionisation

Closed Loop Stripping

(3E)-4,8-Dimethylnona-1,3,7-trien $\left(\mathrm{C}_{11}\right.$-Homoterpen $)$

Trockengewicht (,dry weight")

Elektronenstoßionisation

Frischgewicht (,fresh weight“)

Gramm

Gaschromatographie-Massenspektrometrie

Stunde(n)

Hochleistungsflüssigchromatographie

Interner Standard

Jasmonsäure

Katalase

Flüssigchromatographie-Massenspektrometrie

Lipoxygenase

Methyljasmonat

Methylsalicylat

Minute

Ionenmasse/Ionenladung

Photoakustikspektroskopie

Proteinaseinhibitor

Raumtemperatur

Salicylsäure

systemic aquired resistance

Zeit

Tabelle

(3E,7E)-4,8,12-Trimethyltrideca-1,3,7,11-tetraen

( $\mathrm{C}_{16}$-Homoterpen)

Peroxidase

Polyphenoloxidase 
Nachstehende statistische Abkürzungen und Symbole werden in der Arbeit verwendet:

$\mathrm{n}$

$\mathrm{X}$

Stdf

$\mathrm{p}$

n.s.

*

$* *$

$* * *$
Stichprobenumfang

Mittelwert

Standardfehler des Mittelwerts

Wahrscheinlichkeitswert

nicht signifikant auf dem $5 \%$-Wahrscheinlichkeitsniveau

signifikant auf dem $5 \%$-Niveau

signifikant auf dem $1 \%$-Niveau

signifikant auf dem 0,1\%-Niveau 


\section{$1 \quad$ Einleitung}

Mehr als drei Viertel aller mitteleuropäischen Insektenarten zeigen zumindest in bestimmten Lebensabschnitten direkte Beziehungen zu Pflanzen. Diese Interaktionen stellen dabei dynamische Prozesse in Ökosystemen dar: Der von phytophagen Insekten auf die Pflanzen ausgeübte Druck hat zur Ausbildung zahlreicher pflanzlicher Verteidigungsformen geführt (Howe \& WESTLEY 1993) ebenso wie zu Gegenanpassungen bei den Phytophagen.

Sind Pflanzen biotischen Streßsituationen wie Herbivorenfraß oder Pathogenbefall ausgesetzt, können sie sich mit Abwehrmechanismen wehren. Die Formen dieser Abwehr sind dabei sehr vielfältig und schließen morphologische, physiologische und chemische Mechanismen ein. Sie werden oft auch miteinander kombiniert. Neben einer konstitutiv-unspezifischen Abwehr gibt es eine induzierte, spezifische Form, die erst dann aktiviert wird, wenn die Pflanzen unmittelbar geschädigt werden (KARBAN \& BALDWIN 1997). Eine Reihe von Untersuchungen belegen, welche induzierten Veränderungen Herbivorie im Primär- und Sekundärstoffwechsel der Pflanze nach sich ziehen kann: Dazu gehören Alkaloide (BALDwin et al. 1997), Tannine (MATTSON \& PALMER 1988), oxidative Enzyme (DUfFEY \& FELTON 1991), Proteinaseinhibitoren (GREEN \& RYAN 1972), aber auch flüchtige Blattinhaltsstoffe (DICKE et al. 1990; TURLINGS et al. 1990; BOLAND et al. 1992; DiCKE 1994). Diese induzierten Antworten im pflanzlichen Gewebe können über direkte oder indirekte Wirkungsmechanismen die Herbivoren nachhaltig beeinflussen und sich entscheidend auf die Fraßleistung und damit auf die Fitneß der Herbivoren auswirken. Die „induzierte Resistenz“ kann sogar positive Konsequenzen für die Pflanzenfitneß nach sich ziehen, die auch als ,induzierte Abwehr“ im engeren Sinn bezeichnet wird (KARBAN \& MYERS 1989).

Die durch Befall induzierbaren Abwehrreaktionen können sich lokal auf den Ort des Insektenfraßes beschränken, oder sie sind systemisch und erstrecken sich auch auf nicht befallene Kompartimente der Pflanze. Der Verlauf induzierter Abwehrvorgänge, von der Erkennung der Schädigung bis zur De-novo-Synthese neuer Genprodukte, wird über eine Kaskade von Reaktionsschritten vermittelt. Trotz der Vielfalt an biotischen Schädigungsvarianten sowie an Elicitoren gibt es zwei gut untersuchte Signalwege, die diese Signaltransduktion übernehmen. Dies ist zum einen die „verwundungsinduzierte“ Sig- 
nalkette und zum anderen die hypersensitive Reaktion auf den Pathogenbefall. Auf beide Signalmechanismen wird in Kap. 2 ausführlich eingegangen.

Neben dieser direkten Wechselwirkung zwischen Pflanze und Herbivor oder Pathogen sowie der unmittelbaren Aktivierung der pflanzlichen Abwehr in geschädigten Pflanzen zeigen neuere Forschungen auch die Möglichkeit einer weiteren chemischen Wechselwirkung. Es handelt sich dabei um eine Kommunikation zwischen Pflanzen und Pflanzen, Pflanzen und Herbivoren sowie Vertretern der dritten trophischen Ebene, die für die Abwehr von Schadinsekten sowie für die Fitneß der beteiligten Pflanzen eine wichtige Rolle spielt.

Anfang der 80er Jahre wurden im Freiland erste Hinweise auf diese Wechselwirkung zwischen geschädigten und ungeschädigten Pflanzen gefunden (BALDWIN \& SCHULTZ 1983; RHOADES 1983, 1985; HAUKIOJA et al. 1985). Doch diese frühen Arbeiten wurden scharf kritisiert, und das Phänomen einer Pflanze-Pflanze-Kommunikation wurde für unglaubwürdig gehalten (FOWLER \& LAWTON 1985). Seit den 90er Jahren gibt es jedoch neue Hinweise sowohl aus Freilandversuchen als auch aus physiologischen und molekularbiologischen Arbeiten, die die Möglichkeit einer Resistenzinduktion durch flüchtige Stoffe in gesunden Pflanzen belegen (FARMER \& RYAN 1990; O’DONNELL et al. 1996; ShUlaEV et al. 1997; ARIMURA et al. 2000; Dolch \& TscharnTKE 2000; KARBAN et al. 2000; Übersicht in Bruin et al. 1992; ShOnLE \& BERGELSON 1995; KARBAN \& BALDWIN 1997).

Bereits 1995 erwiesen die Freilandexperimente von DOLCH eine Wechselwirkung zwischen geschädigten und ungeschädigten Schwarzerlen und deren ökologische Bedeutung. Allerdings blieben bei dieser Arbeit wichtige Fragen bezüglich des Mechanismus des Signaltransfers, der Signalinduktion und der induzierten Veränderungen in der Blattchemie ungeklärt. Es stellte sich daher die Aufgabe, die Mechanismen von Ursachen und Folgen der „Kommunikation“ im System Schwarzerle - Erlenblattkäfer (Abb. 1) zwischen einer geschädigten und einer ungeschädigten Pflanze zu untersuchen. Da die Komplexität des Phänomens eine Integration von Feldexperimenten, Labortests und chemischen Analysen notwendig macht, mußten die Untersuchungen zu diesem Phänomen des Signaltransfers zwischen Pflanzen interdisziplinär angelegt werden. 

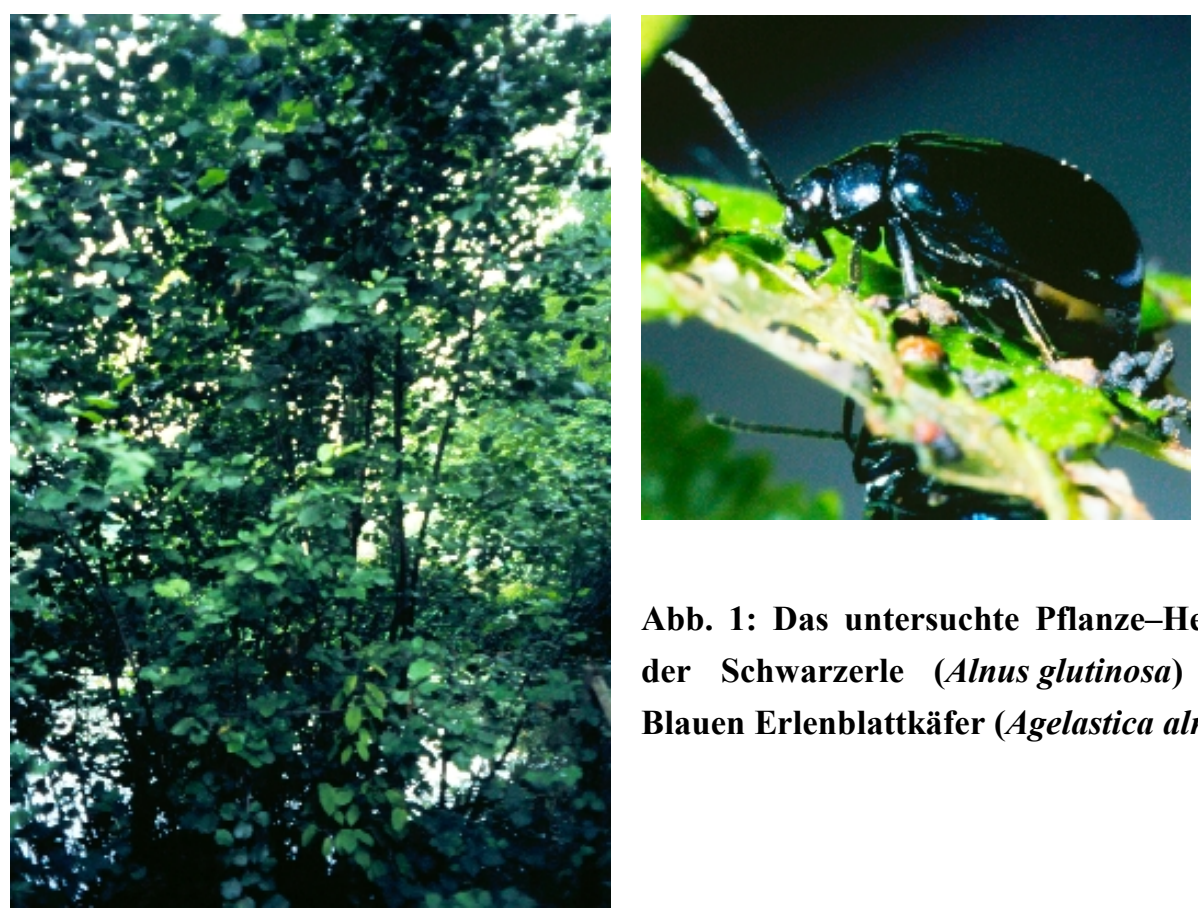

Abb. 1: Das untersuchte Pflanze-Herbivor-System mit der Schwarzerle (Alnus glutinosa) (links) und dem Blauen Erlenblattkäfer (Agelastica alni) (rechts).

Außerdem mußten neue methodische Ansätze für die Freilandversuche an A. glutinosa entwickelt werden, durch die nachgewiesen werden sollte, ob geschädigte Pflanzen über flüchtige Signalstoffe Resistenzen in ungeschädigten Nachbarpflanzen induzieren. Dabei wurden in den Versuchen sowohl natürliche Bestände als auch getopfte Erlen verwendet, um verschiedene Möglichkeiten des Signaltransfers zu testen. Eine Simulation von Herbivorenfraßschädigung erfolgte mechanisch oder durch Jasmonsäure, um die pflanzliche Abwehrreaktion zu induzieren. Chemische (Blattphenolgehalt) und physikalische (Blattwassergehalt, spezifisches Blattgewicht, Blattfestigkeit) Veränderungen der benachbarten Bäume wurden untersucht. Folgende Fragstellungen standen dabei im Vordergrund:

- Erfolgt durch die experimentelle Schädigung eine Resistenzinduktion von ungeschädigten Bäumen in der Nachbarschaft geschädigter Bäume?

- Welche induzierten Veränderungen lassen sich mit den untersuchten Blattparametern bei Alnus glutinosa ermitteln?

- Wie wirken sich die induzierten Veränderungen auf das Fraßverhalten von Agelastica alni aus?

Parallel zu den Freilandexperimenten sollte dem Phänomen der Pflanze-PflanzeKommunikation im Labor mit weiterführenden physiologischen Analysen 
nachgegangen werden. Den Rahmen dieser Laboruntersuchungen veranschaulicht ein Konzeptmodell (Abb. 2).

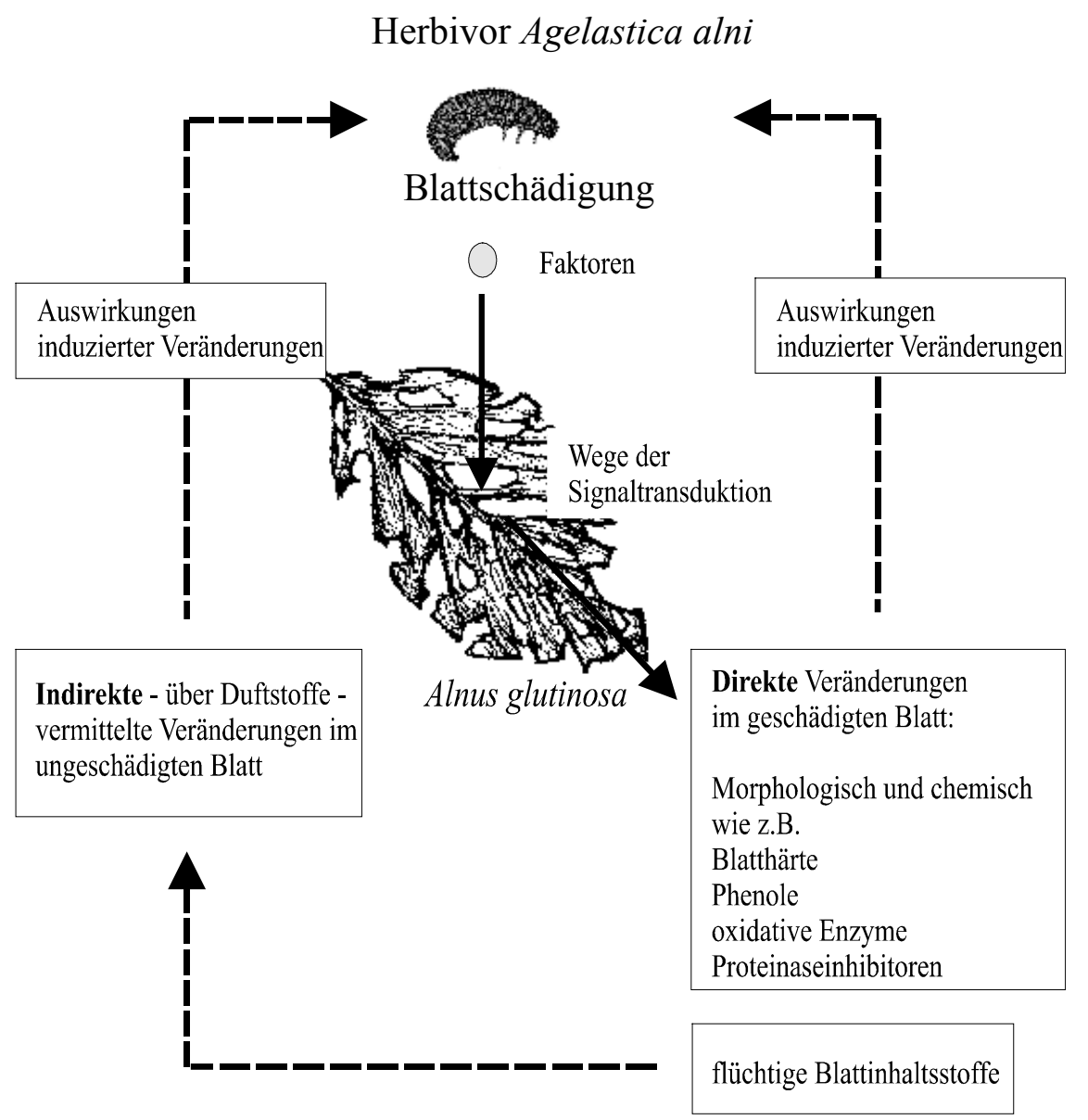

Abb. 2: Konzeptmodell zur Untersuchung der Wechselwirkung zwischen Schwarzerlen und Erlenblattkäfer: Herbivorie, induzierte Resistenz und Signaltransfer zwischen Schwarzerlen.

Für diese modellhaften, deskriptiven Experimente wurden junge Alnus glutinosa-Pflanzen ausgewählt, weil sie infolge ihrer jungen Struktur unproblematischer in der Handhabung waren als alte, ausgewachsene Exemplare von Alnus. Bei weiterführenden Analysen der induzierten Veränderungen im pflanzlichen Gewebe sollten phenolische Verbindungen, die u.a. auch charakteristisch für A. glutinosa sind (HEGNAUER 1964) und deren Funktion in der pflanzlichen Abwehr für viele Baumarten beschrieben ist (MATTSON et al. 1988; TALLAMY \& RAUPP 1991), mit in die Untersuchungen einbezogen werden. Zum anderen wurden proteinogene Verbindungen mit in die Studien aufgenommen, und zwar solche „Abwehr-spezifischen Proteine“ wie oxidative Enzyme und Proteinaseinhibitoren, deren nachhaltige Wirkung auf herbivore Insekten bekannt ist. Es gibt zwar schon zahlreiche Arbeiten über die Induzierbarkeit und Anreicherung 
von proteinogenen Verbindungen nach Fraßschädigung bei krautigen Pflanzen (RYAN 1990; DufFey \& Felton 1991), aber nur einzelne Belege bei Bäumen. So konnte mit den physiologischen Untersuchungen an Alnus diesem lückenhaften Verständnis nachgegangen werden.

Mit den Laboruntersuchungen sollten folgende Fragen angegangen werden:

- Mit welchen Formen pflanzlicher Abwehr (Aktivität von Polyphenoloxidase, Lipoxygenase, Peroxidase, Katalase und Proteinaseinhibitoren) ist im Stoffwechsel der Erle zu rechnen?

- Welche endogenen Signalstoffe sind an der durch Herbivorenfraß vermittelten Abwehr beteiligt? Gibt es Verbindungen im Regurgitat des Herbivoren, denen eine elicitierende Wirkung zugesprochen werden könnte?

- Werden flüchtige Duftstoffkomponenten von geschädigten Erlen abgegeben und wenn ja, um welche Komponenten handelt es sich dabei?

- Lassen sich Hinweise auf eine indirekte - über flüchtige Duftstoffe - vermittelte Resistenzinduktion in ungeschädigten Erlenblättern finden? Und wenn ja, haben die physiologischen Veränderungen im pflanzlichen Gewebe nachhaltige Auswirkungen auf den Herbivoren $A$. alni selbst? 


\section{Grundlagen}

Der Verlauf der induzierten Biosynthese von Abwehrsubstanzen gegen Fraßfeinde und andere Schadorganismen setzt ein effektives Signaltransduktionssystem voraus, das schnell und spezifisch auf die Schädigung antwortet. Dabei induzieren primäre Elicitoren nach ihrer Wechselwirkung mit der pflanzlichen Membran das Signalsystem der Pflanze. Ihre Struktur ist von der Art des abzuwehrenden Pathogens abhängig und kann verschiedenen Substanzklassen angehören: Oligosaccharidfragmente aus den Zellwänden der pathogenen Pilze oder der Pflanze selbst (DOARES et al. 1995); Elicitine-kleine Proteine aus Pilzen-(YU 1995); Enzyme (z.B. Glucosidasen (HOPKE et al. 1994; MATTIACCI et al. 1995) und Fettsäure-Aminosäure Konjugate (z.B. Volicitin (ALBORN et al. 1997)) aus dem Speichelsekret herbivorer Insekten oder auch Sekundärmetabolite des pflanzlichen oder pathogenen Stoffwechsels. Sie aktivieren die endogenen Signalüberträgermoleküle, die die Information einer Schädigung innerhalb einer Zelle, eines Zellverbands oder innerhalb der Pflanze weiterleiten und am Ende die Defensivantwort durch eine De-novo-Synthese der jeweiligen Abwehrsubstanzen bewirken.

Bei Verletzung an Blättern durch herbivore Insekten treten Signalwege des Lipidstoffwechsels in den Vordergrund. Bestuntersuchtes Beispiel hierfür ist Jasmonsäure (JA). Diese entsteht in Pflanzen über den von VICK \& ZIMMERMAN (1984) beschriebenen Octadecansäureweg aus Linolensäure: Nach der Wechselwirkung der pflanzlichen Membran mit exogenen Signalen kommt es zur Lipase-katalysierten Freisetzung der ungesättigten $\mathrm{C}_{18}$-Fettsäure Linolensäure aus der Plasmamembran. Nach Oxidation der Fettsäure wird das Zwischenprodukt (13S)-13-Hydroperoxy-9,11,15-octadecatriensäure in mehreren Reaktionsschritten zu 12-Oxophytodiensäure umgesetzt. Die nachfolgende Reduktion und Kürzung der Seitenkette durch drei anschließende $\beta$-Oxidations-Zyklen liefern schließlich die Jasmonsäure. Diese bewirkt ihrerseits die Aktivierung und Expression von Genen bestimmter Abwehrreaktionen (Abb. 3), die charakteristisch für eine Verwundung sind. 


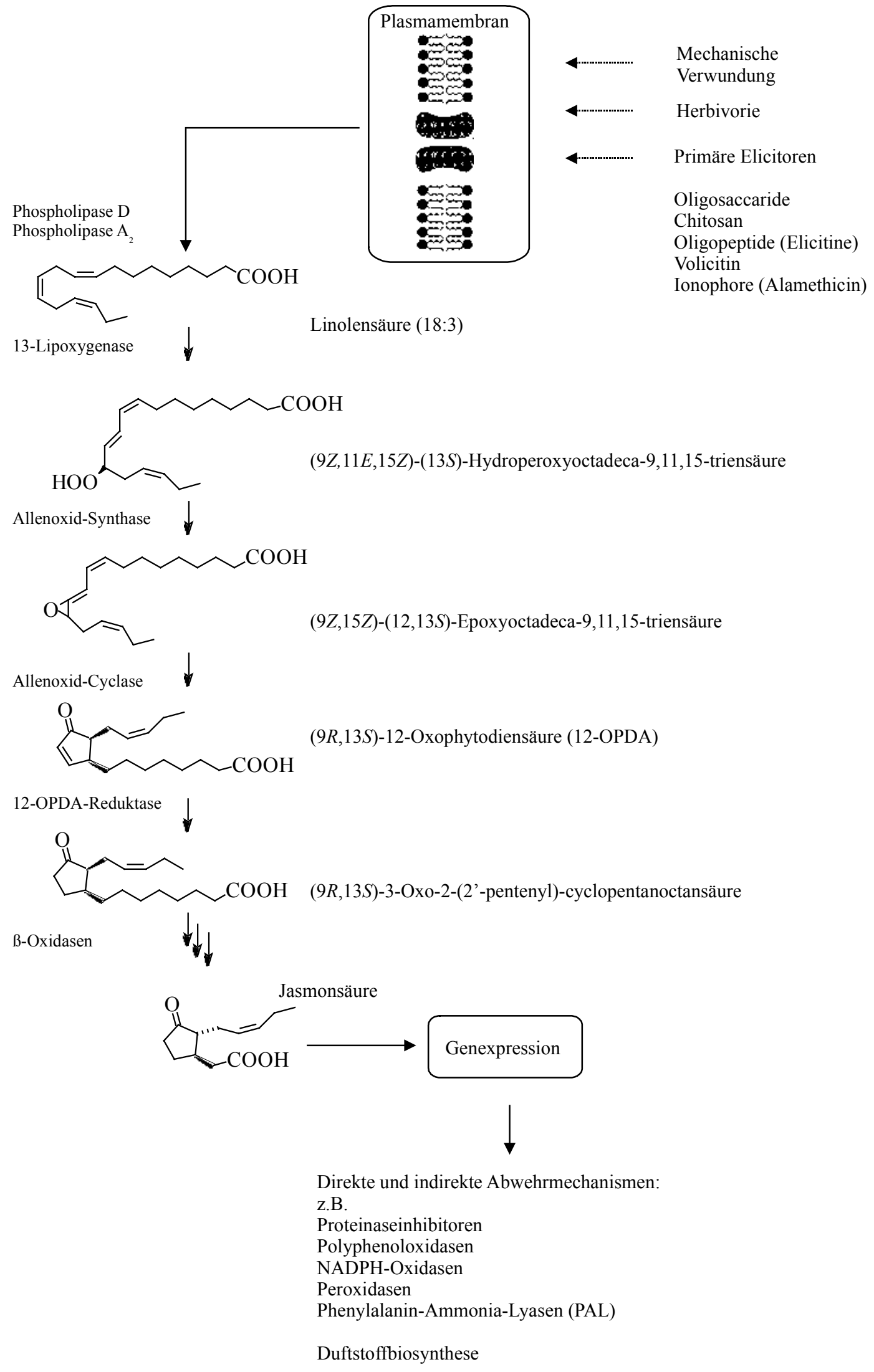

Abb. 3: Schematische Darstellung für den Signalweg von der Schädigung der Pflanze durch Herbivore oder Pathogene bis zur Abwehrreaktion unter Beteiligung von Jasmonsäure. 
Die Beteiligung von Jasmonsäure an der pflanzlichen Antwort als Reaktion auf biotische und abiotische Streßfaktoren wird durch zahlreiche Arbeiten belegt: Faktoren wie mechanische Verletzung, Wassermangel, Pathogenbefall, aber auch Herbivorie resultieren in einem Anstieg endogener Jasmonsäure im verletzten Gewebe; dabei gewinnt die Bedeutung von Jasmonsäure in der Abwehr gegen herbivore Insekten immer mehr an Beachtung (FARMER \& RYAN 1990; FARMER et al. 1992; MUELlen et al. 1993; Reinbothe et al. 1994; SCHALler \& RYAN 1996; BALDWIn 1996; O'DonNELl et al. 1996; Thaler et al. 1996; Crellman \& Mullet 1997; MCConn et al. 1997; WASTERNACK \& PARTHIER 1997; STASWICK \& LEHMAN 1999; THALER et al. 2001).

Beispiele für die elicitierende Wirkung von Jasmonsäure oder ihres Methylesters (MeJA) (= Jasmonate) sind die Bildung zahlreicher sogenannter JIP's (,,jasmonic acidinduced proteins"), die in fünf Klassen eingeteilt werden (Übersicht in REINBOTHE et al. 1994). Dazu gehören Proteinaseinhibitoren (FARMER et al. 1992); antimykotische Proteine (Thionine); Enzyme, die bei der Biosynthese von Sekundärmetaboliten (z.B. Phytoalexine, Lignine, Duftstoffe) eine wichtige Rolle spielen. Ferner haben Jasmonate auch weitere Schlüsselfunktionen bei zahlreichen physiologischen Stoffwechselvorgängen (Übersicht in SEMBDNER \& PARTHIER 1993; CREelman \& Mullet 1997; Herde et al. 1997; STASWICK \& LEHMAN 1999). Aufgrund dieser zentralen Rolle von Jasmonsäure im Sekundärstoffwechsel des pflanzlichen Abwehrsystems können durch künstliche Applikation von Jasmonsäure oder Methyljasmonat in vielen Pflanzensystemen Schädlingsbefall imitiert und die entsprechende Antwort der Pflanze ausgelöst werden. So induziert Jasmonsäure die Biosynthese von Duftstoffen, Alkaloiden, Proteinaseinhibitoren oder auch von Ethylen. Ferner lassen sich die unmittelbaren Auswirkungen der induzierten Veränderungen für die Performance der Herbivoren aufzeigen.

Ein weiteres, wichtiges Pflanzenhormon, das ebenfalls bei der pflanzlichen Abwehrreaktion in der Wundantwort einen entscheidenden Faktor darstellt (MATTOO \& SUTTLE 1991; ABELES 1992) und dem eine Beteiligung an dem Signaltransfer zwischen Pflanzen zugesprochen werden kann, ist Ethylen. Die Ethylenbiosynthese verläuft über das $S$ Adenosylmethionin, das eine positive Ladung am Schwefel trägt. Bedingt durch diese Ladung stellt die Cyclopropanaminosäure eine gute Abgangsgruppe dar, die über die Spaltung der Aminocyclopropan-Carboxylat-Synthase (ACC-Synthase) des $S$-Adenosylmethionins am Schwefel vermittelt wird. Durch eine ACC-Oxidase wird das Cyc- 
lopropan zu Ethylen, Kohlendioxid und Wasser gespalten (YANG \& HoFFMAN 1984; MIYAZAKI \& YANG 1987). Durch einige Arbeiten wird bereits eine Ethylenfreisetzung nach Fraßschädigung durch Herbivore (RIESKE \& RAFFA 1995; KAHL et al. 2000; ARIMURA et al. 2000; BONELlo et al. 2001) sowie nach Elicitorbehandlung (PIEL et al. 1997; ENGELBERTH et al. 2000) belegt.

$\mathrm{Zu}$ den Reaktionsmustern, denen bei Pathogenbefall eine entscheidende Bedeutung zukommt, zählen die hypersensitive Reaktion und die systemisch erworbene Resistenz (SAR). Bei dem Phänomen der hypersensitiven Reaktion kommt es nach dem Eindringen eines Pathogens zu lokalen Zellveränderungen. Der Vorgang vollzieht sich äußerst schnell, kann bereits nach Minuten bis Stunden abgeschlossen sein und konzentriert sich auf einen kleinen Zellbereich. Der eintretende Zelltod an diesen Gewebestellen entzieht biotrophen Erregern die Lebensbasis und bringt sie dadurch zum Absterben. Weiterhin sind an der Infektionsstelle noch zusätzlich Zellveränderungen zu beobachten, die dazu dienen, eindringende Erreger in ihrer Ausbreitung zu begrenzen und sie möglichst am Infektionsort abzukapseln. Neben mechanischen Zellwandmodifikationen wie die Bildung von Wundperiderm muß wohl auch den aktiven Sauerstoffspezies wie Superoxid und Wasserstoffperoxid (,oxidativer burst“) eine besondere Bedeutung zugeschrieben werden (LAMB \& DIXON 1997): Als hochreaktive und damit äußerst schädigende Sauerstoffradikale können sie einen direkten Einfluß auf den Erreger ausüben. Die aktiven Sauerstoffspezies werden aber auch als Signale für den programmierten Zelltod (Apoptose) diskutiert (GREENBERG 1997).

Eine weitere Verteidigungsantwort der Pflanze, insbesondere gegen Pathogene und Mikroorganismen, basiert auf der systemisch erworbene Resistenz. Ausgehend von befallenen Zellen erfolgt die Translokation eines Signals in befallsfreie Teile des gleichen Blattes, aber auch in weiter entfernte Pflanzenteile. Eine solche systemisch aktivierte Resistenz wird durch anorganische und biogene Aktivatoren sowie Pathogene ausgelöst und ist weitgehend dosisunabhängig, unspezifisch und ungerichtet. So lösen Bakterien Abwehrmechanismen gegen Pilze aus und Viren gegen Bakterien wie Pilze. Die SAR stellt somit ein äußerst umfassendes Abwehrsystem dar, das nicht nur gegen den angreifenden Erreger gerichtet ist, sondern gegen eine Vielzahl von Pathogenen. Zu den Genprodukten dieser sogenannten SAR-Gene gehören verschiedene Gruppen von PR-Pro- 
teinen (,pathogenesis related proteins“), wie Chitinasen, Glucanasen oder lytische Enzyme (Übersicht in DURNER et al. 1997; STICHER et al. 1997; DEMPSEY et al. 1999).

Die Rolle einer Signalsubstanz im Zusammenhang mit dem Prozeß der systemisch erworbenen Resistenz wird dabei dem Sekundärmetaboliten Salicylsäure (2-Hydroxybenzoesäure) (SA) zugeschrieben (ENYEDI et al. 1992; DEMPSEY et al. 1999). Zum Beispiel kann Salicylsäure die Expression von PR-Proteinen in Tabak einleiten, so daß sich dadurch die Resistenz gegen den Tabakmosaikvirus erhöht. Salicylsäure ist aber nicht nur ein wirksamer mobiler Signalstoff für die SAR innerhalb der Pflanze. In flüchtiger Form, als Methylsalicylat, kann es in benachbarten Blättern und sogar in benachbarten Pflanzen die Verteidigungsmechanismen aktivieren (SHULAEV et al. 1997).

Neben den gerade skizzierten Reaktionsmustern sind auch noch weitere Signalwege an der Signaltransduktion bei der pflanzlichen Abwehr beschrieben worden, deren Bedeutung im einzelnen noch nicht ganz erfaßt ist. Dazu gehören z.B. die Beteiligung von Membrandepolarisationen, $\mathrm{Ca}^{2+}$-Ionenflüssen (WhITE 2000; BLUME et al. 2000), GProteinen (Roos et al. 1999; JOSEFSSON \& RASK 1997) und die Aktivität von Kinasen (TORII 2000) oder Phosphatasen (VAN GESTELEN 1998).

Die unterschiedlichen Signalkaskaden sowie die verschiedenen Verteidigungsreaktionen dürfen nicht unabhängig voneinander gesehen werden. Sie stehen miteinander in Wechselwirkung und beeinflussen sich, positiv wie auch negativ, gegenseitig. Beispielsweise können Jasmonsäure und Ethylen synergistisch wirken, während Salicylsäure, die bei Pathogenbefall produziert wird, die wundinduzierte Genexpression hemmt, indem sie die Jasmonsäure-Biosynthese inhibiert. Dies könnte, zusammen mit den noch weitgehend unbekannten Signalwegen, auf ein Signalnetzwerk hinweisen, das eine differenzierte, pflanzliche Abwehr ermöglicht und erklärt (PIERTSE \& VAN LOON 1999; WALLING 2000). 


\section{Untersuchungsmaterial}

\subsection{Die Schwarzerle (Alnus glutinosa (L.) (Gaertn.))}

Die Schwarzerle (Alnus glutinosa; Ord.: Fagales; Fam.: Betulaceae) wächst als Baum oder Strauch, der 20 m (max. 30 m) Höhe erreichen kann. Sie hat einen schlanken, geradlinigen Stamm, von dem die Äste mehr oder weniger waagrecht abzweigen. Die Krone ist sehr locker und von länglich-eiförmiger Gestalt. Die Borke ist dunkelgrau bis schwärzlich und durch Quer- und Längsrisse zerklüftet (HEGI 1981). Von der schwärzlichen Borke rührt der Name Schwarzerle her. Der ebenfalls geläufige Name Roterle bezieht sich auf das rötliche Holz (DAHMS 1996)

Die Triebe der Schwarzerle sind kahl und klebrig. Die Laubblätter sind rundlich mit eingekerbter Spitze und sieben Seitennerven. Anfangs sind die Blätter noch klebrig und zartgrün. Später dunkeln sie in der Blattfarbe auf Dunkelgrün, wobei die Unterseite etwas heller ist. Der Blattrand ist grob doppelt gesägt, und die Nervenachseln sind unterseits behaart (Hegi 1981; NeBel 1993; Aichele \& SCHWEIGLER 1994). Die Ausbildung neuer Blätter erfolgt während der gesamten Vegetationsperiode.

Die Erlen sind anemogame Frühblüher. Die Blütezeit, von März bis April, liegt vor der Laubentfaltung. Männliche Kätzchen und weibliche Zapfen sind gestielt und in trugdoldenartigen Gesamtblühständen oberhalb der Laubknospen angeordnet. Sie werden bereits im Spätsommer des Vorjahres angelegt und überwintern. Die männlichen Kätzchen sind im Herbst und Winter bräunlich und werden beim Aufblühen durch ihre Pollen gelb, die sie Anfang März ausstreuen. Die weiblichen, violetten Kätzchen hängen am Zweig unterhalb der männlichen Kätzchen und stehen zu dritt bis fünft blattachselständig zusammen. Ihre Länge beträgt ca. $0,5 \mathrm{~cm}$. Der Baum bildet nach der Bestäubung grüne, festgeschlossene Blütenzäpfchen, die zu $1-2 \mathrm{~cm}$ langen, dunkelschwarzbraunen Früchten heranreifen. Die Samenreife tritt im September bis Oktober ein, und das Ausfallen der Samen kann sich bis zum Frühjahr hinziehen.

Die Entwicklung des Wurzelsystems ist vom Standort abhängig. Es werden bis zu $2 \mathrm{~m}$ tiefe Pfahlwurzeln ausgebildet. Auf flachgründigen Standorten wächst das Wurzelwerk oberflächennah und oft weit ausgebreitet. Die Wurzeln der Erle können mit den Wur- 
zelknöllchenbakterien Frankia alni infiziert sein, die die Bildung von sog. Wurzelknöllchen verursachen. Die Wurzelknöllchenbakterien binden in sauerstoffgeschützten Vesikeln im Knöllchengewebe mittels ihres Nitrogenasesystems $\mathrm{N}_{2}$ und geben organisch gebundenen Stickstoff an den Baum ab. Dieser versorgt wiederum die symbiotischen Wurzelknöllchenbakterien mit Assimilaten (AICHELE \& SCHWEIGLER 1994). Da die Schwarzerle stickstoffixierende Wurzelknöllchenbakterien besitzt, kann somit von einer guten Nährstoffversorgung und von stickstoffreichem Blattgewebe ausgegangen werden.

Die Schwarzerle ist einerseits an Flüssen in Auenwäldern (Alno padion) bestandsbildend und dominiert andererseits in Erlenbruchwäldern (Kl. Anetea glutinosae) (WILMANNS 1984). Sie bevorzugt sicker- oder staunasse bzw. kurzweilig überschwemmte Standorte. Im Vergleich zu anderen Laubbäumen ist die Schwarzerle eine trockenheitsempfindliche Art. Sie erträgt aber von allen einheimischen Baumarten das höchste Maß an Bodennässe (HEGI 1981). Denn in Anpassung an diese „nassen“ Standorte kann Alnus ihr chloroplastenfreies Gewebe sowie ihr Wurzelsystem durch Hypertrophierung der Lenticellen durch sogenannte Thermoosmose mit Sauerstoff versorgen (GROSSE \& SCHRÖDER 1984, 1985; SCHRÖDER 1989). Zusätzlich reagiert sie mit einer ausgeprägten Bildung von Adventivwurzeln (GILL 1975) auf Nässe. Die ökologische Stellung der Schwarzerle als „Besiedler nasser Standorte“ beruht auf ihren ökophysiologischen Ansprüchen und nicht darauf, daß sie von konkurrenzkräftigeren Pflanzenarten auf die ,ungünstigen“, feuchten Standorte abgedrängt wird (ESCHENBACH 1995).

Alnus glutinosa ist in fast ganz Europa heimisch. Das Verbreitungsareal erstreckt sich von Finnland bis in den submediterranen Bereich, und nach Osten kommt sie bis in den asiatischen Teil Rußlands vor. Die Hauptverbreitung der Schwarzerle liegt jedoch im europäischen Westen (HEGI 1981). 


\subsection{Der Blaue Erlenbattkäfer (Agelastica alni (L.))}

Der blaue Erlenblattkäfer (Agelastica alni) (Abb. 4a) ist mit seinem stark gewölbten, fast halbkugeligen Körper ein typischer Vertreter der Familie der Blattkäfer (Chrysomelidae; Subfam.: Galerucinae), die mit über 37.000 bisher beschriebenen Arten eine der umfangreichsten Käferfamilien darstellt (JOLIVET et al. 1988). Das Verbreitungsgebiet von $A$. alni erstreckt sich über ganz Europa und darüber hinaus bis nach Sibirien und Kasachstan. In den 70er Jahren wurden die Käfer auch in Nordamerika entdeckt (Novac et al. 1976).

Die Imagines sind ca. 6-7 mm groß. Sie erscheinen oberseits metallisch violett oder blau und unterseits schwarzblau gefärbt. Die Käfer erscheinen im April, kurz nach dem Öffnen der Blattknospen, auf den Erlen. Dabei ist der Schlupf der Käfer aus ihren Winterquartieren, die in den oberen Bodenschichten und in der Streuauflage in unmittelbarer Nähe zu den Wirtsbäumen liegen, mit der Phänologie ihrer Wirtsbäume synchronisiert (TISCHLER 1977). Nach dem Schlupf beginnen die Imagines mit dem Reifungsfraß. In dieser Zeit findet auch die Paarung der Käfer statt. Die Imagines befressen in typischer Weise - einem Lochfraß - die Erlenblätter. Dieser Blattfraß im Frühjahr kann so weit gehen, daß nur noch wenige Hauptadern oder lediglich die Mittelrippe der Erlenblätter übrigbleibt.

Die Weibchen, deren Hinterleib durch den Eivorrat im Körper oft stark angeschwollen ist, legen nach einem zehn- bis zwölftägigen Reifungsfraß Ende Mai ihre gelben Eier in plattenförmigen Gelegen unterseits an Erlenblättern ab (TISCHLER 1977; BAUR \& BENZ 1983; SCHEIWILLER 1991) (Abb. 4b). Ein Weibchen ist in der Lage, unter günstigen Freilandbedingungen insgesamt 200 bis 400 Eier abzulegen (JEKER 1981), wobei ein einzelnes Gelege aus 60 - 70 ovalen, orangefarbenen Eiern besteht (Abb. 4c).

Die Larven entwickeln sich im Mai bis Juli und durchlaufen in dieser Zeit drei Larvenstadien. Neun bis fünfzehn Tage nach der Eiablage schlüpfen die ersten Larven, die zuerst braun gefärbt sind (Abb. 4d). Die Larven des L1-Stadiums fressen anfangs gregär an der Epidermis der Blattunterseiten (Abb. 4e, f). Die älteren Larven (L2 und L3) sind glänzend schwarz. Sie zeigen eine solitäre Lebensweise (Abb. 4g). Ihr Fraß führt bei Erlen zum Einrollen, Vertrocknen und zur typischen Braunfärbung der Blätter. 

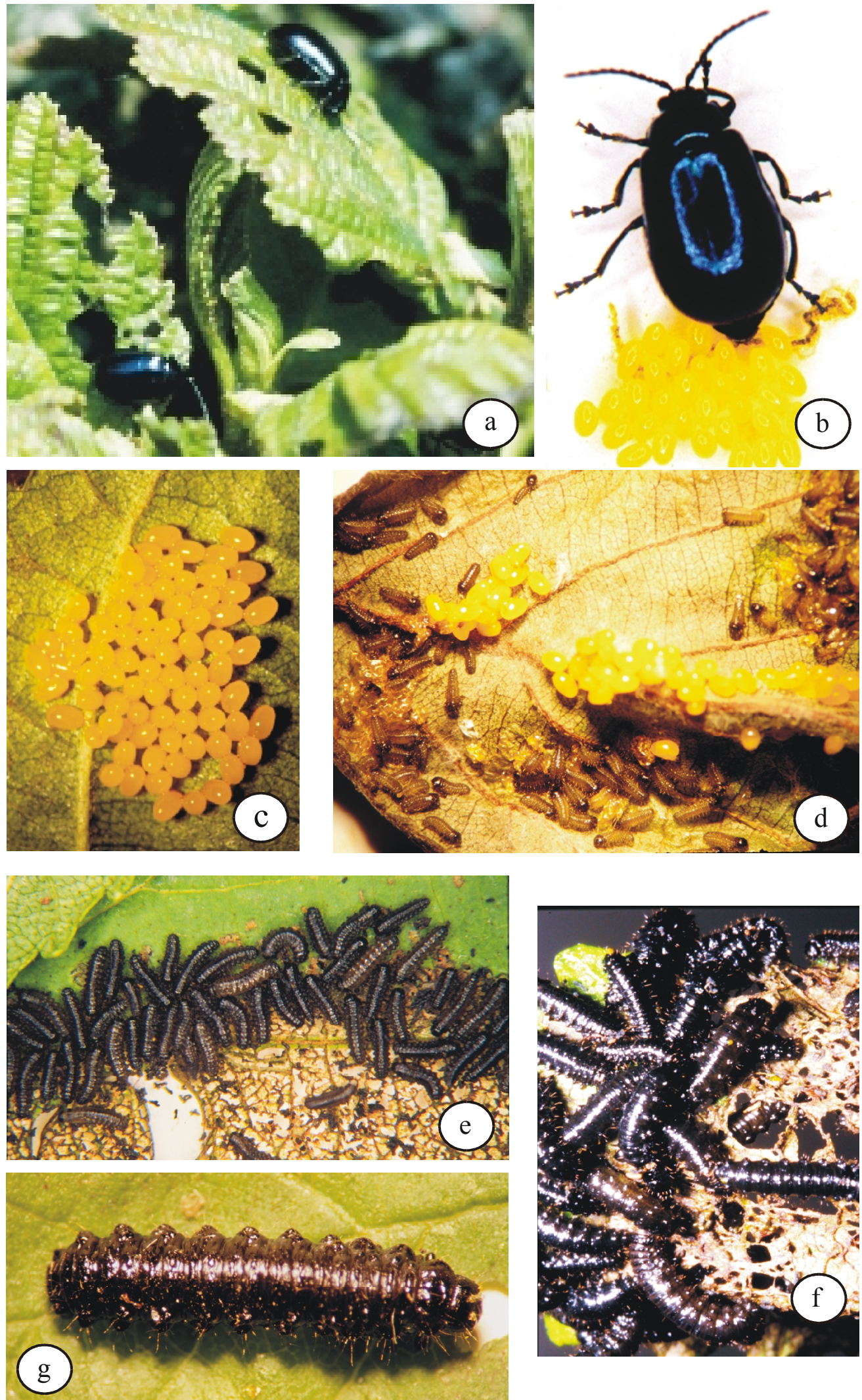

Abb. 4: Lebenszyklus von Agelastica alni. - a) Imagines auf Erlenblättern fressend. - b) Weibchen bei der Eiablage. - c) Eigelege. - d) Frisch geschlüpfte Larven. - e) Gregär fressende L1-Larven. - f) Fressende L2-Larven. - g) Solitär fressende L3-Larve. 
Das letzte Larvenstadium zieht sich im Juli bis August zur Verpuppung in den Boden zurück (ZUCHT 1934).

Die Jungkäfer der neuen Generation erscheinen Ende August bis Mitte September für ca. zwei Wochen, in denen sie an Erlenblättern fressen. Anschließend überwintern sie als Käfer in Bodenverstecken. Die gesamte Entwicklungszeit vom Eistadium bis zum Imaginalstadium dauert im Freiland ca. 77 bis 80 Tage (JEKER 1981).

Sowohl Larven als auch Imagines von A. alni leben oligophag an Alnus glutinosa und Alnus incana (KoCH 1992) und gehen nach Kahlfraß auch auf Blätter benachbarter Bäume von Betula pubescens, Betula verrucosa und Salix caprea über (TISCHLER 1977; MAISNER 1974). Vereinzelt wurde ein Vorkommen von A. alni auch an Prunus mahaleb (MOHR 1966) und Obstbäumen (MAISNER 1974) beobachtet. Bei starker Vermehrung des Erlenblattkäfers kann es mehrmals innerhalb einer Vegetationsperiode zu Kahlfraß an den Wirtsbäumen kommen (TISCHLER 1977).

Die verschiedenen Larvenstadien von $A$. alni können zu ihrer Verteidigung Reflexblut abgeben (Tischler 1977; Deroe \& Pasteels 1982; BÜNnige \& HiLker 1999). Dabei zeigen die einzelnen Larvenstadien deutliche Unterschiede in ihrem Verteidigungsverhalten: Die L1-Larven sitzen in dichten Gruppen auf den Blattunterseiten und zeigen kein Reflexbluten. Im L2-Stadium lösen sich die Larvengruppen nach und nach auf. Dann reagieren die L2-Larven bei sehr starker Reizung mit Reflexbluten. Dabei heben sie zusätzlich ihr Abdomen an und bewegen es seitlich hin und her. Das Verteidigungsverhalten der L3-Larven ähnelt dem der L2-Larven. Bei ihnen ist aber das Verhalten häufiger und länger ausgeprägt. Die Absonderung des Reflexblutes erfolgt über acht paarige Verteidigungsdrüsen, die dorsal auf der Körperoberfläche der Larven verteilt sind. Bei Gefahr werden tuberkelartige Strukturen, an deren Basis Drüsenzellen sitzen, durch Hämolymphdruck ausgestülpt, und ein gelbes Sekret wird auf die Oberfläche abgesondert (Zucht 1934; Deroe \& PAsteels 1982; Jolivet et al. 1988; BÜNNIGE \& HILKER 1999). 


\section{$4 \quad$ Material und Methoden}

\subsection{Anzucht von Alnus glutinosa-Pflanzen für Laborversuche}

Für die einzelnen Experimente im Labor (Kap. 4.4.1.1, Kap. 4.4.1.2, Kap. 4.4.4) wurden Erlenpflanzen angezogen. Da sich das Arbeiten mit dem Blattmaterial alter, aus dem Freiland stammender Erlenbäume wenig reproduzierbar erwies, wurden für die Laborversuche Erlenblätter junger Erlen aus der Klimakammeranzucht eingesetzt. Von diesen Bäumen war die Vorgeschichte bekannt und es war sicher, daß sie keiner Schädigung ausgesetzt waren.

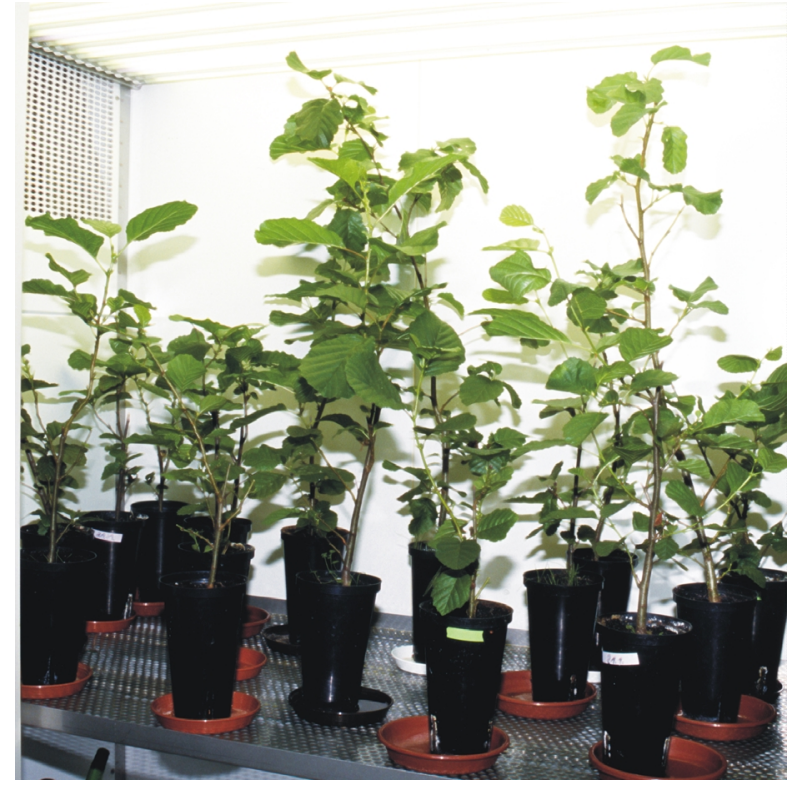

Abb. 5: Anzucht von jungen Alnus glutinosa-Pflanzen in einer Klimakammer.

Zur Anzucht der Erlenpflanzen für Laboranalysen (Kap. 4.4) wurde eine Mischung aus sterilisiertem Torfkultursubstrat (Capriflor, Vehnemoor; detaillierte Zusammensetzung des Substrates s. Anhang) und Sand (Hagebau; $1: 1, \mathrm{v}: \mathrm{v})$ verwendet. Die Sterilisation des Erdsubstrates (jeweils ca. 500 g) erfolgte in einem Mikrowellengerät (Stufe 3, $t=3$ min; Quick Cookmate, Daewoo).

Die Pflanzen von A. glutinosa (Sämlinge mit ausgebildetem Wurzelwerk, 1/2-jährig) wurden von einem Baumschulbetrieb in Schleswig-Holstein (Grebenstein \& Linke) käuflich erworben. Sie wurden in Pflanztöpfe (schlanke Rosentöpfe (Plastik) mit Bodenlöchern und Seitenschlitz) mit einem Durchmesser von $11 \mathrm{~cm}$ und einer Tiefe von $15 \mathrm{~cm}$ gepflanzt. Die weitere Anzucht der Pflanzen erfolgte in einer Klimakammer 
(VB1014, Vötsch-Industrietechnik; Abb. 5) für sechs Monate unter folgenden Bedingungen:

Tagphase: 10 Stunden bei $23{ }^{\circ} \mathrm{C}$ und $70 \%$ relativer Luftfeuchtigkeit

Nachtphase: 14 Stunden bei $17{ }^{\circ} \mathrm{C}$ und $50 \%$ relativer Luftfeuchtigkeit

Danach wurden die Erlenpflanzen in eine begehbare Klimakammer umgesetzt und bei Raumtemperatur und $16 \mathrm{~h}$ Tag : $8 \mathrm{~h}$ Nacht gehalten.

Für die Inkubations-, Container- und Duftversuche (Kap. 4.4.1.1, Kap. 4.4.1.2, Kap. 4.4.4) wurden aus dieser Anzucht Erlenpflanzen gleichen Entwicklungsalters (18 Monate alt) und gleicher Habituserscheinung (Höhe der Pflanzen $=40-60 \mathrm{~cm}$, Stammdurchmesser $=0,7 \mathrm{~cm}$ ) verwendet. Von den Pflanzen wurden unbeschädigte Triebe (bestehend aus jeweils drei vollständig entwickelten Blättern) eingesetzt.

\subsection{Haltung und Zucht von Agelastica alni im Labor}

Für die einzelnen Experimente wie Fraßwahlversuche (Kap. 4.3.4.3, Kap. 4.4.7), Herbivorenfraßschädigung (Kap. 4.4.1.1, Kap. 4.4.1.2) oder Gewinnung von Regurgitat (Kap. 4.4.6.1) wurde eine Zucht von A. alni im Labor etabliert. Dafür wurden Imagines im April, noch vor dem Verlassen des Winterquartiers, aus der Streu am Fuße ihrer Wirtsbäume an verschiedenen geographischen Standorten, die nicht zu den Versuchsflächen der Freilandversuche (Kap. 4.3) zählten, ausgegraben bzw. aufgesammelt.

Imagines von $A$. alni, die für Fraßwahlversuche eingesetzt werden sollten, wurden getrennt nach Geschlecht, Fundort und Funddatum in belüfteten Hartplastikdosen $\left(20 \mathrm{~cm} \times 20 \mathrm{~cm} \times 8 \mathrm{~cm}\right.$, Gerda) bei $12{ }^{\circ} \mathrm{C}$ gehalten.

Zum Aufbau einer Käferzucht wurden Imagines in belüfteten Hartplastikdosen (20 cm x $20 \mathrm{~cm} \times 8 \mathrm{~cm}$, Gerda), die mit Zellstoff ausgelegt waren, bei RT und $16 \mathrm{~h}$ Tag : $8 \mathrm{~h}$ Nacht gehalten. Als Futter dienten frische Erlenblätter, mit denen die Tiere alle zwei Tage versorgt wurden. Da die Weibchen ihre Eier ausschließlich auf der Unterseite der Blätter ablegten, mußte das alte Blattmaterial sorgfältig abgesucht werden. Die Gelege wurden mitsamt der Blattunterlage ausgeschnitten und nach Alter sortiert in mit Filterpapier ausgelegte Petrischalen (Plastik, $\varnothing=9 \mathrm{~cm}$ ) überführt. Die Eigelege wurden täglich kontrolliert und die frischgeschlüpften L1-Larven vorsichtig mit einem feinen Haarpinsel abgesammelt und in belüftete Hartplastikdosen überführt. Die Larven wur- 
den alle zwei Tage mit frischen Erlenblättern gefüttert. Kurz vor der Verpuppung stellten die Larven sowohl ihre Fraßaktivität als auch ihre Mobilität ein. Die Puppen wurden in Weichplastikdosen überführt, deren Boden mit einer dicken Sandschicht bedeckt war. Aufgrund noch ungeklärter Ursachen überlebte nur ein kleiner Anteil der Puppen bis zur Vollendung der Imaginalentwicklung. Die Anzahl der geschlüpften Jungkäfer reichte nicht aus, um eine fortführende Laborzucht zu etablieren.

\subsection{Freilandversuche}

Bei den vorliegenden Freilandversuchen wurde mit drei methodisch verschiedenen Ansätzen an A. glutinosa-Pflanzen untersucht, ob geschädigte Pflanzen über Signalstoffe Resistenzen in ungeschädigten Nachbarpflanzen induzieren können. Dabei wurden mit den verschiedenen Versuchen unterschiedliche Hypothesen bezüglich der Mechanismen des Signaltransfers - über den Boden- oder Luftbereich - zwischen den Erlenpflanzen überprüft.

\subsection{1 „Topfversuch“}

Die Prüfung einer Resistenzinduktion ungeschädigter Nachbarn durch Duftstoffe von geschädigten Bäumen wurde mit eingetopften Erlen überprüft. Damit konnte ein Signaltransfer zwischen den Pflanzen über den Pflanzenwurzel-Bodenbereich ausgeschlossen werden.

Im Vorfeld der Experimente wurden im März 1997 A. glutinosa-Bäume erworben. Einen Teil der Versuchspflanzen stellte freundlicherweise das Hessische Landesamt für Forsteinrichtung, Waldforschung und Waldökologie (Hann. Münden) zur Verfügung. Die restlichen Erlenpflanzen wurden von einem Baumschulbetrieb (Grebenstein \& Linke, Schleswig Holstein) bezogen. Alle Erlen waren zu diesem Zeitpunkt 3-jährig. Ab Anfang April wurden die Pflanzen in Pflanzkübel (30 1) getopft, die keine Löcher im Topfboden besaßen. Um Staunässe zu verhindern, wurden Löcher in ca. $10 \mathrm{~cm}$ Höhe über dem Topfboden gebohrt. In der letzten Aprilwoche wurden die getopften Erlenpflanzen auf einer Versuchsfläche des Botanischen Gartens der Universität Göttingen plaziert. Für jede Wiederholung (insgesamt $n=6$ ) wurden jeweils 25 Töpfe zu einem 
Plot zusammengestellt, der aus fünf parallel angeordneten Reihen mit je fünf Töpfen bestand (Abb. 6).

Übersicht Versuchsfläche

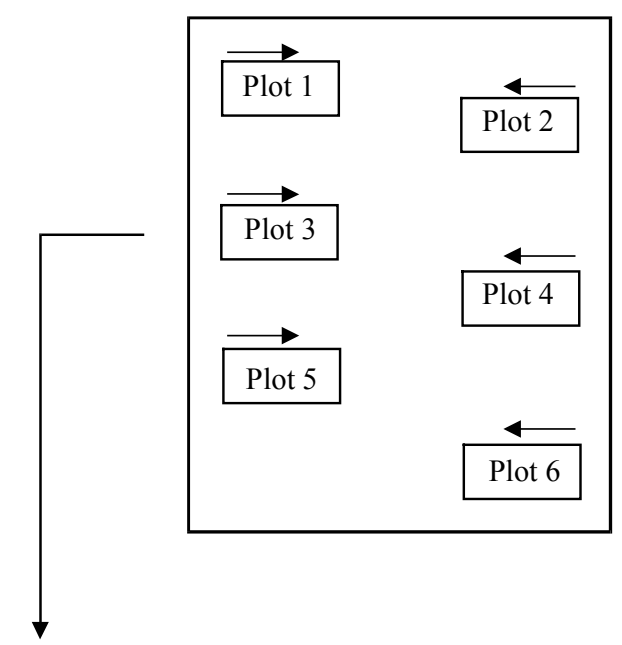

Versuchseinheit: "Topfversuche"

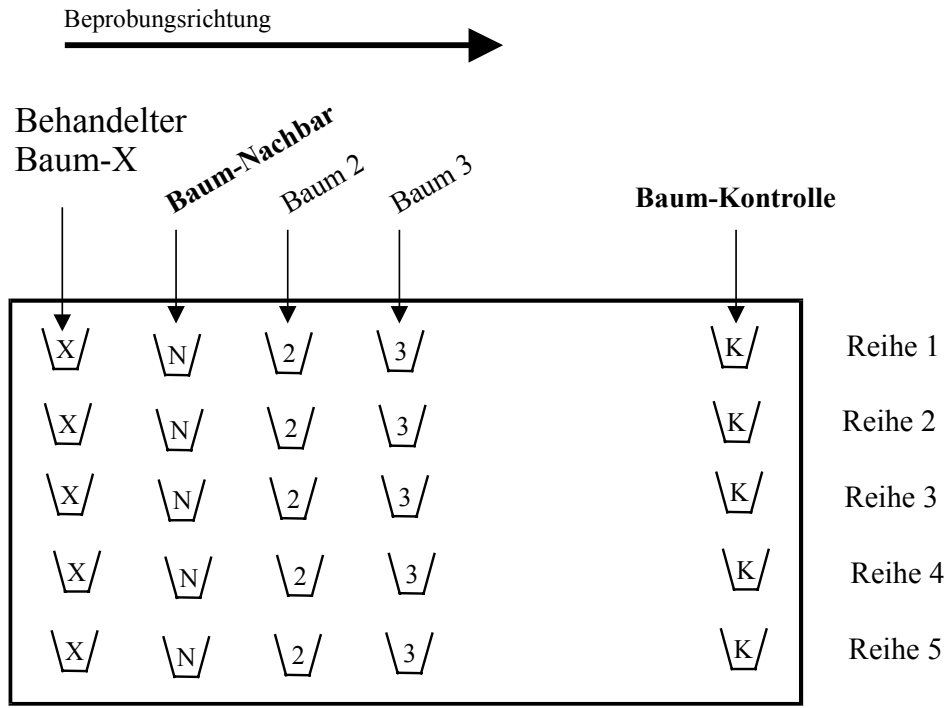

$\bigsqcup=$ getopfte Erle

Abb. 6: Schematische Darstellung des Versuchsaufbaus „Topfversuch“ 1997 (Neuer Botanischer Garten Göttingen). Auf der Versuchsfläche (14,5 m x 26 m) wurden 6 Versuchswiederholungen (Plot 1 - Plot 6) so verteilt, daß sie im größtmöglichen Abstand zueinander standen. Jede Versuchseinheit (= Plot) bestand aus 25 Töpfen, die in fünf parallel angeordneten Reihen mit jeweils fünf Töpfen aufgestellt waren. Die geschädigte Pflanze erhielt die Bezeichnung „Baum-X“ (X). Der unmittelbar benachbarte Baum die Bezeichnung „Baum-Nachbar“ $(\mathrm{N})$ und der am entferntesten stehende Baum der Reihe die Bezeichnung „Baum-Kontrolle“ (K). Die zwischen „Baum-Nachbar“ und „Baum-Kontrolle“ stehenden Pflanzen wurden mit „Baum 2“ und „Baum 3“ benannt. 
Nach dem Blattaustrieb im Frühjahr (21. Mai 1997) wurde in jeder Reihe des Plots die erste Erle „Baum-X“ zur Simulation starken Phytophagenfraßes experimentell geschädigt, indem alle vorhandenen Blätter jeweils zur Hälfte - längs zur Blattachse - mit einer desinfizierten Schere (zur Vermeidung von Krankheitsübertragungen) abgeschnitten wurden.

Die Bäume jeder Versuchsreihe wurden mit Ziffern benannt, wobei die beschnittene Erle die Bezeichnung „Baum-X“, der unmittelbar benachbarte Baum die Bezeichnung „Baum-Nachbar“ und der am weitesten entfernt stehende Baum die Bezeichnung „Baum-Kontrolle“ erhielt. Die zwischen „Baum-Nachbar“ und „Baum-Kontrolle“ stehenden Erlenpflanzen wurden mit „Baum 2“ und „Baum 3“ bezeichnet. Der mittlere Abstand der Töpfe innerhalb der Reihe betrug $15 \mathrm{~cm}$. Zwischen den Reihen lag der Abstand bei $45 \mathrm{~cm}$. Dabei bildete der Abstand der Reihe „Baum 3“ zur Reihe „BaumKontrolle“ eine Ausnahme, denn er wies 5,65 m auf. Bei diesem Versuchsaufbau war kein Kontakt der Pflanzen untereinander gegeben. Der Stammdurchmesser wurde von allen Versuchsbäumen erfaßt. Die Meßdaten sind in Tab. C-1 (Anhang) wiedergegeben.

\subsection{2 „Reihenversuch“}

Die Überprüfung einer Resistenzinduktion ungeschädigter Nachbarn von geschädigten Bäumen, die über den Boden-Wurzelbereich und über den Luftbereich vermittelt werden könnte, erfolgte an natürlichen Erlenbeständen. Diese befinden sich am Ortsrand von Bovenden (Gemeinde Göttingen, ca. $4 \mathrm{~km}$ nördlich von Göttingen) am Bach Weende. Auf diesem Versuchsareal, einem ca. $10 \mathrm{~m}$ breiten und $500 \mathrm{~m}$ langen Streifen, wachsen insgesamt ca. 200 Erlen, die 1995 angepflanzt worden waren (mdl. Mitteilung der Gemeindeverwaltung Bovenden). Die Erlenpflanzen stehen hier in zwei parallel angeordneten Reihen.

Für die Versuchswiederholungen wurden 12 Erlengruppen ausgewählt, die sich jeweils entweder aus sieben oder acht Erlenbäumen zusammensetzten. Innerhalb jeder Wiederholung erfolgte folgende Einteilung und Bezeichnung der Bäume:

Am ersten Baum „Baum-X“ wurde Herbivorenfraß simuliert, und die Auswirkungen dieser Schädigung wurden am unmittelbar benachbarten, ungeschädigten Baum „BaumNachbar“ untersucht. Der am entferntesten stehende Baum diente als Kontrolle und 
erhielt die Bezeichnung „Baum-Kontrolle“. Die sich zwischen den Bäumen „BaumNachbar“ und „Baum-Kontrolle“ befindlichen Erlen wurden mit „Baum 2“, „Baum 3“, „Baum 4“, „Baum 5“ und „Baum 6“ numeriert (Abb. 7).

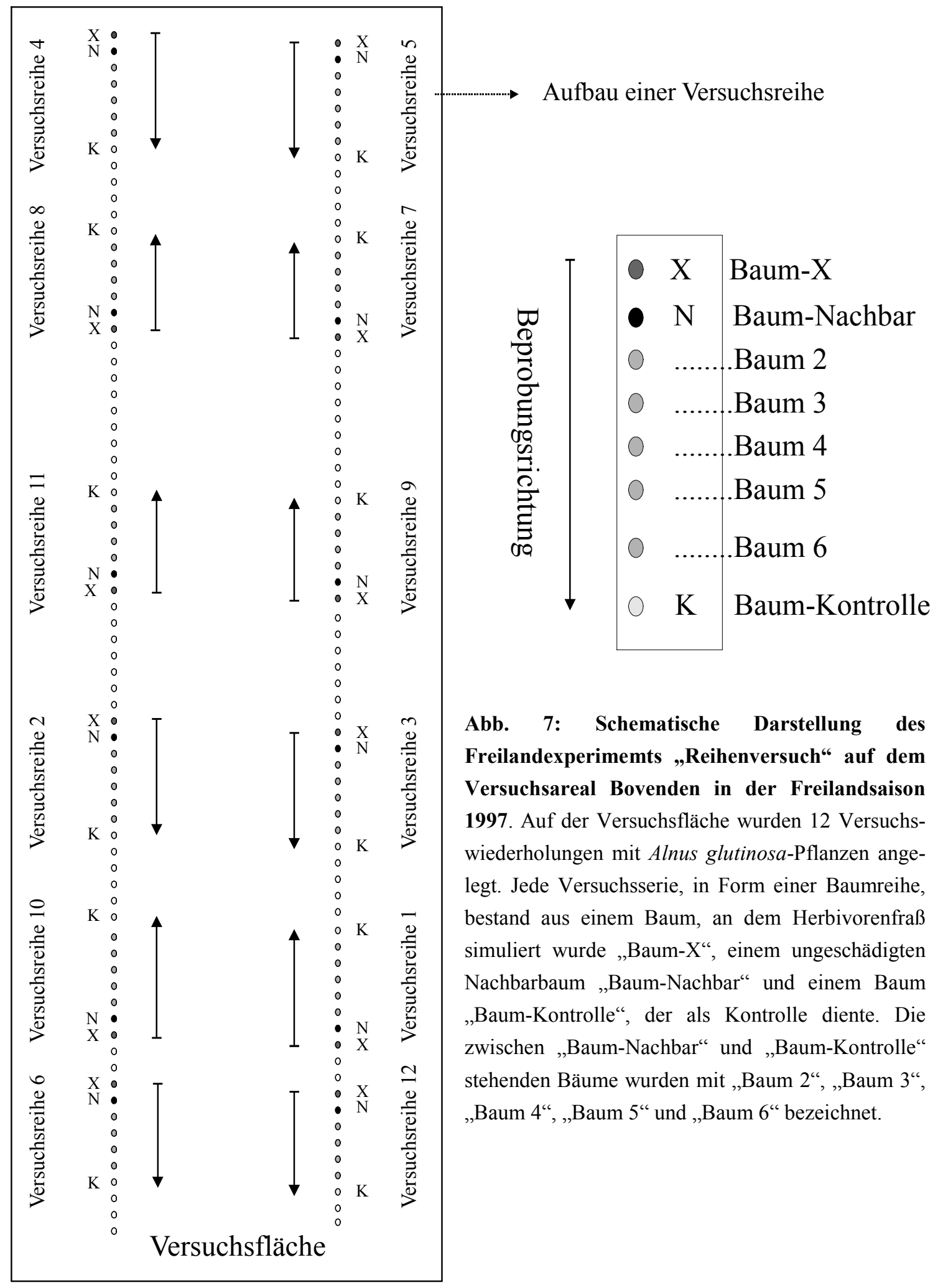


Die mittleren Baumabstände zwischen den in dem Versuch involvierten Bäumen sowie der mittlere Stammdurchmesser (Parameter zur Charakterisierung des Baumalters dieser Erlenpflanzen) sind in der folgenden Aufstellung wiedergegeben. Die Originaldaten sind in Tab. C-2 (Anhang) dargestellt.

\begin{tabular}{l|l|l|l|l|l|l|l|l} 
& Baum-X & Baum-N & Baum 2 & Baum 3 & Baum 4 & Baum 5 & Baum 6 & Baum-K \\
\hline $\begin{array}{l}\text { Stammdurch- } \\
\text { messer [cm] }\end{array}$ & $0,60 \pm$ & $0,61 \pm$ & $0,57 \pm$ & $0,61 \pm$ & $0,59 \pm$ & $0,64 \pm$ & $0,61 \pm$ & $0,59 \pm$ \\
$\begin{array}{l}\text { Mittelwert } \pm \\
\text { Stdf }\end{array}$ & 0,02 & 0,01 & 0,02 & 0,01 & 0,02 & 0,03 & 0,02 & 0,01 \\
\hline $\begin{array}{l}\text { Abstand zum } \\
\text { Baum-X [m] }\end{array}$ & & $2,02 \pm$ & $4,08 \pm$ & $6,10 \pm$ & $8,18 \pm$ & $10,03 \pm$ & $12,12 \pm$ & $13,05 \pm$ \\
Mittelwert \pm & & 0,04 & 0,07 & 0,09 & 0,09 & 0,09 & 0,16 & 0,31 \\
Stdf & & & & & & &
\end{tabular}

(Angegeben sind der Mittelwert des Stammdurchmesser [cm], gemessen in $1 \mathrm{~m}$ Höhe über dem Erdboden, aller Versuchspflanzen und der Abstand [m] der Bäume der Position „Baum-Nachbar“ (Baum-N) bis „Baum-Kontrolle“ (Baum-K) zum geschädigten Baum „Baum-X“.)

Nach dem Blattaustrieb im Frühjahr wurde die erste Erle „Baum-X“ zur Simulierung starken Phytophagesfraßes experimentell geschädigt (Durchführung vgl. „Topfversuch“, Kap. 4.3.1). Diese Behandlung erfolgte am 22. Mai 1997.

\subsection{3 „JA-Versuch“}

Die Überprüfung einer Resistenzinduktion ungeschädigter Nachbarn durch Duftstoffe von geschädigten Bäumen erfolgte mit eingetopften Erlen, um auszuschließen, daß ein Signaltransfer über den Pflanzenwurzel-Bodenbereich erfolgt. Eine Induktion der pflanzlichen Abwehr wurde durch exogene Jasmonsäureapplikation erreicht.

Die im Versuch verwendeten Erlen wurden im Frühjahr 1997 als 4-jährige Pflanzen vom Hessischen Landesamt für Forsteinrichtung, Waldforschung und Waldökologie (Hann. Münden) erworben und im gleichen Jahr in Pflanzkübel (30 1) getopft, die gebohrte Löcher in ca. $10 \mathrm{~cm}$ Höhe über dem Topfboden aufwiesen. Die Pflanzen wurden unter Freilandbedingungen ein Jahr lang in diesen Töpfen herangezogen. Bei Versuchsbeginn (1998) waren sie 5-jährig. Die zu diesem Zeitpunkt ermittelten durchschnittlichen Stammdurchmesser ([cm], gemessen in $1 \mathrm{~m}$ Höhe über dem Erdboden) aller Versuchsbäume (,Baum-JA“, „Baum-K“, „Baumnachbar 1 bis 4“, n=6) sind 
in der folgenden Auflistung angegeben. Die einzelnen Meßdaten sind in Tab. C-3 (Anhang) aufgelistet.

\begin{tabular}{l|c|c|c|c|c} 
& Baum-JA & Baumnachbar 1 & Baumnachbar 2 & Baumnachbar 3 & Baumnachbar 4 \\
\hline $\begin{array}{l}\text { Stammdurch- } \\
\text { messer [cm] }\end{array}$ & $1,80 \pm 0,10$ & $1,59 \pm 0,25$ & $2,01 \pm 0,05$ & $1,82 \pm 0,07$ & $1,60 \pm 0,14$ \\
Mittelwert \pm Stdf & Baum-K & Baumnachbar 1 & Baumnachbar 2 & Baumnachbar 3 & Baumnachbar 4 \\
\hline $\begin{array}{l}\text { Stammdurch- } \\
\text { messer [cm] }\end{array}$ & $1,61 \pm 0,11$ & $1,78 \pm 0,17$ & $1,90 \pm 0,09$ & $1,84 \pm 0,09$ & $1,71 \pm 0,15$ \\
$\begin{array}{l}\text { Mittelwert } \pm \text { Stdf } \\
\text { Ste }\end{array}$ & & & &
\end{tabular}

In der letzten Aprilwoche 1998 wurden diese Topfpflanzen weitläufig auf einer Versuchsfläche verteilt, die vom Botanischen Garten der Universität Göttingen zur Verfügung gestellt wurde. Der Versuch bestand aus 12 Topfgruppen (Mindestentfernung der einzelnen Topfgruppen zueinander: $12 \mathrm{~m}$ ), wobei eine Topfgruppe sich aus fünf Töpfen zusammensetzte. Um eine Topfpflanze „JA“ oder „K“ wurden vier Topfpflanzen, Nachbar 1 - 4, gestellt (Abb. 8). Der mittlere Abstand der benachbarten Töpfe zum mittig angeordneten Topf betrug $20 \mathrm{~cm}$. Bei der Anordnung der Pflanzen innerhalb der Topfgruppe wurde darauf geachtet, daß sich die Pflanzen nicht untereinander berührten. Die mittlere Pflanze „JA“ wurde nach dem Blattaustrieb Anfang Mai mit Jasmonsäure (wäßrige Lösung (1 mM)), die von Prof. Boland (MPI für Chemische Ökologie, Jena) zur Verfügung gestellt wurde, besprüht. Für die Kontrollgruppe wurde der gleiche Versuchsaufbau verwendet. Hier wurde die mittlere Pflanze „K“ nur mit dem Lösungsmittel Wasser behandelt. Um störende Fremdeinwirkungen während der Behandlung auszuschließen und um die Bäume der Position „Nachbar“ nicht mit zu behandeln, wurden die Erlenpflanzen „JA“ und „K“ an einer geschützten Stelle im Innenhof einer Gewächshausanlage, die weit entfernt von der Versuchsfläche lag, behandelt. Nach der Sprühbehandlung blieben die Pflanzen solange hier stehen, bis ihre Blätter abgetrocknet waren. 


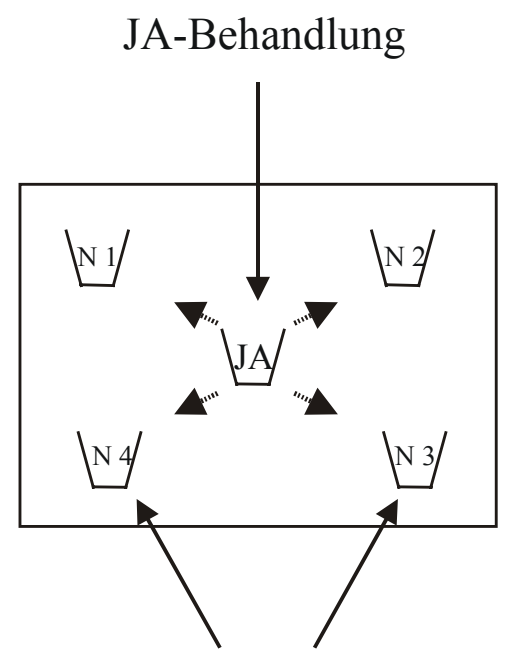

Baumnachbar-JA

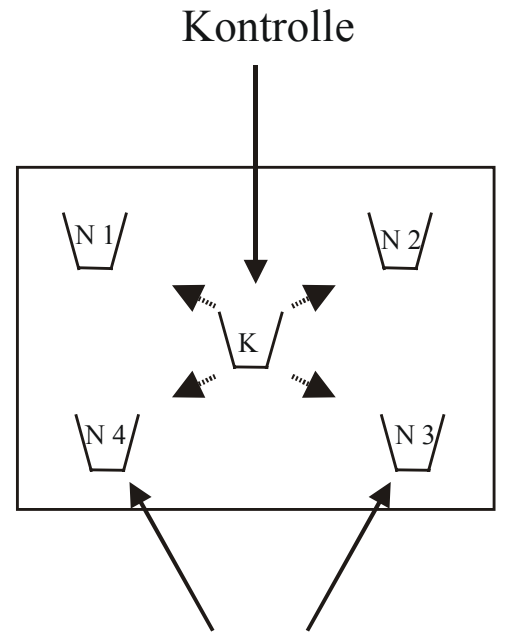

Baumnachbar-Kon

Abb. 8: Schematische Darstellung des Versuchsaufbaus „JA-Versuch“ 1998 (Neuer Botanischer Garten Göttingen). Jede Topfgruppe bestand aus fünf Töpfen mit jeweils einer 5-jährigen Erlenpflanze. Eine Topfpflanze „JA“ bzw. „K“ wurde von vier Pflanzen N 1 - N 4, „Baumnachbar“, umgeben. Die mittlere Pflanze wurde entweder mit einer $1 \mathrm{mM}$ Jasmonsäurelösung „JA“ (JA-Behandlung) oder mit Leitungswasser „K“ (Kontrolle) besprüht.

\subsubsection{Untersuchungen der Auswirkungen der simulierten Herbivorie im Freiland}

Zu festgesetzten Zeiträumen, die in Tab. 1 und Tab. 2 aufgelistet sind, wurden phänologische, physikalische und chemische Veränderungen an den Bäumen der Versuche „Topfversuch“ (Kap. 4.3.1), „Reihenversuch“ (Kap. 4.3.2) und „JA-Versuch“ (Kap. 4.3.3) untersucht. Die Bäume der Versuchsvarianten „Reihenversuch“ und „Topfversuch“ wurden an insgesamt sechs Zeitpunkten beprobt (Tab. 1) und die des „JA-Versuchs“" an insgesamt sieben Zeitpunkten (Tab. 2).

Die Erstaufnahme des Befalls (= Ausgangssituation) lag kurz vor der Durchführung der Behandlung der simulierten Herbivorie oder JA-Sprühapplikation. Die übrigen Termine wurden über die Vegetationsperiode verteilt (Tab. 1, Tab. 2). An diesen Tagen erfolgte eine Bonitur der relativen Blattschädigung an den Erlenbäumen (Kap. 4.3.4.1), und es wurden Blattproben sowohl für physikalische (Kap. 4.3.4.2.1, Kap. 4.3.4.2.2, Kap. 4.3.4.2.3) und chemische Untersuchungen (Kap. 4.3.4.2.4) als auch für Fraßwahlversuche im Labor (Kap. 4.3.4.3) gesammelt. 
Tab. 1: Zeiträume der Fraßschadensaufnahmen und Blattprobenentnahmen für die Versuche „Topfversuch“ und „Reihenversuch“ in der Freilandsaison 1997. Die Zahlenangabe in der Klammer gilt für den „Reihenversuch”. Wenn nur eine Zahlenangabe angegeben ist, gilt sie für beide Versuche.

\begin{tabular}{|c|l|l|l|}
\hline Zeitpunkt & \multicolumn{1}{|c|}{ Beprobungszeitraum } & \multicolumn{2}{c|}{ Datum } \\
& & \multicolumn{1}{c|}{ Topfversuch } & Reihenversuch \\
\hline 1 & 3 Tage vor der simulierten Herbivorie & 18. Mai & 19. Mai \\
\hline 2 & Tag der simulierten Herbivorie & 21. Mai & 22. Mai \\
\hline 3 & 7 Tage nach der simulierten Herbivorie & 28. Mai & 29. Mai \\
\hline 4 & 21 Tage nach der simulierten Herbivorie & 11. Juni & 12. Juni \\
\hline 5 & 41 (42) Tage nach der simulierten Herbivorie & 2. Juli & 4. Juli \\
\hline 6 & 107 (105) Tage nach der simulierten Herbivorie & 5. September & 4. September \\
\hline
\end{tabular}

Tab. 2: Zeiträume der Fraßschadensaufnahmen und der Blattprobenentnahmen für den ,JA-Versuch" in der Freilandsaison 1998. (JA = Jasmonsäure)

\begin{tabular}{|c|l|c|}
\hline Zeitpunkt & \multicolumn{1}{|c|}{ Beprobungszeitraum } & Datum \\
\hline 1 & 1 Tag vor der JA-Sprühapplikation & 6. Mai \\
\hline & 1. JA-Behandlung (Sprühapplikation von JA (1 mM), 1. Wiederholung & 7. Mai \\
\hline 2 & 5 Tage nach der JA-Sprühapplikation & 12. Mai \\
\hline 3 & 12 Tage nach der JA-Sprühapplikation & 19. Mai \\
\hline 4 & 33 Tage nach der JA-Sprühapplikation & 9. Juni \\
\hline & 2. JA-Behandlung (Sprühapplikation von JA (1 mM), 2. Wiederholung & 12. Juni \\
\hline 5 & 5 Tage nach der JA-Sprühapplikation & 17. Juli \\
\hline 6 & 12 Tage nach der JA-Sprühapplikation & 24. Juli \\
\hline 7 & 33 Tage nach der JA-Sprühapplikation & 15. August \\
\hline
\end{tabular}

Bei den Freilandversuchen „Topfversuch“ und „Reihenversuch“ wurden an jedem Beprobungstermin jeweils 15 Blätter von jedem Erlenbaum der Position „Baum-Nachbar“ und „Baum-Kontrolle“ mit einer Schere abgeschnitten. Bei dem Freilandversuch „JAVersuch“ wurden an jedem Beprobungstermin jeweils 13 Blätter der vier benachbarten Erlenbäumen „Baumnachbar-JA“ und „Baumnachbar-Kon“ mit einer Schere entfernt. Dabei wurden Blätter gewählt, deren Farbe und Größe auf ein ähnliches Alter hindeuteten. Jeweils drei Blätter pro Baum wurden zur Bestimmung des Phenolgehalts (Kap. 4.3.4.2.4) direkt im Freiland eingefroren. Die restlichen Blätter wurden bis zur weiteren Aufarbeitung in einer Styroporbox gekühlt. Von diesen wurden jeweils drei Blätter zur Bestimmung des Blattwassergehalts (Kap. 4.3.4.2.1), des spezifischen Blattgewichts (Kap. 4.3.4.2.2), der Blattfestigkeit (Kap. 4.3.4.2.3) sowie der Fraßpräferenz von A. alni (Kap. 4.3.4.3) eingesetzt. Eine Ausnahme bildete dabei der „JA-Versuch“: Hier wurde nur ein Blatt für den Fraßpräferenztest verwendet. 


\subsubsection{Relative Blattschädigung}

Für die Bäume der Versuche „Topfversuch“ (Kap. 4.3.1), „Reihenversuch“ (Kap. 4.3.2) und „JA-Versuch“ (Kap. 4.3.3) wurde der im Verlauf des Jahres auftretende Herbivorenfraßschaden zu den genannten Beprobungsterminen (Tab. 1, Tab. 2) in Prozent der geschädigten Blattfläche geschätzt und protokolliert. Bei der Klassifizierung und Aufnahme des Befalls wurde immer der Gesamthabitus mit allen Blättern eines Baumes betrachtet (Blätter gesamt; Blätter geschädigt), so daß der auftretende Schaden als relativer Fraßschaden angegeben werden kann.

\subsubsection{Untersuchungen zur Ermittlung von physikalischen und chemischen Veränderungen}

Bei einer Resistenzinduktion können sowohl physikalische als auch chemische Blatteigenschaften verändert werden. Um festzustellen, mit welchen Veränderungen dabei im Blattgewebe von A. glutinosa zu rechnen sind, wurden der prozentuale Blattwassergehalt, das spezifische Blattgewicht, die Blattfestigkeit und der Blattphenolgehalt der benachbarten und der als Kontrolle dienenden Erlen ermittelt.

\subsection{Prozentualer Blattwassergehalt}

Das Frischgewicht (FW) der gepflückten Blätter wurde auf einer Feinwaage (MC-1, Sartorius) bestimmt. Nach dem Einscannen der Blätter mit einem Flachbettscanner (Hewlett Packard Scan Jet II CX) zur Ermittlung der Blattfläche wurden die Blätter $48 \mathrm{~h}$ bei $60{ }^{\circ} \mathrm{C}$ im Trockenschrank getrocknet. Anschließend wurde das Trockengewicht (DW) ermittelt. Der Gewichtsverlust stellt den prozentualen Wassergehalt des Blattes pro $\mathrm{cm}^{-2}$ Blattfläche dar.

\subsection{Spezifisches Blattgewicht}

Das spezifische Blattgewicht ist ein charakteristisches Maß für die Einlagerung nichtabbaubarer Substanzen in die Zellwände dar. Der Quotient aus Trockensubstanz und Blattflächeneinheit ergibt das spezifische Blattgewicht (MOONEY \& GULMON 1982). 


\subsection{Blattfestigkeit}

Der Widerstand beim Durchstoßen einer definierten Fläche eines Blattes gilt als Maß für die Blattfestigkeit. Die Werte dieses Parameters wurden mit der Methode nach FEENY (1970) ermittelt (Abb. 9).

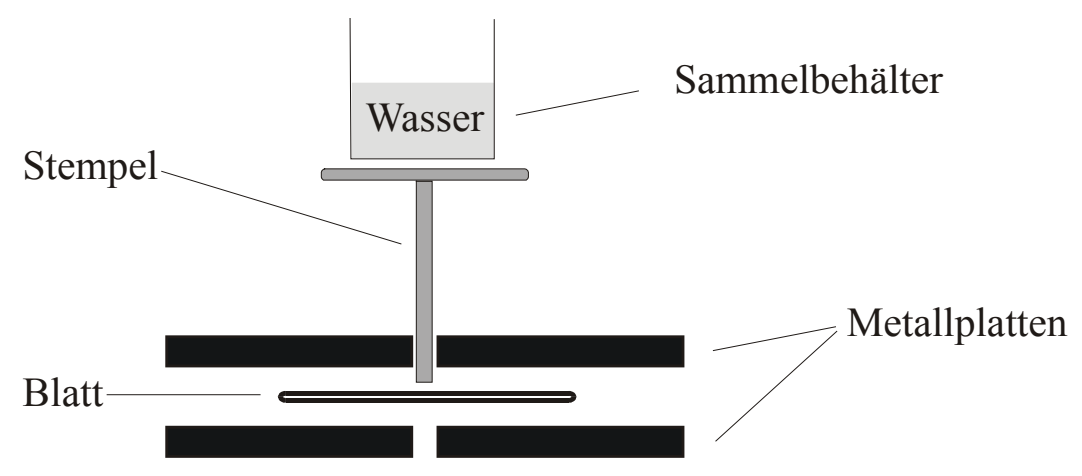

Abb. 9: Versuchsaufbau zur Bestimmung der Blattfestigkeit (Methode nach FEENY (1970)).

Zur Bestimmung der Blattfestigkeit wurden die zu untersuchenden Blätter zwischen zwei Metallplatten $(14,5 \mathrm{~cm}$ x 14,5 cm x 1,2 cm) über ein Loch $(\varnothing=0,5 \mathrm{~cm})$ gelegt, das sich in der Mitte von beiden Platten befand. Ein Stempel (bestehend aus Stempelstiel $(\varnothing=0,5 \mathrm{~cm})$ und einer Platte) wurde über eine Führungsschiene durch das Loch geführt, bis er auf die Blattfläche traf. Dann wurde mit einem dünnen Wasserstrahl, dessen Volumen sich in einem Sammelbehälter auffing, solange der Druck auf den Stempel erhöht, bis dieser die Blattfläche durchstieß. Dieser Widerstand, der dem Durchstoßen von einer definierten Fläche des Blattes entgegengesetzt wird, bildet ein Maß für die Blattfestigkeit.

\subsection{Phenolgehalt}

Die quantitative Bestimmung des Phenolgehalts erfolgte nach der in Kap. 4.4.3.1 beschriebenen Methode. Für den „Reihenversuch“ (Kap. 4.3.2) konnten keine Blattphenolgehalte ermittelt werden, weil die Proben bei der Tiefkühllagerung durch einen Gerätedefekt unbrauchbar wurden. 


\subsubsection{Fraßwahlverhalten des Herbivoren Agelastica alni}

Die beste Methode zur Feststellung induzierter Resistenz stellen Biotests dar, bei denen die Auswirkungen auf die Herbivoren getestet werden. Für die Fraßwahlversuche wurden an den Tagen der Fraßschadensbonitierung (Tab. 1, Tab. 2) im Freiland frische Erlenblätter gepflückt. Bei den Freilandexperimenten „Topfversuch“ (Kap. 4.3.1) und „Reihenversuch“ (Kap. 4.3.2) wurden drei Blätter von dem unmittelbar benachbarten „Baum-Nachbar“ und dem am weitesten entfernt liegenden „Baum-Kontrolle“ gesammelt. Aus drei Blättern eines Baumes wurde jeweils eine Blattscheibe ausgestanzt (Durchführung s.u.). Somit entstanden für den Fraßwahlversuch drei Petrischalen pro Baumpaar „Baum-Nachbar“ und „Baum-Kontrolle“ mit jeweils zwei Blattscheiben (,Baum-Nachbar“ vs. „Baum-Kontrolle). Für eine Kontrollschale, die zur Bestimmung des Verhältnisses von Frisch- zu Trockenmasse diente und die dasselbe Analyseverfahren ohne Herbivoren durchlief, wurden zusätzlich noch zwei Blattscheiben des Baumpaares benötigt. Bei dem „JA-Versuch“ (Kap. 4.3.3) wurde ein Blatt von den unmittelbar benachbarten vier Bäumen gesammelt, und zwar jeweils von der Behandlungsvariante „Baumnachbar-JA“ „Baumnachbar-Kon“. Aus dem Blatt eines Baumes „Baumnachbar-JA“ und „Baumnachbar-Kontrolle“ wurde jeweils eine Blattscheibe ausgestanzt (Durchführung s.u.). Somit entstanden für den Fraßwahlversuch vier Petrischalen pro Behandlungsvariante „Jasmonsäure“ und „Wasser“ mit jeweils zwei Blattscheiben („Baumnachbar-JA“ vs. „Baumnachbar-Kontrolle“). Für eine Kontrollschale waren noch zwei Blattscheiben von jeder Behandlungsvariante erforderlich.

Vorbereitung und Durchführung der Fraßwahlversuche

Mit einem Locheisen wurden kleine Blattstückchen $(\varnothing=1 \mathrm{~cm})$ aus den Erlenblättern ausgestanzt und gewogen (MC-1, Sartorius). Beim Ausstanzen der Blattstücke wurde darauf geachtet, Stücke mit möglichst feinen Blattnerven, aber nicht direkt am Blattrand und an der Blattmittelrippe zu entnehmen. Die Blattstücke wurden dann auf Petrischalen, die mit Filterpapier ausgelegt und mit $500 \mu 1$ Wasser befeuchtet wurden, verteilt. Die räumliche Anordnung (rechts / links) der Blattstücke auf den Petrischalen erfolgte nach dem Zufallsprinzip. Anschließend wurde zu jeder Petrischale entweder eine Imago oder eine Larve von A. alni, die aus der Laborzucht (Kap. 4.2) stammten, gesetzt. Dabei wurde darauf geachtet, daß innerhalb der einzelnen Versuche wie auch zwischen den 
verschiedenen Beprobungsterminen immer Tiere gleichen Alters verwendet wurden. Bei Versuchsende nach $18 \mathrm{~h}$ wurden die alten Blattstückchen entfernt, ggf. mit Wasser von Kotresten gereinigt und bei $60{ }^{\circ} \mathrm{C} 48 \mathrm{~h}$ lang in einem Trockenschrank getrocknet und das Trockengewicht bestimmt. Aus mehreren Kontrollwerten (ohne Larvenfraß) wurde jeweils das mittlere Trockengewicht der Blattscheiben bestimmt. Mit ihm wurde das Trockengewicht der gefressenen Blattmenge wie folgt berechnet:

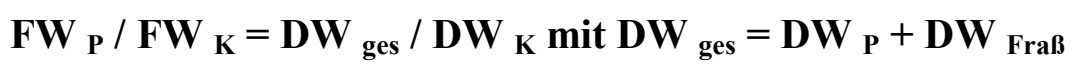

Durch Umformung erhält man eine Formel zur Berechnung des Trockengewichts der gefressenen Blattmenge:

$$
\mathrm{DW}_{\mathrm{Fra \beta}}=\left(\mathrm{FW}_{\mathrm{P}} / \mathbf{F W _ { K }}\right) * \mathrm{DW}_{\mathrm{K}}-\mathbf{D W _ { P }}
$$

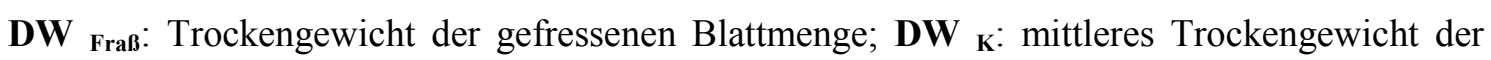
Kontrollen; FW к: mittleres Frischgewicht der Kontrollen; FW p: Frischgewicht der Probe; DW P: Trockengewicht der Probe ohne die gefressene Blattmenge; $\mathbf{D W}_{\text {ges: }}$ Trockengewicht der Probe incl. die gefressene Blattmenge (theoretische Größe). 


\subsection{Laboranalysen}

\subsubsection{Physiologische Untersuchungen zu Veränderungen im Blattgewebe von Alnus glutinosa}

\subsubsection{Inkubationsversuche}

In Inkubationsversuchen sollten die Auswirkungen verschiedener Behandlungsvarianten auf den Stoffwechsel von A. glutinosa festgestellt werden. Dabei erfolgte die Applikation einmal in Form einer wäßrigen Lösung der zu untersuchenden Verbindung. Zum anderen wurden verschiedene Duftkomponenten jeweils als Einzelkomponenten in volatiler Form auf ihre Signalwirkung in der Induktion von physiologischen Veränderungen im Stoffwechsel von A. glutinosa getestet. Parallel dazu wurden unterschiedliche Varianten der Blattverletzungen wie Herbivorenfraß oder mechanische Verletzung untersucht. Die allgemeine Versuchsdurchführung der verschiedenen Behandlungsvarianten mit Vorbereitung, Durchführung und eingesetzten Substanzen sowie deren Konzentrationen wird in dem Behandlungsprotokoll (Kap. 4.4.2) beschrieben.

Tab. 3 gibt eine Übersicht der durchgeführten Inkubationsversuche sowie der analysierten chemischen und physiologischen Veränderungen nach verschiedenen Behandlungsvarianten. $\mathrm{Zu}$ festgelegten Zeitpunkten $(\mathrm{t})$ wurden die Experimente beendet und die physiologischen Veränderungen (Phenolgehalte, Aktivitätsbestimmung von Polyphenoloxidase, Peroxidase, Lipoxygenase, Katalase und Proteinaseinhibitoren) analysiert. Jede Assayreihe bestand dabei aus den verschiedenen Behandlungsvarianten und wurde mehrmals wiederholt (Anzahl der Versuchswiederholungen $=\mathrm{n}$ ). 
융

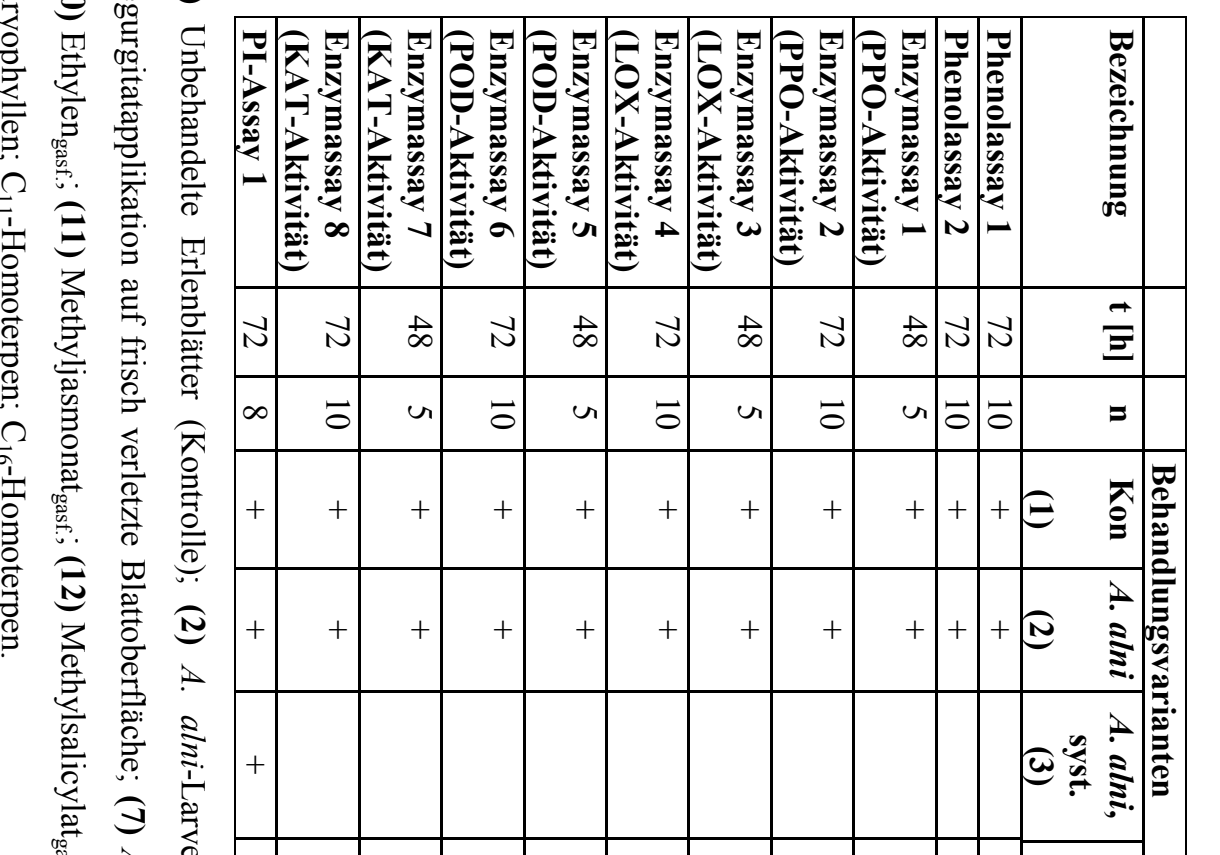

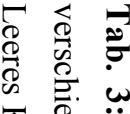

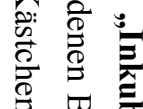

II

을.

思

क्ष

?

产

둥.

๑

产言点

言 :

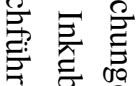

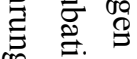

芯苛

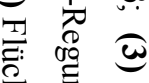

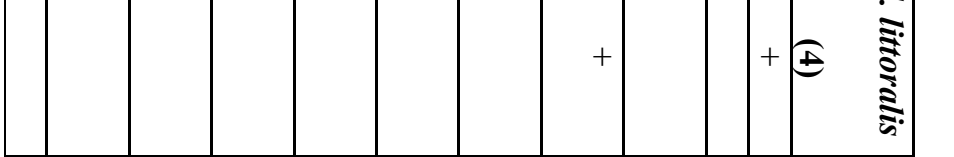

융

व्व

吾

항

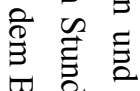

我

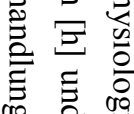

긍

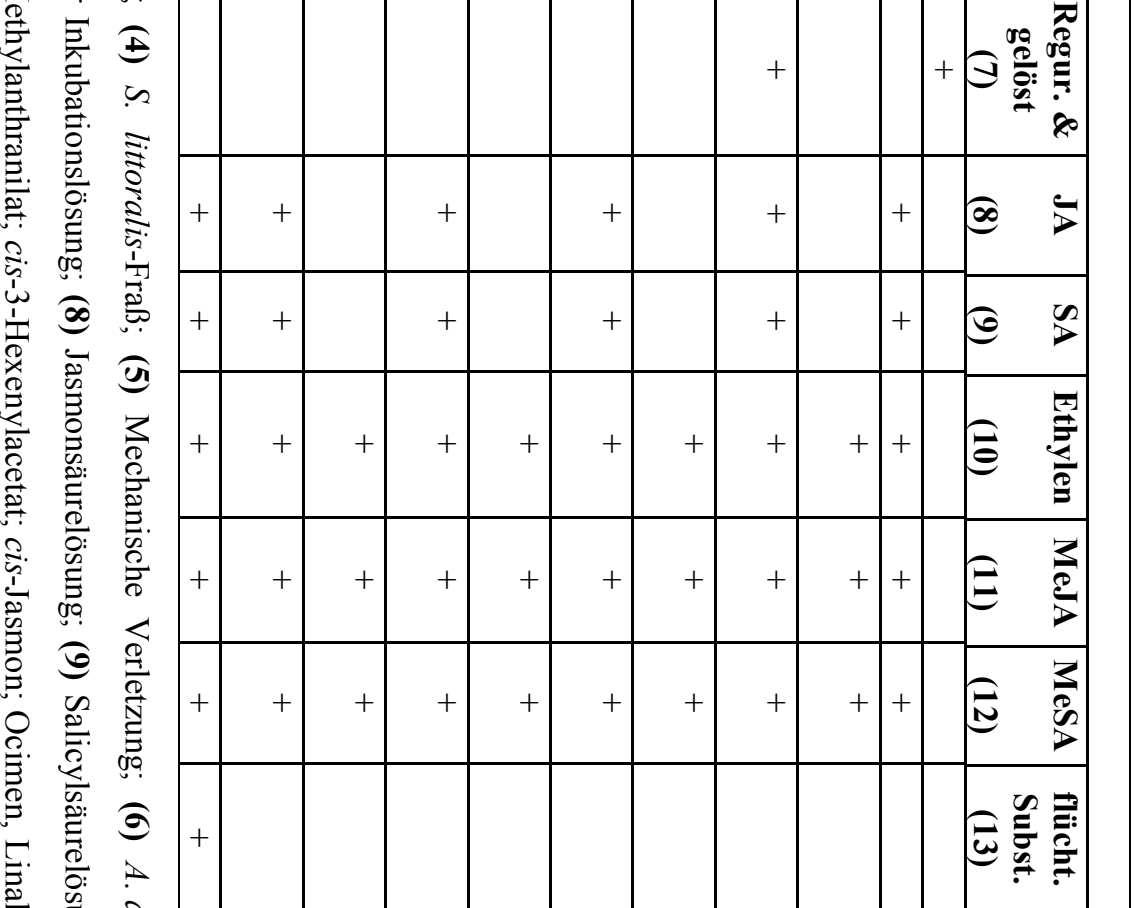

:

总产 


\subsubsection{2 „Containerversuche“}

Um die Auswirkungen geschädigter Erlen bzw. von fraßinduzierten Duftstoffen auf unverletzte Nachbarn zu untersuchen, wurden „Containerversuche“ durchgeführt. In der ersten, geschlossenen Glaskammer befand sich ein Trieb unbehandelter Erlenblätter

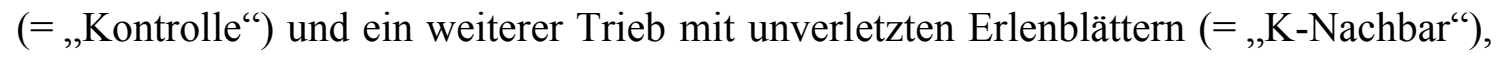
auf den die Auswirkungen des ersten Triebes untersucht werden sollten. Beide Triebe standen in unmittelbarer Nähe zueinander, berührten sich aber nicht mit ihren Blattflächen. In einer zweiten, geschlossenen Glaskammer befand sich ein Trieb mit Erlenblättern, der über den gesamten Versuchszeitraum hinweg durch Fraß von A. alniLarven (5 Larven pro Blatt) $\left(=, A\right.$. alni $\left.{ }^{\star 6}\right)$ geschädigt wurde. Um ein Entkommen der Larven von den Fraßblättern zu verhindern, wurden die Larven zusammen mit dem Blatt von einem „Gaze“-Käfig umschlossen. Neben dem fraßgeschädigten Trieb wurde ein befallsfreier, unverletzter Erlentrieb positioniert (=,A-Nachbar“). Da immer beide Pflanzen (,Kontrolle“- „K-Nachbar“) und (,A. alni" - „A-Nachbar“) zusammen in einem Glascontainer inkubiert wurden, konnten die Auswirkungen der behandelten Erlenblätter auf die benachbarten, unverletzten Erlenblätter untersucht werden, wobei ein Signaltransfer nur über den Gasraum mittels flüchtiger Duftstoffe möglich war.

$\mathrm{Zu}$ festgelegten Zeitpunkten ( $\mathrm{t}$ ) wurden die „Containerversuche“ beendet und die physiologischen Veränderungen (Phenolgehalte, Aktivitätsbestimmung von Polyphenoloxidase, Peroxidase, Lipoxygenase und Proteinaseinhibitoren) der Behandlungsvarianten „Kontrolle“, „K-Nachbar“, „A. alni“ und „A-Nachbar“ analysiert. Mit einem Fraßwahlversuch wurden die unmittelbaren Auswirkungen veränderter Blattqualitäten auf den Herbivoren A. alni untersucht.

Containerversuch-Phenolassay: Quantitative Phenolbestimmung nach $\mathrm{t}=3 \mathrm{~h} ; 6 \mathrm{~h}$; $12 \mathrm{~h} ; 24 \mathrm{~h} ; 48 \mathrm{~h}$ und $72 \mathrm{~h}$ (für alle Zeitpunkte: $\mathrm{n}=7$ ).

Containerversuch-Enzymassay: Aktivitätsbestimmung der Enzyme Polyphenoloxidase, Peroxidase und Lipoxygenase nach $\mathrm{t}=72 \mathrm{~h}$ (für alle Enzyme: $\mathrm{n}=9$ ).

Containerversuch-Proteinaseinhibitoraktivitätsassay: Aktivitätsbestimmung der Proteinaseinhibitoren nach $\mathrm{t}=72 \mathrm{~h}(\mathrm{n}=6)$. 
Containerversuch-Fraßwahlversuche: Für die Untersuchung der unmittelbaren Auswirkungen veränderter Blattqualitäten auf den Herbivoren A. alni wurden Blattstücke der Behandlungsvarianten „Kontrolle“, „K-Nachbar“, „A. alni““ und „A-Nachbar nach Inkubation für $\mathrm{t}=72 \mathrm{~h}$ und $\mathrm{t}=96 \mathrm{~h}$ eingesetzt.

\subsubsection{Behandlungsprotokoll}

Die nachfolgende Auflistung gilt als Grundlage für die allgemeine Versuchsdurchführung mit verschiedenen Behandlungsvarianten, wie sie in den Inkubationsversuchen (Kap. 4.4.1.1) sowie in den CLS-Analysen (Kap. 4.4.4.2) angewandt wurden. Das Protokoll gibt einen detaillierten Überblick über Vorbereitung, Durchführung und verwendete Substanzen sowie eingesetzte Konzentrationen.

Allgemeine Vorbereitung der Pflanzen

Das in den folgenden Versuchsvarianten eingesetzte Blattmaterial von A. glutinosa stammte von den Erlenpflanzen aus der Klimakammeranzucht (Kap. 4.1). Kurz vor Versuchsbeginn wurden von diesen Pflanzen unbeschädigte Triebe mit jeweils drei Blättern abgeschnitten und sofort in ein Glasgefäß mit Wasser gestellt. Dieses wurde mit einem Stück Alufolie abgedichtet. Anschließend wurden die Blatttriebe vorsichtig in einen Exsikkator überführt, der zur Inkubation mit einem Deckel verschlossen wurde.

Kontrolle

Als Kontrollvariante $\mathrm{zu}$ den einzelnen Versuchsbehandlungen dienten unbehandelte Erlentriebe, die nur mit Wasser als Inkubationslösung in den Exsikkatoren inkubiert wurden (Kontrolle). Bei der Versuchsvariante der Inkubation mit flüchtigen Duftstoffkomponenten wurde zu den unbehandelten Erlenblätter zusätzlich Filterpapier plaziert, auf das das Lösungsmittel Dichlormethan aufgetragen worden war.

Agelastica alni-Fraß

Für die Messungen mit Fraß durch $A$. alni wurden entweder fünf Larven oder drei Imagines pro Blatt verwendet (Agelastica alni-Fraß). Die Tiere stammten aus der eigenen Laborzucht (Kap. 4.2). 
Agelastica alni, systemisch

Bei dieser Versuchsvariante wurden ungeschädigte Blätter, die direkt benachbart zu A. alni-befressenen Blättern positioniert waren, eingesetzt (Agelastica alni, systemisch). Alle Blätter gehörten zum selben Trieb. Damit wurde überprüft, ob in Folge einer systemischen Reaktion eine Aktivierung pflanzlicher Abwehrmechanismen in noch nicht geschädigtem Gewebe erfolgt.

\section{Spodoptera littoralis-Fraß (Lepidoptera: Noctuidae)}

Für die Messungen mit Raupenfraß durch $S$. littoralis wurden zwei bis zehn Raupen (je nach Larvenstadium, vorwiegend aber L3-Larven (5 Stück pro Blatt)) pro Blatt verwendet (Spodoptera littoralis-Fraß). Das eingesetzte Raupenmaterial wurde der Insektenzucht des Max-Planck-Institutes für Chemische Ökologie (Jena), entnommen (Anzucht und Haltung der Tiere siehe Anhang B).

\section{Mechanische Verletzung}

Um die Auswirkungen einer mechanischen Verletzung an Erlenblättern zu testen, wurde die Blattfläche mit einem „Fakirstempel“ (Metallstempel $(\varnothing=3,5 \mathrm{~cm})$ mit 48 Metallstiften von ca. 1,5 cm Länge und $\varnothing=0,1 \mathrm{~mm}$; Zoutkamp, Holland) gelocht (Mechanische Verletzung).

Regurgitatapplikation (Regurgitat, gelöst / Regurgitat, mech.)

Das von den $A$. alni-Larven frisch gewonnene Regurgitat (zur Gewinnung Kap. 4.4.6) wurde kurz abzentrifugiert und der klare Überstand mit einer Glaskapillare aufgenommen. Das Regurgitat wurde entweder in die wäßrige Inkubationslösung gemischt (30 $\mu 1$ Regurgitat / 2,5 ml wäßriger Inkubationslösung; Regurgitat, gelöst) oder auf die frisch mechanisch verletzten Blattoberflächen (Durchführung der Blattverletzung nach Punkt „Mechanische Verletzung“) geträufelt (Regurgitat, mech.).

Inkubation mit Jasmonsäure und Salicylsäure

Jasmonsäure (JA) und Salicylsäure (SA) wurden jeweils als wäßrige Lösung (1 mM) appliziert. Nachdem die Erlentriebe von der Pflanze abgeschnitten worden waren, wurden sie direkt in die Inkubationslösung mit der jeweiligen Testsubstanz gestellt. Durchschnittlich nahmen die Triebe ein Volumen von $2 \mathrm{ml}$ pro Tag von der 
Inkubationslösung auf. Die weitere Inkubation erfolgte wie unter Punkt „Allgemeine Vorbereitung der Pflanzen“ beschrieben.

Inkubation mit Methyljasmonat $_{\text {gasf., }}$ Methylsalicylat ${ }_{\text {gasf., }}$, Ethylen $_{\text {gasf. }_{\text {. }}}$

Die Vorbereitung der Erlentriebe und das Bestücken der Exsikkatoren erfolgte wie unter Punkt „Allgemeine Vorbereitung der Pflanzen“ beschrieben. Für die Applikation über die Gasphase wurden Methyljasmonat (MeJA; Dr. Roman Kaiser, Givaudan Roure AG) und Methylsalicylat (MeSA) (Sigma) in Dichlormethan gelöst $\left(1 \mu g \mu l^{-1}\right)$. Von dieser Lösung wurden jeweils $5 \mu 1$ auf je ein Filterpapier getropft. Nach dem Verdampfen des Lösungsmittels wurde das Filterpapier in den Exsikkator $(\mathrm{V}=2700 \mathrm{ml})$ gehängt, ohne daß es zu einem Kontakt mit den Blättern kam. Ethylen (Messer) wurde mit einer gasdichten Spritze in den Exsikkator injiziert $(\mathrm{V}=1 \mathrm{ml})$. Somit ergaben sich folgende Konzentrationen der eingesetzten Substanzen (bezogen auf das Volumen des Exsikkators und unter der Voraussetzung, daß die Substanzen vollständig in die Gasphase übergehen): MeJA $=0,008^{*} 10^{-3} \mathrm{~mol} / \mathrm{l} ; \mathrm{MeSA}=0,012^{*} 10^{-3} \mathrm{~mol} / \mathrm{l}$.

Inkubation mit weiteren flüchtigen Komponenten

Die Applikation der flüchtigen Komponenten [Methylanthranilat (Sigma), cis-3-Hexenylacetat (Sigma), cis-Jasmon, Ocimen (Fluka), Linalool (Fluka), Caryophyllen (Fluka), 4,8-Dimethylnona-1,3,7-trien $\left(\mathrm{C}_{11}\right.$-Homoterpen; Synthese Arbeitskreis Prof. Boland (MPI für Chemische Ökologie, Jena)), 4,8,12-Trimethyltrideca-1,3,7,11-tetraen $\left(\mathrm{C}_{16^{-}}\right.$ Homoterpen, Synthese Arbeitskreis Prof. Boland (MPI für Chemische Ökologie, Jena))] erfolgte über die Gasphase. Die Substanzen wurden, wie unter Punkt „Inkubation mit

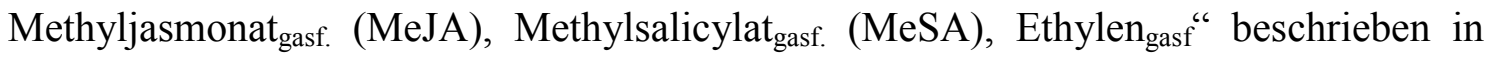
Dichlormethan gelöst $\left(1 \mu \mathrm{g} \mu \mathrm{l}^{-1}\right)$. Jeweils $5 \mu \mathrm{l}$ dieser Lösungen wurden auf je ein Filterpapier getropft, das nach dem Verdampfen des Lösungsmittels in den Exsikkator ( $\mathrm{V}=2700 \mathrm{ml}$ ) gehängt wurde. Somit ergaben sich folgende Konzentrationen der eingesetzten Substanzen (bezogen auf das Volumen des Exsikkators und unter der Voraussetzung, daß die Substanzen vollständig in die Gasphase übergehen): Methylanthranilat $=$ $0,012 * 10^{-3} \mathrm{~mol} / \mathrm{l} ;$ cis-3-Hexenylacetat $=0,013 * 10^{-3} \mathrm{~mol} / \mathrm{l} ;$ cis-Jasmon $=0,011^{*} 10^{-3}$ $\mathrm{mol} / \mathrm{l}$; Ocimen $=0,013 * 10^{-3} \mathrm{~mol} / \mathrm{l} ;$ Linalool $=0,012 * 10^{-3} \mathrm{~mol} / \mathrm{l} ;$ Caryophyllen $=$ $0,009 * 10^{-3} \mathrm{~mol} / \mathrm{l} ; \quad 4,8$-Dimethylnona-1,3,7-trien $=0,012 * 10^{-3} \mathrm{~mol} / 1 ; 4,8,12$-Trimethyltrideca-1,3,7,11-tetraen $=0,008 * 10^{-3} \mathrm{~mol} / 1$. 


\subsubsection{Durchführung der chemischen und physiologischen Analysen}

\subsubsection{Phenolgehalt}

Die Bestimmung des Phenolgehalts erfolgte nach der Folin-Denis-Methode (SWAIN \& HILlis 1959). Bis auf leichte Modifikationen wurde die Quantifizierung wie von MARTIN \& MARTIN (1982) beschrieben durchgeführt.

Nach Beendigung der Inkubations- und Containerversuche wurde das Pflanzenmaterial bei $45^{\circ} \mathrm{C}$ über Nacht im Trockenschrank getrocknet. Vor der Bestimmung des Trockengewichts (DW) wurden die Blattstiele entfernt. Das abgewogene Blattmaterial wurde in

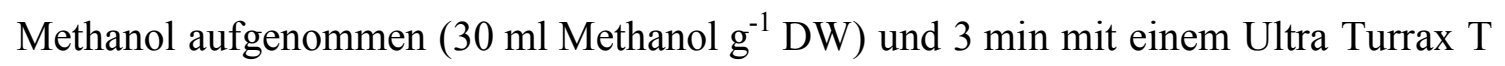
25 zerkleinert. Anschließend erfolgte die Extraktion im Trockenschrank ( $\left.75^{\circ} \mathrm{C}, 3 \mathrm{~h}\right)$, wobei die Proben mehrmals gut durchmischt wurden. Nach Inkubationsende wurden die Proben auf Raumtemperatur abgekühlt und kurz abzentrifugiert. Das Volumen des methanolischen Überstandes wurde bestimmt und der Extrakt nach folgendem Schema weiter verarbeitet:

5 oder $10 \mu 1$ Methanolextrakt (abhängig vom Phenolgehalt der Probe) wurden auf ein Endvolumen von $850 \mu 1$ mit Aqua bidest. aufgefüllt und gut durchmischt. Zu diesem wässrigen Methanolextrakt wurden $50 \mu 1$ Folin-Reagenz (Sigma) gegeben und gut mit einem Vortex gemischt. Anschließend wurden $100 \mu 1$ einer gesättigten $\mathrm{Na}_{2} \mathrm{CO}_{3}$-Lösung zu dem Ansatz hinzugefügt. Nach 30-minütiger Inkubation der Proben bei Raumtemperatur wurde die Absorption mit einem Photometer (Perkin Elmer, UV/Vis Spektrometer Lambda 2S) bei $725 \mathrm{~nm}$ in Plastikküvetten vermessen. Mittels einer $10 \mathrm{mM}$ GuaiacolEichlösung wurde eine lineare Regressionsgerade zur Bestimmung der Phenolmenge ermittelt, die als $\mathrm{DW}^{-1}\left[\mathrm{mg} \mathrm{g}^{-1}\right]$ berechnet wurde.

\subsubsection{Enzymaktivitäten}

Nach Beendigung der einzelnen Inkubations- und Containerversuche wurden die Erlenblätter in flüssigem Stickstoff gemörsert, in gekühltem 0,1 $\mathrm{M} \mathrm{NaHPO}_{4} / \mathrm{Na}_{2} \mathrm{PO}_{4}$-Puffer (pH 7,2) mit 0,1\%(w/v) Natriumdodecylsulfat (SDS) und 0,1\%(w/v) Polyvinylpolypyrrolidon (PVPP) aufgenommen. Das Homogenat wurde 10 min lang mit $12000 \mathrm{~g}$ 
bei $4{ }^{\circ} \mathrm{C}$ abzentrifugiert. Der klare Überstand wurde entweder sofort für die nachfolgenden Bestimmungen der Enzymaktivitäten von Polyphenoloxidasen, Lipoxygenasen, Peroxidasen und Katalasen weiterverwendet oder in flüssigem Stickstoff schockgefroren und bei $-80{ }^{\circ} \mathrm{C}$ gelagert.

Die Bestimmung des eingesetzten Proteingehalts der Pflanzenproben erfolgte nach der Methode nach BRADFORD (1976) mit Coomassie Brilliant Blue G 250 (Serva). Mit Rinderserumalbumin (BSA)-Eichlösungen wurde eine lineare Regressionsgerade erstellt und zur Bestimmung der Proteinmenge herangezogen.

\subsection{Polyphenoloxidase}

Die Bestimmung der Polyphenoloxidase-Aktivität (PPO-Aktivität) wurde modifiziert nach SHERMAN et al. (1991) durchgeführt. Der Nachweis der Polyphenoloxidase-Aktivität beruht auf der photometrischen Änderung der Absorption von Dihydroxyphenylalanin (DOPA) zu Quinonpolymeren. Um aus der Pflanzenprobe für den Enzymassay störendes $\mathrm{H}_{2} \mathrm{O}_{2}$ und störende Peroxidaseaktivität zu elimieren, wurde dem Reaktionsansatz Katalase (Sigma) zugesetzt. Die Reaktion wurde durch die Zugabe des Proteins gestartet. Die Absorptionsmessung wurde in einem Photometer (Perkin Elmer, UV/Vis Spektrometer Lambda 2S) bei einer Wellenlänge von $490 \mathrm{~nm}$ in Plastikküvetten über einen Zeitraum von 5 min durchgeführt. Die Polyphenoloxidase-Aktivität wird als $\left(\Delta \mathrm{E}_{490} \mathrm{~min}^{-1} \mathrm{mg}^{-1}\right.$ Protein) angegeben. Die einzelnen Reaktionsansätze zur Messung der Polyphenoloxidase-Aktivität setzten sich wie folgt zusammen:

$850 \mu 1 \mathrm{~L}-3,4$ DOPA (Sigma, $5 \mathrm{mg} \mathrm{ml}^{-1}$, in $0,1 \mathrm{M} \mathrm{NaHPO}_{4} / \mathrm{Na}_{2} \mathrm{PO}_{4}$-Puffer mit pH 7,0 gelöst; wurde 5 min lang vor dem Einsatz belüftet),

$100 \mu 1$ Katalase (280 $\mathrm{U} \mathrm{ml}^{-1}$, Sigma, in $\mathrm{NaHPO}_{4} / \mathrm{Na}_{2} \mathrm{PO}_{4}$-Puffer mit pH 7,0 gelöst), $50 \mu 1$ Proteinextrakt.

\subsection{Lipoxygenase}

Die Bestimmung der Lipoxygenase-Aktivität (LOX-Aktivität) erfolgte modifiziert nach HiLDEBRAND \& HYMOWITZ (1982). Im Zuge der LOX-Reaktion wird an ein cis,cis-1,4Pentadienyl-System einer mehrfach ungesättigten Fettsäure $\mathrm{O}_{2}$ angelagert. Unter Verschiebung einer Doppelbindung und Ausbildung eines konjugierten Diensystems ent- 
steht ein Fettsäurehydroperoxid, wie es in Abb. 10 am Beispiel des Linolsäurehydroperoxids gezeigt ist. Der Nachweis der Lipoxygenase-Aktivität beruht also auf der Bildung UV-aktiver konjugierter, dienhaltiger Hydroperoxide, die in einem Photometer (Perkin Elmer, UV/Vis Spektrometer Lambda 2S) bei einer Wellenlänge von $234 \mathrm{~nm}$ in Quarzküvetten über einen Zeitraum von $5 \mathrm{~min}$ gemessen wurden. Die Lipoxygenase-Aktivität wird als $\left(\Delta \mathrm{E}_{234} \mathrm{~min}^{-1} \mathrm{mg}^{-1}\right.$ Protein) angegeben. Die einzelnen Reaktionsansätze zur Messung der Lipoxygenase-Aktivität setzten sich wie folgt zusammen:

$950 \mu \mathrm{l}$ Linolsäure (Fluka, $1 \mathrm{mM}$; gelöst in 0,1 $\mathrm{M} \mathrm{NaHPO}{ }_{4} / \mathrm{Na}_{2} \mathrm{PO}_{4}$-Puffer mit pH 7,0), $50 \mu 1 \quad$ Proteinextrakt.<smiles>CCCC=CCC=CCCC(=O)O</smiles><smiles>CCCC=CC=CC(CCC(=O)O)OCC(=O)O[Na]</smiles>

Abb. 10: Schematischer Verlauf der durch die Lipoxygenase (LOX) katalysierten Bildung von Linolsäurehydroperoxid.

\subsection{Peroxidase}

Die Peroxidase-Aktivität (POD-Aktivität) wurde modifiziert nach RIDGE \& OSBORNE (1970) mit Guaiacol als H-Donor bestimmt. Die einzelnen Reaktionsansätze zur Messung der Peroxidase-Aktivität setzten sich folgendermaßen zusammen:

$940 \mu \mathrm{l}$ Guaiacol (1-Methoxyphenol, Sigma, $10 \mathrm{mM}$, gelöst in 0,1 $\mathrm{M} \mathrm{NaHPO}_{4} / \mathrm{Na}_{2} \mathrm{PO}_{4}$ Puffer mit $\mathrm{pH} 7,0)$ mit

$10 \mu \mathrm{H}_{2} \mathrm{O}_{2}(10 \mathrm{mM})$ als Cofaktor, $50 \mu 1$ Proteinextrakt.

Das Volumen des Reaktionsansatzes betrug $1 \mathrm{ml}$. Gestartet wurde die Reaktion durch die Zugabe des Proteins, und die photometrischen Veränderungen wurden in einem Photometer (Perkin Elmer, UV/Vis Spektrometer Lambda 2S) bei einer Wellenlänge von $436 \mathrm{~nm}$ in Plastikküvetten über einen Zeitraum von $5 \mathrm{~min}$ gemessen. Aus der Stei- 
gung der Absorptionsänderung wurde die Peroxidase-Aktivität $\left(\Delta \mathrm{E}_{470} \mathrm{~min}^{-1} \mathrm{mg}^{-1}\right.$ Protein) ermittelt.

\subsection{Katalase-Aktivität}

Die Bestimmung der Katalase-Aktivität (KAT-Aktivität) erfolgte modifiziert nach FACCIOLI (1979). Sie beruht auf der Abnahme von $\mathrm{H}_{2} \mathrm{O}_{2}$, die in einem Photometer (Perkin Elmer, UV/Vis Spektrometer Lambda 2S) bei einer Wellenlänge von $240 \mathrm{~nm}$ in Quarzküvetten über einen Zeitraum von 5 min gemessen wurde. Aus der Steigung der Absorptionsänderung wurde die Katalase-Aktivität $\left(\Delta \mathrm{E}_{240} \mathrm{~min}^{-1} \mathrm{mg}^{-1}\right.$ Protein) berechnet. Die einzelnen Reaktionsansätze zur Messung der Katalase-Aktivität setzten sich wie folgt zusammen:

$950 \mu 1 \mathrm{H}_{2} \mathrm{O}_{2}$ (Sigma, $30 \mathrm{mM}$, gelöst in 0,1 $\mathrm{M} \mathrm{NaHPO}_{4} / \mathrm{Na}_{2} \mathrm{PO}_{4}$-Puffer mit pH 7,0), $50 \mu 1$ Proteinextrakt.

\subsubsection{Bestimmung der Proteinaseinhibitoraktivitäten}

Nach Beendigung der Inkubations- und Containerversuche (Kap. 4.4.1.1, Kap. 4.4.1.2) wurden die Erlenblätter gewogen und das Frischgewicht (FW) bestimmt. Die Blattmasse wurde zuerst in flüssigem Stickstoff schockgefroren, mit einem Glaspistill grob gemörsert und dann in gekühltem Proteinextraktionspuffer (Zusammensetzung Tab. D, Anhang) aufgenommen. Anschließend wurde die Lösung mit einem Vortex gut durchmischt und bei einer Temperatur von $4{ }^{\circ} \mathrm{C} 20$ min mit $12000 \mathrm{~g}$ zentrifugiert. Der Überstand wurde vorsichtig abgenommen und in ein neues Eppendorfgefäß überführt. Bis zur weiteren Bestimmung des Proteingehalts und der Proteinaseinhibitoraktivitäten konnte der Überstand entweder auf Eis gekühlt aufbewahrt werden oder in flüssigem Stickstoff schockgefroren und bei $-80^{\circ} \mathrm{C}$ gelagert werden.

Die Bestimmung des Proteingehalts der eingesetzten Proben erfolgte nach der von BRADFORD (1976) beschriebenen Methode (siehe auch Kap. 4.4.3.2). Die quantitative Bestimmung der Aktivität der Proteinaseinhibitoren (PIs) wurde mit dem „Radialdiffusionsassay“, modifiziert nach JoNGSMA et al. (1993, 1994), ermittelt, wobei Trypsin ( $1 \mathrm{mg} \mathrm{ml}^{-1}$,Typ III, Fluka) als Proteinase zur Herstellung des Agarsubstrates eingesetzt wurde. Abb. 11 zeigt eine schematische Darstellung dieser Methode. 


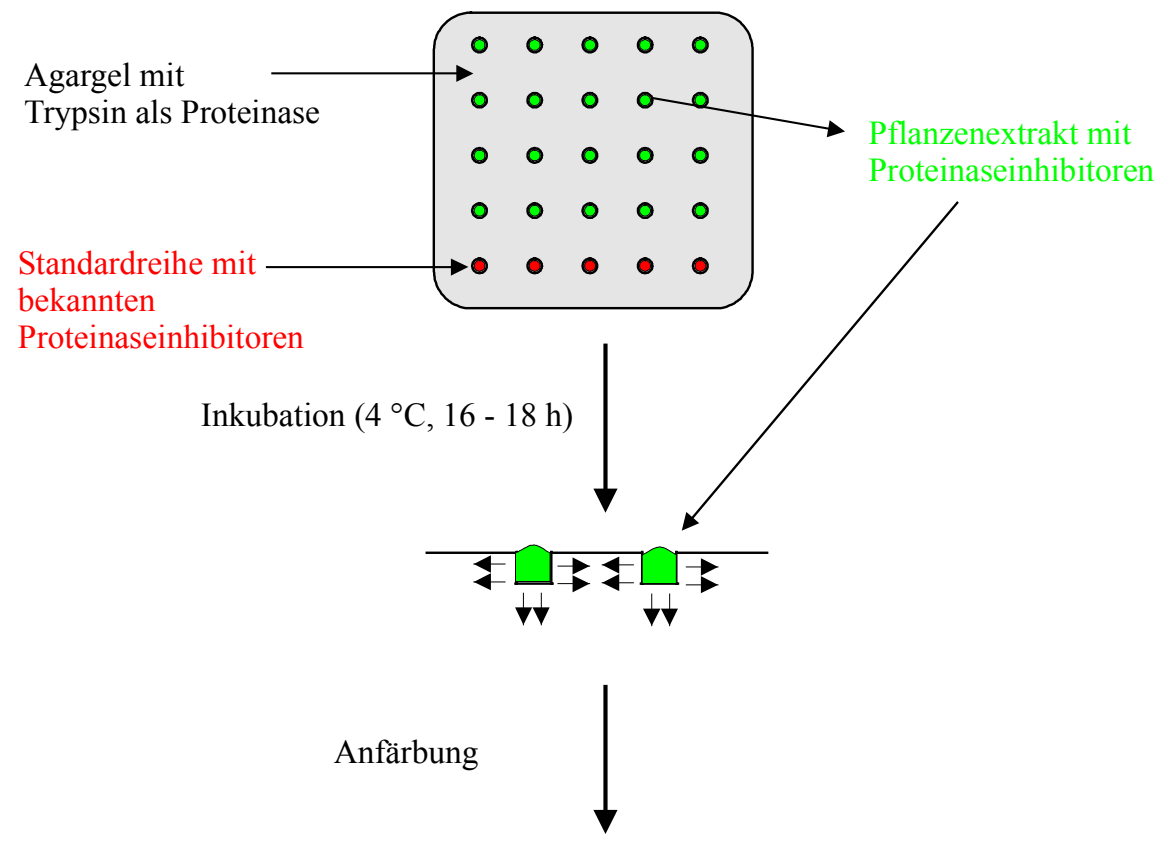

Anfärbung der Agarplatte mit einer Färbelösung (bestehend aus APNE und Fast Blue gelöst in Dimethylsulfoxid / Tris-Puffer $\left.\left(37^{\circ} \mathrm{C}, 1 \mathrm{~h}\right)\right)$
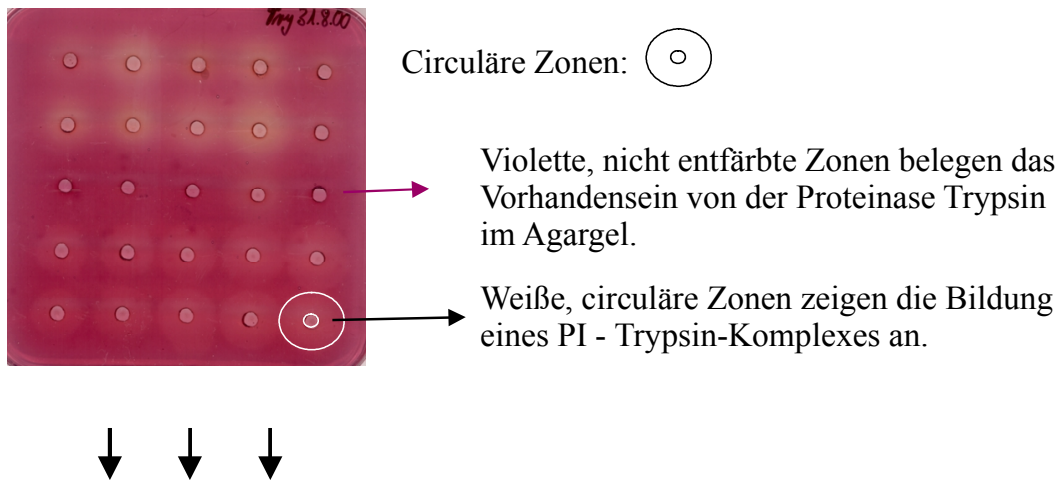

Quantifizierung

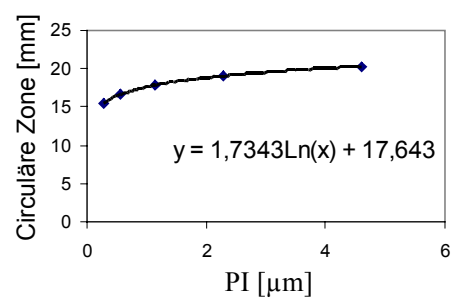

Die Aktivitätsbestimmung der Proteinaseinhibitoren aus den Pflanzenproben erfolgte durch Vermessen der weißen, circulären Zonen.

Mittels einer Standardreihe mit bekannten Proteinaseinhibitoren wurde eine logarithmische Regressionsgerade zur Aktivitätsbestimmung ermittelt.

\footnotetext{
Abb. 11: Schematische Darstellung der quantitativen Bestimmung von Proteinaseinhibitoren durch den „Radialdiffusionsassay“. Die Pflanzenproben sowie bekannte PI-Standards wurden in Vertiefungen einer Agarplatte, in der Trypsin als Proteinase gelöst war, pipettiert. Während der Inkubation $\left(4^{\circ} \mathrm{C}\right.$ und 16 - 18 h) diffundierten sämtliche Inhaltsstoffe aus den Pflanzenproben in das Agargel. Mit einer Anfärbung (Färbelösung bestehend aus APNE (N-acetyl-phenylalanin-ß-naphthylester) und Fast Blue, gelöst in Dimethylsulfoxid / Tris-Puffer $\left.(0,1 \mathrm{mM}, \mathrm{pH} 7,6)\left(37^{\circ} \mathrm{C}, 1 \mathrm{~h}\right)\right)$ konnte die Aktivität der Proteinaseinhibitoren quantifiziert werden.
} 
Kurz bevor die Proben auf die Agarplatte aufgetragen wurden, wurden mit einem Korkbohrer $(\varnothing=4 \mathrm{~mm})$ in regelmäßigen Abständen Löcher in die Agarplatte gestanzt. Dabei hing die Anzahl der Löcher pro Platte von der Menge der zu untersuchenden Pflanzenproben und von der Aktivität der Proteinaseinhibitoren der Probe ab. In diese Vertiefungen wurden anschließend die Proben pipettiert.

Es folgte eine Inkubation der Agarplatte für $16-18 \mathrm{~h}$ bei einer Temperatur von $4{ }^{\circ} \mathrm{C}$. Nach Inkubationsende wurden die Agarplatten mit $25 \mathrm{ml}$ einer frisch zubereiteten Färbelösung - bestehend aus APNE ( $N$-acetyl-phenylalanin- $\beta$-naphthylester, Bachem) und Fast Blue (Serva) gelöst in Dimethylsulfoxid / Tris-Puffer $(0,1 \mathrm{mM}, \mathrm{pH} 7,6)$ - eine Stunde bei $37^{\circ} \mathrm{C}$ inkubiert. Nach Beendigung des Färbens wurde die Färbelösung abgegossen und die Platte vorsichtig mit VE-Wasser gespült.

Die Aktivität der Proteinaseinhibitoren wurde durch Vermessung der weißen, circulären Zonen quantifiziert, die das Vorhandensein von Proteinaseinhibitoren anzeigen. Mittels einer Eichlösung mit Proteinaseinhibitorstandards aus Sojabohne (Boehringer) wurde eine logarithmische Regressionsgerade zur Bestimmung der Proteinaseinhibitoraktivität ermittelt, die als $\left[\mu \mathrm{g}\right.$ PI $\mathrm{mg}^{-1}$ Protein $\left.\mathrm{g}^{-1} \mathrm{FW}\right]$ angegeben wird. 


\subsubsection{Duftanalytik}

\subsubsection{Ethylen}

Eine Voraussetzung für den Nachweis emittierter Ethylenmengen ist eine empfindliche Nachweistechnik. Für die nachfolgenden Versuche wurde daher ein Nachweisverfahren für Spurengase - die photoakustische Spektroskopie (PAS) - eingesetzt (Abb. 12), die von URBAN (1995) für biologische Systeme entwickelt wurde. Die photoakustische Spektroskopie erlaubt es, die Konzentration von Spurengasen extrem empfindlich und zeitgleich zu messen. Die Ethylenmessungen wurden in Zusammenarbeit mit Dr. Frank Kühnemann am Institut für Angewandte Physik (Universität Bonn) durchgeführt.

Das Grundprinzip der PAS beruht auf dem photoakustischen Effekt, bei dem die absorbierte Lichtenergie in Wärme umgewandelt wird. Mit einem abstimmbaren Laserstrahl werden die Gasmoleküle in einer photoakustischen Zelle angeregt und zum Schwingen gebracht. Die angeregten, schwingenden Moleküle geben ihre Energie durch Zusammenstöße mit anderen Molekülen ab, wobei die Schwingungsenergie mit übertragen wird. Dadurch kommt es zu einer Freisetzung von Wärmeenergie, die sich als Druckwellen in der Gasphase über der Probe ausbreitet. Da das Anregungslicht des Lasers durch den Chopper mit einer bestimmten Frequenz unterbrochen wird, entstehen rhythmisch mit der Frequenz der Meßstrahlung Druckwellen, die mit einem empfindlichen Mikrophon aufgenommen werden. Die Strahlungsenergie wird also erst in thermische Energie und dann durch Modulation in akustische Wellen umgesetzt.

Um die Ethylenmessungen an pflanzlichen Systemen durchzuführen, muß die zugeführte Luft vor ihrem Eintritt in die Probenkammer zur Reinigung über einen Platinkatalysator geleitet werden, an dem alle vorhandenen Luftverunreinigungen oxidiert werden. Ein nachfolgender Flußregler steuert den Luftstrom, der durch die Probenkammern fließt und dabei die von der Pflanze emittierten Substanzen aufnimmt und mittransportiert. Eine temperaturgeregelte Kühlfalle mit flüssigem Stickstoff entfernt alle störenden Bestandteile, wie zum Beispiel Feuchtigkeit sowie schwer flüchtige Verbindungen. Die Luft strömt dann gereinigt durch die photoakustische Zelle. 


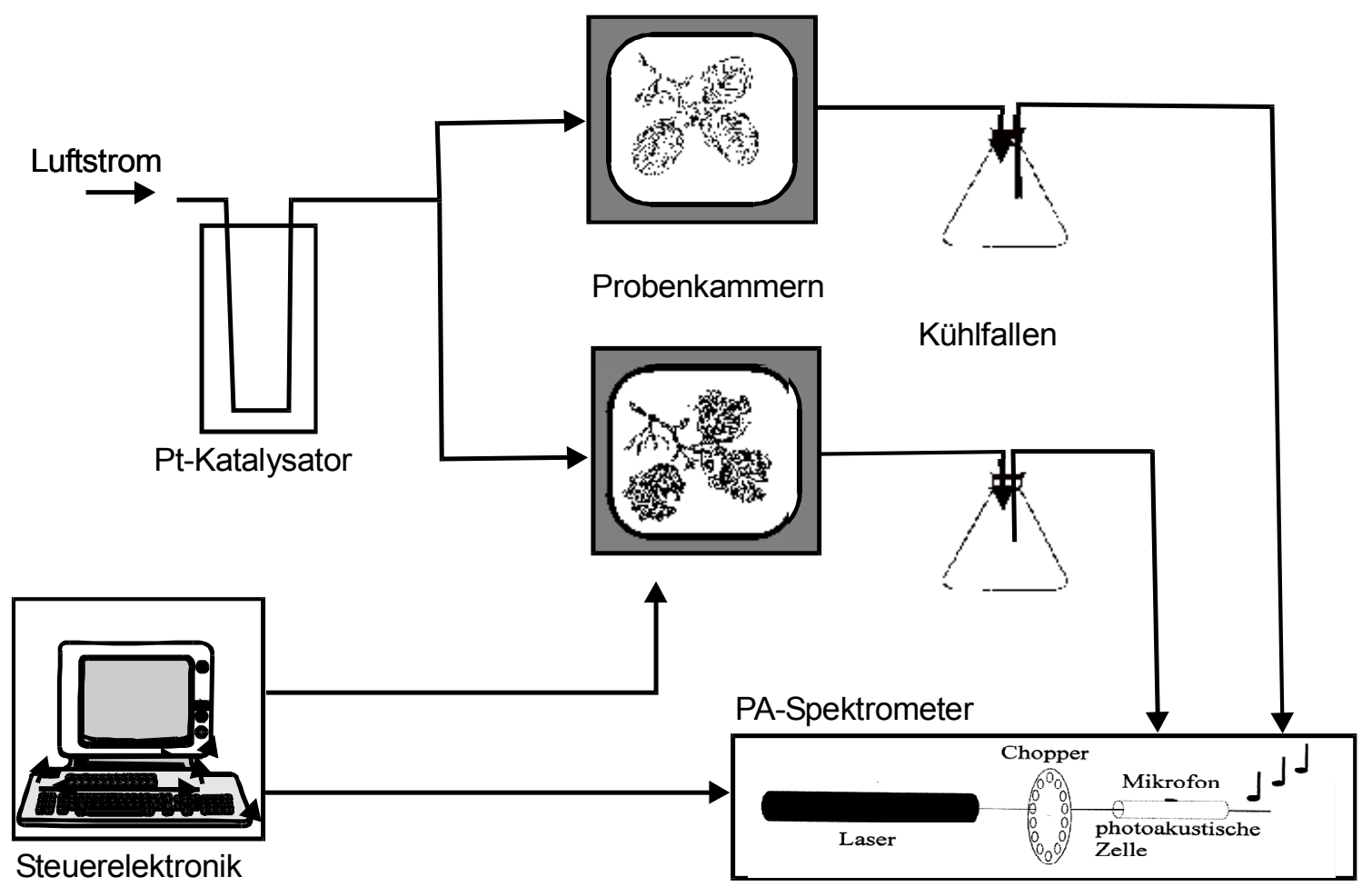

und Verstärker

Abb. 12: Schematische Darstellung der photoakustischen Spektroskopie zur Messung von Ethylen.

Versuchsdurchführung

Endständige Triebe mit drei Blättern von A. glutinosa, die kurz vor Versuchsbeginn frisch von einer Erlenpflanze aus der Klimakammeranzucht (Kap. 4.1) abgeschnitten worden waren, wurden auf zwei Glasküvetten $(\mathrm{V}=600 \mathrm{ml})$ verteilt und unter kontrollierten Bedingungen in einer Klimakammer bei $14 \mathrm{~h}$ Licht und $10 \mathrm{~h}$ Dunkel, $20^{\circ} \mathrm{C}$ und $70 \%$ relativer Luftfeuchtigkeit exponiert. In der ersten Glasküvette befanden sich Blatttriebe, denen bei Versuchsstart die Herbivoren A. alni hinzugesetzt wurden. Die zweite Küvette beinhaltete unbehandelte, nicht geschädigte Blatttriebe, die als Kontrolle dienten. Die Luft floß mit einer konstanten Rate $\left(11 \mathrm{~h}^{-1}\right)$ durch die photoakustische Zelle. Da die Zeiten für den Gasaustausch in der Pflanzenkammer und den Gastransport in die photoakustische Zelle bekannt waren, konnte aus den in der photoakustische Zelle gemessenen Konzentrationen die Ethylenemissionsrate der Erlenblätter berechnet werden. Die Kalibrierung erfolgte mit definierten Ethylenmengen. Die Empfindlichkeit dieser Methode lag bei 100 ppt. Es wurden zwei Versuche durchgeführt: Versuch 1 mit drei Imagines von A. alni (jeweils pro Blatt), $\mathrm{t}=36 \mathrm{~h}$ und Versuch 2 mit drei Larven 
von $A$. alni (jeweils pro Blatt), $\mathrm{t}=72$ h. Pro Versuch wurden drei Blätter von A. glutinosa eingesetzt.

\subsubsection{Flüchtige Blattinhaltsstoffe}

Zur Untersuchung der flüchtigen Blattinhaltsstoffe wurde das Closed Loop Stripping (CLS) (Abb. 13) an Pflanzen von A. glutinosa durchgeführt, die aus der eigenen Anzucht (Kap. 4.1) entnommen wurden. Von den Pflanzen wurden die endständigen Triebspitzen, bestehend aus drei Blättern, abgeschnitten und in $10 \mathrm{ml}$ Präparategläser mit entionisiertem Wasser gestellt, die mit einem Alupapier abgedichtet wurden. Die Pflanzen wurden vorsichtig in $750 \mathrm{ml}$ Exsikkatoren überführt und die Glasgefäße mit einem Teflonstopfen verschlossen. Die anschließende Inkubation der Pflanzen erfolgte bei RT, einer Lichtintensität von ca. 4000 Lx und einer Tag-Nachtphase von $10 \mathrm{~h} \mathrm{Licht}$ : 14 h Dunkelheit.
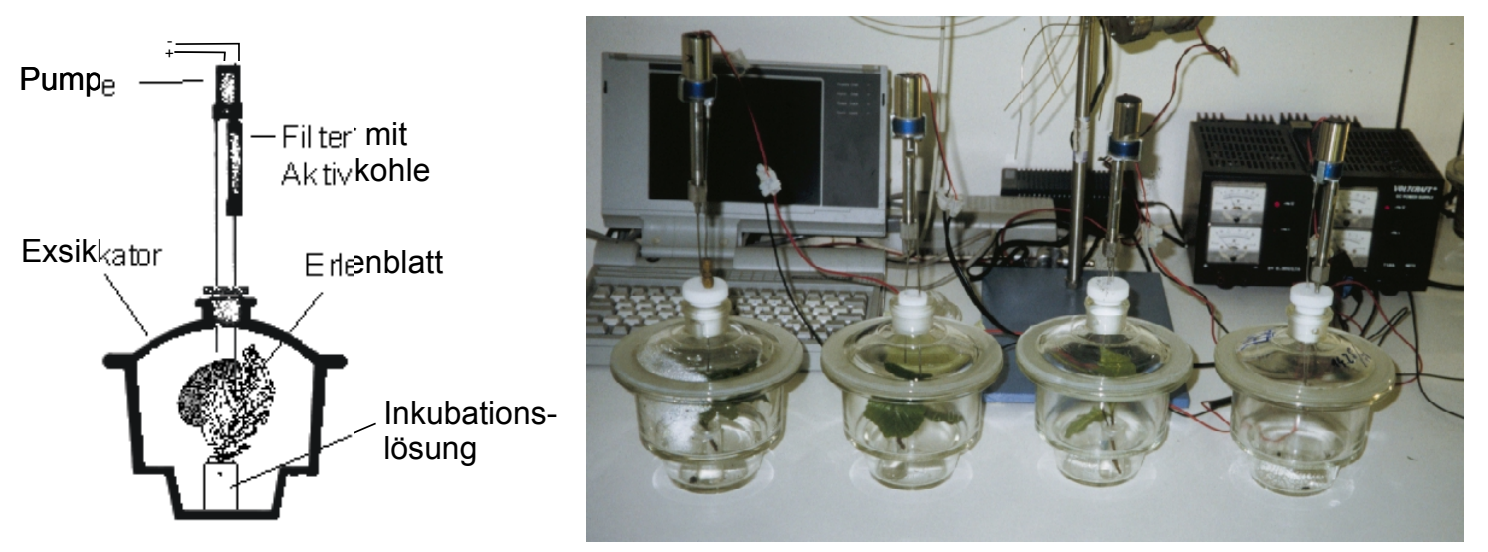

Abb. 13: Versuchsaufbau der Closed Loop Stripping-Analyse zur Anreicherung von flüchtigen Blattinhaltsstoffen. Die Inkubation der Erlentriebe erfolgte in geschlossenen Glasexsikkatoren. Die während dieser Zeit emittierten Duftstoffe wurden mittels CLS auf einem Aktivkohlefilter angereichert. Dazu wälzte eine Miniaturpumpe den Luftraum in den Exsikkatoren kontinuierlich um. Der Luftstrom wurde dadurch über den Aktivkohlefilter geleitet, so daß die flüchtigen Verbindungen an der Aktivkohle adsorbierten und angereichert wurden. Die Desorption der Duftkomponenten erfolgte durch Eluieren des Filters mit Dichlormethan. Anschließend konnte dieses Eluat direkt mittels GC-MS vermessen werden.

Das Luftvolumen des Exsikkators wurde über den Aktivkohlefilter (Länge $=6 \mathrm{~cm}$, $\varnothing=0,5 \mathrm{~cm}$, mit 1,5 mg Aktivkohle gepackt (CLSA-Filter, Le Ruisseau de Montbrun, F 
09350)) mittels einer Drehschieberpumpe (12 V-Drehschieberpumpe (Fürgut, 88139 Aitrach)) gepumpt. Während des Pumpens adsorbierten die von der Pflanze freigesetzten Duftstoffe an der Aktivkohle. Zur Desorption der Substanzen wurde der Kohlefilter aus dem Filterhalter entnommen und mit $2 \times$ je $15 \mu 1$ Dichlormethan gespült. Anschließend wurde dem Eluat $5 \mu \mathrm{n}$-Bromdecan (7,2 $\mathrm{mM}$ in Dichlormethan gelöst) interner Standard zugesetzt und die Lösung auf $40 \mu 1$ Gesamtvolumen mit Dichlormethan ergänzt. Die Probe wurde unmittelbar nach dem Eluieren mittels GC-MS (Finnigan GC und Finnigan GCQ (70 eV, EI)) unter folgenden Bedingungen vermessen:

Temperaturprogramm:

$40{ }^{\circ} \mathrm{C}(2 \mathrm{~min}) \stackrel{10^{\circ} \mathrm{C} / \min }{\longrightarrow} 200{ }^{\circ} \mathrm{C}(0 \mathrm{~min}) \stackrel{30^{\circ} \mathrm{C} / \mathrm{min}}{\longrightarrow} 280{ }^{\circ} \mathrm{C}(1 \mathrm{~min})$

Injektortemperatur: $220^{\circ} \mathrm{C}$, Injektionsvolumen: $1 \mu 1$, Scanbereich: $50-470 \mathrm{~m} / \mathrm{z}$, Solvent delay: $2 \mathrm{~min}$, Splitverhältnis: $1: 10$, Interface-Temperatur: $250{ }^{\circ} \mathrm{C}$, Trägergasfluß: $3,0 \mathrm{ml} \mathrm{min}{ }^{-1}$.

Nach folgenden Behandlungsvarianten wurde das von A. glutinosa-Trieben abgegebene Duftspektrum per CLS angereichert und mittels GC-MS untersucht (Durchführung Kap. 4.4.2): Unverletzte Blätter von A. glutinosa (Kontrolle); Fraß von A. alni (Larven); mechanische Verletzung; Inkubation mit Jasmonsäure (JA); Inkubation mit Salicylsäure (SA).

Für die zeitabhängige Untersuchung des induzierten Duftprofils der Blätter von $A$. glutinosa unter Fraß von A. alni (3 Blätter und 15 Larven) wurde eine neuartige „Duftsammel-Technik“ eingesetzt. Mit dieser Technik war es möglich, die Produktion der emittierten Duftstoffe Online zu verfolgen. Für diese Messungen wurde eine elektronische Sensortechnik zNose ${ }^{\mathrm{TM}}$ (Estal) angewandt. Dieses Gerät setzt sich aus folgenden Elementen zusammen: einem Filter mit Tenax-Adsorbens zur Duftstoffanreicherung, einem GC zur Trennung der Komponenten und einem SAW-Detektor (,surface acoustic wave“). Die Identifizierung der Komponenten erfolgt bei dieser Methode über den Vergleich der Retentionszeiten eingesetzter Referenzsubstanzen. Für die Messungen wurden folgende $z \mathrm{Nose}^{\mathrm{TM}}$-Parameter verwendet: Sammelzeit: $30 \mathrm{~s}$ in Tenax-Filter; GCTemperaturprogramm: $40^{\circ} \mathrm{C} \stackrel{3^{\circ} \mathrm{C} / \mathrm{sec}}{\longrightarrow} 180^{\circ} \mathrm{C}$, GC-Säule: DB 5, $1 \mathrm{~m}$; SAW-Detektor $40{ }^{\circ} \mathrm{C}$ ). Die Durchführung dieser Messungen wurden von Dr. Maritta Kunert (MPI für Chemische Ökologie, Jena) übernommen. 


\subsubsection{Quantifizierung von Jasmon- und Salicylsäure}

\section{Vorbereitung und Behandlung der Pflanzen}

Für das Experiment zur Bestimmung der endogenen Konzentrationen von Jasmonsäure und Salicylsäure wurden die Triebspitzen mit jeweils drei Blättern von 18-monatigen Erlenpflanzen (Höhe: 40-60 cm, Stammdurchmesser: 0,7 cm), die in einer Klimakammer aufgezogen wurden (Kap. 4.1), abgeschnitten und in Schnappdeckelgläschen mit Wasser überführt. Für die Fraßversuche wurden Larven von A. alni (5 Tiere pro Blatt) verwendet. Den Tieren wurde die Möglichkeit gegeben, an den Blättern ungestört zu fressen. Zu bestimmten Zeitpunkten $(\mathrm{t}=0 ; 1 ; 2 ; 2,5 ; 3 ; 5,5 ; 6 ; 7,5 ; 9 ; 10,5 ; 12$ - 39 (alle 3 h), 45; 48 und 50 h) wurden die verschiedenen Versuchsansätze beendet und die Blattproben (jeweils drei Blätter) für die Quantifizierung eingesetzt. Für den Kontrollansatz wurden die Pflanzen ohne den Herbivoren gehalten. Die Durchführung der Versuche erfolgte bei Raumtemperatur mit einem Tag- und Nachtrhythmus von 16 h Licht : $8 \mathrm{~h}$ Dunkel und einer Beleuchtungsstärke von 4000 Lx. Insgesamt wurde jede Zeitreihe 4-mal wiederholt.

\section{Probenaufarbeitung zur Quantifizierung von Jasmon- und Salicylsäure}

Als Methodenvorlage zur Quantifizierung der Jasmonsäure aus Blattmaterial diente ein von MCCLOUD \& BALDWIN (1997) entwickeltes Verfahren, das von KoCH et al. (1999) für die Salicylsäurebestimmung weiter modifiziert wurde.

Als Ausgangsmaterial dienten Blattproben, von denen nach Versuchsende zuerst zur Bestimmung des eingesetzten Frischgewichts (FW) die Blattstiele entfernt wurden. Anschließend wurden die Blattstückchen (1 g FW) in flüssigem Stickstoff schockgefroren und mit einem Porzellanpistill grob zerkleinert. Das gemörserte Blattmaterial wurde dann in $30 \mathrm{ml}$ einer Aceton-Zitronensäurelösung (3,3 : 1, Aceton : Zitronensäure (50 mM), v:v) aufgenommen. Zu dieser Mischung wurden die internen Standards [9,10$\left.{ }^{2} \mathrm{H}_{2}\right]-9,10$-Dihydrojasmonsäure (146 ng) und $\left[3,4,5,6,-{ }^{2} \mathrm{H}_{4}\right]$-Tetradeuterosalicylsäure (500 ng) (Abb. 14) zugegeben, die von Thomas Koch (MPI für Chemische Ökologie, Jena) synthetisiert und zur Verfügung gestellt wurden. Durch anschließende 10-minütige Behandlung mit dem Ultra Turrax T25 wurde die Mischung homogenisiert. Die 
Suspension wurde in ein Präparateglas $(50 \mathrm{ml})$ überführt und bei RT über Nacht stehengelassen.

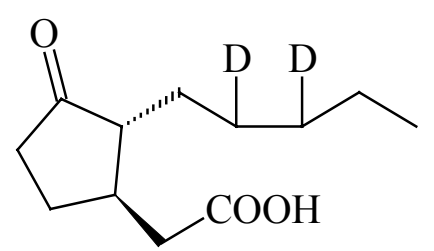

(a)<smiles>[2H]c1c([2H])c([2H])c(C(=O)O)c(O)c1[2H]</smiles>

Abb. 14: Verwendete interne Standards. - a) $\left[9,10-{ }^{2} \mathrm{H}_{2}\right]-9,10$-Dihydrojasmonsäure. - b) $\left[3,4,5,6-{ }^{2} \mathrm{H}_{4}\right]-$ Tetradeuterosalicylsäure.

Nach Inkubationsende wurden die verbleibenden wäßrigen Lösungen unter leichtem Vakuum filtriert, um feste pflanzliche Bestandteile zu entfernen. Der filtrierte, wäßrige Rückstand wurde dreimal mit je $10 \mathrm{ml}$ Diethylether extrahiert. Die etherischen Lösungsmittelfraktionen wurden zu einer Lösung vereinigt und auf Aminopropyl-Festphasenextraktionskartuschen (500 mg Aminopropyl-SPE, Macherey-Nagel) geladen. Durch Anlegen eines leichten Unterdruckes wurde eine konstante Durchlaufrate erlangt. Nach dem Waschen der Kartuschen mit $7 \mathrm{ml}$ einer Trichlormethan : 2-Propanol-Lösung (2 : 1, v/ v) erfolgte die Elution der gebundenen Jasmon- und Salicylsäure, sowie der zugegebenen Standards durch zweimalige Zugabe einer Ether : Essigsäurelösung (50 : 1, v / v) $(1 \times 8 \mathrm{ml}$ und $1 \times 3 \mathrm{ml})$. Das Lösungsmittel wurde durch Abblasen mit Argon entfernt und der resultierende Rückstand wurde anschließend in etwa 1,5 ml Ether gelöst. Danach erfolgte die Veresterung der Säuregruppen mit Diazomethan. Nach ca. 5-minütiger Einwirkung der Diazomethanlösung wurden die Proben im Argonstrom wiederum eingeengt und der Probenrückstand in $50 \mu$ l Dichlormethan aufgenommen. Diese Proben ließen sich dann ohne weitere Reinigungsschritte direkt mittels GC-MS untersuchen. Die Vermessung erfolgte dabei im selected-ion-monitoring (SIM) Modus, d.h. es wurden zur Steigerung der Empfindlichkeit nur ausgewählte Ionen bestimmter Masse detektiert.

Für die JA-Bestimmung erfolgte die Messung für das Fragment der Masse m/z 83, welches den Basispeak von Jasmonsäure und des dazugehörigen Standards $\left[9,10-{ }^{2} \mathrm{H}_{2}\right]-$ 9,10-Dihydro-JA darstellt. Für die SA-Bestimmung erfolgte das Monitoring der Fragmente der Masse m/z 120 für Salicylsäure und m/z 124 für den dazugehörigen [3,4,5,6,${ }^{2} \mathrm{H}_{4}$ ]-Tetradeuterosalicylsäure-Standard (Abb. 15). 

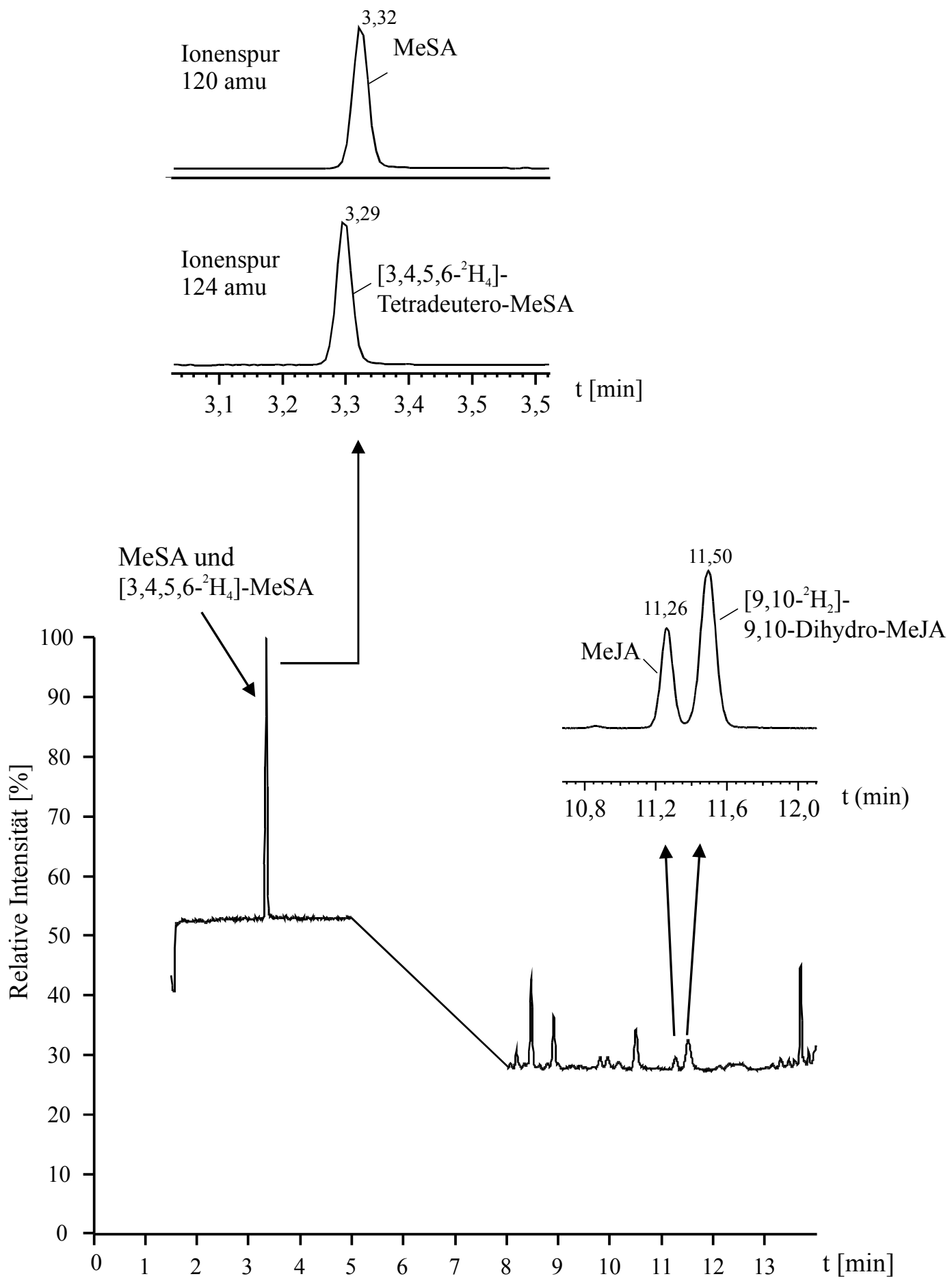

Abb. 15: GC-MS Chromatogramm einer Pflanzenprobe mit zugesetzten internen Standards und

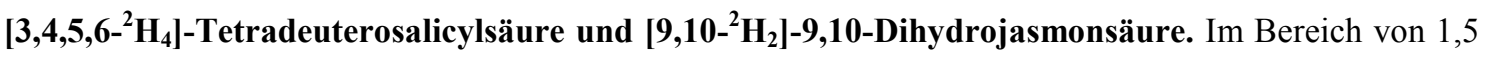
bis 5,0 min erfolgte die Detektion der Ionen im SIM-Modus (120 amu und $124 \mathrm{amu}$ ). In diesem Zeitintervall coeluierten MeSA und MeSA- $\mathrm{d}_{4}$ zum gleichen Zeitpunkt. Die beiden Komponenten konnten aber durch den Modus der Ionenspur über $120 \mathrm{amu}$ (für MeSA) und $124 \mathrm{amu}$ (für MeSA-d $_{4}$ ) getrennt werden. Ab 8 min erfolgte die Detektion der Ionen im SIM-Modus (83 amu), so daß MeJA und 9,10-DihydroMeJA bestimmt werden konnten. MeJA = Methyljasmonat, MeSA = Methylsalicylat. 
Pro Messung wurde ein Probenvolumen von $1 \mu 1$ in den Gaschromatographen injiziert und mittels GC-MS (GC: Trace GC 2000 series; MS: Thermoquest Trace MS (70 eV, EI)) vermessen.

Temperaturprogramm:

$80{ }^{\circ} \mathrm{C}(2 \mathrm{~min}) \stackrel{8^{\circ} \mathrm{C} / \min }{\longrightarrow} 127^{\circ} \mathrm{C}(5 \mathrm{~min}) \stackrel{30^{\circ} \mathrm{C} / \min }{\longrightarrow} 280{ }^{\circ} \mathrm{C}(3 \mathrm{~min})$

Injektortemperatur: $260^{\circ} \mathrm{C}$, Scanbereich: SIM-Monitoring m/z 83, 120, 124, Solvent delay: 1,5 min, Splitverhältnis: 1:10, Interface Temperatur: $250{ }^{\circ} \mathrm{C}$, Trägergasfluß: 3,0 $\mathrm{ml} \min ^{-1}$

\section{Quantifizierung und Auswertung}

Zur Quantifizierung von Jasmonsäure und Salicylsäure aus den Pflanzenproben wurden die Peakflächen der Probenmessungen integriert und das Verhältnis der Flächen von authentischer Verbindung zu Standard ermittelt. Zur Umrechnung der Peakfläche in die Absolutmengen an Jasmon- und Salicylsäure wurde für jede Verbindung eine Eichgerade verwendet, die von Parallelmessungen von Thomas Koch (MPI für Chemische Ökologie, Jena) übernommen werden konnte. 


\subsubsection{Untersuchungen zur Charakterisierung des Regurgitats von Agelastica alni-Larven}

\subsubsection{Chemische Untersuchungen}

\section{Gewinnung des Regurgitats}

Die Larve des Erlenblattkäfers $A$. alni wurde mit einer Federstahlpinzette vorsichtig hinter dem Kopf gegriffen und hochgehoben. Der Druck mit der Pinzette wurde dabei so lange erhöht, bis die Larve einen Tropfen vor ihren Mundwerkzeugen absonderte. Dabei hielt man den Kopf über eine Glaskapillare, so daß das Regurgitat sofort in die Kapillare gesaugt wurde. Anschließend wurden von dem frisch gewonnenen Regurgitat Aliquots von $5 \mu 1$ abgenommen, in $15 \mu$ l Methanol aufgenommen und bei $16000 \mathrm{~g}$ für 3 min zentrifugiert. Nach der Zentrifugation wurde der Überstand abgenommen und direkt mit APCI LC-MS vermessen, wobei folgende Einstellungen verwendet wurden:

LC-MS: $\quad$ Thermoquest LCQ mit LC-MS APCI interface (Thermoquest, San José)

HPLC: $\quad$ Hewlett Packard HP 1100 (Hewlett Packard, Waldbronn)

HPLC-Säule: Grom-Sil ODS-3 CP RP-18 (125 mm x 2 mm) mit einer Körnung von $3 \mu \mathrm{m}$ (Grom, Herrenberg)

Laufmittel: Wasser G Chromasolv ${ }^{\circledR}$ für die Gradientenelution (Riedel de Haën, Seelze); Acetonitril G Chromasolv ${ }^{\circledR}$ super gradient grade (Riedel de Haën, Seelze); Essigsäure (Merck, Darmstadt)

\section{LC-Einstellungen:}

Injektionsvolumen: 10-20 $\mu 1$

Laufmittel: A: Wasser mit 0,5 \% Essigsäure

B: Acetonitril mit 0,5 \% Essigsäure

Flußrate: $0,2 \mathrm{ml} \mathrm{min}^{-1}$, Diodenarray-Detektor

Lösungsmittelgradient:

\begin{tabular}{|l|l|l|l|l|}
\hline Zeit [min] & 0 & 3 & 30 & 45 \\
\hline Anteil Acetonitril [\%] & 0 & 0 & 100 & 100 \\
\hline
\end{tabular}




\section{MS Einstellungen:}

Verdampfertemperatur: $450{ }^{\circ} \mathrm{C}$; Reaktandgasflußrate in relativen Einheiten: 20; Hilfsgasflußrate in relativen Einheiten: 8; Entladungsstrom: $5 \mu \mathrm{A}$; Kapillartemperatur: 150 ${ }^{\circ} \mathrm{C}$; Kapillarspannung: $45 \mathrm{~V}$; Linsenausgleichsspannung 45 V; Scan-Bereich: 90 - 1500 m/z; APCI: Positiv-Ionisierungmodus.

\subsubsection{Elektrophysiologische Untersuchungen}

Um die Aktivität von Ionenkanälen in einem definierten System untersuchen zu können, entwickelten Mueller und Rudin (MUELLER et al. 1962) die Methode der „black lipid membranes“ zur Herstellung künstlicher planarer Lipidmembranen. Die Anwendung dieser Technik ermöglicht es, in In-vitro-Studien die Leitfähigkeitseigenschaften porenbildender Strukturen zu untersuchen. Der apparative Versuchsaufbau zur Messung der Membranaktivität an einer bimolekularen Lipidmembran ist in Abb. 16 schematisch dargestellt. Als Meßküvette wird eine Teflonküvette (3,0 x 2,0 x 1,2 cm) verwendet, die aus zwei gleich großen Kammern besteht. Die beiden Kammern sind durch eine Trennwand, in der sich eine kreisrunde Bohrung $(\varnothing=1 \mathrm{~mm})$ befindet, geteilt. Im Boden der beiden Kammern befindet sich jeweils ein kleiner Magnetrührer (Abb. 16a). Die Meßküvette und die dazugehörigen Ag-Elektroden befinden sich in einem Faradayschen Käfig, der zur Schwingungsabschirmung auf einer luftgelagerten Steinplatte aufgebaut ist.

Vor der Versuchsdurchführung erfolgte eine sorgfältige Reinigung der Teflonküvette zuerst mit Ethanol und anschließend mit n-Hexan. Die Küvette wurde an der Luft getrocknet. Die weiteren Vorbereitungen zum Ziehen einer künstlichen Membran, für die das Lipid 1-Hexadecanoyl-2-[cis-9-octadecenoyl]-sn-glycero-3-phosphocholin (Sigma) verwendet wurde, gliederten sich in folgende Arbeitsschritte:

Um die Lipophilie des Teflons zu erhöhen und um die Ausbildung des Bilayers im Experiment zu verbessern, wurde der Rand der Bohrung in der Kammerzwischenwand mit einer Imprägnierlösung ( $5 \mathrm{mg}$ Lipid $\mathrm{ml}^{-1} \mathrm{n}$-Hexan) vorbehandelt. Nach dem Verdampfen des Lösungsmittels wurden die beiden Kammern mit einem Magnetrührer bestückt und mit ca. 3,0 ml Elektrolytlösung (KCl-Lösung (100 mM), die $10 \mathrm{mM}$ Hepes enthielt und mit $\mathrm{KOH}$ auf $\mathrm{pH}$ 7,0 eingestellt wurde) gefüllt. 

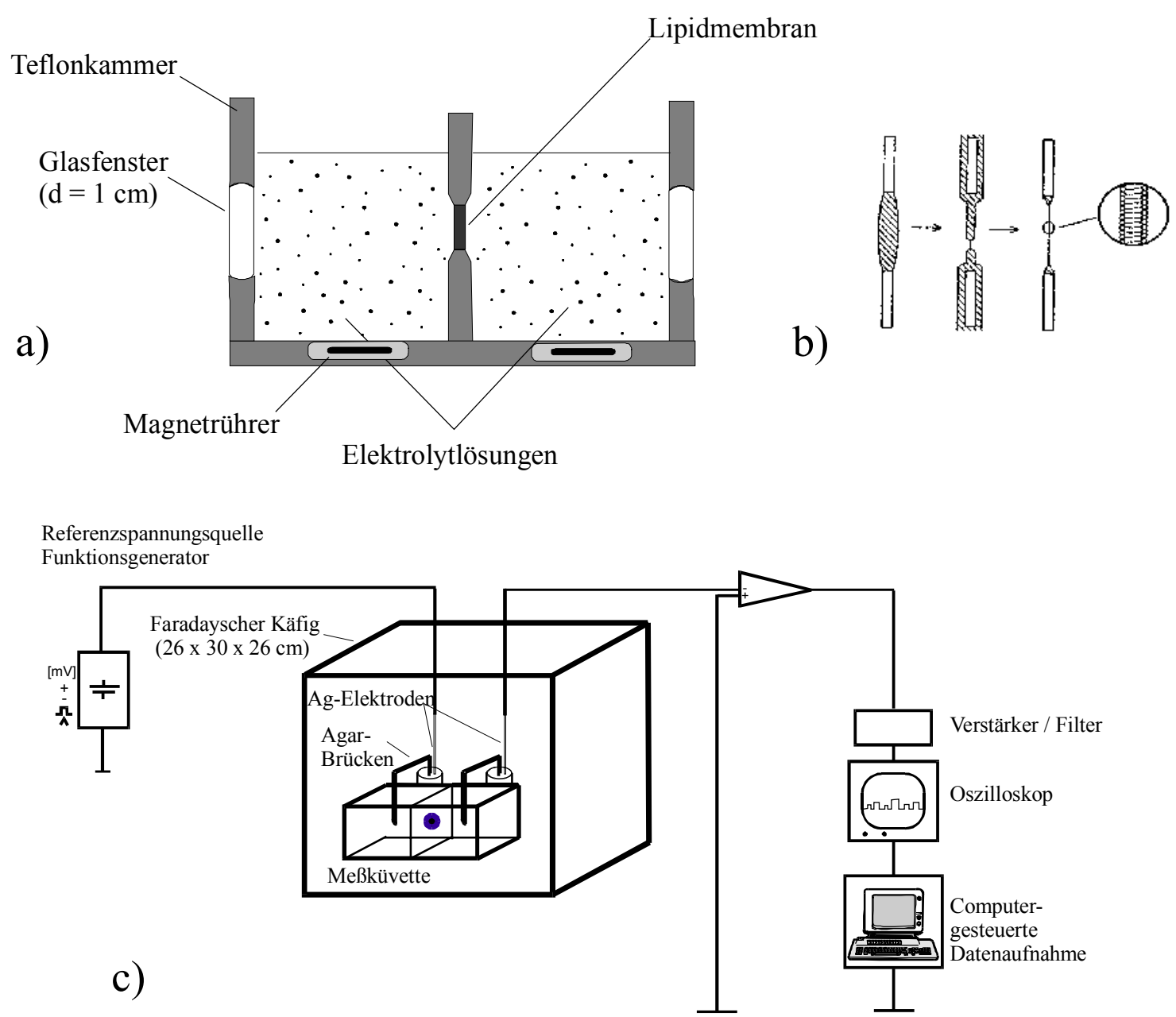

Abb. 16: Schematische Darstellung der Apparatur zur Messung von Ionenkanälen an einer künstlichen Membran in Anlehnung an Mueller und Rudin (MuelLER et al. 1962). Als Meßküvette (a) wurde bei dieser Methode eine zweikammerige Teflonküvette verwendet. Die mittlere Trennwand wies eine $1 \mathrm{~mm}$ große, kreisrunde Bohrung auf. Der Rand dieser Öffnung wurde zuerst mit einer lipidhaltigen Lösung vorimprägniert, bevor die Lipidlösung zur Membranbildung aufgetragen wurde. Der Vorgang der Membranbildung konnte mit einem Okular verfolgt werden. Dabei erfolgt eine Farbänderung der Lipidschicht über ein schillerndes Interferenzmuster bis zur Schwarzfärbung (black lipid membrane) (b). Die Registrierung und Aufzeichnung der Kanalströme erfolgte über ein Oszilloskop und eine computergesteuerte Datenaufnahme. Zur Abschirmung elektrischer und mechanischer Störquellen befand sich die Meßküvette in einem Faradayschen Käfig, der auf einer luftgelagerten Steinplatte installiert war (c).

Die Küvette wurde dann in die Apparatur eingesetzt. Über Agarbrücken wurde der Kontakt der Elektrolytlösung zu den Ag-Elektroden hergestellt und die Membran mit einer Lipidlösung (15 mg Lipid $\mathrm{ml}^{-1} \mathrm{n}$-Decan) gezogen. Zum Ziehen der Membran 
wurde die Spitze einer Eppendorfpipette $(10 \mu l)$ kurz in die Lipidlösung eingetaucht. Die dabei durch die Kapillarwirkung in die Spitze gelangte Lösung wurde über die Bohrung gestrichen und so die Öffnung der Scheidewand mit einem Tropfen dieser Lipidlösung verschlossen. Die entstehende dünne Haut wurde solange dünner, bis sich ein Lipidbilayer gebildet hatte. $\mathrm{Zu}$ Beginn dieses Prozesses waren im reflektierten Licht schillernde Farbreflexe zu sehen. Im allgemeinen ist diese Beobachtung konstruktiver Interferenzen nur bei Schichten möglich, die dicker als die Wellenlängen des sichtbaren Lichts sind. Am unteren Rand des Films beginnend, breiteten sich zunehmend schwarze Flecken aus. Nachdem die Bildung des Bilayers abgeschlossen war, war er zu dünn, um die Farberscheinungen im reflektierten Licht hervorzurufen. Die gesamte Membran erschien deshalb schwarz („,black lipid membranes“) (Abb. 16b). Dieser Vorgang konnte bei schräger Beleuchtung durch eine Kaltlichtleuchte (KL 2000, Olympus) an der Bohrung mit Hilfe eines Okulars (Okular 1,2-fach, 240 - 300 mm, Spindler \& Hoyer) optisch verfolgt werden.

Nach der Bildung der Membran wurde die Elektrolytlösung 1 min mit den Magnetrührern gut durchmischt. Anschließend wurden die Kapazität und die Leitfähigkeit der Membran bestimmt. Danach wurden 5 oder $10 \mu$ Probe (frisch gewonnenes Rohregurgitat von $A$. alni-Larven (Kap. 4.4.6)) in eine Kammer der Küvette zugegeben und erneut ca. 1 min gerührt, um eine gute Durchmischung der Probe mit der Elektrolytlösung zu erzielen. Nach dem Abschalten der Rührer wurde die Aufzeichnung der Messung gestartet. Hierzu wurden unterschiedliche Spannungen an die Membran angelegt und die resultierenden Signale über einen Verstärker (Low-noise current preamplifier SR 570, Stanford) auf dem Oszilloskop (Oszilloskop TDS 210, Tektronix) verfolgt. Wurden Veränderungen beobachtet, so wurden diese Meßwerte mit einer PC-vermittelten Software (WAVEWork für Windows V 4.2) aufgezeichnet. 


\subsubsection{Fraßwahlversuche}

Die Vorbereitung der Petrischalen sowie die weitere Durchführung und Auswertung der Fraßwahlversuche erfolgte wie in Kap. 4.3.4.3 beschrieben. In dem Biotest wurde den Larven von $A$. alni, die aus der Laborzucht entnommen wurden (Kap. 4.2), jeweils ein Blattstückchen von unbehandelten „Kontrolle“ und von behandelten Testblättern angeboten. Folgende Blätter aus jeweils unterschiedlichen Inkubationsversuchen wurden in den Fraßwahlversuchen eingesetzt (Überblick in Tabelle 4):

- A. glutinosa-Blätter nach Behandlung mit verschiedenen, chemischen Induktoren

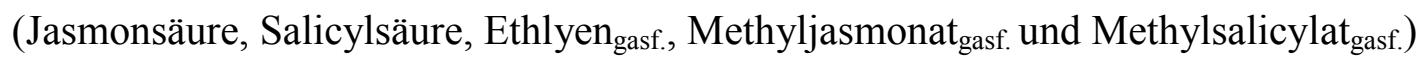

Um Erkenntnisse über die Auswirkungen verschiedener chemischer Induktoren, wie Jasmonsäure und Salicylsäure, auf Veränderungen im Blattgewebe und damit auf das Fraßverhalten von A. alni zu gewinnen, wurden Fraßwahlversuche durchgeführt. In diesen Versuchen wurde den Tieren die Möglichkeit gegeben, zwischen Blättern der „Kontrolle“ und denen der „Behandlung“ zu wählen.

Als Ausgangsmaterial diente Blattmaterial der A. glutinosa-Pflanzen aus der eigenen Anzucht (Kap. 4.1), von denen die endständigen Triebspitzen abgeschnitten und in $10 \mathrm{ml}$ Präparategläser mit Lösungsmittel überführt wurden. Je nach Versuchsvariante wurde für die „Kontrolle“ Wasser und für die „Behandlung“ Jasmonsäure (1 mM) oder Salicylsäure (1 mM) als Lösungsmittel gewählt. Die Applikation von Methyljasmonat, Methylsalicylat und Ethylen erfolgte über die Gasphase (Vorbereitung und Durchführung wie in Kap. 4.4.2 beschrieben). Die einzelnen Triebspitzen wurden, jeweils getrennt nach „Kontrolle“ und „Behandlung“, in $2700 \mathrm{ml}$ Exsikkatoren überführt und für die Versuche 1 - 9 unterschiedlich lang inkubiert ( $\mathrm{t}=$ Inkubationszeit in [h]) (Tab. 4). Nach Inkubationsende wurden die Blätter der jeweiligen Versuchsvariante aus den Exsikkatoren entnommen und für die Bestückung der einzelnen Petrischalen verwendet.

- A. glutinosa-Blätter nach Inkubation mit fraßinduzierten Duftstoffen („Containerversuche")

Um die Auswirkungen der flüchtigen Duftstoffe induzierter Erlenblätter auf unbehandelte, nicht induzierte Erlenblätter im Fraßwahlverhalten gegenüber des Herbivoren $A$. 
alni zu untersuchen, wurden abgeschnittene Triebspitzen von A. glutinosa-Pflanzen für den Biotest verwendet, die nach dem Versuchsprinzip „Container-Versuche“ (Kap. 4.4.1.2) behandelt worden waren. Nach Inkubationsende $(t=3 \mathrm{~d}$ (Versuch 10) und $\mathrm{t}=4$ d (Versuch 11)) wurden die Blätter aus den Containern entnommen. In den Fraßwahlversuchen wurde den Larven von $A$. alni jeweils ein Blattstückchen aus dem ersten Container von der unbehandelten Pflanze „Kontrolle“ sowie dem benachbarten, unbehandelten Trieb „K-Nachbar“, und aus dem zweiten Container von den mit Herbivoren geschädigten Blättern ,A. alni“ sowie den benachbarten, nicht befallenen Blättern „,ANachbar“ angeboten (4er-Fraßwahlversuch).

Tab. 4: Übersicht über die in den Fraßwahlversuchen verwendeten Blätter von Alnus glutinosa nach verschiedenen Inkubationsvarianten. Angegeben ist die Behandlung der Erlenblätter, die in den Fraßwahlversuchen eingesetzt wurden: unbehandelte Blätter $=$ Kontrolle, nach Inkubation mit Jasmon-

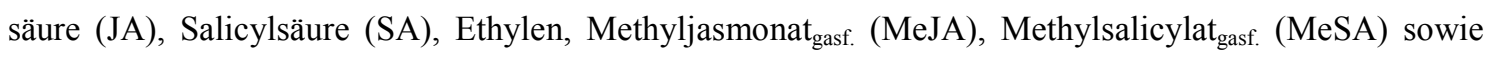
nach der Inkubation mit fraßinduzierten Duftstoffen („Containerversuche“). Angegeben ist die Anzahl der Wiederholungen (n) pro Versuchsvariante. Pro Petrischale wurde eine Larve von Agelastica alni eingesetzt.

\begin{tabular}{|c|c|c|c|}
\hline Versuch & \begin{tabular}{|l|} 
im Fraßwahlversuch \\
angebotene Blattstücke
\end{tabular} & $\begin{array}{l}\text { Art und Dauer }[\mathrm{h}] \text { der Behandlung von } \\
\text { A. glutinosa-Blättern }\end{array}$ & $\mathbf{n}$ \\
\hline 1 & Kontrolle $v s$. Kontrolle & Inkubation mit Wasser für $48 \mathrm{~h}$ & 30 \\
\hline 2 & Kontrolle $v s$. JA & Inkubation mit Jasmonsäure $(1 \mathrm{mM}), 43 \mathrm{~h}$ & 20 \\
\hline 3 & Kontrolle vs. JA & Inkubation mit Jasmonsäure (1 mM), $67 \mathrm{~h}$ & 30 \\
\hline 4 & Kontrolle vs. SA & Inkubation mit Salicylsäure $(1 \mathrm{mM}), 43 \mathrm{~h}$ & 30 \\
\hline 5 & Kontrolle vs. SA & Inkubation mit Salicylsäure $(1 \mathrm{mM}), 67 \mathrm{~h}$ & 30 \\
\hline 6 & Kontrolle vs. Ethylen & Inkubation mit Ethylen ${ }_{\text {gasf., }}, 48 \mathrm{~h}$ & 30 \\
\hline 7 & Kontrolle vs. MeJA & $\begin{array}{l}\text { Inkubation mit Methyljasmonat }{ }_{\text {gasf. }}(5 \mu \mathrm{g} / 5 \mu \mathrm{l}) \text {, } \\
48 \mathrm{~h}\end{array}$ & 30 \\
\hline 8 & Kontrolle vs. MeSA & Inkubation mit Methylsalicylat ${ }_{\text {gasf. }}(5 \mu \mathrm{g} / 5 \mu \mathrm{l}), 48 \mathrm{~h}$ & 30 \\
\hline 9 & $\begin{array}{l}\text { Kontrolle } v s . \text { MeJA vs. } \\
\text { MeSA }\end{array}$ & $\begin{array}{l}\text { Inkubation mit gasförmigem Methyljasmonat bzw. } \\
\text { Methylsalicylat }(5 \mu \mathrm{g} / 5 \mu \mathrm{l}), 48 \mathrm{~h}\end{array}$ & 24 \\
\hline 10 & $\begin{array}{l}\text { Kontrolle vs. K-Nachbar } \\
\text { vs. A. alni vs. A-Nachbar }\end{array}$ & $\begin{array}{l}\text { „Containerversuche“: Einfluß des emittierten } \\
\text { Duftbouquets geschädigter Blätter (,A. alni“) für die } \\
\text { Resistenzinduktion in ungeschädigten Blättern (,„A- } \\
\text { Nachbar“); als Kontrolle dazu, ohne Fraßschädigung } \\
(,, K o n t r o l l e “) \text { und (,,K-Nachbar“), } 3 \text { d }\end{array}$ & 35 \\
\hline 11 & $\begin{array}{l}\text { Kontrolle vs. K-Nachbar } \\
\text { vs. A. alni vs. A-Nachbar }\end{array}$ & wie Versuchsvariante 10 , nur $4 \mathrm{~d}$ & 35 \\
\hline
\end{tabular}




\subsection{Photographien}

Die Farbphotographien der Standorte sowie der Imagines, Larven und Eier von A. alni erfolgten im Freiland bzw. im Labor mit den Spiegelreflexkameras Nikon F4 (mit Makroobjektiv Nikkor 105 mm, Zwischenring und Elektronenblitz SB-24 mit TTLSteuerung) und einer am Photobinokular (STEMI 2000-C (Zeiss)) angeschlossenen Kamera MC 80 DX (Zeiss) und der Steuereinheit Exposure Control Unit. Die Photographien der histologischen Präparate wurden am Mikroskop AXIOSKOP (mit Fluoreszenzvorrichtung HBO 50/AC (Zeiss)) mit einer angeschlossenen Spiegelreflexkamera MC 80 DX und der Steuereinheit „Exposure Control Unit“ erstellt. Als Filmmaterial wurden Kodak Ektachrome 200 und Fuji Sensia 100 verwendet.

\subsection{Statistische Auswertung}

Die statistischen Datenanalysen erfolgten nach Verfahren wie sie bei SACHS (1992) beschrieben sind. Sie wurden mit dem Software-Paketen „STATISTICA für Windows, Version 5.1“ und „SPSS für Windows, Version 9.0“ am Personalcomputer ausgewertet. An den nachfolgenden Textstellen der untersuchten Parameter wird noch einmal gesondert auf die Grundlagen der statistischen Auswertung der einzelne Versuche hingewiesen.

In den Freilandversuchen „Reihenversuch“, „Topfversuch“ und „JA-Versuch“ wurde für die Variable „relative Blattschädigung“ eine einfaktorielle Varianzanalyse durchgeführt. Für die restlichen Variablen wurde mit dem t-Test überprüft, ob die Behandlungsvarianten „Baum-Nachbar“ und „Baum-Kontrolle“ bzw. „Baumnachbar-JA“ und „Baumnachbar-Kon“ sich zu dem jeweiligen Beobachtungszeitpunkt unterscheiden. Zur Vermeidung von Pseudoreplikationen wurden bei den Blattparametern Blattwassergehalt, spezifisches Blattgewicht, Blattfestigkeit, Phenolgehalt und bei der Fraßmenge von A. alni die Baummittelwerte für die statistischen Analysen verwendet.

Bei allen Variablen (Blattwassergehalt, spezifisches Blattgewicht, Blattfestigkeit, Phenolgehalt und Fraßmenge) wurden dabei normalverteilte Grundgesamtheiten vorausgesetzt. Weiterhin wurde bei allen Freilandexperimenten überprüft, ob der Stammdurchmesser sowie die Baumposition einen Einfluß auf die untersuchten Blattmerkmale 
(Blattwasser, spezifisches Blattgewicht, Phenolgehalt, Blattfestigkeit oder die gefressene Blattmenge durch Imagines oder Larven von $A$. alni im Fraßwahlversuch) ausüben. Die dabei verwendeten Datensätze stammten von den Erhebungen der gewonnenen Blattanalysen vor der experimentellen Schädigung (1. Beprobungstermin). Weder die grafische Darstellung der Datensätze noch eine statistische Analyse ließen Rückschlüsse auf eine Beziehung zwischen dem Stammdurchmesser bzw. der Baumposition und den Blattparametern (Blattwassergehalt, spezifisches Blattgewicht, Blattfestigkeit, Phenolgehalt oder der Fraßmenge) schließen. Daher wurde darauf verzichtet, den Baumdurchmesser oder die Baumposition als Kovariate mit in die Varianzanalysen einzubeziehen.

Die statistische Auswertung der Containerversuche (Kap. 4.4.1.2) sowie der Fraßwahlversuche (mit einem 2er-Fraßwahldesign: Kap. 4.3.4.3; Versuche 1 - 8, Kap. 4.4.7) erfolgte mit dem gepaarten t-Test. Für den 3er-Fraßwahlversuch (Versuch 9, Kap. 4.4.7) wurde eine einfaktorielle Varianzanalyse durchgeführt, um $\mathrm{zu}$ testen, ob eine Klassierungsvariable einen Datensatz beeinflußt. Ein Newman-Keuls-Test $(p<0,05)$ ermöglichte die Zuordnung in signifikant unterschiedliche Gruppen und wurde bei der graphischen Darstellung der Mittelwerte berücksichtigt.

Bei den physiologischen Untersuchungen (Inkubationsversuche (Kap. 4.4.1.1)) wurde mit den Behandlungsvarianten zuerst eine Varianzanalyse durchgeführt. Wenn die Varianzanalyse zur Verwerfung der Nullhypothese bezüglich eines Faktors geführt hat, wurde mit dem multiplen Mittelwertsvergleich geprüft, ob signifikante Unterschiede zwischen einzelnen Mittelwerten bestehen. Als posteriori-Testverfahren wurde dafür der Newman-Keuls-Test gewählt.

Im Rahmen der Arbeit wurden bei der graphischen Darstellung der Versuchsergebnisse jeweils die Mittelwerte und der Standardfehler angegeben. 


\section{$5 \quad$ Ergebnisse}

\subsection{Freilandversuche}

Bei den vorliegenden Freilandversuchen wurde mit drei methodisch verschiedenen Ansätzen an A. glutinosa-Pflanzen das Phänomen einer „Pflanze - Pflanze - Kommunikation“" untersucht. Es sollte überprüft werden, ob geschädigte Pflanzen über Signalstoffe Resistenzen in ungeschädigten Nachbarpflanzen induzieren können. Die Überprüfung einer Resistenzinduktion ungeschädigter Nachbarn von geschädigten Bäumen, die ausschließlich über den Luftbereich mittels Duftstoffen vermittelt werden könnte, wurde in dem „Topfversuch“ (Kap. 4.3.1) nachgegangen. Die zweite Möglichkeit einer Resistenzinduktion ungeschädigter Nachbarpflanzen, die auch über den Boden-Wurzelbereich vermittelt werden könnte, erfolgte an natürlichen Erlenbeständen im „Reihenversuch“ (Kap. 4.3.2), der zeitgleich zum „Topfversuch“ durchgeführt wurde. Eine experimentelle Schädigung zur Simulierung starker Herbivorie wurde bei beiden Versuchen durch mechanische Blattverletzung erzeugt. Der dritte Versuch, der „JA-Versuch“ (Kap. 4.3.3), betraf auch die Möglichkeit einer über Duftstoffe aktivierten Resistenz. Nur wurde bei diesem Versuch Herbivorie durch exogene Jasmonsäureapplikation simuliert.

\subsection{1 „Topfversuch“}

Der „Topfversuch“ diente der Überprüfung einer Resistenzinduktion ungeschädigter Nachbarn, die nur über flüchtige Duftstoffe vermittelt werden könnte. In Abb. 17 ist der „Topfversuch“ mit einer Versuchseinheit dargestellt. Die Auswirkungen der experimentellen Schädigung wurden auf die unmittelbar benachbarten Bäume „Baum-Nachbar“ und die weiter entfernt stehenden Pflanzen „Baum-Kontrolle“ untersucht. 

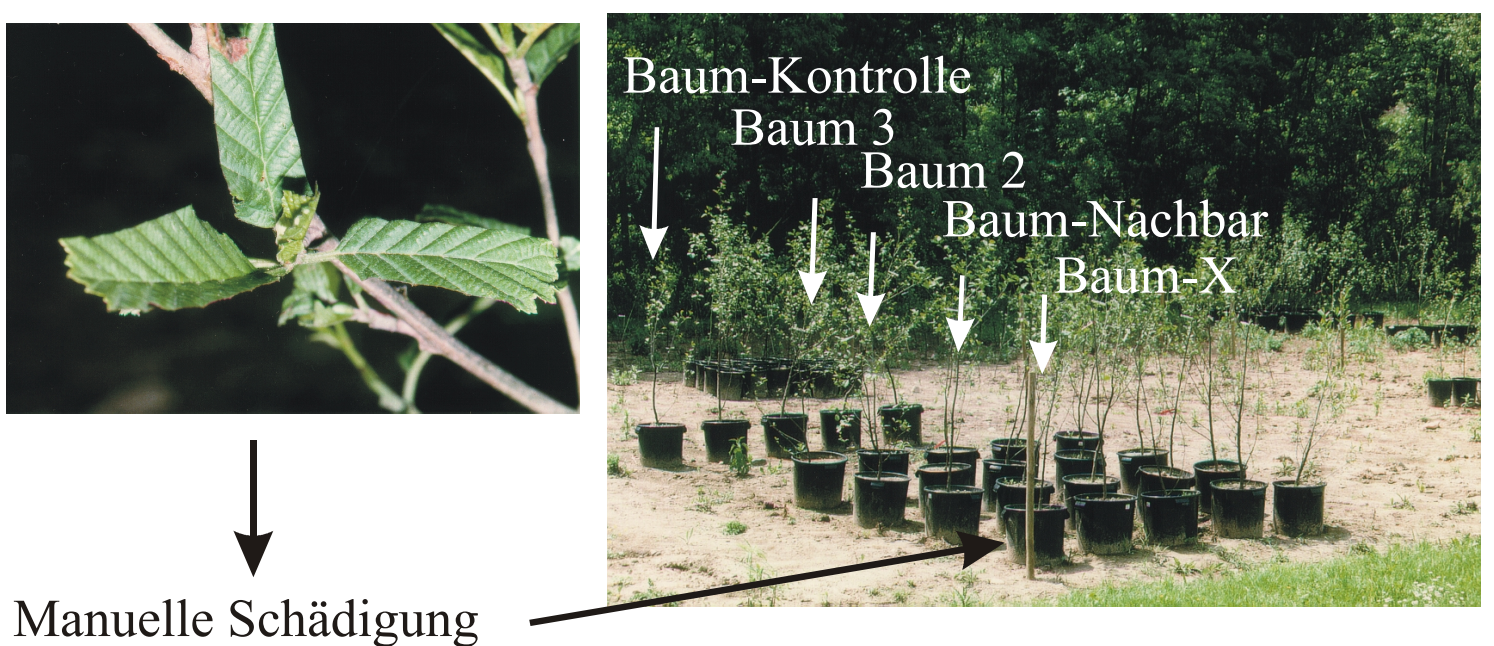

Abb. 17: „Topfversuch“ mit eingetopften Alnus glutinosa-Pflanzen.

\subsubsection{Relative Blattschädigung}

Für die Erlenpflanzen wurde der im Verlauf der Beobachtungsperiode durch herbivore Insekten auftretende Fraßschaden in Prozent der geschädigten Blattfläche optisch bonitiert. Diese Resultate der relativen Blattschädigung an den Versuchspflanzen sind in Abb. 18 als Mittelwerte mit Standardfehler dargestellt. Bei der Erstaufnahme des Befalls belief sich der prozentuale Fraßschaden an den untersuchten Bäumen „Baum-X“, „Baum-Nachbar“, „Baum 3“, „Baum 4“ und „Baum-Kontrolle“ auf durchschnittlich $3 \%$. Am Tag der Behandlung erfolgte die zweite Bonitierung des auftretenden Fraßschadens. Innerhalb von drei Tagen vergrößerte sich das Ausmaß der Schädigung auf ca. 11 \%. Sieben Tage nach der simulierten Herbivorie lag der Schädigungsgrad an den untersuchten Erlenbaumpositionen bei ca. 22 \%. Dieses Ausmaß konnte auch an den folgenden Beobachtungszeitpunkten, 21 und 41 Tage nach der Behandlung, ermittelt werden. Ein massiver Anstieg des Fraßschadens konnte am letzten Termin, 107 Tage nach der experimentellen Schädigung, festgestellt werden. $\mathrm{Zu}$ diesem Beobachtungszeitpunkt waren die Bäume bis zu 80 \% geschädigt. Auswirkungen der experimentellen Herbivorie auf das Ausmaß der relativen Blattschädigung an den untersuchten Erlenbäumen „Baum-Nachbar“, „Baum-2“, „Baum-3“ und „Baum-Kontrolle“ waren zu keinem Beobachtungszeitpunkt an diesen Baumvarianten erkenntlich (Tab. 5). 

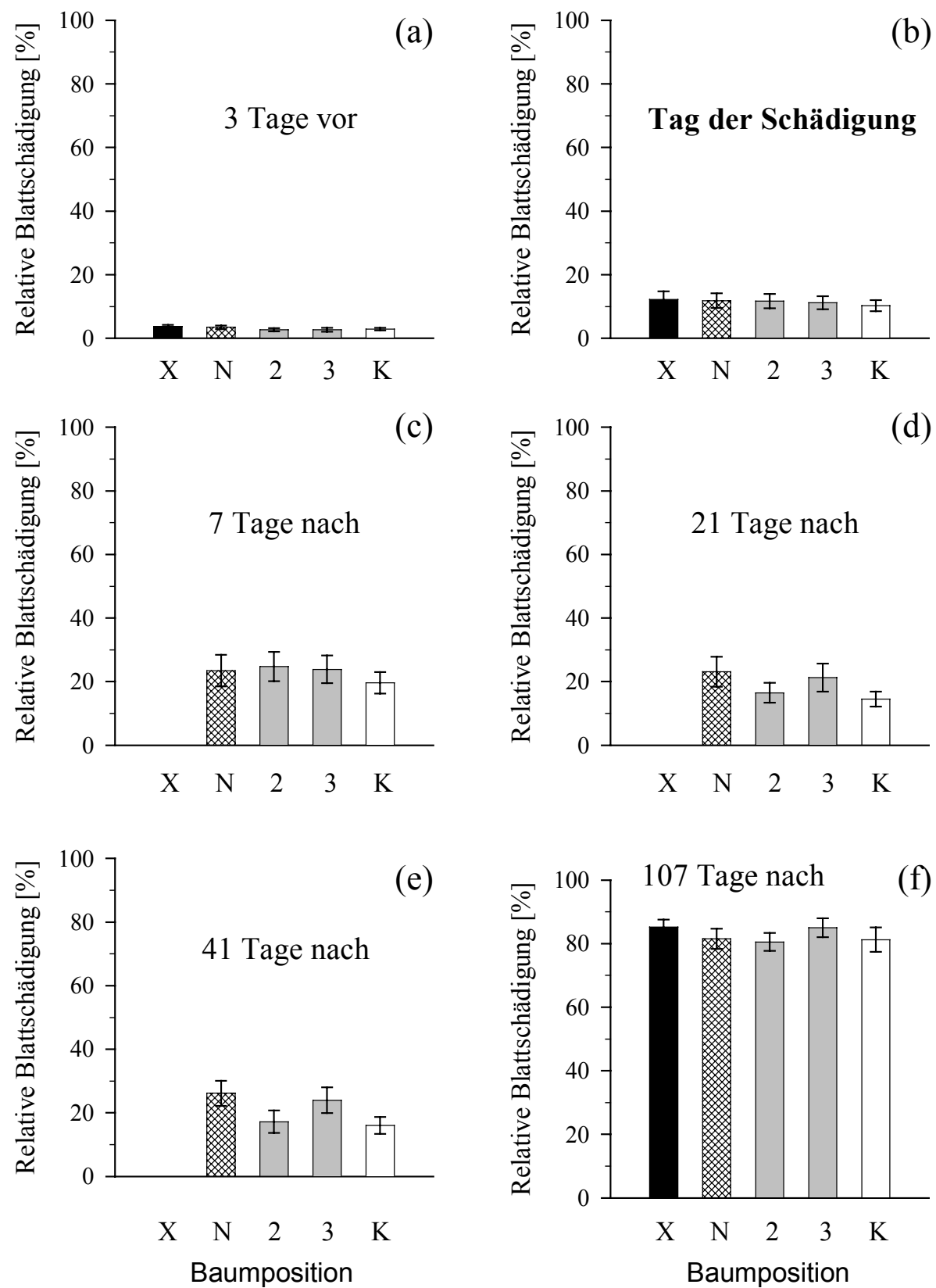

Abb. 18: „Topfversuch“. Darstellung des Herbivorenfraßschadens an den Blättern von Alnus glutinosa im Freiland. Dargestellt ist die relative Blattschädigung in Prozent [\%] der Blattfläche der untersuchten Bäume „Baum-X“ (X), „Baum-Nachbar“ (N), „Baum 2“ (2), „Baum 3“ (3) und „Baum-Kontrolle“ $(\mathrm{K})$ im zeitlichen Verlauf $(\mathrm{a}-\mathrm{f})$ von drei Tagen vor der simulierten Herbivorie bis 107 Tage nach der Schädigung. Dargestellt sind die Mittelwerte und der Standardfehler. $n=6$. Die statistischen Daten der einfaktoriellen Varianzanalyse sind Tab. 5 zu entnehmen. 
Tab. 5: Auswirkungen einer simulierten Herbivorie auf die relative Blattschädigung [\%] von Alnus glutinosa-Pflanzen im Freiland (,Topfversuch“). Vergleich von „Baum-Nachbar“, „Baum 2“, „Baum 3“ und „Baum-Kontrolle“ zu den angegebenen Zeitpunkten. Die statistischen Werte wurden mit Hilfe einer einfaktoriellen Varianzanalyse berechnet. Die grafische Darstellung der Daten ist in Abb. 18 abgebildet.

\begin{tabular}{|l|c|c|c|}
\hline Zeitpunkt & $\mathrm{F}$ & $\mathrm{p}$ & $\mathrm{n}$ \\
\hline 3 Tage vor & 0,326 & 0,806 & 24 \\
\hline Tag der Schädigung & 0,043 & 0,987 & 24 \\
\hline 7 Tage nach & 0,128 & 0,942 & 24 \\
\hline 21 Tage nach & 0,529 & 0,667 & 24 \\
\hline 41 Tage nach & 0,721 & 0,551 & 24 \\
\hline 107 Tage nach & 0,135 & 0,937 & 24 \\
\hline
\end{tabular}

\subsubsection{Prozentualer Blattwassergehalt}

In der nachfolgenden Grafik (Abb. 19a) sind die Ergebnisse der prozentualen Blattwasserbestimmung der benachbarten Erle „Baum-Nachbar“ und der als Kontrolle dienenden Erle „Baum-Kontrolle“ zu den sechs Untersuchungszeitpunkten dargestellt. Die Blattwassergehalte der Erlen „Baum-Nachbar“ und „Baum-Kontrolle“ lagen durchschnittlich bei $70 \%$. Ein Effekt der Schädigung auf den Blattwassergehalt konnte nicht erkannt werden (Tab. 6).

\subsubsection{Spezifisches Blattgewicht}

Die berechneten Daten des spezifischen Blattgewichts der beprobten Erlenbäume „Baum-Nachbar“ und „Baum-Kontrolle“ zu den einzelnen Beobachtungsterminen vor und nach der simulierten Herbivorie sind in Abb. 19b wiedergegeben. Die spezifischen Blattgewichte der Erlen „Baum-Nachbar“ und „Baum-Kontrolle“ betrugen am ersten Beprobungstermin im Durchschnitt etwa 5,2 mg Blatttrockenmasse $\mathrm{cm}^{-2}$ Blattfläche und veränderten sich im zeitlichen Verlauf leicht. Auswirkungen der simulierten Herbivorie auf das spezifische Blattwassergewicht der benachbarten Bäume konnten nicht festgestellt werden. Ein Vergleich der ermittelten spezifischen Blattgewichte der Baumpositionen „Baum-Nachbar“ und „Baum-Kontrolle“ zu den angegebenen Zeitpunkten ergab keine signifikanten statistischen Werte (Tab. 6). 

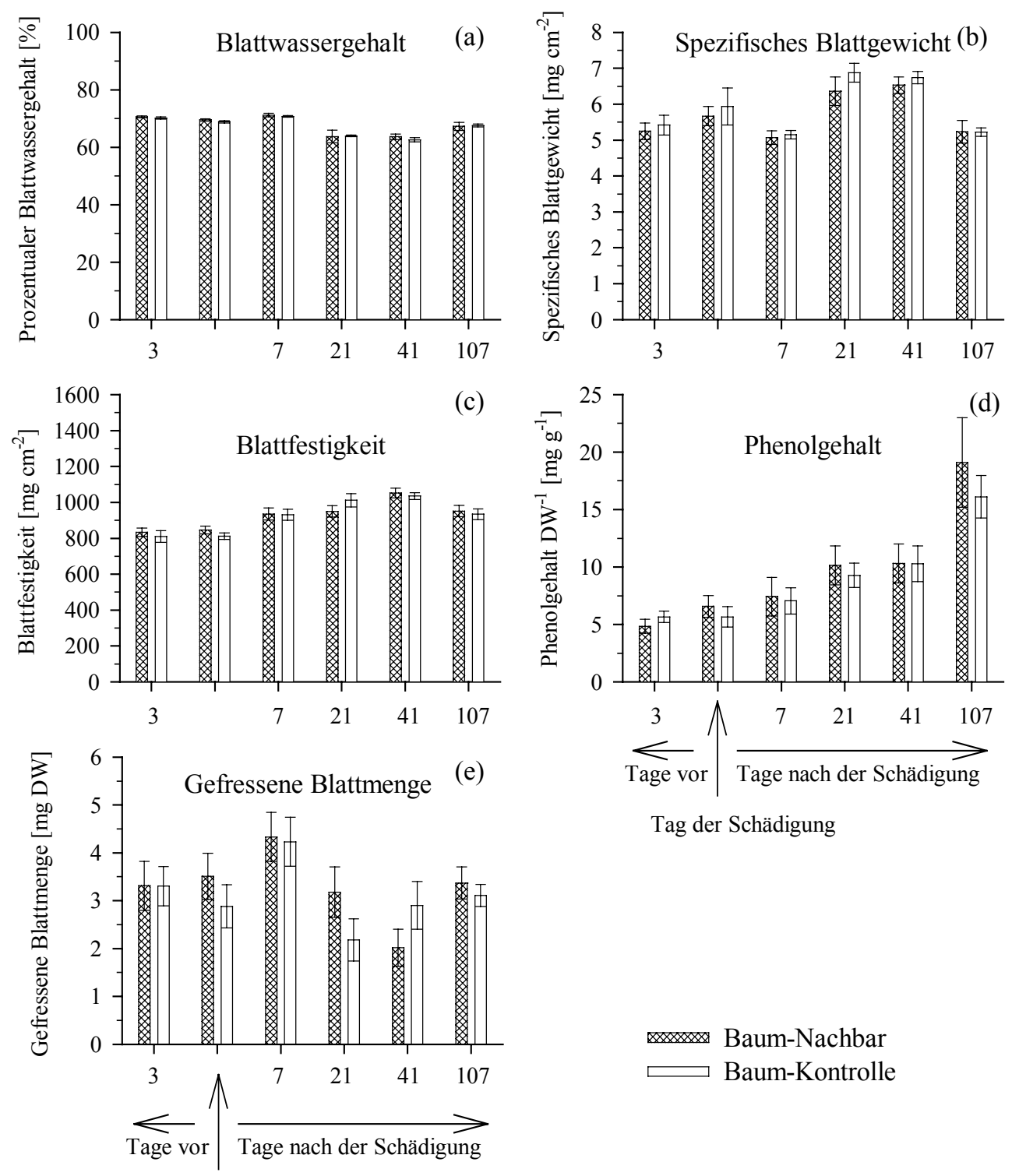

Baum-Nachbar

Baum-Kontrolle

Tag der Schädigung

Abb. 19: „Topfversuch“. Auswirkungen einer simulierten Herbivorie auf die Parameter (prozentualer Blattwassergehalt; spezifisches Blattgewicht; Blattfestigkeit; Phenolgehalt; gefressene Blattmenge) der Blätter einer unmittelbar benachbarten, unverletzten Erle Alnus glutinosa (,BaumNachbar“6). In zeitlichen Intervallen von drei Tagen vor der simulierten Herbivorie bis 107 Tage nach der Behandlung erfolgte eine Bestimmung der Parameter der Blätter von Erlenpflanzen „Baum-Nachbar“ und einer weiter entfernt liegenden Erle „Baum-Kontrolle“. Angegeben sind der Mittelwert und der Standardfehler. $\mathrm{n}=12$. Die statistischen Daten des t-Tests sind Tab. 6 und Tab. 7 zu entnehmen. Alle gepaarten Vergleiche $=$ nicht signifikant, siehe Tab. 6 und Tab. 7. - a) Prozentualer Blattwassergehalt [\%]. - b) Spezifisches Blattgewicht $\left[\mathrm{mg} \mathrm{cm}^{-2}\right]$. - c) Blattfestigkeit $\left[\mathrm{mg} \mathrm{cm}^{-2}\right] .-$ d) Phenolgehalt DW ${ }^{-1}\left[\mathrm{mg} \mathrm{g}^{-1}\right] .-$ e) Gefressene Blattmenge [mg DW]. 
Tab. 6: Auswirkungen einer simulierten Herbivorie auf die Parameter (prozentualer Blattwassergehalt [\%]; spezifisches Blattgewicht $\left[\mathrm{mg} \mathrm{cm}^{-2}\right]$; Blattfestigkeit $\left[\mathrm{mg} \mathrm{cm}^{-2}\right]$; Phenolgehalt $\mathrm{DW}^{-1}\left[\mathrm{mg}^{\circ}\right.$ $\left.\mathrm{g}^{-1}\right]$ ) von Alnus glutinosa-Pflanzen im Freiland („Topfversuch“). Vergleich von „Baum-Nachbar“ und „Baum-Kontrolle“ zu den angegebenen Zeitpunkten. Die statistischen Werte wurden mit Hilfe des t-Tests berechnet. Die grafische Darstellung der Daten ist in Abb. 19 dargestellt.

\begin{tabular}{|c|c|c|c|c|}
\hline Untersuchter Parameter & Zeitpunkt & $\bar{t}$ & $\mathrm{p}$ & $\mathrm{n}$ \\
\hline \multirow[t]{6}{*}{ Prozentualer Blattwassergehalt } & 3 Tage vor & $-0,320$ & 0,755 & 12 \\
\hline & Tag der Schädigung & $-1,187$ & 0,263 & 12 \\
\hline & 7 Tage nach & $-0,900$ & 0,389 & 12 \\
\hline & 21 Tage nach & 0,099 & 0,923 & 12 \\
\hline & 41 Tage nach & $-0,725$ & 0,485 & 12 \\
\hline & 107 Tage nach & 0,294 & 0,775 & 12 \\
\hline \multirow[t]{6}{*}{ Spezifisches Blattgewicht } & 3 Tage vor & 0,601 & 0,561 & 12 \\
\hline & Tag der Schädigung & 0,775 & 0,456 & 12 \\
\hline & 7 Tage nach & 0,251 & 0,806 & 12 \\
\hline & 21 Tage nach & 0,974 & 0,353 & 12 \\
\hline & 41 Tage nach & 0,469 & 0,649 & 12 \\
\hline & 107 Tage nach & 0,026 & 0,979 & 12 \\
\hline \multirow[t]{6}{*}{ Blattfestigkeit } & 3 Tage vor & $-0,469$ & 0,648 & 12 \\
\hline & Tag der Schädigung & $-0,381$ & 0,711 & 12 \\
\hline & 7 Tage nach & $-0,852$ & 0,414 & 12 \\
\hline & 21 Tage nach & 0,579 & 0,575 & 12 \\
\hline & 41 Tage nach & $-0,194$ & 0,850 & 12 \\
\hline & 107 Tage nach & $-0,097$ & 0,924 & 12 \\
\hline \multirow[t]{6}{*}{ Phenolgehalt } & 3 Tage vor & 0,720 & 0,487 & 12 \\
\hline & Tag der Schädigung & $-0,440$ & 0,669 & 12 \\
\hline & 7 Tage nach & $-0,634$ & 0,540 & 12 \\
\hline & 21 Tage nach & $-0,134$ & 0,896 & 12 \\
\hline & 41 Tage nach & $-0,311$ & 0,762 & 12 \\
\hline & 107 Tage nach & $-0,009$ & 0,993 & 12 \\
\hline
\end{tabular}

\subsubsection{Blattfestigkeit}

Die Blattfestigkeitswerte (Abb. 19c) lagen für die untersuchten Erlen der Position „Baum-Nachbar“ und „Baum-Kontrolle“ für die ersten beiden Termine im Durchschnitt bei ca. $820 \mathrm{mg} \mathrm{cm}^{-2}$ und stiegen bis zum fünften Beobachtungszeitpunkt auf $1040 \mathrm{mg}$ $\mathrm{cm}^{-2}$ an. Bis zum letzten Beprobungszeitpunkt verringerte sich der Blattfestigkeitswert auf $950 \mathrm{mg} \mathrm{cm}^{-2}$. Effekte der simulierten Herbivorie auf die Blattfestigkeit der benachbarten Bäume „Baum-Nachbar“ konnten nicht nachgewiesen werden. Mit den Blattfestigkeitsanalysen ließen sich keine signifikanten Unterschiede zwischen „Baum-Nachbar“ und „Baum-Kontrolle“ zu den jeweiligen Zeitpunkten aufzeigen (Tab. 6). 


\subsubsection{Phenolgehalt}

Die Abb. 19d gibt den Phenolgehalt der Blätter von den Bäumen „Baum-Nachbar“ und „Baum-Kontrolle“ zu den sechs Zeitpunkten wieder. Die Erlenblätter beider Baumvarianten des ersten Beprobungstermins zeichneten sich durch einen Phenolgehalt von ca. 5 $\mathrm{mg} \mathrm{g}^{-1} \mathrm{DW}$ aus, der sich im zeitlichen Verlauf leicht erhöhte. Am letzten Termin erreichte der Phenolgehalt der Erlenbäume „Baum-Nachbar“ und „Baum-Kontrolle“ einen Wert von durchschnittlich $20 \mathrm{mg} \mathrm{g}^{-1}$ DW. Da sich zu keinen Beobachtungszeitpunkt signifikante Unterschiede zwischen den Erlenbäumen „Baum-Nachbar“ und „BaumKontrolle" abzeichneten, kann eine Auswirkung der simulierten Herbivorie auf den Phenolgehalt der Baumposition „Baum-Nachbar“ ausgeschlossen werden (Tab. 6).

\subsubsection{Fraßpräferenz von Agelastica alni}

Die Biotestergebnisse zur Fraßpräferenz von A. alni zwischen Blättern von den unterschiedlichen Baumpositionen „Baum-Nachbar“ und „Baum-Kontrolle“ sind in Abb. 19e wiedergegeben. Für die Blätter, die bei der Erstaufnahme gesammelt wurden, belief sich das Trockengewicht der gefressenen Blattmenge für „Baum-Nachbar“ und „BaumKontrolle“ auf ca. 3,2 mg. Am Tag der Behandlung erfolgte ein weiterer Test zur Fraßpräferenz. Von diesen Blättern konsumierten die Herbivoren etwa gleich viel wie von den Blättern der Vorbehandlung. Für die Erlenblätter, die 7, 21, 42 und 107 Tage nach der Schädigung gesammelt und im Biotest angeboten wurden, ließen sich zu keinem Zeitpunkt Unterschiede bezüglich konsumierter Blattmenge zwischen den Erlenbaumvarianten „Baum-Nachbar“ und „Baum-Kontrolle“ ermitteln (Abb. 19e) (Tab. 7).

Begleitend zu diesen Fraßwahlversuchen, bei denen den Imagines von A. alni Blattscheiben von Blättern verschiedener Baumposition angeboten wurden, erfolgten zu den beiden Terminen, 21 und 41 Tage nach der experimentellen Schädigung, auch Fraßwahlversuche mit Larven von A. alni. Die Larven konsumierten von den Blattproben, die 21 Tage nach der Schädigung gesammelt worden waren, jeweils ein Trockengewicht von 1,47 \pm 0,21mg (,Baum-Nachbar“) und 1,81 \pm 0,16 mg (,Baum-Kontrolle“). Von den Blattproben, die 42 Tage nach der Schädigung gesammelt worden waren, ergab sich ein Trockengewicht von 1,43 $\pm 0,33 \mathrm{mg}$ (,Baum-Nachbar“) und 1,87 $\pm 0,23$ mg (,Baum-Kontrolle"). 
Tab. 7: Auswirkungen einer simulierten Herbivorie auf die Fraßpräferenz von Agelastica alni-Imagines bzw. A. alni-Larven („L“) gegenüber Alnus glutinosa-Blättern unterschiedlicher Baumposition im Fraßwahlversuch. Vergleich der gefressenen Blattmenge [mg DW] von Blättern der Baumposition „Baum-Nachbar“ und „Baum-Kontrolle“ zu den angegebenen Zeitpunkten. Die statistischen Werte wurden mit Hilfe des gepaarten t-Tests berechnet. Die grafische Darstellung der Daten ist in Abb. 19 dargestellt.

\begin{tabular}{|l|l|l|l|}
\hline Zeitpunkt & $\mathrm{t}$ & \multicolumn{1}{|c|}{$\mathrm{p}$} & \multicolumn{1}{|c|}{$\mathrm{n}$} \\
\hline 3 Tage vor & $-0,006$ & 0,995 & 12 \\
\hline Tag der Schädigung & $-0,811$ & 0,436 & 12 \\
\hline 7 Tage nach & $-0,100$ & 0,922 & 12 \\
\hline 21 Tage nach & $-1,117$ & 0,290 & 12 \\
& $0,640(\mathrm{~L})$ & $0,536(\mathrm{~L})$ & $12(\mathrm{~L})$ \\
\hline 41 Tage nach & 0,805 & 0,439 & 12 \\
& $1,079(\mathrm{~L})$ & $0,306(\mathrm{~L})$ & $12(\mathrm{~L})$ \\
\hline 107 Tage nach & $-0,477$ & 0,657 & 12 \\
\hline
\end{tabular}

Die Fraßpräferenz von verschiedenen $A$. alni-Entwicklungsstadien gegenüber Blattproben verschiedener Baumpositionen, „Baum-Nachbar“ und „Baum-Kontrolle“, läßt zu keinem Beobachtungstermin signifikante Hinweise auf induzierte Veränderungen im Blattgewebe erkennen, die sich nachhaltig auf das Fraßverhalten von $A$. alni auswirken (Tab. 7).

\subsubsection{Zusammenfassung „Topfversuch“}

Mit dem vorliegenden „Topfversuch“ sollte die Wechselwirkung zwischen A. glutinosaPflanzen dargestellt werden, bei der über die Abgabe von flüchtigen Signalstoffen Resistenzen in ungeschädigten Nachbarpflanzen induziert werden könnten. Die Auswirkungen der experimentellen Schädigung wurden auf die unmittelbar benachbarten Bäume „Baum-Nachbar“ und die weiter entfernt stehenden Pflanzen „Baum-Kontrolle“ untersucht. Die Analysen lieferten keine Hinweise bei den analysierten Parametern (relative Blattschädigung, spezifisches Blattgewicht, Blattfestigkeit, Phenolgehalt und gefressene Blattmenge im Fraßwahlversuch) auf eine induzierte Abwehr bei den unmittelbar benachbarten Bäumen. 


\subsection{2 „Reihenversuch“}

Zur Überprüfung einer Resistenzinduktion ungeschädigter Nachbarn von geschädigten Bäumen, die über den Boden oder über den Luftbereich vermittelt wird, wurde eine Versuchsfläche ausgewählt, die mit natürlichen Erlenbeständen versehen war (Abb. 20) Die Auswirkungen der experimentellen Schädigung wurden auf die unmittelbar benachbarten Bäume „Baum-Nachbar“ und weiter entfernt stehenden Pflanze „BaumKontrolle“ untersucht (Abb. 20).

\section{Manuelle Schädigung}

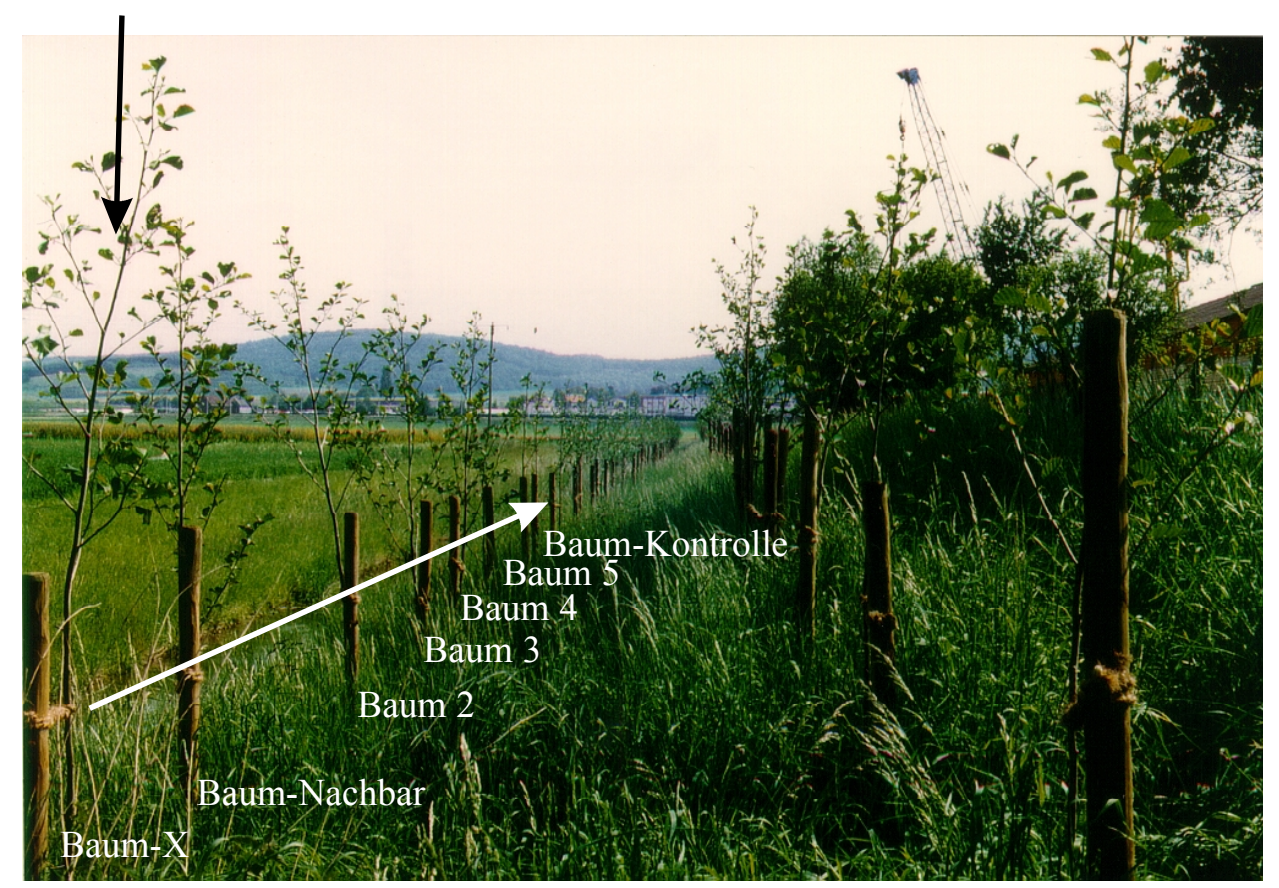

Abb. 20: „Reihenversuch“ mit natürlich wachsenden Erlenbeständen am Standort Bovenden.

\subsubsection{Relative Blattschädigung}

Für die Bäume des „Reihenversuchs“ wurde der im Verlauf der Beobachtungsperiode durch herbivore Insekten auftretende Fraßschaden an allen Versuchspflanzen in Prozent der geschädigten Blattfläche bonitiert und protokolliert. Diese Boniturdaten der relativen Blattschädigung sind als Mittelwert mit Standardfehler in Abb. 21 dargestellt. 

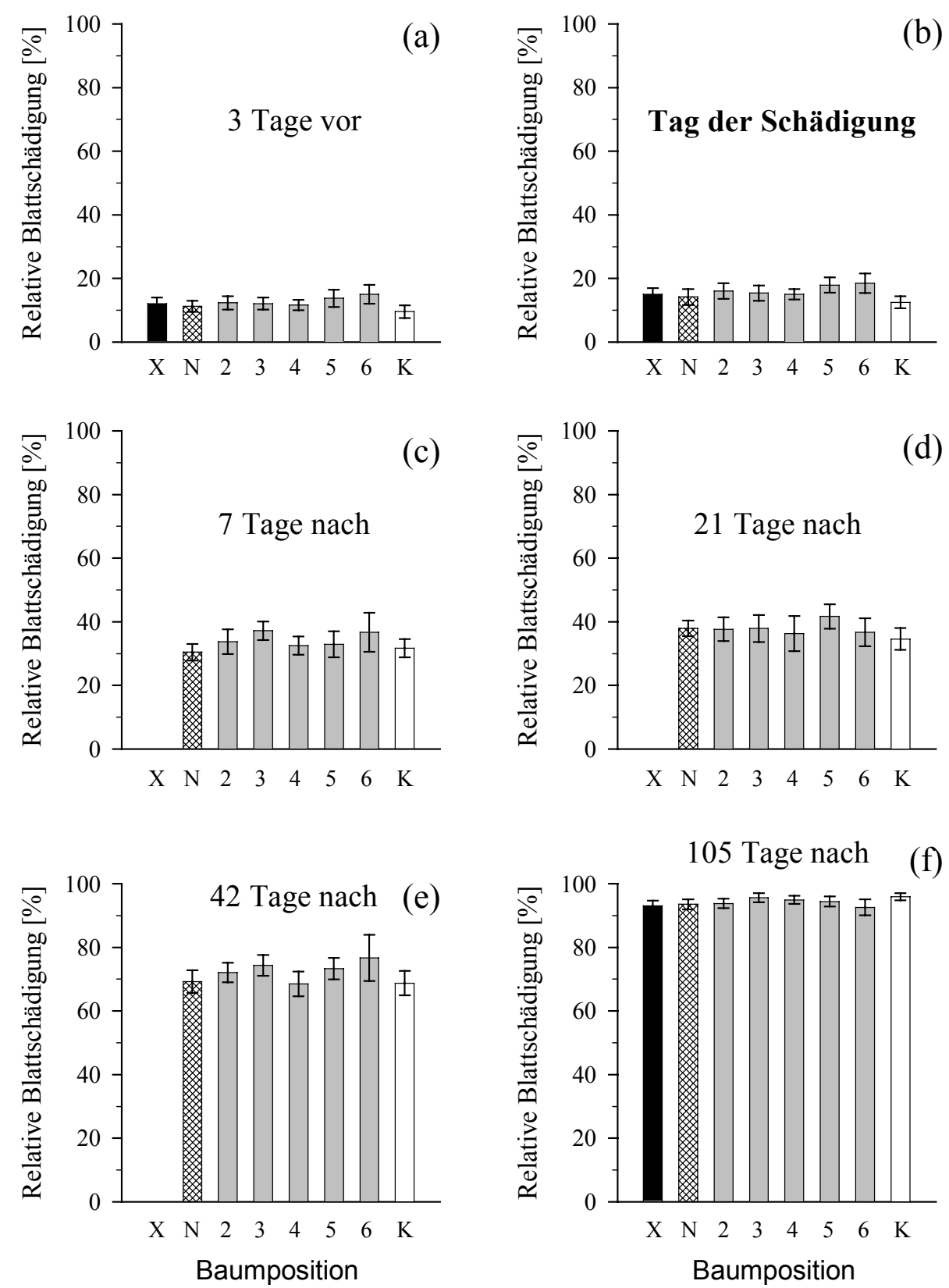

Abb. 21: „Reihenversuch“. Auswirkungen einer simulierten Herbivorie auf die relative Blattschädigung [\%] von Alnus glutinosa-Pflanzen im Freiland. In zeitlichen Intervallen von drei Tagen vor der simulierten Herbivorie bis 105 Tage nach der Behandlung erfolgte eine Bestimmung der auftretenden Herbivorenfraßschäden an den Erlenpflanzen der Baumposition „Baum-X“ (X), „Baum-Nachbar“ (N), „Baum 2“ (2), „Baum 3“ (3), „Baum 4“ (4), „Baum 5“ (5), „Baum 6“ (6) und „Baum-Kontrolle“ (K). Angegeben sind der Mittelwert und der Standardfehler. $n=12$ (Ausnahme „Baum 6“: $n=6$ ). Die statistischen Daten der einfaktoriellen Varianzanalyse sind Tab. 8 zu entnehmen. 
Bei den Erlenbäumen „Baum-X“, „Baum-Nachbar“, „Baum 2“, „Baum 3“, „Baum 4“, „Baum 5“, „Baum 6“ und „Baum-Kontrolle“ lag die relative Blattschädigung für alle untersuchten Erlenbaumpositionen an den ersten beiden Beobachtungszeitpunkten bei durchschnittlich $12 \%$ (drei Tage vor der simulierten Herbivorie) bzw. $15 \%$ (Tag der Schädigung). An den nachfolgenden Beobachtungsterminen vermehrte sich die relative Blattschädigung von $33 \%$ (7 Tage nach) über $40 \%$ (21 Tage nach) und $73 \%$ (42 Tage nach) auf $95 \%$ (105 Tage nach). Die simulierte Herbivorie ließ keinen Effekt auf Veränderungen in der Blattqualität der benachbarten, unbehandelten Bäume „Baum-Nachbar“ sowie auf die Bäume der Position „Baum 2“, Baum 3“, „Baum 4“, „Baum 5“, „Baum 6“ und „Baum-Kontrolle“ erkennen. Das Ausmaß der relativen Herbivorenfraßschädigung unterschied sich nicht zwischen den Erlenbäumen unterschiedlicher Positionen zu den jeweiligen Beobachtungsterminen (Tab. 8).

Tab. 8: Auswirkungen einer simulierten Herbivorie auf die relative Blattschädigung [\%] von Alnus glutinosa-Pflanzen im Freiland („Reihenversuch“). Vergleich von „Baum-Nachbar“, „Baum 2“, „Baum 3“, „Baum 4““, „Baum 5“, „Baum 6“ und „Baum-Kontrolle“ zu den angegebenen Zeitpunkten. Die statistischen Werte wurden mit Hilfe einer einfaktoriellen Varianzanalyse berechnet. Die grafische Darstellung der Daten ist in Abb. 21 wiedergegeben.

\begin{tabular}{|l|c|c|c|}
\hline Zeitpunkt & $\mathrm{F}$ & $\mathrm{p}$ & $\mathrm{n}$ \\
\hline 3 Tage vor & 0,961 & 0,457 & 78 \\
\hline Tag der Schädigung & 1,015 & 0,422 & 78 \\
\hline 7 Tage nach & 0,259 & 0,954 & 78 \\
\hline 21 Tage nach & 0,305 & 0,932 & 78 \\
\hline 42 Tage nach & 0,543 & 0,773 & 78 \\
\hline 105 Tage nach & 0,567 & 0,754 & 78 \\
\hline
\end{tabular}

\subsubsection{Prozentualer Blattwassergehalt}

Der prozentuale Blattwassergehalt wurde von den Erlen einer unmittelbar zum geschädigten Baum benachbarten Erle „Baum-Nachbar“ und der weiter entfernt stehenden Erle „Baum-Kontrolle“ bestimmt. Die Resultate dieser Blattwasserbestimmung zu den sechs Untersuchungszeitpunkten sind in Abb. 22a dargestellt. Der prozentuale Blattwassergehalt lag für die Erlen „Baum-Nachbar“ und „Baum-Kontrolle“ im Durchschnitt bei $70 \%$. Die simulierte Herbivorie wirkte sich zu keinem Zeitpunkt auf den prozentualen 
Blattwassergehalt aus, da die Bestimmungen keine signifikanten Unterschiede beim Vergleich von „Baum-Nachbar“ und „Baum-Kontrolle“ erkennen ließen (Tab. 9).
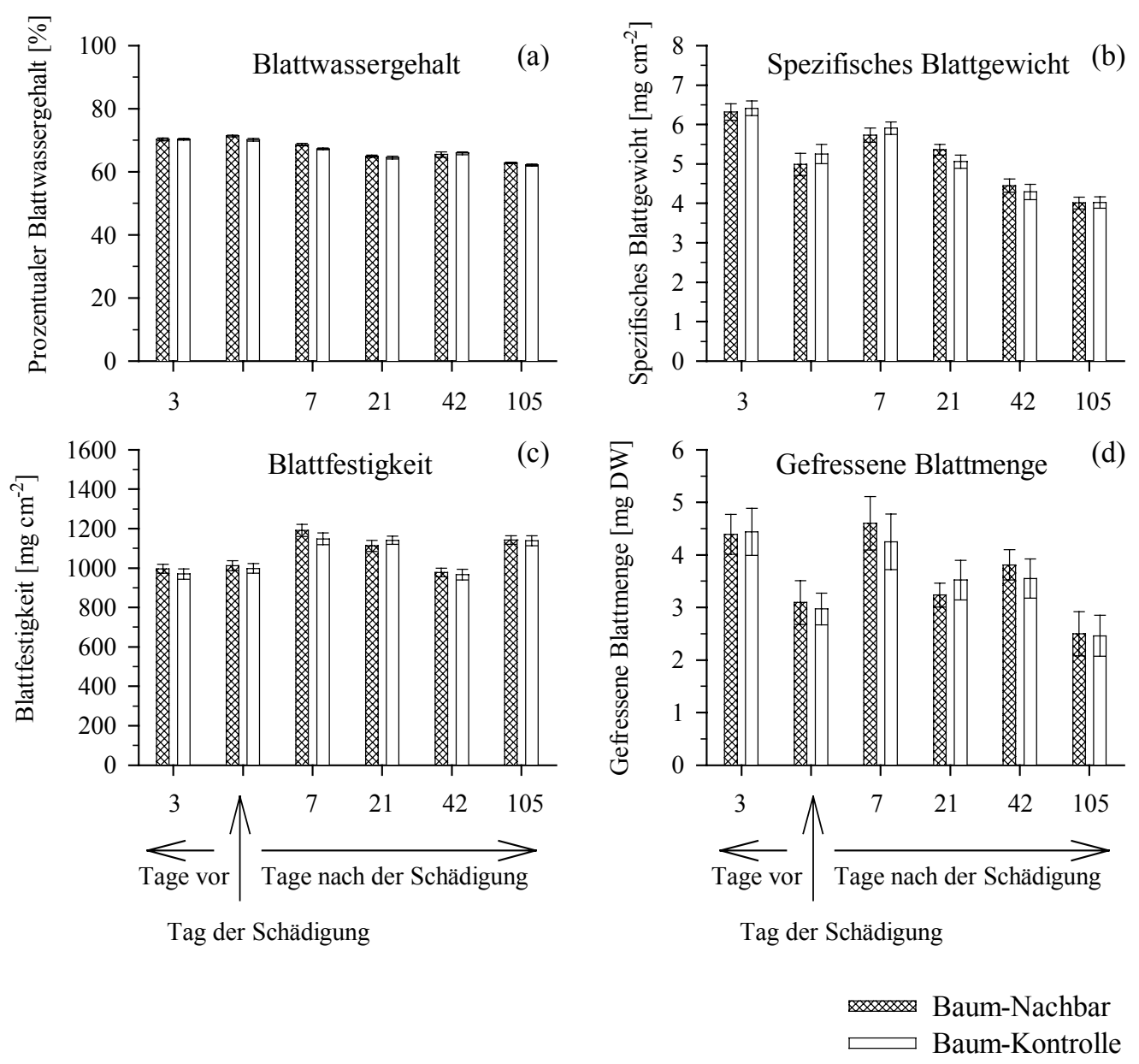

\begin{abstract}
Abb. 22: „Reihenversuch“. Auswirkungen einer simulierten Herbivorie auf die untersuchten Parameter (prozentualer Blattwassergehalt; spezifisches Blattgewicht; Blattfestigkeit; gefressene Blattmenge) der Blätter einer unmittelbar benachbarten, unverletzten Erle Alnus glutinosa („Baum-Nachbar“). In zeitlichen Intervallen von drei Tagen vor der simulierten Herbivorie bis 105 Tage nach der Behandlung erfolgte eine Bestimmung der Parameter der Blätter von Erlenpflanzen „BaumNachbar“ und „Baum-Kontrolle“. Angegeben sind der Mittelwert und der Standardfehler. n = 12. Die statistischen Daten des t-Tests sind Tab. 9 und Tab. 10 zu entnehmen. Alle gepaarten Vergleiche $=$ nicht signifikant, siehe Tab. 9 und Tab. 10. - a) Prozentualer Blattwassergehalt [\%]. - b) Spezifisches Blattgewicht $\left[\mathrm{mg} \mathrm{cm}^{-2}\right]$. - c) Blattfestigkeit $\left[\mathrm{mg} \mathrm{cm}^{-2}\right]$. - d) Gefressene Blattmenge [mg DW].
\end{abstract}


Tab. 9: Auswirkungen einer simulierten Herbivorie auf die Parameter (prozentualer Blattwasser-

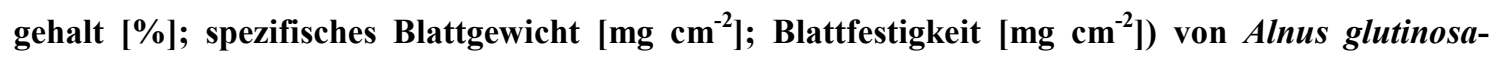
Pflanzen im Freiland („Reihenversuch“). Vergleich von „Baum-Nachbar“ und „Baum-Kontrolle“ zu den angegebenen Zeitpunkten. Die statistischen Werte wurden mit Hilfe des t-Tests berechnet. Die grafische Darstellung der Daten ist in Abb. 21 wiedergegeben.

\begin{tabular}{|c|l|c|c|c|}
\hline Untersuchter Parameter & Zeitpunkt & $\mathrm{t}$ & $\mathrm{p}$ & $\mathrm{n}$ \\
\hline Prozentualer Blattwassergehalt & 3 Tage vor & 0,145 & 0,886 & 24 \\
\hline & Tag der Schädigung & $-0,142$ & 0,265 & 24 \\
\hline & 7 Tage nach & $-1,308$ & 0,204 & 24 \\
\hline & 21 Tage nach & $-0,213$ & 0,833 & 24 \\
\hline & 42 Tage nach & 0,794 & 0,435 & 24 \\
\hline & 105 Tage nach & $-0,983$ & 0,336 & 24 \\
\hline & & & & \\
\hline Spezifisches Blattgewicht & 3 Tage vor & 0,211 & 0,834 & 24 \\
\hline & Tag der Schädigung & 0,449 & 0,657 & 24 \\
\hline & 7 Tage nach & 0,682 & 0,502 & 24 \\
\hline & 21 Tage nach & $-1,245$ & 0,225 & 24 \\
\hline & 42 Tage nach & $-0,418$ & 0,679 & 24 \\
\hline & 105 Tage nach & 0,021 & 0,983 & 24 \\
\hline & & & & \\
\hline & 3 Tage vor & $-0,588$ & 0,562 & 24 \\
\hline & Tag der Schädigung & $-0,253$ & 0,802 & 24 \\
\hline & 7 Tage nach & $-0,756$ & 0,457 & 24 \\
\hline & 21 Tage nach & 0,637 & 0,531 & 24 \\
\hline & 42 Tage nach & $-0,132$ & 0,896 & 24 \\
\hline & 105 Tage nach & 0,036 & 0,971 & 24 \\
\hline
\end{tabular}

\subsubsection{Spezifisches Blattgewicht}

Das spezifische Blattgewicht wurde von den Erlenpflanzen einer unmittelbar zum geschädigten Baum benachbarten Erle „Baum-Nachbar“ und der weiter entfernt positionierten Erle „Baum-Kontrolle“ zu sechs Zeitpunkten bestimmt (Abb. 22b). Die spezifischen Blattgewichte der Erlen „Baum-Nachbar“ und „Baum-Kontrolle“ betrugen am ersten Beprobungstermin im Durchschnitt etwa 6,4 mg Blatttrockenmasse $\mathrm{cm}^{-2}$ Blattfläche und fielen im zeitlichen Verlauf leicht ab. Die simulierte Herbivorie übte keine feststellbaren Effekte auf das spezifische Blattgewicht der Erlenbäume „BaumNachbar“ aus; die Bestimmungen zeigten zu keinem Beobachtungszeitpunkt signifikante Unterschiede zwischen „Baum-Nachbar“ und „Baum-Kontrolle“ auf (Tab. 9). 


\subsubsection{Blattfestigkeit}

Die Abb. 22c stellt die Mittelwerte mit Standardfehler der Blattfestigkeitsbestimmung der untersuchten Erlen „Baum-Nachbar“ und „Baum-Kontrolle“ zu den sechs Beprobungsterminen dar. Die Blattfestigkeitswerte lagen für die untersuchten Erlen „BaumNachbar“ und „Baum-Kontrolle“ für die ersten beiden Termine im Durchschnitt bei ca. $1000 \mathrm{mg} \mathrm{cm}^{-2}$ und stiegen bis zum Ende der Beobachtungsperiode leicht an. Eine Auswirkung der simulierten Herbivorie auf die Blattfestigkeit der benachbarten Bäume war nicht ersichtlich, denn zu keinem Zeitpunkt unterschieden sich die untersuchten Bäume „Baum-Nachbar“ und „Baum-Kontrolle“ voneinander (Tab. 9).

\subsubsection{Fraßpräferenz von Agelastica alni}

Die Versuchsergebnisse zur Fraßpräferenz von A. alni zwischen Blättern der Baumposition „Baum-Nachbar“ und „Baum-Kontrolle“ sind in Abb. 22d abgebildet. Für die Erlenblätter, die drei Tage vor der Behandlung bzw. am Tag der Behandlung gesammelt wurden, lag das Trockengewicht der gefressenen Blattmenge für beide Baumpositionen bei ca. 4,3 mg bzw. $3 \mathrm{mg}$. Von den Blattproben, die 7, 21, 42 und 105 Tage nach der Behandlung von den Bäumen „Baum-Nachbar“ und „Baum-Kontrolle“ gesammelt wurden, konsumierten die Imagines von A. alni immer gleich viel (Abb. 22d, Tab. 10).

Begleitend zu diesen Fraßwahlversuchen, bei denen den Imagines von $A$. alni Blattscheiben von Blättern verschiedener Baumposition angeboten wurden, erfolgten zu den beiden Terminen, 21 und 42 Tage nach der experimentellen Schädigung, auch Fraßwahlversuche mit Larven von A. alni. Damit sollte ausgeschlossen werden, daß die verschiedenen Entwicklungsstadien Unterschiede in der Fraßpräferenz zeigen könnten. Die Larven konsumierten von den Blattproben, die am 12. Juni (21 Tage nach der Schädigung) gesammelt worden waren, jeweils ein Trockengewicht von 2,46 $\pm 0,38 \mathrm{mg}$ („Baum-Nachbar“) und 2,22 \pm 0,26 mg (,Baum-Kontrolle“). Von den Blattproben, die am 4. Juli (42 Tage nach der Schädigung) gesammelt worden waren, verzehrten sie jeweils ein Trockengewicht von 2,70 \pm 0,27 mg (,Baum-Nachbar“) und 2,72 \pm 0,30 mg (,Baum-Kontrolle“).

Eine signifikante Auswirkung der simulierten Herbivorie auf die Fraßpräferenz von A. alni-Imagines und Larven zwischen Blättern unterschiedlicher Baumposition „Baum- 
Nachbar“ und „Baum-Kontrolle“ konnte zu keinem Zeitpunkt festgestellt werden (Tab. $10)$.

Tab. 10: Auswirkungen einer simulierten Herbivorie auf die Fraßpräferenz von Agelastica alniImagines bzw. A. alni-Larven (,L“) gegenüber Blättern unterschiedlicher Baumposition im Fraßwahlversuch. Vergleich der gefressenen Blattmenge [mg DW] von Blättern der Baumposition „BaumNachbar“ und „Baum-Kontrolle“ zu den angegebenen Zeitpunkten. Die statistischen Werte wurden mit Hilfe des gepaarten t-Tests berechnet. Die grafische Darstellung der Daten ist in Abb. 22 dargestellt.

\begin{tabular}{|l|c|l|l|}
\hline Zeitpunkt & \multicolumn{1}{|c|}{$\mathrm{t}$} & \multicolumn{1}{|c|}{$\mathrm{p}$} & $\mathrm{n}$ \\
\hline 3 Tage vor & 0,891 & 0,929 & 24 \\
\hline Tag der Schädigung & $-0,281$ & 0,781 & 24 \\
\hline 7 Tage nach & $-0,372$ & 0,713 & 24 \\
\hline 21 Tage nach & 0,571 & 0,574 & 24 \\
& $-0,46(\mathrm{~L})$ & $0,651(\mathrm{~L})$ & $20(\mathrm{~L})$ \\
\hline 42 Tage nach & $-0,515$ & 0,611 & 24 \\
& $0,028(\mathrm{~L})$ & $0,977(\mathrm{~L})$ & $20(\mathrm{~L})$ \\
\hline 105 Tage nach & $-0,063$ & 0,950 & 24 \\
\hline
\end{tabular}

\subsubsection{Zusammenfassung „Reihenversuch“}

Mit dem vorliegenden „Reihenversuch“ sollte eine Wechselwirkung an freiwachsenden A. glutinosa-Pflanzen dargestellt werden, bei der über die Abgabe von Signalstoffen Resistenzen in ungeschädigten Nachbarpflanzen induziert werden könnten. Die Auswirkungen der experimentellen Schädigung wurden auf die unmittelbar benachbarten Bäume „Baum-Nachbar“ und die weiter entfernt stehenden Pflanzen „Baum-Kontrolle“ untersucht. Die Analysen lieferten keine Hinweise bei den analysierten Parametern (relative Blattschädigung, spezifisches Blattgewicht, Blattfestigkeit und gefressene Blattmenge im Fraßwahlversuch) auf eine induzierte Abwehr bei den unmittelbar benachbarten Bäumen. 


\subsection{3 „JA-Versuch“6}

Nachdem die ersten beiden Freilandversuche - „Topfversuch“ (Kap. 5.1.1) und „Reihenversuch“ (Kap. 5.1.2) - keine Indizien für einen Signaltransfer zwischen den geschädigten und den unbehandelten, benachbarten Erlenpflanzen erbrachten, wurde ein weiteres Freilandexperiment durchgeführt. Es basierte auf den in der Zwischenzeit im Labor neu gewonnenen, eigenen Erkenntnissen. Bei diesem „JA-Versuch“ (Abb. 23) wurden getopfte Erlenpflanzen eingesetzt, um einen Signaltransfer zwischen den Pflan-

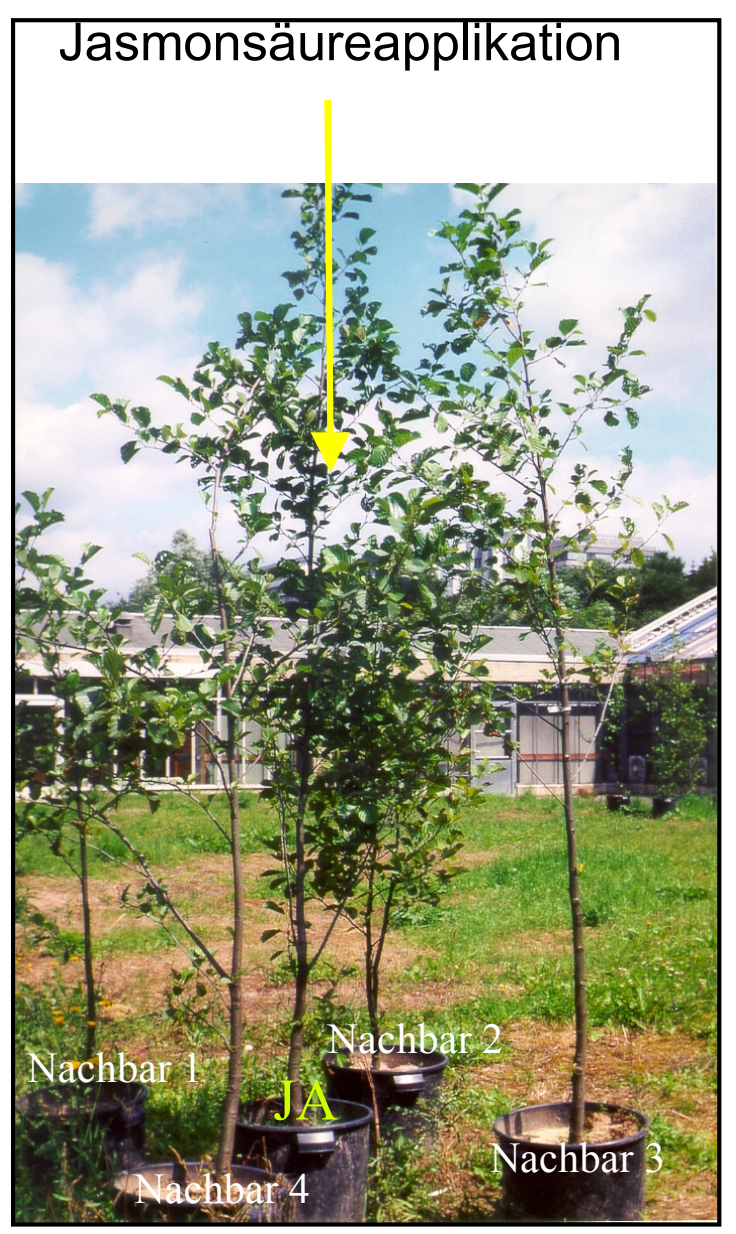
zen nur über die Gasphase zuzulassen. Um die Abwehr der Erle wirkungsvoll zu aktivieren, wurde starke Herbivorie durch exogene Applikation von Jasmonsäure simuliert. Von diesem Signalstoff ist bekannt, daß er pflanzliche Abwehrreaktionen auslöst und eine induzierte Resistenz gegen herbivore Fraßinsekten vermittelt (COHEN et al. 1993; THALER et al. 1996).

Abb: 23: „JA-Versuch“ mit eingetopften Alnus glutinosa-Pflanzen. Dargestellt ist eine Topfgruppe. (Photografiert im August 1995).

\subsubsection{Relative Blattschädigung}

Für die Erlenpflanzen „Baumnachbar-JA“ und „Baumnachbar-Kon“ wurde der im Verlauf der Beobachtungsperiode auftretende Herbivorenschaden in Prozent der geschädigten Blattfläche geschätzt und festgehalten. Diese Boniturdaten der relativen Blattschädigung sind als Mittelwert mit Standardfehler in Abb. 24a dargestellt. 
Das Ausmaß der Blattschädigung betrug an dem ersten Beobachtungszeitpunkt, einem Tag vor der Jasmonsäurebehandlung, für beide Erlenbäume „Baumnachbar-JA“ und „Baumnachbar-Kon“ ca. 3\%. Ein Unterschied zwischen beiden Baumpositionen war nicht gegeben. Mit fortschreitender Beobachtungszeit stieg der Fraßschaden an den Erlenbäumen beider Versuchsbehandlungen an und erreichte am Versuchsende nach 66 Tagen ein Ausmaß von fast $55 \%$ bei „Baumnachbar-Kon“ und nur $30 \%$ bei „Baumnachbar-JA“.

$\mathrm{Zu}$ allen Zeitpunkten nach den JA-Behandlungen lag das Ausmaß der Fraßschädigung an den Bäumen der Baumposition „Baumnachbar-JA“ immer signifikant unter der der Baumposition „Baumnachbar-Kon“ (Tab. 11). Somit zeigte die JA-Behandlung einen deutlichen Einfluß auf die Blattqualität der benachbarten, unbehandelten Bäume, so daß diese deutlich weniger von Herbivorenfraßschädigung gekennzeichnet waren.

\subsubsection{Prozentualer Blattwassergehalt}

Der prozentuale Blattwassergehalt wurde von den Erlen der Behandlungsvariante „Baumnachbar-JA“ und „Baumnachbar-Kon“ bestimmt. Die Ergebnisse zu den sieben Untersuchungszeitpunkten sind in Abb. 24b wiedergegeben.

Der prozentuale Blattwassergehalt belief sich im Mittel auf $65 \%$. Signifikante Unterschiede zwischen den verschiedenen Behandlungsvarianten „Baumnachbar-Kon“ und „Baumnachbar-JA“ konnten zu keinem Untersuchungszeitpunkt ermittelt werden (Tab. 11).

\subsubsection{Spezifisches Blattgewicht}

Die Ergebnisse der spezifischen Blattgewichtsbestimmung der Erlenbäume „Baumnachbar-JA“ und „Baumnachbar-Kon“ zu den einzelnen Beobachtungsterminen, vor und nach der JA-Applikation, sind in Abb. 24c abgebildet. Das spezifische Blattgewicht der untersuchten Erlen „Baumnachbar-JA“ und „Baumnachbar-Kon“ lag durchschnittlich um 6,5 mg Blatttrockenmasse $\mathrm{cm}^{-2}$ Blattfläche. Ein Einfluß der Jasmonsäurebehandlung auf das spezifische Blattgewicht der benachbarten Bäume konnte zu keinem Zeitpunkt wahrgenommen werden (Tab. 11). 

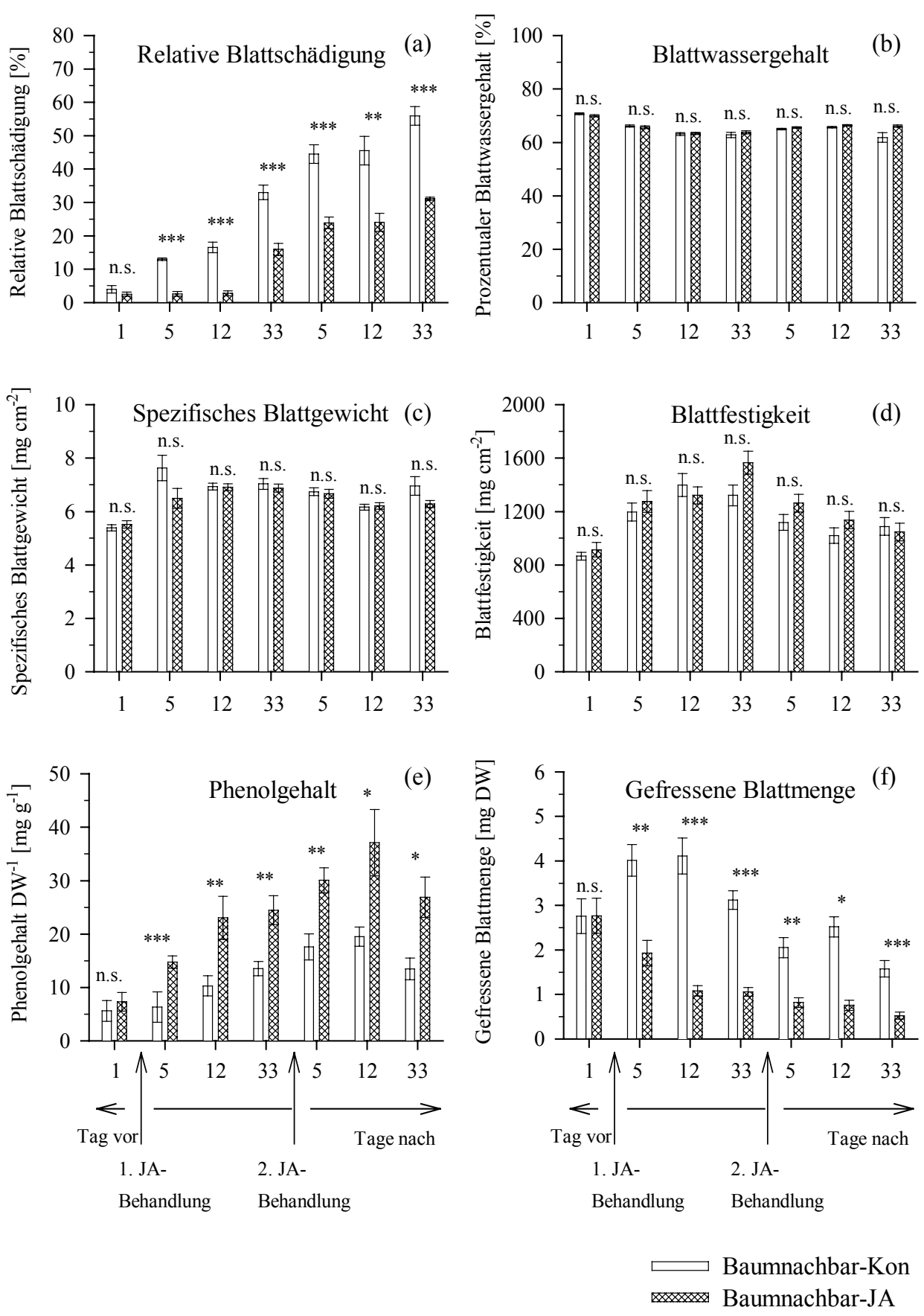

Abb. 24: „JA-Versuch“. Indirekte Auswirkungen einer Jasmonsäure (JA)-Behandlung auf die Parameter (relative Blattschädigung; prozentualer Blattwassergehalt; spezifisches Blattgewicht; Blattfestigkeit; Phenolgehalt; gefressene Blattmenge) bei benachbarten, ungeschädigten Alnus glutinosa-Pflanzen. In zeitlichen Intervallen von einem Tag vor der Jasmonsäure-Applikation bis 33 Tage nach der Behandlung erfolgte eine Bestimmung der Parameter an Erlenpflanzen der Behandlungsvariante „Baumnachbar-JA“ und „Baumnachbar-Kon“. Angegeben sind der Mittelwert und der Standardfehler. $\mathrm{n}=6$. Die statistischen Daten des t-Tests sind Tab. $11 \mathrm{zu}$ entnehmen. n.s. $=$ nicht signifikant. $*=\mathrm{p}<0,05$. $* *=\mathrm{p}<0,01$. $* * *=\mathrm{p}<0,001$. - a) Relative Blattschädigung [\%]. - b) Prozentualer Blattwassergehalt [\%]. - c) Spezifisches Blattgewicht $\left[\mathrm{mg} \mathrm{cm}^{-2}\right]$. - d) Blattfestigkeit $\left[\mathrm{mg} \mathrm{cm}^{-2}\right]$. - e ) Phenolgehalt $\mathrm{DW}^{-1}$ $\left[\mathrm{mg} \mathrm{g}^{-1}\right]$ - f) Gefressene Blattmenge [mg DW]. 
Tab. 11: Indirekte Auswirkungen einer Jasmonsäure (JA)-Behandlung auf die Parameter (relative Blattschädigung [\%]; prozentualer Blattwassergehalt [\%]; spezifisches Blattgewicht $\left[\mathrm{mg} \mathrm{cm}^{-2}\right]$; Blattfestigkeit [mg cm$\left.{ }^{-2}\right]$; Phenolgehalt $\mathrm{DW}^{-1}\left[\mathrm{mg} \mathrm{g}^{-1}\right]$; gefressene Blattmenge [mg DW]) von Alnus glutinosa-Pflanzen im Freiland („JA-Versuch“). Vergleich von „Baumnachbar-Kon“ und „Baumnachbar-JA“ zu den angegebenen Zeitpunkten. Die statistischen Werte wurden mit Hilfe des t-Tests berechnet. Die grafische Darstellung der Daten ist in Abb. 24 wiedergegeben.

\begin{tabular}{|c|c|c|c|c|}
\hline Untersuchter Parameter & Zeitpunkt & $\mathrm{t}$ & $P$ & $\mathrm{n}$ \\
\hline \multirow[t]{7}{*}{ Relative Blattschädigung } & 1 Tag vor 1. JA-Behandlung & 1,047 & 0,319 & 12 \\
\hline & 5 Tage nach 1 . JA.-Behandlung & 12,241 & $<0,001$ & 12 \\
\hline & 12 Tage nach 1. JA.-Behandlung & 8,186 & $<0,001$ & 12 \\
\hline & 33 Tage nach 1. JA.-Behandlung & 6,011 & $<0,001$ & 12 \\
\hline & 5 Tage nach 2. JA.-Behandlung & 6,344 & $<0,001$ & 12 \\
\hline & 12 Tage nach 2. JA.-Behandlung & 4,243 & 0,002 & 12 \\
\hline & 33 Tage nach 2 . JA.-Behandlung & 8,809 & $<0,001$ & 12 \\
\hline \multirow[t]{7}{*}{ Prozentualer Blattwassergehalt } & 1 Tag vor 1. JA-Behandlung & 0,691 & 0,505 & 12 \\
\hline & 5 Tage nach 1 . JA.-Behandlung & 0,509 & 0,621 & 12 \\
\hline & 12 Tage nach 1 . JA.-Behandlung & $-0,299$ & 0,770 & 12 \\
\hline & 33 Tage nach 1. JA.-Behandlung & $-1,595$ & 0,142 & 12 \\
\hline & 5 Tage nach 2. JA.-Behandlung & $-1,430$ & 0,183 & 12 \\
\hline & 12 Tage nach 2. JA.-Behandlung & $-1,243$ & 0,242 & 12 \\
\hline & 33 Tage nach 2. JA.-Behandlung & $-2,169$ & 0,055 & 12 \\
\hline \multirow{7}{*}{ Spezifisches Blattgewicht } & 1 Tag vor 1. JA-Behandlung & $-0,648$ & 0,532 & 12 \\
\hline & 5 Tage nach 1 . JA.-Behandlung & 0,281 & 0,784 & 12 \\
\hline & 12 Tage nach 1. JA.-Behandlung & 0,058 & 0,955 & 12 \\
\hline & 33 Tage nach 1. JA.-Behandlung & 0,961 & 0,359 & 12 \\
\hline & 5 Tage nach 2. JA.-Behandlung & 0,347 & 0,735 & 12 \\
\hline & 12 Tage nach 2. JA.-Behandlung & $-0,245$ & 0,811 & 12 \\
\hline & 33 Tage nach 2. JA.-Behandlung & 2,039 & 0,069 & 12 \\
\hline \multirow[t]{7}{*}{ Blattfestigkeit } & 1 Tag vor 1. JA-Behandlung & $-0,504$ & 0,625 & 12 \\
\hline & 5 Tage nach 1 . JA.-Behandlung & $-0,410$ & 0,690 & 12 \\
\hline & 12 Tage nach 1. JA.-Behandlung & 0,536 & 0,603 & 12 \\
\hline & 33 Tage nach 1. JA.-Behandlung & $-0,944$ & 0,367 & 12 \\
\hline & 5 Tage nach 2. JA.-Behandlung & $-1,017$ & 0,333 & 12 \\
\hline & 12 Tage nach 2. JA.-Behandlung & $-0,910$ & 0,384 & 12 \\
\hline & 33 Tage nach 2. JA.-Behandlung & 1,075 & 0,307 & 12 \\
\hline \multirow[t]{7}{*}{ Phenolgehalt } & 1 Tag vor 1. JA-Behandlung & $-0,619$ & 0,549 & 12 \\
\hline & 5 Tage nach 1. JA.-Behandlung & $-5,113$ & $<0,001$ & 12 \\
\hline & 12 Tage nach 1. JA.-Behandlung & $-3,127$ & 0,010 & 12 \\
\hline & 33 Tage nach 1. JA.-Behandlung & $-3,483$ & 0,006 & 12 \\
\hline & 5 Tage nach 2. JA.-Behandlung & $-4,088$ & 0,002 & 12 \\
\hline & 12 Tage nach 2. JA.-Behandlung & $-2,719$ & 0,022 & 12 \\
\hline & 33 Tage nach 2. JA.-Behandlung & $-2,633$ & 0,025 & 12 \\
\hline \multirow[t]{7}{*}{ Gefressene Blattmenge } & 1 Tag vor 1. JA-Behandlung & $-0,035$ & 0,973 & 12 \\
\hline & 5 Tage nach 1. JA.-Behandlung & 3,415 & 0,007 & 12 \\
\hline & 12 Tage nach 1. JA.-Behandlung & 8,014 & $<0,001$ & 12 \\
\hline & 33 Tage nach 1. JA.-Behandlung & 8,906 & $<0,001$ & 12 \\
\hline & 5 Tage nach 2. JA.-Behandlung & 3,992 & 0,002 & 12 \\
\hline & 12 Tage nach 2. JA.-Behandlung & 3,808 & 0,034 & 12 \\
\hline & 33 Tage nach 2. JA.-Behandlung & 5,344 & $<0,001$ & 12 \\
\hline
\end{tabular}




\subsubsection{Blattfestigkeit}

In der Grafik (Abb. 24d) sind die Mittelwerte mit Standardfehler der Blattfestigkeitsbestimmung der untersuchten Erlen „Baumnachbar-JA“ und „Baumnachbar-Kon“ zu den sieben Beprobungsterminen wiedergegeben. Die Blattfestigkeit der untersuchten Erlen der Position „Baumnachbar-JA“ und „Baumnachbar-Kon“ betrug beim ersten Termin durchschnittlich $850 \mathrm{mg} \mathrm{cm}^{-2}$. Sie stieg innerhalb der folgenden 33 Tage für beide Erlenpositionen leicht an. Nach der zweiten Jasmonsäurebehandlung fielen die Werte der Festigkeit bis zum Ende der Beobachtungsperiode leicht ab. Die Jasmonsäureapplikation zeigte keine klaren Auswirkungen auf die Blattfestigkeit der benachbarten Bäume „Baumnachbar-JA“ (Tab. 11).

\subsubsection{Phenolgehalt}

In Abb. 24e sind die Mittelwerte mit Standardfehler der Phenolbestimmungen für die Erlenpflanzen „Baumnachbar-JA“ und „Baumnachbar-Kon“ $\mathrm{zu}$ den sieben Untersuchungszeitpunkten dargestellt. An dem ersten Beobachtungszeitpunkt konnte ein Phenolgehalt von ca. $6 \mathrm{mg} \mathrm{g}^{-1}$ Blatttrockengewicht für beide Erlenbaumpositionen bestimmt werden. Die Erlenpflanzen „Baumnachbar-Kon“ und „Baumnachbar-JA“ unterschieden sich nicht signifikant in ihren Phenolgehalten voneinander. Aber im zeitlichen Verlauf stiegen die Werte für „Baumnachbar-Kon“ auf das Dreifache und für „Baumnachbar-JA“ auf das Sechsfache an. An den folgenden sechs Beobachtungsterminen konnte ein signifikanter Einfluß der JA-Behandlung beim „Baumnachbar-JA“ nachgewiesen werden (Tab. 11).

\subsubsection{Fraßpräferenz von Agelastica alni}

Die Ergebnisse der Laborversuche zur Fraßpräferenz von A. alni-Larven zwischen Blättern unterschiedlicher Baumposition „Baumnachbar-JA“ und „Baumnachbar-Kon“ sind in Abb. 24f abgebildet. Für die Blätter, die bei der Erstaufnahme gesammelt wurden, lag das Trockengewicht der gefressenen Blattmenge bei ca. $3 \mathrm{mg}$. Dabei zeigten die Imagines von A. alni keinen Unterschied im Fraßverhalten zwischen Blättern der Baumgruppe „Baumnachbar-JA“ und „Baumnachbar-Kon“. Die Fraßmenge stieg im 
Laufe von zwölf Tagen für die Blattstücke der Baumposition „Baumnachbar-Kon“ auf ca. 4 mg an, während von den Blattstücken der Baumposition „Baumnachbar-JA“ deutlich weniger als die Hälfte gefressen wurde. Ab dem vierten Beobachtungszeitpunkt nahm die Menge der konsumierten Blattmenge für beide Baumpositionen „Baumnachbar-JA“ und „Baumnachbar-Kontrolle“ ab. Weiterhin zeigten die A. alni-Imagines einen deutlichen Unterschied in ihrem Fraßverhalten den Blattstückchen verschiedener Baumpositionen gegenüber. Sie konsumierten immer deutlich weniger von den Blattstücken der Baumposition „Baumnachbar-JA“ (Tab. 11). Somit nahm die Jasmonsäure-Behandlung einen deutlichen Einfluß auf die Blattqualität der benachbarten, unbehandelten Bäume.

\subsubsection{Zusammenfassung „JA-Versuch“}

Mit dem vorliegendem „JA-Versuch“ sollte eine Wechselwirkung zwischen A. glutinosa-Pflanzen dargestellt werden. Es wurde der Frage nachgegangen, ob „stark geschädigte“ Pflanzen, deren Abwehrsystem mit einem Elicitor induziert worden war, über die Abgabe von flüchtigen Signalstoffen Resistenzen in ungeschädigten Nachbarpflanzen induzieren können.

Die Untersuchungen der Parameter relative Blattschädigung (a), quantitativer Phenolgehalt (b) und konsumierte Blattmenge im Fraßwahlversuch (c) lieferten Hinweise auf eine induzierte Abwehr bei den unmittelbar benachbarten Bäumen. Das spezifische Blattgewicht und die Blattfestigkeit der benachbarten Bäume erbrachten nach der simulierten Herbivorie dagegen keine signifikanten Veränderungen. 


\subsection{Laborversuche}

In Laborversuchen wurden die Mechanismen des Signaltransfers und der Signalinduktion, die für die Wechselwirkung zwischen Erlenpflanzen und den Herbivoren in Frage kommen, näher untersucht. Die Untersuchungen sollten klären mit welchen Formen pflanzlicher Abwehr im Stoffwechsel der Erle zu rechnen ist. Dabei wurden neben den direkten über Herbivorenfraß induzierten Veränderungen (Kap. 5.2.1, Kap. 5.2.3) die indirekten - über flüchtige Duftstoffe - vermittelten physiologischen Veränderungen in ungeschädigten Erlenblättern untersucht (Kap. 5.2.2). Die Induktion von physiologischen Veränderungen durch biotische und abiotische Streßfaktoren erfolgt über Kaskaden. Es sollte geklärt werden, welche endogenen Signalstoffe an der nach Herbivorenfraß vermittelten Abwehr beteiligt sind (5.2.4). Weiterhin sollte ermittelt werden, ob Verbindungen im Regurgitat des Herbivoren eine elicitierende Wirkung zugesprochen werden könnte (Kap. 5.2.5). Die Auswirkungen induzierter Blattveränderungen auf die herbivoren Insekten wurde in Fraßwahlversuchen überprüft, um Hinweise auf eine induzierte Resistenz zu bekommen (Kap. 5.2.6).

\subsubsection{Inkubationsversuche}

\subsubsection{Phenolgehalte}

In der ersten Versuchsserie (Phenolassay 1, Kap. 4.4.1.1) wurden die Effekte verschiedener Schädigungsvarianten entweder durch den Herbivoren $A$. alni bzw. simuliert durch mechanische Verletzung oder nach Applikation von Regurgitat der Herbivoren auf den Phenolgehalt bestimmt (Abb. 25a).

Der Herbivorenfraß der A. alni-Larven bewirkte eine 3,8-fache Zunahme der Blattphenole im befressenen Blattgewebe, das nach Fraßschädigung einen Phenolgehalt von $21,78 \pm 2,95 \mathrm{mg} \mathrm{g}^{-1} \mathrm{DW}$ aufwies. Auch der Fraß des Herbivoren S. littoralis vergrößerte den Phenolgehalt, wobei nur eine 2,2-fache Zunahme des Phenolgehalts erreicht wurde. Die mechanische Verletzung des Blattgewebes, hervorgerufen durch Lochen mit einem „Fakir-Stempel“, führte zu keinen signifikanten Veränderungen im Phenolgehalt der verletzten Blätter. Das Regurgitat, das kurz vor der Applikation von den Larven des 
Erlenblattkäfers frisch gesammelt worden war, veränderte den Phenolgehalt signifikant 1,5-fach, wenn es auf frisch mechanisch-verletztes Blattgewebe aufgetragen wurde. Wurde das Regurgitat als wäßrige Lösung appliziert, so daß eine Aufnahme über den Transpirationssog der Blätter erfolgte, waren die Auswirkungen auf den Phenolgehalt nicht signifikant (Abb. 25a).
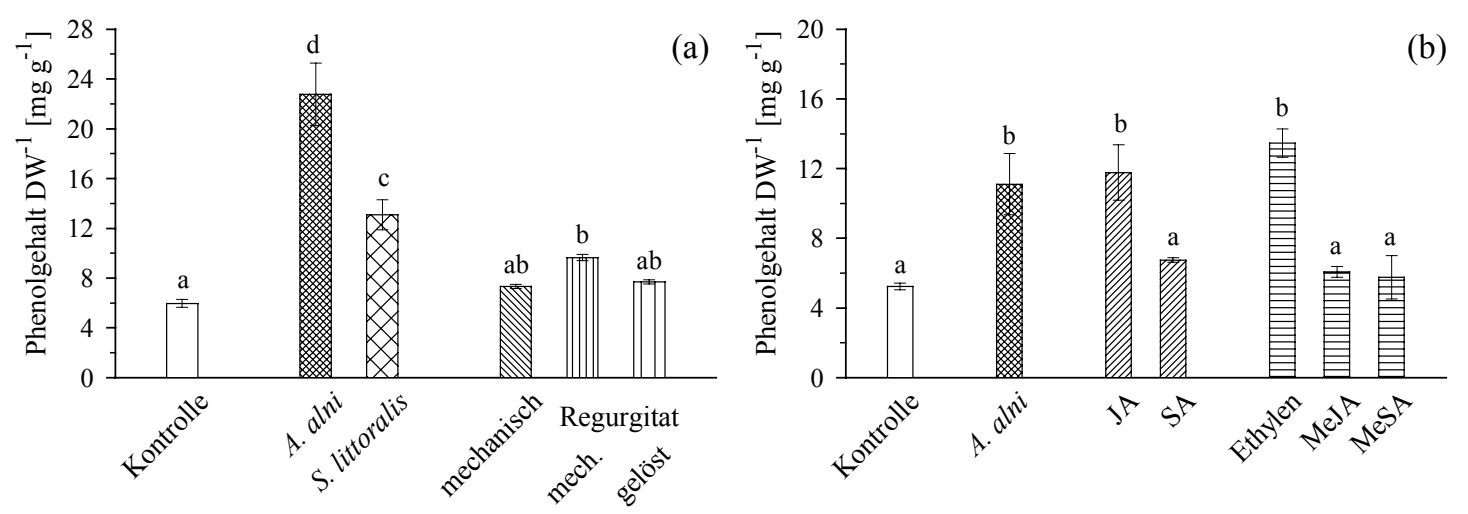

\begin{abstract}
Abb. 25: Auswirkungen verschiedener Behandlungsvarianten auf den Phenolgehalt von Alnus glutinosa-Blättern nach 72-stündiger Inkubation. - a) Dargestellt sind Phenolgehalte $\mathrm{DW}^{-1}\left[\mathrm{mg} \mathrm{g}^{-1}\right]$ ungeschädigter Blätter (Kontrolle), nach Herbivorenfraß von Agelastica alni- und Spodoptera littoralis-Larven sowie die Auswirkungen mechanischer Schädigung und die Applikation von A. alni-Larven-Regurgitat, das entweder auf mechanisch verletzte Blätter (mech.) oder über den Transpirationssog appliziert wurde (gelöst). ANOVA $(\mathrm{F}=29,20, \mathrm{p}<0,001, \mathrm{n}=60)$. - b) Dargestellt sind Phenolgehalte $\mathrm{DW}^{-1}\left[\mathrm{mg} \mathrm{g}^{-1}\right]$ ungeschädigter Blätter (Kontrolle), nach Herbivorenfraß von Agelastica alni-Larven, nach Inkubation mit Jasmonsäure (JA), Salicylsäure (SA) Ethylen, Methyljasmonat (MeJA) und Methylsalicylat (MeSA). ANOVA $(\mathrm{F}=18,57, \mathrm{p}<0,001, \mathrm{n}=70)$. Verschiedene Buchstaben zeigen signifikante Unterschiede $(\mathrm{p}<$ 0,05, Newman Keuls-Test) an. DW $=$ Trockengewicht.
\end{abstract}

In einer zweiten Versuchsserie (Phenolassay 2, Kap. 4.4.1.1) wurden die Veränderungen nach Inkubation mit den verschiedenen Signalstoffen wie Jasmon- und Salicylsäure sowie mit den flüchtigen Komponenten Ethylen, Methyljasmonat und Methylsalicylat auf den Phenolgehalt untersucht. Dabei wurden Phenolgehaltsveränderungen, hervorgerufen durch Herbivorenfraß, als Vergleich mit in die Untersuchungen einbezogen (Abb. 25b).

Der Grundgehalt phenolischer Verbindungen in den unbehandelten Erlenblättern lag bei dieser Versuchsserie bei 5,23 $\mathrm{mg} \mathrm{g}^{-1} \mathrm{DW}$ und erhöhte sich nach $A$. alni-Fraß signifikant 2,2-fach. Die octadecanoide Verbindung Jasmonsäure vergrößerte den Phenolgehalt in einem ähnlichen Ausmaß wie Herbivorenfraßschädigung (2,3-fach). Ein signifikanter 
Effekt von Salicylsäure auf Veränderungen im Phenolgehalt konnte nicht beobachtet werden (Abb. 25b). Weiterhin wurden die Auswirkungen der flüchtigen Verbindungen Ethylen, Methyljasmonat und Methylsalicylat auf den Phenolgehalt im Blattgewebe untersucht. Ethylen veränderte den Phenolgehalt um den Faktor 2,6 und zeigte somit den größten Effekt von allen untersuchten Behandlungsvarianten. Weder Methyljasmonat noch Methylsalicylat beeinflußten signifikant den Gehalt phenolischer Verbindungen im Blattgewebe (Abb. 25b).

\subsubsection{Enzymaktivitäten}

In kurzzeitigen $(\mathrm{t}=48 \mathrm{~h})$ und langfristigen $(\mathrm{t}=72 \mathrm{~h})$ Inkubationsversuchen wurden verschiedene Behandlungsweisen wie Herbivorenfraßschädigung, Applikation von Signalstoffen (Jasmon- und Salicylsäure) sowie von flüchtigen Duftstoffen wie Ethylen, Methyljasmonat und Methylsalicylat untersucht, um ihre Bedeutung für Aktivitätsveränderungen bei den Enzymen Polyphenoloxidase, Lipoxygenase, Peroxidase und Katalase in dem Blattgewebe von $A$. glutinosa zu erfassen.

\subsection{Polyphenoloxidase}

In der Abb. 26a sind die Ergebnisse der Polyphenoloxidase-Aktivitätsbestimmung nach verschiedenen Schädigungsvarianten entweder durch den Herbivoren bzw. simuliert durch mechanische Verletzung oder nach Applikation von Regurgitat der Herbivoren dargestellt (Enzymassay 1, Kap. 4.4.1.1). In unbehandelten Erlenblättern konnte nach 72-stündiger Inkubation eine Polyphenoloxidase-Aktivität von 55,12 $\pm 2,67\left[\Delta \mathrm{E}_{490}\right.$ min $^{-}$

${ }^{1} \mathrm{mg}^{-1}$ Protein] festgestellt werden, die durch Herbivorenfraß von $A$. alni-Larven um den Faktor 3,1-fach sowie von S. littoralis-Larven 2,6-fach signifikant gesteigert wurde. Die mechanische Verletzung des Blattgewebes, hervorgerufen durch Lochen mit einem „Fakir-Stempel“, führte zu keinen signifikanten Veränderungen der Enzymaktivität im Blattgewebe verletzter Blätter gegenüber unbehandelten Blättern. Das Larvenregurgitat, das kurz vor der Applikation von den Larven des Erlenblattkäfers frisch gesammelt worden war, veränderte die Enzymaktivität signifikant 1,4-fach, wenn es auf frisch mechanisch verletztes Blattgewebe aufgetragen wurde. Die Applikation des Regurgitats 
als wäßrige Lösung, aufgenommen über den Transpirationssog der Blätter, zeigte keine signifikanten Auswirkungen auf die Enzymaktivität der Polyphenoloxidase (Abb. 26a).

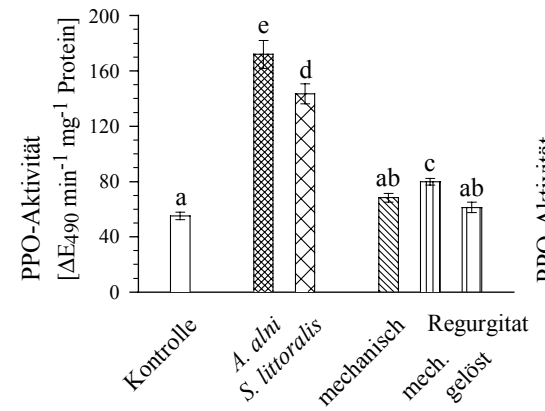

(a)

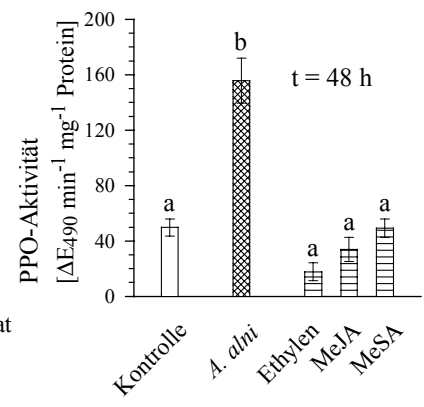

(b)

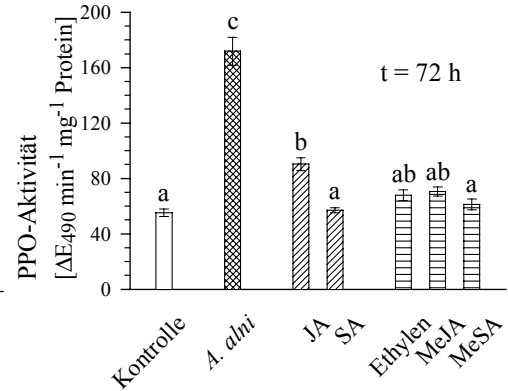

(c)

Abb. 26: Auswirkungen verschiedener Behandlungsweisen auf die Polyphenoloxidase-Aktivität (PPO-Aktivität) $\left[\Delta \mathbf{E}_{490} \mathrm{~min}^{-1} \mathrm{mg}^{-1}\right.$ Protein] im Blattgewebe von Alnus glutinosa-Blättern nach unterschiedlichen Inkubationszeiten. - a) PPO-Aktivitäten ungeschädigter Blätter, nach Herbivorenfraß von A. alni- und S. littoralis-Larven, sowie die Auswirkungen mechanischer Schädigung und die Applikation von $A$. alni-Larven-Regurgitat, das entweder auf mechanisch verletzte Blätter (mech.) oder über den Transpirationssog appliziert wurde (gelöst), $\mathrm{t}=72 \mathrm{~h}$. ANOVA $(\mathrm{F}=75,19, \mathrm{p}<0,001, \mathrm{n}=60)$. - b) PPOAktivitäten ungeschädigter Blätter, nach Herbivorenfraß von $A$. alni, nach Inkubation mit Ethylen, Methyljasmonat und Methylsalicylat, $\mathrm{t}=48 \mathrm{~h}$. ANOVA $(\mathrm{F}=31,83, \mathrm{p}=0,00, \mathrm{n}=25)$. - c) PPO-Aktivitäten ungeschädigter Blätter, nach Herbivorenfraß von $A$. alni, nach Inkubation mit Jasmonsäure (JA), Salicylsäure (SA), Ethylen, Methyljasmonat und Methylsalicylat, $\mathrm{t}=72 \mathrm{~h}$. ANOVA $(\mathrm{F}=68,23, \mathrm{p}<0,001, \mathrm{n}=$ 70). Angegeben sind der Mittelwert und der Standardfehler. Verschiedene Buchstaben zeigen signifikante Unterschiede $(\mathrm{p}<0,05$, Newman Keuls-Test $)$ an. Kontrolle $=$ ungeschädigte Blätter. MeJA = Methyljasmonat. MeSA = Methylsalicylat.

Weiterhin wurden die Auswirkungen der Verbindungen Jasmon- und Salicylsäure sowie die der flüchtigen Verbindungen Ethylen, Methyljasmonat und Methylsalicylat auf die Enzymaktivität im Blattgewebe untersucht (Enzymassay 2, Kap. 4.4.1.1). Die flüchtigen Duftstoffe Ethylen, Methyljasmonat sowie Methylsalicylat veränderten die Polyphenoloxidase-Aktivität im Blattgewebe weder nach 48- noch nach 72-stündiger Inkubation (Abb. 26b, c). Jasmonsäure steigerte die Enzymaktivität signifikant um den Faktor 1,64 (Abb. 26c). Hingegen zeigte die zweite Signalsubstanz, Salicylsäure, keinen Effekt (Abb. 26c). 


\subsection{Lipoxygenase}

Abb. 27 stellt die Ergebnisse der Lipoxygenase-Aktivitätsbestimmung (Enzymassay 3, 4; Kap. 4.4.1.1) nach Herbivorenfraß von A. alni-Larven sowie nach der Applikation von Jasmonsäure, Salicylsäure bzw. nach Inkubation mit den flüchtigen Verbindungen Ethylen, Methyljasmonat und Methylsalicylat graphisch dar. In unbehandelten Erlenblättern konnte nach 72-stündiger Inkubation eine Lipoxygenase-Aktivität von 456,22 土 $23,11\left[\Delta \mathrm{E}_{234} \mathrm{~min}^{-1} \mathrm{mg}^{-1}\right.$ Protein] festgestellt werden (Abb. 27b). Nach Herbivorenfraß von $A$. alni-Larven vergrößerte sich die Aktivität signifikant um den Faktor 2,7. Jasmonsäure steigerte die Enzymaktivität signifikant 1,7-fach (Abb. 27b). Weder Salicylsäure noch die flüchtigen Duftstoffe Ethylen, Methyljasmonat und Methylsalicylat zeigten nach 48 und 72 Stunden irgendwelche Auswirkungen auf physiologische Veränderungen der Lipoxygenase-Aktivität (Abb. 27a, b).

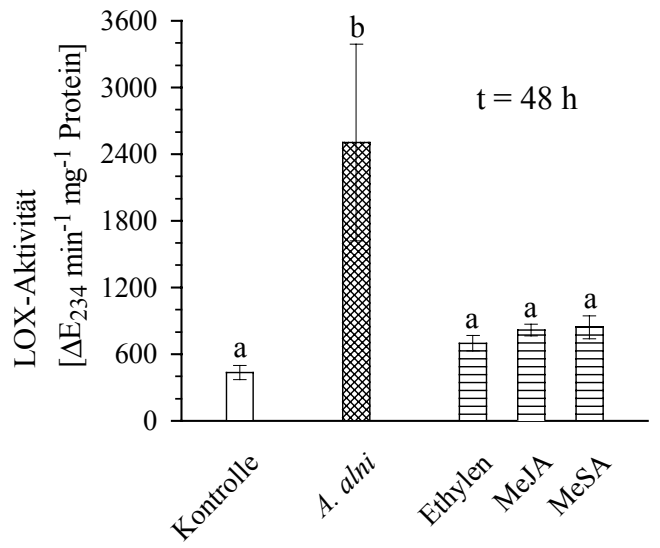

(a)

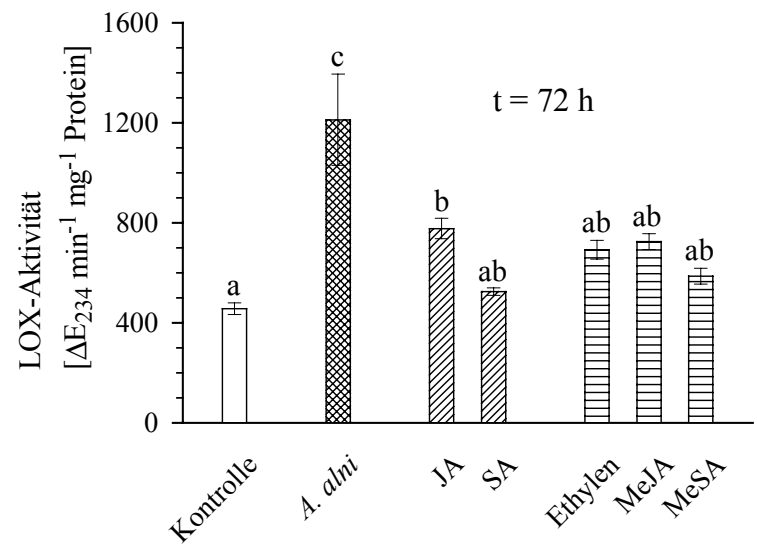

(b)

Abb. 27: Auswirkungen verschiedener Behandlungsweisen auf die Lipoxygenase-Aktivität (LOXAktivität) $\left[\Delta \mathrm{E}_{234} \mathrm{~min}^{-1} \mathrm{mg}^{-1}\right.$ Protein] im Blattgewebe von Alnus glutinosa-Blättern nach zwei verschiedenen Inkubationszeiten. - a) LOX-Aktivitäten ungeschädigter Blätter, nach Herbivorenfraß von Agelastica alni, nach Inkubation mit Ethylen, Methyljasmonat und Methylsalicylat, $\mathrm{t}=48 \mathrm{~h}$. ANOVA (F $=4,21, \mathrm{p}=0,012, \mathrm{n}=25$ ). - b) LOX-Aktivitäten ungeschädigter Blätter, nach Herbivorenfraß von A. alni, nach Inkubation mit Jasmonsäure (JA), Salicylsäure (SA), Ethylen, Methyljasmonat und Methylsalicylat, $\mathrm{t}=72 \mathrm{~h}$. ANOVA $(\mathrm{F}=11,15, \mathrm{p}<0,001, \mathrm{n}=70)$. Angegeben sind der Mittelwert und der Standardfehler. Verschiedene Buchstaben zeigen signifikante Unterschiede $(\mathrm{p}<0,05$, Newman Keuls-Test) an. Kontrolle $=$ ungeschädigte Blätter. MeJA = Methyljasmonat. MeSA = Methylsalicylat 


\subsection{Peroxidase}

In Abb. 28 sind die Ergebnisse der Peroxidase-Aktivitätsbestimmung (Enzymassay 5, 6; Kap. 4.4.1.1) nach Larvenfraß von A. alni sowie nach der Applikation von Jasmonsäure, Salicylsäure bzw. nach Inkubation mit den flüchtigen Verbindungen Ethylen, Methyljasmonat und Methylsalicylat wiedergegeben. Bei den Kontrollen konnte eine Peroxidase-Aktivität von 7,06 $\pm 0,61\left[\Delta \mathrm{E}_{470} \mathrm{~min}^{-1} \mathrm{mg}^{-1}\right.$ Protein $]$ ermittelt werden, die nach 72 stündigem Herbivorenfraß von $A$. alni-Larven signifikant um den Faktor 13,7 vergrößert wurde. Jasmonsäure steigerte die Enzymaktivität signifikant um den Faktor 2,7. Keine Auswirkungen auf physiologische Veränderungen der Peroxidase zeigten Salicylsäure und die Duftstoffkomponenten Ethylen, Methyljasmonat und Methylsalicylat, weder nach 48- noch nach 72-stündiger Inkubation (Abb. 28a, b).

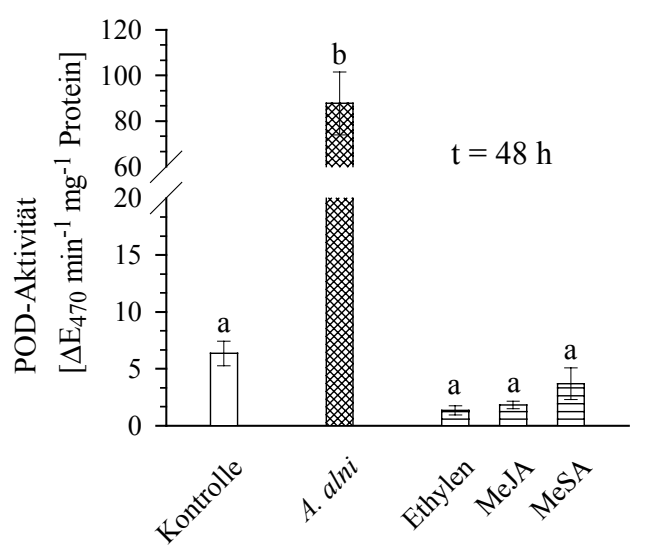

(a)

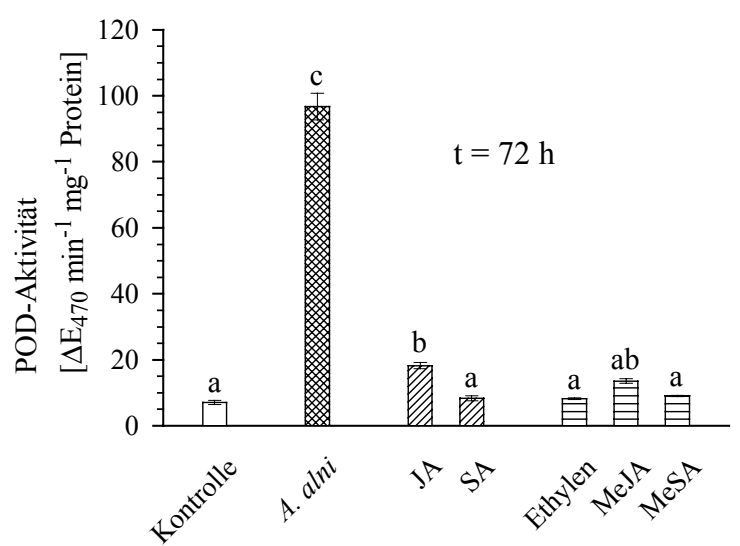

(b)

Abb. 28: Auswirkungen verschiedener Behandlungsweisen auf die Peroxidase-Aktivität (POD-Aktivität) $\left[\Delta \mathrm{E}_{470} \mathrm{~min}^{-1} \mathrm{mg}^{-1}\right.$ Protein] im Blattgewebe von Alnus glutinosa-Blättern nach zwei verschiedenen Inkubationszeiten. - a) POD-Aktivitäten ungeschädigter Blätter, nach Herbivorenfraß von Agelastica alni, nach Inkubation mit Ethylen, Methyljasmonat und Methylsalicylat, $\mathrm{t}=48 \mathrm{~h}$. ANOVA $(\mathrm{F}=$ 36,73, $\mathrm{p}=0,00, \mathrm{n}=25)$. - b) POD-Aktivitäten ungeschädigter Blätter, nach Herbivorenfraß von A. alni, nach Inkubation mit Jasmonsäure (JA), Salicylsäure (SA), Ethylen, Methyljasmonat und Methylsalicylat, $\mathrm{t}=72 \mathrm{~h}$. ANOVA $(\mathrm{F}=304,70, \mathrm{p}<0,001, \mathrm{n}=70)$. Angegeben sind der Mittelwert und der Standardfehler. Verschiedene Buchstaben zeigen signifikante Unterschiede $(\mathrm{p}<0,05$, Newman Keuls-Test) an. Kontrolle $=$ ungeschädigte Blätter. MeJA = Methyljasmonat. MeSA = Methylsalicylat. 


\subsection{Katalase}

In der folgenden Grafik (Abb. 29) sind die Daten der Katalase-Aktivitätsbestimmung (Enzymasay 7, 8; Kap. 4.4.1.1) nach Herbivorenfraß von A. alni-Larven sowie nach der Applikation von Jasmonsäure, Salicylsäure bzw. nach Inkubation mit den flüchtigen Verbindungen Ethylen, Methyljasmonat und Methylsalicylat abgebildet. Nach 72-stündiger Inkubation lag in unbehandelten Erlenblättern eine Katalaseaktivität von 507,22 \pm $39,22\left[\Delta \mathrm{E}_{240} \mathrm{~min}^{-1} \mathrm{mg}^{-1}\right.$ Protein] vor. Weder Herbivorenfraß von $A$. alni-Larven noch Jasmonsäure, Salicylsäure und die Duftkomponenten Ethylen und Methylsalicylat beeinflußten die Katalaseaktivität. Nur Methyljasmonat steigerte die Aktivität signifikant um den Faktor 2,1 (Abb. 29b). Diese beobachteten Effekte zeichneten sich bereits nach 48-stündiger Inkubation mit den Duftstoffen Ethylen, Methylsalicylat und Methyljasmonat ab (Abb. 29a).

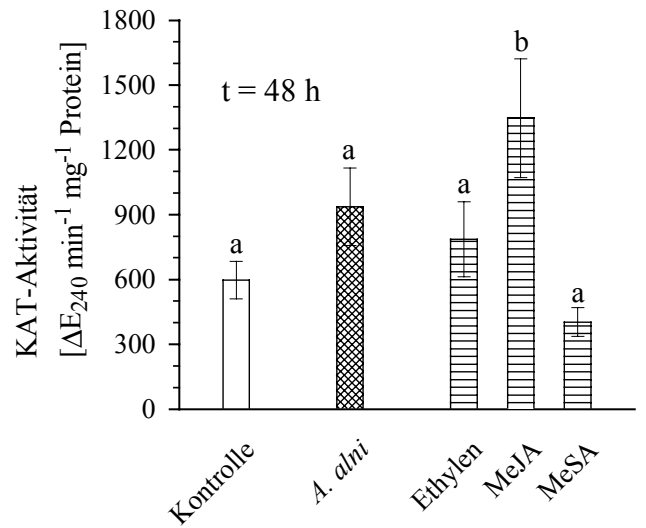

(a)

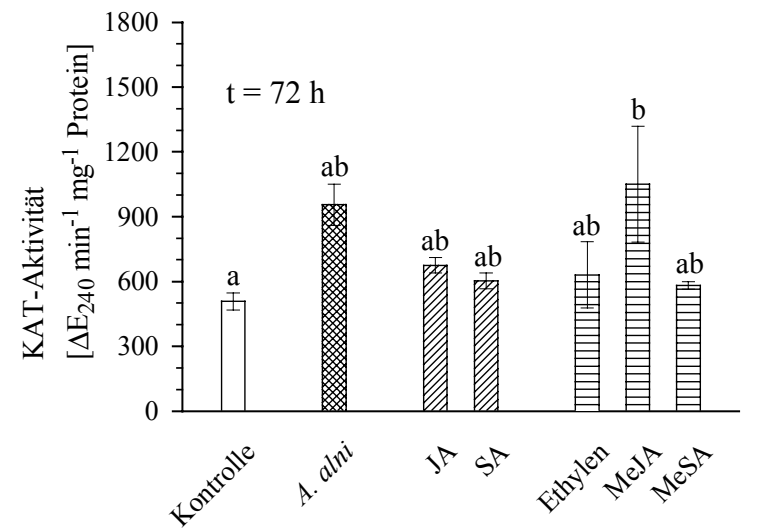

(b)

Abb. 29: Auswirkungen verschiedener Behandlungsweisen auf die Katalase-Aktivität (KAT-Aktivität) $\left[\Delta \mathbf{E}_{240} \mathrm{~min}^{-1} \mathrm{mg}^{-1}\right.$ Protein] im Blattgewebe von Alnus glutinosa-Blättern nach zwei verschiedenen Inkubationszeiten. - a) KAT-Aktivitäten ungeschädigter Blätter, nach Herbivorenfraß von Agelastica alni, nach Inkubation mit Ethylen, Methyljasmonat und Methylsalicylat, $\mathrm{t}=48 \mathrm{~h}$. ANOVA $(\mathrm{F}=4,32, \mathrm{p}=$ $0,01, \mathrm{n}=25)$. - b) KAT-Aktivitäten ungeschädigter Blätter, nach Herbivorenfraß von $A$. alni, nach Inkubation mit Jasmonsäure (JA), Salicylsäure (SA), Ethylen, Methyljasmonat und Methylsalicylat, $\mathrm{t}=72 \mathrm{~h}$. ANOVA $(\mathrm{F}=2,70, \mathrm{p}=0,021, \mathrm{n}=10)$. Angegeben sind der Mittelwert und der Standardfehler. Verschiedene Buchstaben zeigen signifikante Unterschiede $(p<0,05$, Newman Keuls-Test) an. Kontrolle $=$ ungeschädigte Blätter. MeJA = Methyljasmonat. MeSA = Methylsalicylat. 


\subsubsection{Proteinaseinhibitoraktivitäten}

Verschiedene Behandlungsvarianten wie Herbivorenfraß, Applikation von Signalstoffen (Jasmon- und Salicylsäure, Ethylen, Methyljasmonat und Methylsalicylat) sowie die Inkubation mit flüchtigen Duftstoffen (Methylanthranilat, cis-3-Hexenylacetat, cis-Jasmon, Ocimen, Linalool, Caryophyllen, $\mathrm{C}_{11^{-}}$und $\mathrm{C}_{16}$-Homoterpen) wurden auf ihre Auswirkungen bezüglich Proteinaseinhibitor-Aktivitätsveränderungen untersucht (Kap. 4.4.1.1). Die Aktivitätsveränderungen der Proteinaseinhibitoren in den Blättern von A. glutinosa wurden nach 72-stündiger Inkubation mittels des Radialdiffusionsassays quantifiziert. Unbehandelte Blätter von A. glutinosa wiesen eine Grundaktivität der Proteinaseinhibitoren von 3,76 $\pm 0,39 \mu \mathrm{g} \mathrm{mg}^{-1}$ Protein $\mathrm{g}^{-1} \mathrm{FW}$ auf (Abb. 30 ). Nach Herbivorenfraß von $A$. alni-Larven erhöhte sich diese signifikant auf 20,6 $\pm 2,17 \mu \mathrm{g} \mathrm{mg}^{-1}$ Protein $\mathrm{g}^{-1} \mathrm{FW}$ und lag damit 5,5-fach über der Aktivität der Kontrollblätter. Nicht nur in dem direkt befressenen Blattgewebe, sondern auch in dem Blattgewebe benachbarter, ungeschädigter Blätter vergrößerte sich die PI-Aktivität 3,6-fach, so daß aufgrund eines systemischen Effekts eine Aktivierung in noch nicht geschädigtem Gewebe erfolgte.

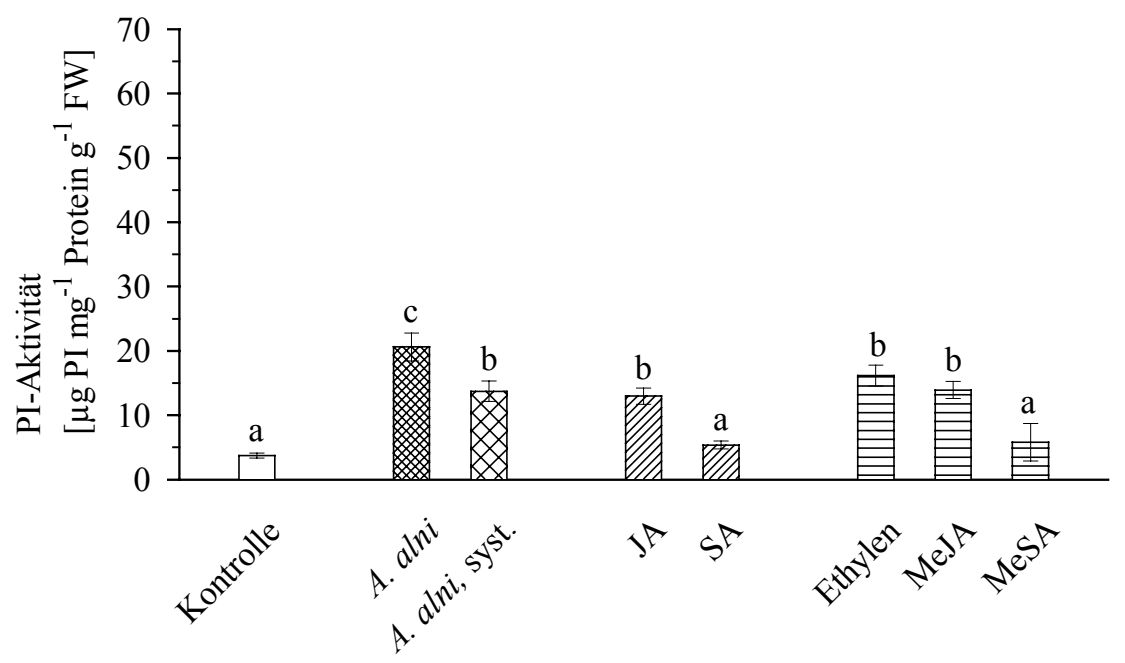

Abb. 30: Auswirkungen verschiedener Behandlungsweisen auf die Aktivität von Proteinaseinhibi-

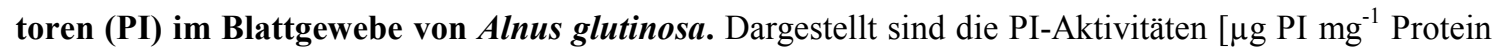
$\mathrm{g}^{-1}$ FW] ungeschädigter Blätter (Kontrolle), nach Herbivorenfraß von Agelastica alni-Larven sowie die systemische Induktion in benachbarten, unbefressenen Blättern (A. alni, syst.), nach Inkubation mit den Signalstoffen (Jasmonsäure (JA), Salicylsäure (SA), Ethylen, Methyljasmonat (MeJA) und Methylsalicylat (MeSA). Die PI-Aktivitätsbestimmung erfolgte nach 72-stündiger Inkubation mit dem Radialdiffusionsassay mit Trypsin als Proteinase. Angegeben sind der Mittelwert und der Standardfehler. ANOVA $(\mathrm{F}=18,91, \mathrm{p}<0,001, \mathrm{n}=64)$. Verschiedene Buchstaben zeigen signifikante Unterschiede $(\mathrm{p}<$ 0,05 , Newman Keuls-Test) an. FW = Frischgewicht. 
Der Signalstoff Jasmonsäure vermehrte die Aktivität der Proteinaseinhibitoren signifikant um den 3,4-fachen Wert (Abb. 30). Dieser Effekt konnte durch Salicylsäure, einer weiteren Signalsubstanz in der pflanzlichen Abwehr, nicht hervorgerufen werden. Die Inkubation der Erlenblätter mit den flüchtigen Signalstoffen Ethylen, Methyljasmonat und Methylsalicylat belegte nur für die beiden Verbindungen Ethylen und Methyljasmonat einen signifikant positiven Einfluß auf die Aktivität der Proteinaseinhibitoren: Ethylen vergrößerte die Aktivität 4,3-fach und Methyljasmonat 3,7-fach. Methylsalicylat wirkte sich nicht auf die Aktivität der Proteinaseinhibitoren im Blattgewebe aus. Weiterhin wurden aus dem fraßinduzierten Erlenduftspektrum (Abb. 38) einzelne Duftstoffkomponenten, wie z.B. Methylanthranilat, cis-3-Hexenylacetat, Ocimen, Linalool, Caryophyllen, $\mathrm{C}_{11^{-}}(\mathrm{DMNT})$ und $\mathrm{C}_{16}$-Homoterpen (TMTT) bezüglich ihrer physiologischen Auswirkung auf die Aktivität der Proteinaseinhibitoren getestet. Die Resultate dieser Aktivitätsbestimmungen der Proteinaseinhibitoren sind in Abb. 31 dargestellt.

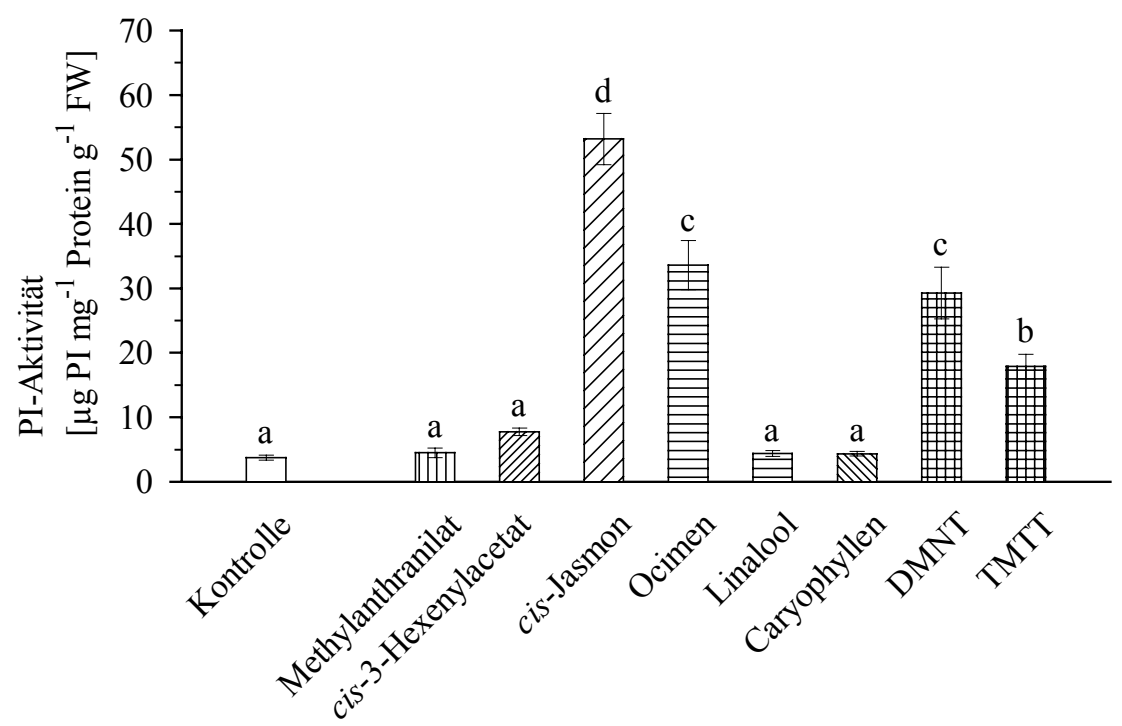

Abb. 31: Auswirkungen verschiedener Duftstoffe auf die Aktivität von Proteinaseinhibitoren (PI) im Blattgewebe von Alnus glutinosa. Dargestellt sind die PI-Aktivitäten [ $\mu \mathrm{g}$ PI $\mathrm{mg}^{-1} \mathrm{Protein}^{-1} \mathrm{FW}$ ] ungeschädigter Blätter (Kontrolle) und nach Inkubation mit verschiedenen Duftstoffen (Methylanthranilat, cis-3-Hexenylacetat, cis-Jasmon, Ocimen, Linalool, Caryophyllen, DMNT und TMTT. Die Aktivitätsbestimmung der PI erfolgte nach 72-stündiger Inkubation mit dem Radialdiffusionsassay mit Trypsin als Proteinase. Angegeben sind der Mittelwert und der Standardfehler. ANOVA (F = 53,66, p < 0,001, n =72). Verschiedene Buchstaben zeigen signifikante Unterschiede ( $p<0,05$, Newman Keuls-Test) an. $\mathrm{FW}=$ Frischgewicht. DMNT $=4,8$-Dimethylnona-1,3,7-trien $\left(\mathrm{C}_{11}\right.$-Homoterpen $)$. TMTT $=4,8,12$-Trimethyltrideca-1,3,7,11-tetraen $\left(\mathrm{C}_{16}\right.$-Homoterpen). 
Für die aromatische Verbindung Methylanthranilat, die aliphatische Verbindung cis-3Hexenylacetat und für die beiden Terpene Linalool und Caryophyllen konnten keine signifikanten Effekte auf die Aktivitäten der Proteinaseinhibitoren nachgewiesen werden (Abb. 31). Hingegen veränderten cis-Jasmon, das Monoterpen Ocimen und die beiden Homoterpene, das $\mathrm{C}_{11}$ - und $\mathrm{C}_{16}$-Homoterpen, signifikant die Aktivität der Proteinaseinhibitoren. Dabei beeinflußte cis-Jasmon die Aktivität der Proteinaseinhibitoren am stärksten: Es konnte eine Aktivität der Proteinaseinhibitoren von 53,18 $\pm 3,99 \mu \mathrm{g} \mathrm{mg}^{-1}$ Protein $\mathrm{g}^{-1} \mathrm{FW}$ bestimmt werden, die 14,1-fach über der der unbehandelten Blätter lag. Die Effekte des Monoterpens Ocimen und die des $\mathrm{C}_{11}$-Homoterpens erreichten nicht dieses Ausmaß. Ocimen vergrößerte die Aktivität der Proteinaseinhibitoren 8,9-fach und das $\mathrm{C}_{11}$-Homoterpen 7,8-fach. Der Einfluß des $\mathrm{C}_{16}$-Homoterpens war etwa nur halb so groß wie der des Ocimens. Es bewirkte eine 4,7-fache Veränderung der Aktivität der Proteinaseinhibitoren (Abb. 31). 


\subsection{2 „Containerversuche ${ }^{6}$}

\section{Container 1}

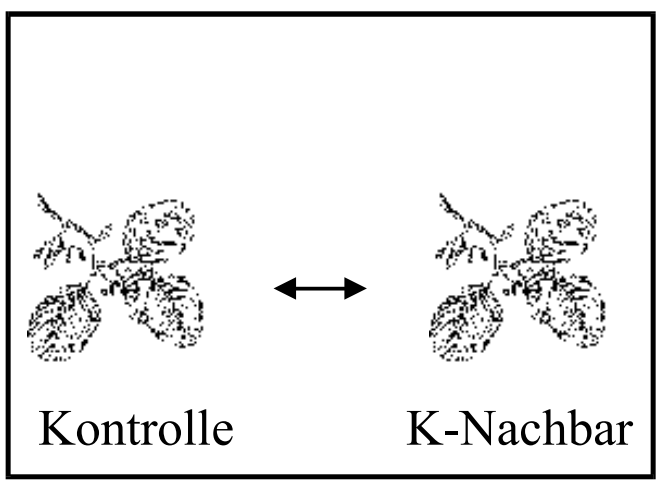

Container 2

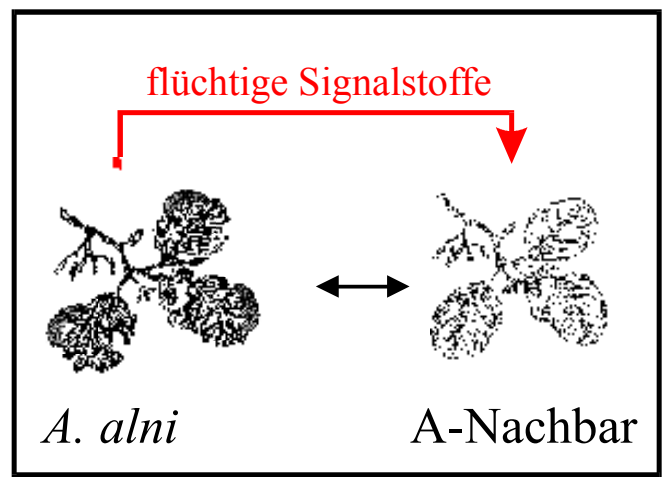

Abb. 32: Schematische Darstellung zur Versuchsanordnung der Containerversuche. In einem Glasgefäß befand sich ein Erlentrieb, der mit Larven von Agelastica alni besetzt war (,A. alni $\left.{ }^{\star}\right)$. Um den fraßinduzierten Trieb wurde eine befallsfreie Pflanze „A-Nachbar“ plaziert, so daß emittierte Duftstoffe ungehindert über den Gasraum zu den ungeschädigten Blättern gelangen konnten. Ein weiterer Glascontainer mit gleichem Versuchsaufbau, aber ohne Larvenfraß, diente als Kontrolle.

Kann eine befallene Pflanze mit einer benachbarten, befallsfreien Pflanze kommunizieren und sie veranlassen, ihre Abwehrmechanismen zu aktivieren? Dieser Frage wurde mit Containerversuchen (Kap. 4.4.1.2) nachgegangen, die schematisch in Abb. 32 dargestellt sind. $\mathrm{Zu}$ bestimmten Zeitpunkten wurden die Phenolgehalte, die Aktivität oxidativer Enzyme (Polyphenoloxidase, Peroxidase und Lipoxygenase) sowie die von Proteinaseinhibitoren untersucht. Über Fraßwahlversuche mit $A$. alni-Larven wurden Veränderungen der Blattqualität überprüft.

\subsubsection{Phenolgehalte}

Die Untersuchungen der Auswirkungen fraßinduzierter Duftstoffe auf unverletztes Blattgewebe erbrachten quantitative Veränderungen der Blattphenolmenge. Diese erhöhte sich in den benachbarten, nicht befallenen Blättern nach 72-stündiger Inkubation in den Containern signifikant 1,5-fach (Abb. 33, Tab. 12). Ein solcher Effekt war weder nach kurzzeitiger Inkubation noch nach 24- oder 48-stündiger Inkubation feststellbar gewesen (Abb. 33, Tab. 12). 


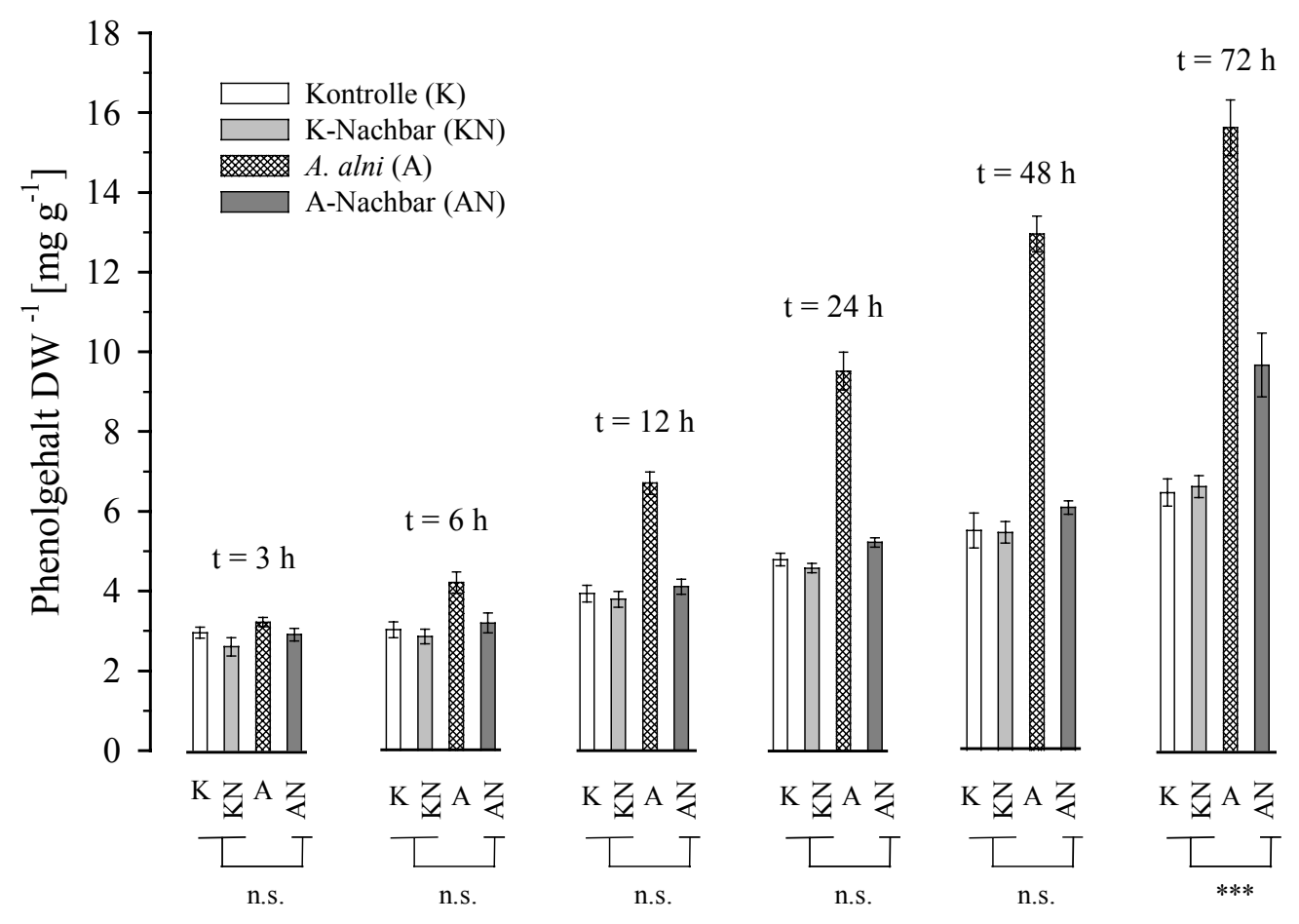

Abb. 33: Auswirkungen fraßinduzierter Duftstoffe auf den Phenolgehalt $D^{-1}$ [mg g $\left.{ }^{-1}\right]$ ungeschädigter Alnus glutinosa-Blätter. Dargestellt ist der zeitliche Verlauf (t =3;6;12;24;48; 72 h) der Auswirkungen fraßinduzierter Duftstoffe geschädigter A. glutinosa-Blätter (A = Herbivorenfraß von Agelastica alni-Larven) auf den Phenolgehalt im Blattgewebe ungeschädigter, benachbarter Blätter (AN). Als Kontrolle dienten unbefallene Blätter $(\mathrm{K})$ und ungeschädigte, benachbarte Blätter $(\mathrm{KN})$. Der Phenolgehalt $\mathrm{DW}^{-1}\left[\mathrm{mg} \mathrm{g}^{-1}\right]$ wurde zu den angegebenen Zeitpunkten $\mathrm{t}[\mathrm{h}]$ photometrisch bestimmt. Angegeben sind der Mittelwert und der Standardfehler. DW = Trockengewicht. Die statistischen Daten des gepaarten t-Tests sind Tab. 12 zu entnehmen. n.s. = nicht signifikant. $* * *=\mathrm{p}<0,001$.

Tab. 12: Auswirkungen fraßinduzierter Duftstoffe auf den Phenolgehalt $D^{-1}$ [mg g ${ }^{-1}$ ungeschädigter Alnus glutinosa-Blätter. Vergleich von „Kontrolle“ und „K-Nachbar“ vs. „A-Nachbar“ zu den angegebenen Inkubationszeiten. Die statistischen Werte wurden mit Hilfe des gepaarten t-Tests berechnet. Die grafische Darstellung der Daten ist in Abb. 33 wiedergegeben.

\begin{tabular}{|c|c|c|c|}
\hline Zeitpunkt & $\mathrm{t}$ & $\mathrm{p}$ & $\mathrm{n}$ \\
\hline $3 \mathrm{~h}$ & $-0,58$ & 0,571 & 21 \\
\hline $6 \mathrm{~h}$ & $-0,99$ & 0,334 & 21 \\
\hline $12 \mathrm{~h}$ & $-1,04$ & 0,312 & 21 \\
\hline $24 \mathrm{~h}$ & $-1,21$ & 0,241 & 21 \\
\hline $48 \mathrm{~h}$ & $-1,61$ & 0,124 & 21 \\
\hline $72 \mathrm{~h}$ & $-4,95$ & $<0,001$ & 21 \\
\hline
\end{tabular}




\subsubsection{Enzymaktivitäten}

Als Folge der 48-stündigen Inkubation mit fraßinduzierten Duftstoffen wurde eine erhöhte Enzymaktivität der untersuchten Enzyme Polyphenoloxidase, Peroxidase und Lipoxygenase in den benachbarten, nicht befallenen Blättern festgestellt, deren Veränderungen in der nachfolgenden Abbildung (Abb. 34) grafisch dargestellt sind. Die Enzymaktivität veränderte sich um das 3,2-fache bei den Polyphenoloxidasen, um das 2,6fache bei Lipoxygenasen und um das 4,7-fache bei Peroxidasen.

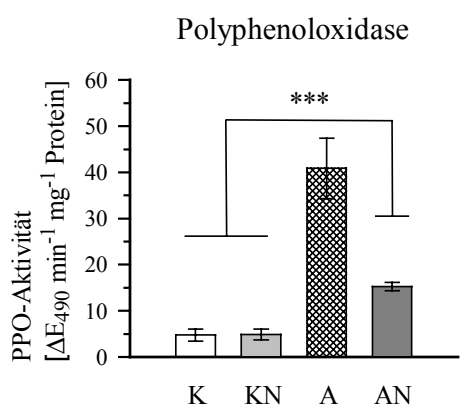

(a)

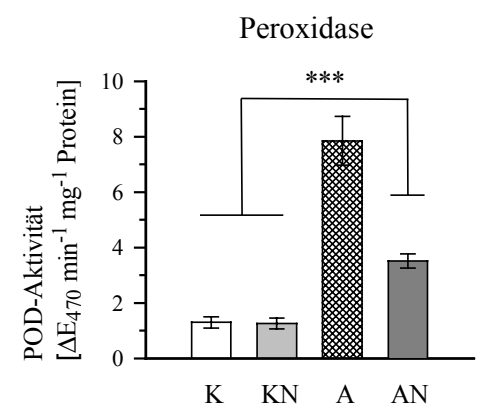

(b)

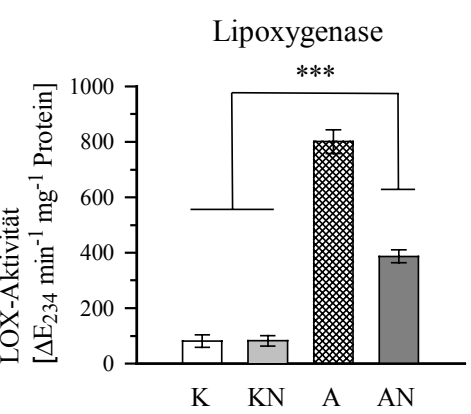

(c)
Kontrolle (K)

K-Nachbar (KN)

A. alni (A)

A-Nachbar (AN)
Abb. 34: Auswirkungen fraßinduzierter Duftstoffe auf die Aktivität oxidativer Enzyme im Blattgewebe von ungeschädigten Alnus glutinosa-Blättern. Dargestellt ist der Einfluß fraßinduzierter Duftstoffe geschädigter A. glutinosa-Blätter (A = Herbivorenfraß von Age-

lastica alni-Larven) auf die Aktivität oxidativer Enzyme im Blattgewebe ungeschädigter, benachbarter Blätter (AN). Als Kontrolle dienten unbefallene Blätter $(\mathrm{K})$ und ungeschädigte, benachbarte Blätter $(\mathrm{KN})$. Die Aktivität der Enzyme wurde nach 72-stündiger Inkubation in den Containern photometrisch bestimmt. Angegeben sind der Mittelwert und der Standardfehler. - a) Polyphenoloxidase-Aktivität (PPO) $\left[\Delta \mathrm{E}_{490} \mathrm{~min}^{-1} \mathrm{mg}^{-1}\right.$ Protein]. - b) Peroxidase-Aktivität (POD) [ $\Delta \mathrm{E}_{470} \mathrm{~min}^{-1} \mathrm{mg}^{-1}$ Protein]. - c) LipoxygenaseAktivität (LOX) $\left[\Delta \mathrm{E}_{234} \mathrm{~min}^{-1} \mathrm{mg}^{-1}\right.$ Protein]. Die statistischen Daten des gepaarten t-Tests sind Tab. $13 \mathrm{zu}$ entnehmen. $* * *=\mathrm{p}<0,001$.

Tab. 13: Auswirkungen fraßinduzierter Duftstoffe auf die Aktivität oxidativer Enzyme im Blattgewebe von ungeschädigten Alnus glutinosa-Blättern. Vergleich von „Kontrolle“ und „K-Nachbar“ vs. „A-Nachbar“. Die statistischen Werte wurden mit Hilfe des gepaarten t-Tests berechnet. Die grafische Darstellung der Daten ist in Abb. 34 wiedergegeben.

\begin{tabular}{|c|c|c|c|}
\hline untersuchtes Enzym & $\mathrm{t}$ & $\mathrm{p}$ & $\mathrm{n}$ \\
\hline PPO-Aktivität & $-7,79$ & $<0,001$ & 27 \\
\hline POD-Aktivität & $-8,50$ & $<0,001$ & 27 \\
\hline LOX-Aktivität & $-8,91$ & $<0,001$ & 27 \\
\hline
\end{tabular}




\subsubsection{Proteinaseinhibitoraktivitäten}

Die quantitative Bestimmung der Aktivität der Proteinaseinhibitoren in den A. glutinosa-Blättern erfolgte nach 72-stündiger Inkubation in den Glascontainern und wurde mittels des Radialdiffusionsassays ermittelt. Die ermittelten Werte der Aktivität der Proteinaseinhibitoren der unterschiedlich behandelten Blätter sind in Abb. 35 dargestellt.

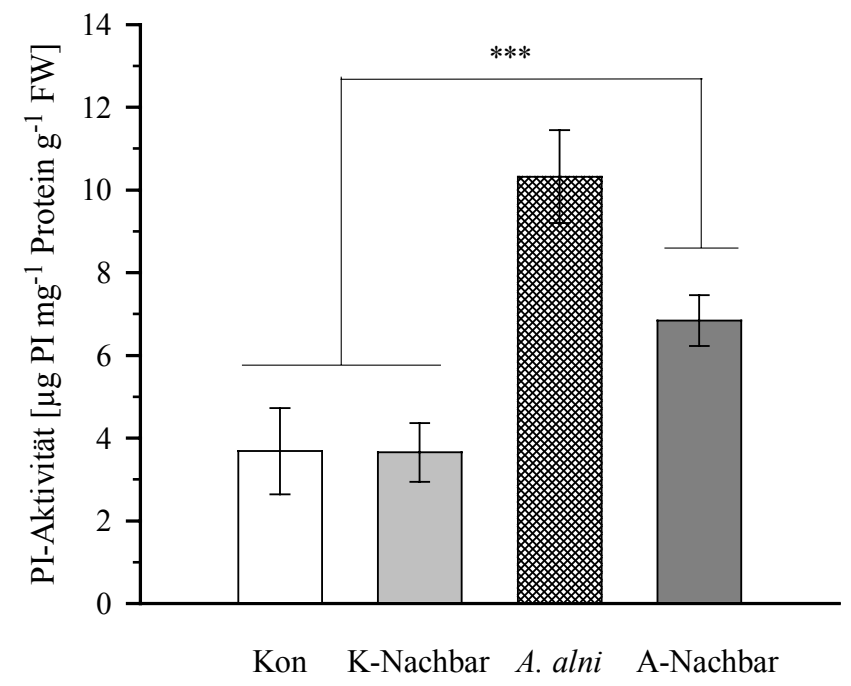

Abb. 35: Auswirkungen fraßinduzierter Duftstoffe auf die Aktivität von Proteinaseinhibitoren (PI) im Blattgewebe von Alnus glutinosa-Blättern. Dargestellt ist der Einfluß fraßinduzierter Duftstoffe geschädigter A. glutinosaBlätter (A. alni) auf die Aktivität von PI im Blattgewebe ungeschädigter, benachbarter Blätter (A-Nachbar). Als Kontrolle dienten unbefallene Blätter (Kon) und ungeschädigte, benachbarte Blätter (K-Nachbar). Die PI-Aktivität wurde nach 72-stündiger Inkubation in den Containern mit dem Radialdiffusionsassay mit Trypsin als Proteinase bestimmt. Angegeben sind der Mittelwert und der Standardfehler. Die statistische Auswertung erfolgte mit einem gepaarten t-Test. „Kontrolle“ und „K-Nachbar“ vs. „A-Nachbar“: $\mathrm{t}=3,12, \mathrm{p}=0,0065, \mathrm{n}=18 .{ }^{* * *}=\mathrm{p}<$ 0,001 .

Die Blätter der unbehandelten Erlentriebe wiesen eine PI-Aktivität von 3,68 \pm 1,05 $\mu \mathrm{g}$

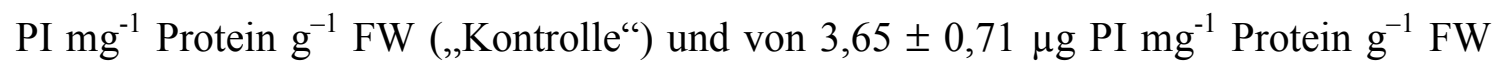
(,K-Nachbar“) auf, wobei sich die PI-Aktivität nicht signifikant zwischen „Kontrolle“ und „K-Nachbar“ unterschied. Durch Herbivorenfraß stieg die PI-Aktivität der , $A$. alni“'-Blätter um den Faktor 2,8 signifikant auf 10,32 $\pm 1,12 \mu \mathrm{g} \mathrm{PI} \mathrm{mg}^{-1}$ Protein $^{-1} \mathrm{FW}$ an und unter dem Einfluß dieser befressenen, induzierten Blätter vergrößerte sich in den benachbarten Blättern „A-Nachbar“ die PI-Aktivität 1,9-fach $\left(6,84 \pm 0,61 \mu \mathrm{g} \mathrm{PI} \mathrm{mg}{ }^{-1}\right.$ Protein $\left.\mathrm{g}^{-1} \mathrm{FW}\right)(, \mathrm{K}$ ontrolle“ und „K-Nachbar“ vs. ,A-Nachbar“: $\mathrm{t}=3,12, \mathrm{n}=18, \mathrm{p}<$ $0,0065)$. 


\subsubsection{Zusammenfassung „Containerversuche“}

Die vorliegenden Ergebnisse der „Containerversuche“ belegen, daß die emittierten Duftstoffe fraßinduzierter Erlenblätter bei genügend hoher, stationärer Konzentration in benachbarten, befallsfreien Blättern chemische und physiologische Veränderungen bewirken können. Die Erlenblätter reagierten mit einer Vermehrung des Phenolgehalts und einer Aktivitätssteigerung der Enzyme Polyphenoloxidase, Peroxidase und Lipoxygenase sowie von Proteinaseinhibitoren. 


\subsubsection{Duftstoffuntersuchungen}

Ein zentraler Punkt der Untersuchung bestand in der Charakterisierung der Signale, die über den Luftraum zwischen Erlenpflanzen die Wechselwirkung zwischen geschädigten und benachbarten, ungeschädigten Pflanzen vermitteln. Ferner sollte geklärt werden, ob potentielle Signalsstoffe, denen auch eine Funktion in der Resistenzinduktion ungeschädigter Pflanzen zugesprochen werden kann, sich unter den emittierten Verbindungen befinden. Zur Untersuchung der Veränderungen in der Gasphase geschädigter Pflanzen wurden zwei unterschiedliche Analysenmethoden eingesetzt: Die photoakustische Spektroskopie für den empfindlichen, selektiven Nachweis von Ethylen (Kap. 4.4.4.1) und die Closed Loop Stripping-Analyse für weitere flüchtige Blattinhaltsstoffe (Kap. 4.4.4.2).

\subsubsection{Ethylen}

Ein Befall mit den Herbivoren A. alni führte zu einer Induktion von Ethylen, dessen Online-Monitoring sowie Quantifizierung über die photoakustische Spektroskopie erfolgte. Die folgende Grafik (Abb. 36) zeigt exemplarisch den zeitlichen Verlauf der Ethylenfreisetzung von befallenen, d.h. mit A. alni-Imagines besetzten, und unbefallenen A. glutinosa-Blättern über einen Zeitraum von $36 \mathrm{~h}$. Während dieser Zeit konnten die Herbivoren ungestört an allen angebotenen Blättern fressen. Ca. zehn Stunden nach Versuchsstart war bei der Versuchsvariante Herbivorenfraß - nach Abklingen des „Wundethylens“, welches durch Abschneiden der Erlentriebe hervorgerufen wurde und auch bei der Kontrolle auftrat - ein langsamer Anstieg in der Ethylenproduktion zu verzeichnen, der nach weiteren sechs Stunden ein deutliches Maximum von 7,5 ppb Ethylen erreichte. Innerhalb der nächsten zwölf Stunden nahm das emittierte Ethylen stetig ab und pendelte sich um einen Wert von $1 \mathrm{ppb}$ ein, der bis zum Versuchsende $(t=36 \mathrm{~h})$ beibehalten wurde. Unbehandelte Erlenblätter zeigten einen anderen Verlauf in der Ethylenproduktion (Abb. 36). Sehr früh, fast zeitgleich mit dem Start der Meßwertaufnahme setzte auch hier eine starke Produktion des Wundethylens mit einem Wert von 4,0 ppb ein, der aber nach zwei Stunden wieder auf einen Grundwert von 1 ppb Ethylen abfiel. Für die restliche Versuchsdauer blieb die Ethylenproduktion 
konstant bei 1,5 ppb Ethylen und lag damit unter der der befallenen Erlenblätter. Es zeigte sich also, daß Herbivorie durch $A$. alni eine deutliche Steigerung der Ethylenbiosynthese induziert.
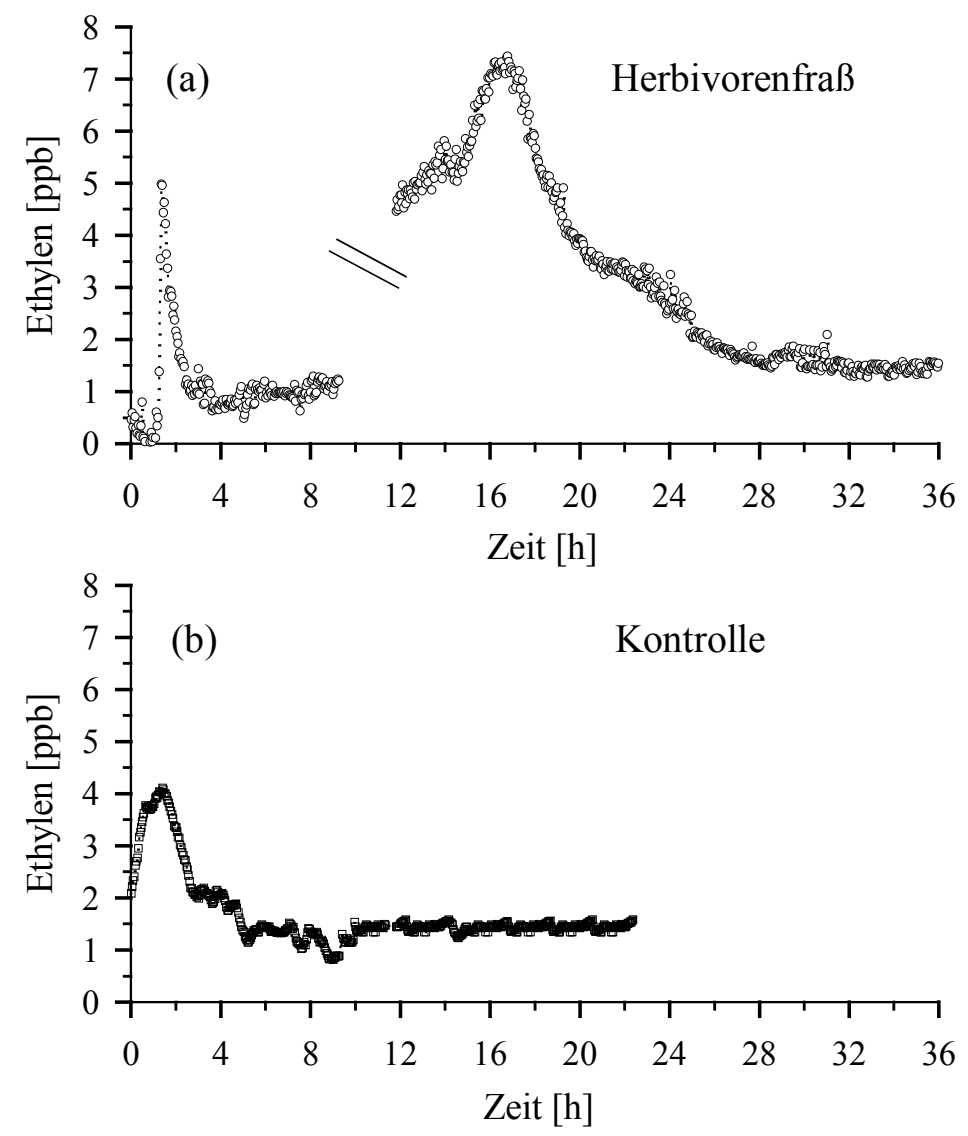

Abb. 36: Zeitlicher Verlauf der Ethylenfreisetzung [ppb] von Alnus glutinosa-Blättern nach Herbivorenfraß von Agelastica alni-Imagines. - a) Imaginesfra $\beta$ von $A$. alni (3 Tiere pro Blatt). - b) ungeschädigte Blätter (Kontrolle). Der Nachweis und die Quantifizierung der emittierten Ethylenmengen erfolgte über die photoakustische Spektroskopie. Versuchszeitraum $t=36 \mathrm{~h}$.

In einem zweiten Experiment erfolgte eine Langzeituntersuchung des induzierten Ethylenprofils der Blätter von A. glutinosa unter Fraß von A. alni-Larven, das in Abb. 37 dargestellt ist. Die Ethylenproduktion unterlag in dem 72-stündigen Experiment einem „Rhythmus“, wobei in der Dunkelphase, von Mitternacht bis in den Morgen, das Optimum der Emission lag. Mit dem Einsetzen des Lichts fiel die Emissionsrate über die Tagesstunden hin ab und stieg erst wieder mit dem Einsetzen der Dunkelphase an. Das erste Ethylenoptimum lag bei ca. 3 ppb, die anderen beiden Ethylenoptima lagen bei ca. 7 ppb Ethylen. Der Peak bei $t=30 \mathrm{~h}$ wurde durch einen technischen Gerätefehler verursacht. Unbehandelte Erlenblätter gaben ca. 1 ppb Ethylen 
ab, und im Verlauf der Ethylenproduktion war kein „Rhythmus“ zu erkennen (Daten nicht abgebildet).

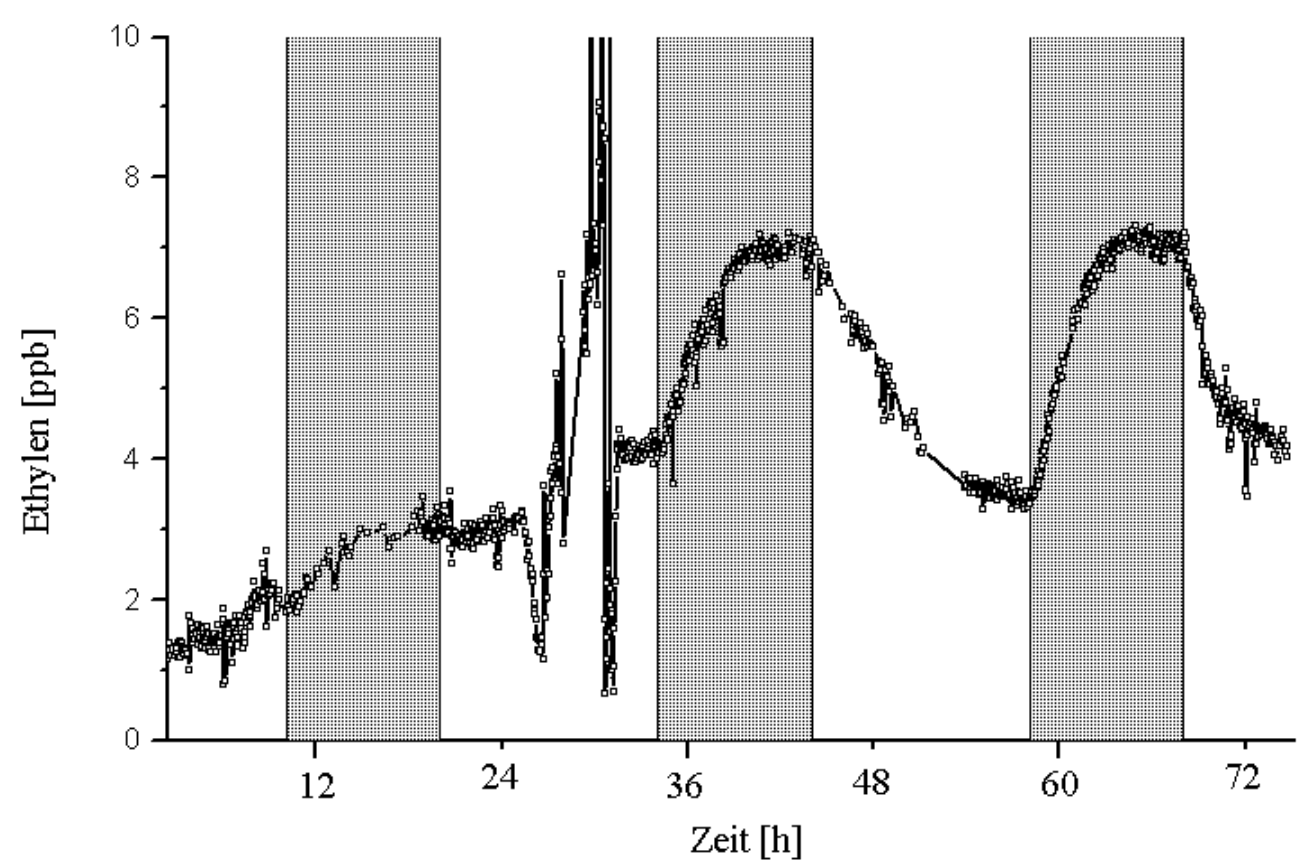

Abb. 37: Zeitlicher Verlauf der Ethylenabgabe [ppb] von Alnus glutinosa-Blättern nach Herbivorenfraß von Agelastica alni-Larven (3 Tiere pro Blatt) über einen Zeitraum von $\mathbf{t}=72 \mathrm{~h}$. Die grau hinterlegten Felder geben die Dunkelphase von $22^{00}$ bis $8^{00}$ an. Der Nachweis und die Quantifizierung der emittierten Ethylenmengen erfolgte mittels photoakustischer Spektroskopie. Der Peak bei $t=30 \mathrm{~h}$ wurde durch einen Gerätefehler verursacht.

\subsubsection{Flüchtige Blattinhaltsstoffe}

Für die weitere Untersuchung flüchtiger Verbindungen, die von geschädigten Erlen abgegeben werden, schlossen sich Closed Loop Stripping Analysen an. Dabei wurden die emittierten Duftstoffe im geschlossenen System auf einen Aktivkohlefilter gesammelt, mit Dichlormethan eluiert und mittels GC-MS identifiziert.

Es ist zunächst gelungen, eine induzierte Bildung flüchtiger Synomone für A. glutinosa zu belegen. Ein Duftprofil von Blättern der Schwarzerle nach Fraßschädigung von $A$. alni stellt Abb. 38 dar. Das von der Schwarzerle emittierte Duftbouquet setzte sich aus verschiedenen Duftkomponenten zusammen, die bei einer unverletzten Pflanze nicht gefunden wurden. Basierend auf der biosynthetischen Herkunft können die emittierten Duftstoffe verschiedenen Verbindungsklassen zugeordnet werden: lipoxygenaseabgeleitete Produkte von ungesättigten Fettsäuren wie 3-Hexenylacetat oder Decanal, aro- 
matische (Phenylalanin-Ammonia-Lyase (PAL)-abgeleitete) Verbindungen wie Methylanthranilat, Methylsalicylat und Indol. Den mengenmäßig größten Anteil besitzen die Terpene $ß$-Ocimen, Linalool, 4,8-Dimethylnona-1,3,7-trien, 4,8,12-Trimethyltrideca-1,3,7,11-tetraen, Caryophyllen, Farnesen, Humulen, $\mathrm{C}_{10} \mathrm{H}_{14}$ und $\mathrm{C}_{10} \mathrm{H}_{16} \mathrm{O}$.

\section{Kontrolle}

Alnus glutinosa
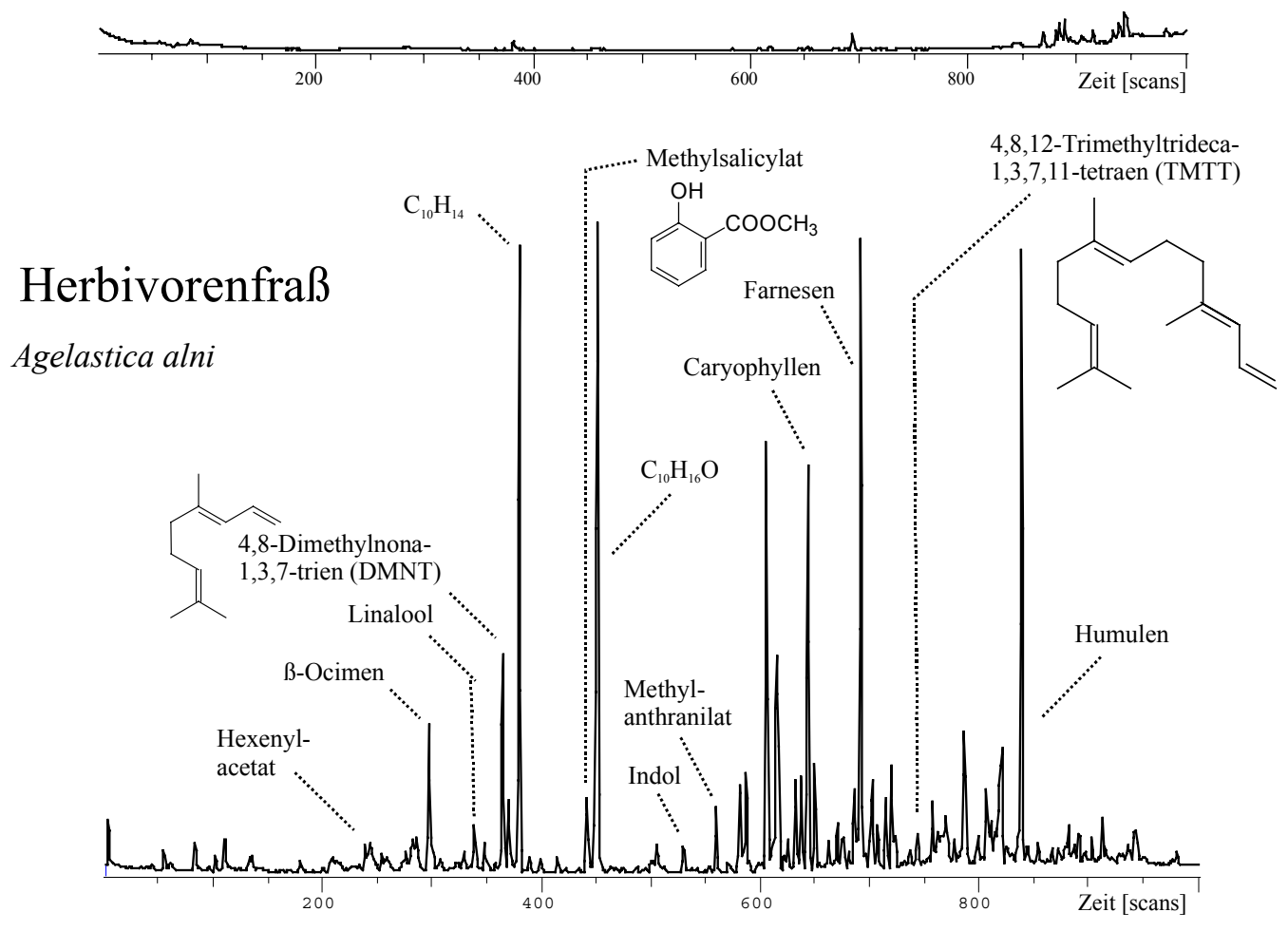

Abb. 38: Gaschromatographisches Profil der flüchtigen Komponenten des Duftes von Alnus glutinosa nach Herbivorenfraß von Agelastica alni-Larven. Folgende Zuordnungen konnten getroffen werden: 3-Hexenylacetat; ß-Ocimen; Linalool; 4,8-Dimethylnona-1,3,7-trien (DMNT); $\mathrm{C}_{10} \mathrm{H}_{14}$; Methylsalicylat; $\mathrm{C}_{10} \mathrm{H}_{16} \mathrm{O}$; Indol; Methylanthranilat; Caryophyllen; Farnesen; 4,8,12-Trimethyltrideca-1,3,7,11tetraen (TMTT); Humulen.

In zusätzlichen Analysen erfolgte eine zeitabhängige Untersuchung des induzierten Duftprofils der Blätter von A. glutinosa unter Fraß von $A$. alni. Diese Ergebnisse der zeitabhängigen Emission für die sechs Duftstoffgruppen Ocimen; (Linalool; DMNT; 
$\left.\mathrm{C}_{10} \mathrm{H}_{14}\right) ; \mathrm{C}_{10} \mathrm{H}_{16} \mathrm{O}$; Verbindung RT 15,8; Farnesen; Verbindung RT 34,9 nach Herbivorenfraß für den Zeitraum von 99,9 Stunden sind in Abb. 39 zusammengestellt.

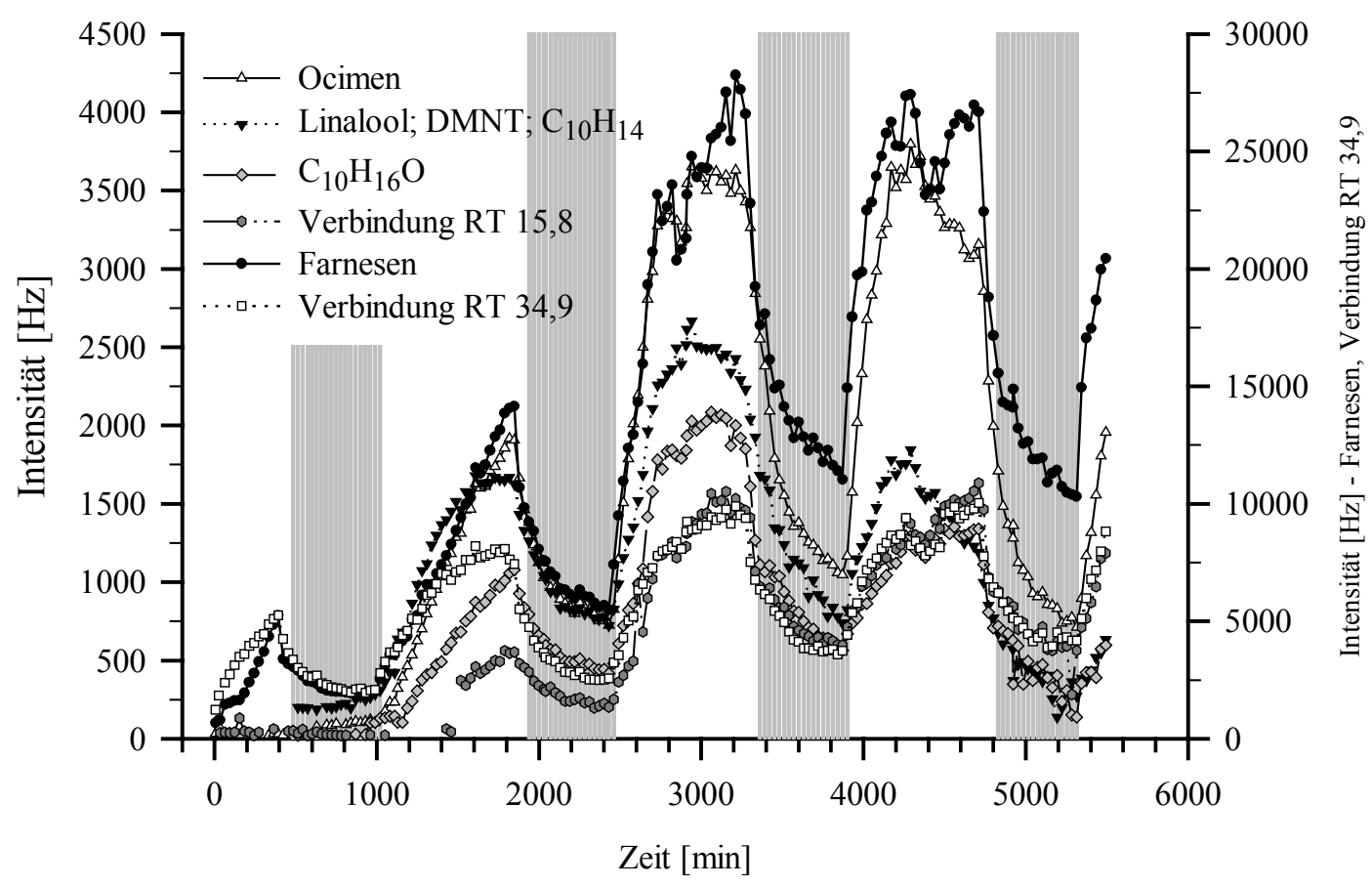

Abb. 39: Zeitlicher Verlauf der induzierten Duftstoffgruppen Ocimen, (Linalool; DMNT; $\mathrm{C}_{10} \mathrm{H}_{14}$ ); $\mathrm{C}_{10} \mathrm{H}_{16} \mathrm{O}$; Verbindung RT 15,8; Farnesen; Verbindung RT 34,9 von Alnus glutinosa bei Fraß von Agelastica alni-Larven über einen Zeitraum von $\mathbf{t}=\mathbf{6 0 0 0} \mathbf{m i n}$. Das Online-Monitoring der abgegebenen Duftstoffe erfolgte mittels zNose ${ }^{\mathrm{TM}}$. Grau-hinterlegte Felder: Nachtphase von $22^{00}$ bis $7^{00} \mathrm{Uhr}$. Angegeben sind die relativen Duftstoffmengen.

Mit Aufnahme der Fraßaktivität der Herbivoren A. alni begann die Duftproduktion, die mit fortschreitender Fraßzeit zunahm. Die Emission der flüchtigen Sekundärmetaboliten unterlag dabei einem „Tag-Nacht-Rhythmus“. In den Nachtphasen, jeweils von $22^{00}$ bis $7^{00} \mathrm{Uhr}$, nahm die Duftproduktion aller untersuchten Duftstoffe kontinuierlich ab. Mit Einsetzen der Lichtphase startete auch wieder die Duftemission, wobei innerhalb weniger Stunden das Optimum in der abgegebenen Duftmenge erreicht wurde. Die emittierten Duftmengen aller untersuchten Duftgruppen erreichten am dritten Tag ihr größtes Ausmaß, wobei die Ocimen- und Farnesenmengen deutlich über den Mengen der übrigen Duftstoffe lagen. Danach nahmen die produzierten Duftmengen deutlich ab; Ausnahmen bildeten dabei die Substanzen Ocimen und Farnesen, deren abgegebene Menge am vierten Tag der Menge ähnelte, die auch am dritten Tage abgegeben worden war. 
In weiteren Experimenten erfolgte nun die Prüfung, ob unterschiedliche Varianten der Schädigung sich auf das von den Erlen emittierte Duftspektrum auswirken. Wurden die Blätter der Testpflanzen mit einem „Fakir“-Stempel gelocht, so wurde durch diese mechanische Verletzung nicht das Duftbouquet induziert, das ein Herbivorenfraß verursachte. In Spuren konnten cis-3-Hexenylacetat sowie Decanal nachgewiesen werden. Die externe Applikation von Jasmonsäure an die Pflanzen induzierte ähnliche Duftmuster wie der Befall mit Herbivoren. Dennoch gab es Unterschiede zwischen fraß- und jasmonatinduziertem Duftmuster, die in Differenzen relativer Anteile einzelner Verbindungen bestanden. Weiterhin konnten nur Spuren von MeSA, DMNT und TMTT analysiert werden. Im CLS-Duftspektrum nach exogener Salicylsäureapplikation wurden in Spurenanteilen einige Terpene gefunden. Methylsalicylat stellte die Hauptkomponente dar. 


\title{
5.2.4 Quantifizierung von Jasmon- und Salicylsäure
}

Als Reaktion auf Herbivorie emittieren Erlenpflanzen flüchtige Verbindungen (Kap. 5.2.3.2). Die Synthese dieser Verbindungen kann durch octadecanoide Signalstoffe wie z.B. Jasmonsäure ausgelöst werden (PIEL et al. 1997). Für A. glutinosa sollte daher geklärt werden, wie hoch die erreichten endogenen Konzentrationen der Signalstoffe Jasmon- und Salicylsäure in befallenen und unbefallenen Blättern sind und vor allem, welcher Kinetik die Biosynthese dieser Phytohormone unterliegt. Die Daten dieser Jasmon- und Salicylsäurebestimmung sind in Abb. 40a und b für unbehandelte und mit Herbivoren besetzten Blätter von A. glutinosa dargestellt.
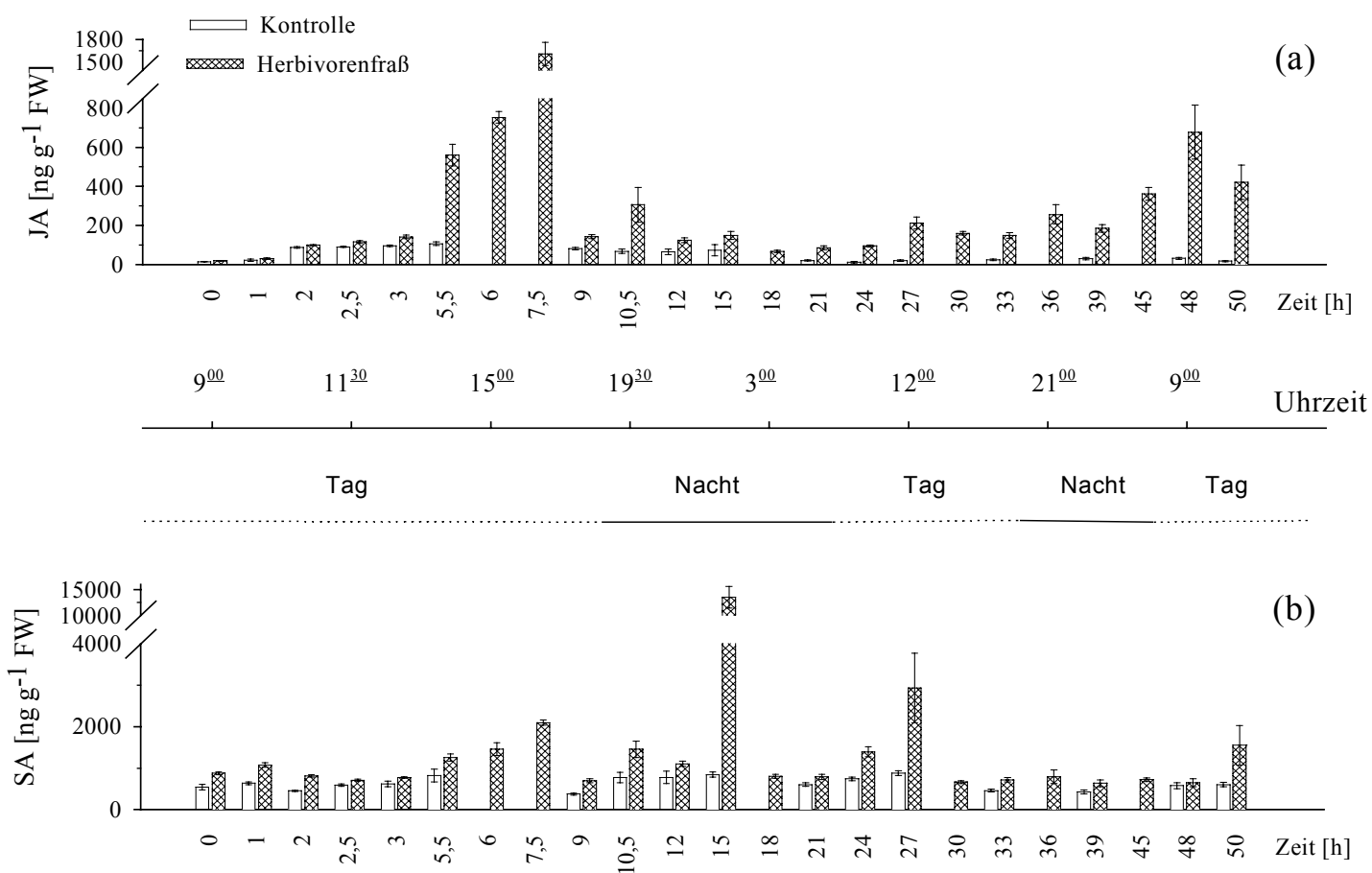

\begin{abstract}
Abb. 40: Zeitlicher Verlauf der endogenen Jasmonsäure- und Salicylsäurekonzentration im Blattgewebe von Alnus glutinosa ohne Herbivorie (= Kontrolle) und nach Herbivorenfraß von Agelastica alni-Larven über einen Zeitraum von 50 Stunden. - a) Jasmonsäuregehalt (JA) $\left[\mathrm{ng} \mathrm{g}^{-1} \mathrm{FW}\right]$ geschädigter und ungeschädigter Blätter. - b) Salicylsäuregehalt (SA) [ng g $\left.{ }^{-1} \mathrm{FW}\right]$ geschädigter und ungeschädigter Blätter. Angegeben sind der Mittelwert und der Standardfehler $(n=4)$. Der Nachweis und die Quantifizierung des endogenen Jasmon- und Salicylsäuregehalts erfolgte mittels GC-MS. FW = Frischgewicht.
\end{abstract}

Als Ausgangsgehalt konnte ein Jasmonsäurewert von ca. $19 \mathrm{ng} \mathrm{g}^{-1} \mathrm{FW}$ ermittelt werden. Mit fortschreitender Fraßdauer der Larven war ein deutlicher Anstieg des endogenen 
Jasmonsäuregehalts zu verzeichnen, der bereits nach 7,5 Stunden ein erstes Maximum von $1610 \mathrm{ng} \mathrm{g}^{-1} \mathrm{FW}$ erreichte (Abb. 40a). Danach fiel der Jasmonsäuregehalt wieder ab und schwankte um einen Wert von $146 \mathrm{ng} \mathrm{g}^{-1} \mathrm{FW}$. Nach 45 h Fraßzeit kam es zu einem zweiten Anstieg in den ermittelten Jasmonsäurewerten, der aber deutlich kleiner war als der erste und der nach 48 Stunden einen Wert von 680 ng g $^{-1}$ FW erreichte. Danach konnte wieder eine Abnahme im Jasmonsäuregehalt verzeichnet werden. Die Bestimmung des Jasmonsäuregehalts der unbefallenen Blätter zeigte nicht den gleichen zeitlichen Verlauf wie die der befallenen Blätter (Abb. 40a). Die Jasmonsäuremengen stiegen zwar zu Anfang auch bei den Kontrollen leicht an, lagen aber immer deutlich unter denen der befressenen Blätter.

Der Grundwert des endogenen Salicylsäuregehalts lag zu Beginn der Zeitreihe für die Kontrollblätter bei ca. $544 \mathrm{ng} \mathrm{g}^{-1} \mathrm{FW}$ und für die geschädigten Blätter bei ca. $874 \mathrm{ng} \mathrm{g}^{-1}$ FW (Abb. 40b). Die beiden Gruppen unterschieden sich nicht in ihrem Salicylsäuregehalt. Mit fortschreitender Fraßdauer war jedoch ein minimaler Anstieg der Salicylsäurekonzentrationen zu verzeichnen. $\mathrm{Zu}$ einzelnen Zeitpunkten, $\mathrm{t}=15 \mathrm{~h}$ und $\mathrm{t}=27 \mathrm{~h}$, wurden hohe Salicylsäuregehalte beobachtet. Zu allen untersuchten Zeitpunkten lagen die ermittelten Salicylsäuregehalte der unbefallenen Blätter immer unter denen der befallenen Blätter. 


\subsubsection{Charakterisierung des Regurgitats von Agelastica alni-Larven}

\subsubsection{Chemische Untersuchungen}

Das Regurgitat von $A$. alni-Larven wurde untersucht, um Informationen über die chemische Zusammensetzung zu erhalten. Im Regurgitat von Lepidopterenlarven nachgewiesene Acylglutaminkonjugate wie z.B. das Volicitin werden als Elicitoren pflanzlicher Abwehrreaktionen, besonders für die De-novo-Biosynthese von Duftstoffen, diskutiert (ALBORN et al. 1997). Es sollte daher überprüft werden, ob Verbindungen wie das Volicitin oder strukturverwandte Acylaminosäuren auch in dem Speichel von $A$. alni vorkommen.

Das Larvenregurgitat war eine gelb-bräunliche Flüssigkeit, die meistens in klarer, gelbbrauner Farbe erscheint (Abb. 41a). Lichtmikroskopische Untersuchungen von Ausstrichen des Regurgitats zeigten, daß auch feste Bestandteile im Speichel zu finden waren: Identifiziert werden konnten kleine Blattstückchen und weitere Fragmente der pflanzlichen Nahrung (Abb. 41b, c). Weiterhin konnten auch Mikroorganismen erkannt werden, die sich durch eine schnelle Beweglichkeit auszeichneten.
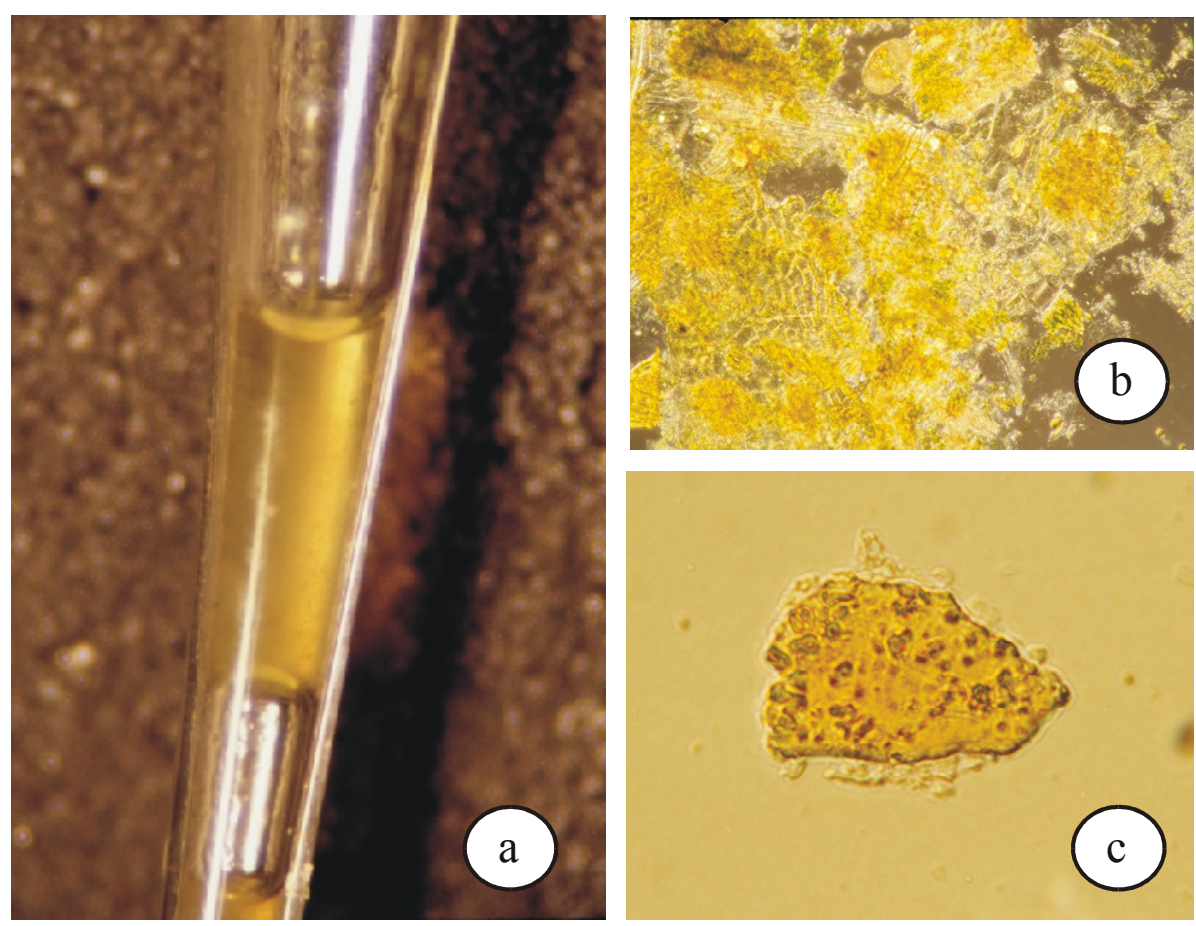

Abb. 41: Makroskopische Untersuchungen des Regurgitats von Agelastica alni-Larven. Legende siehe nächste Seite. 
Legende zu Abb. 41: Makroskopische Untersuchungen des Regurgitats von Agelastica alni-Larven. - a) Gesammeltes Regurgitat von $A$. alni-Larven in einer Glaskapillare. Die Flüssigkeit erscheint in gelbbrauner Farbe. - b) Lichtmikroskopische Aufnahme der Regurgitatflüssigkeit. Die Lösung wies neben noch nicht zersetzten Zellfragmenten der pflanzlichen Nahrung auch Mikroorganismen auf. - c) Detailansicht: Zellfragment aus der pflanzlichen Nahrung.

Zur chemischen Analyse des Regurgitats wurde die Hochleistungsflüssigchromatographie in Kombination mit einem Massenspektrometer verwendet. In der Abb. 42 (oben) ist das HPLC-Chromatogramm (Totalionenstrom bzw. Ionenspur $\mathrm{m} / \mathrm{z}=405$ ) des Regurgitats von A. alni-Larven dargestellt. Zum Vergleich dazu wurde ein HPLCChromatogramm des Regurgitats von S. littoralis-Larven, abgebildet (Abb. 42, unten; von Dieter Spiteller (MPI für Chemische Ökologie, Jena) zur Verfügung gestellt).

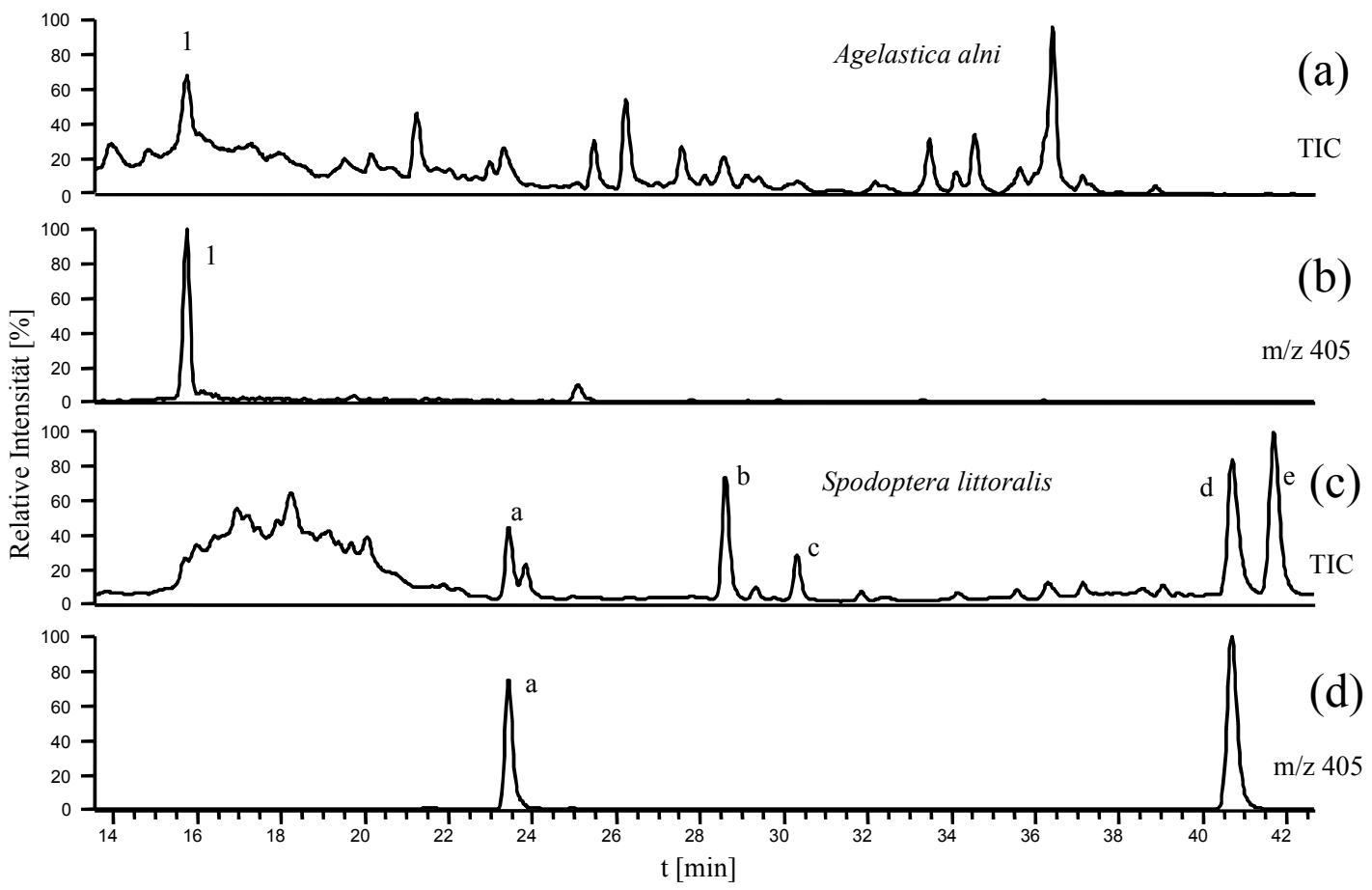

Abb. 42: HPLC-Chromatogramme von Regurgitaten zweier herbivorer Insekten. - a) Totalionenstromchromatogramm (TIC) des Regurgitats von Agelastica alni-Larven nach Fraß auf Alnus glutinosa-Blättern. - b) Ionenspur m/z 405 des Regurgitats von A. alni-Larven nach Fraß auf Erlenblättern. c) Totalionenstrom des Regurgitats von Spodoptera littoralis nach Fraß auf synthetischer Diät. - d) Ionenspur m/z 405 des Regurgitats von S. littoralis nach Fraß auf synthetischer Diät. Folgende Zuordnungen konnten getroffen werden Verbindung 1 = unbekannt; (a) Volicitin, (b) Linolenoylglutamin, (c) Linoylglutamin, (d) 17 Linolenoxylinolenoylglutamin, (e) 17 Linolenoxylinoylglutamin. $\mathrm{m} / \mathrm{z}=$ Ionenmasse/Ionenladung. 
Vergleicht man die beiden HPLC-Chromatogramme von A. alni (Abb. 42a, b) mit S. littoralis (Abb. 42c, d) miteinander, so lassen sich deutliche Unterschiede erkennen. Die bereits aus dem Regurgitat von S. littoralis-Raupen identifizierten Verbindungen wie Volicitin (17-Hydroxylinolenoylglutamin) (a), Linolenoylglutamin (b), Linoylglutamin (c), 17 Linolenoxylinolenoylglutamin (d) und 17-Linolenoxylinoylglutamin (e) konnten aufgrund ihrer Retenstionszeit und der MS-Spektren nicht im Regurgitat von $A$. alni nachgewiesen werden.

Dennoch erschien eine Verbindung, Verbindung 1 (Abb. 42 a, b), aus dem Regurgitat von A. alni aufgrund ihres APCI-MS Spektrums (Abb. 43) interessant, da ihr Massenspektrum zahlreiche Ionen $(\mathrm{m} / \mathrm{z}=130,147,259,405)$ aufwies, die auch bei Volicitin zu finden sind (Abb. 44).

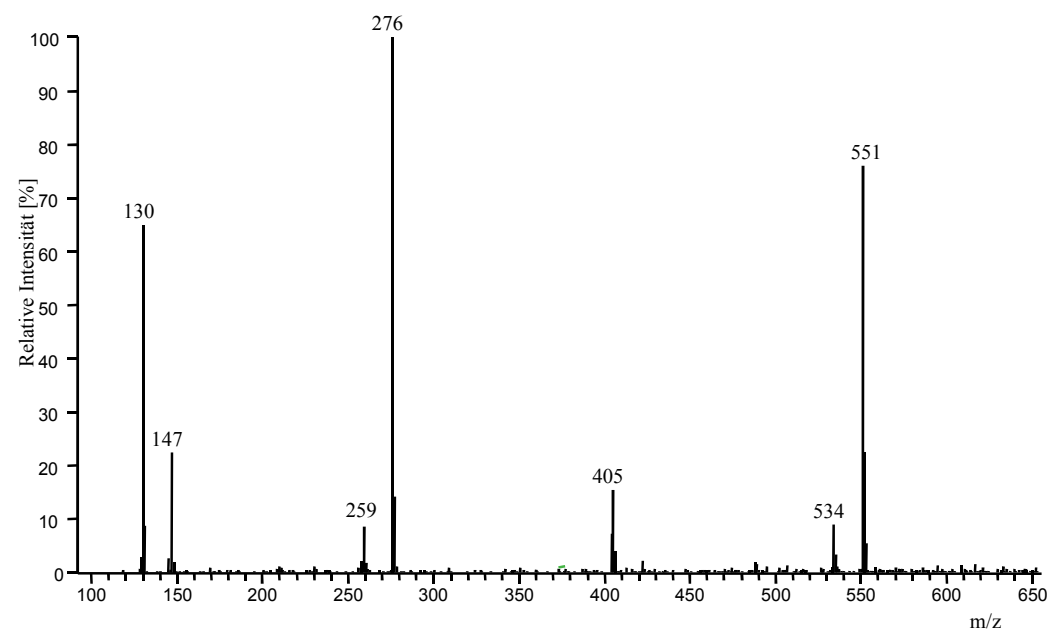

Abb. 43: APCI-MS Spektrum von Verbindung 1 aus dem Regurgitat von Agelastica alni-Larven.

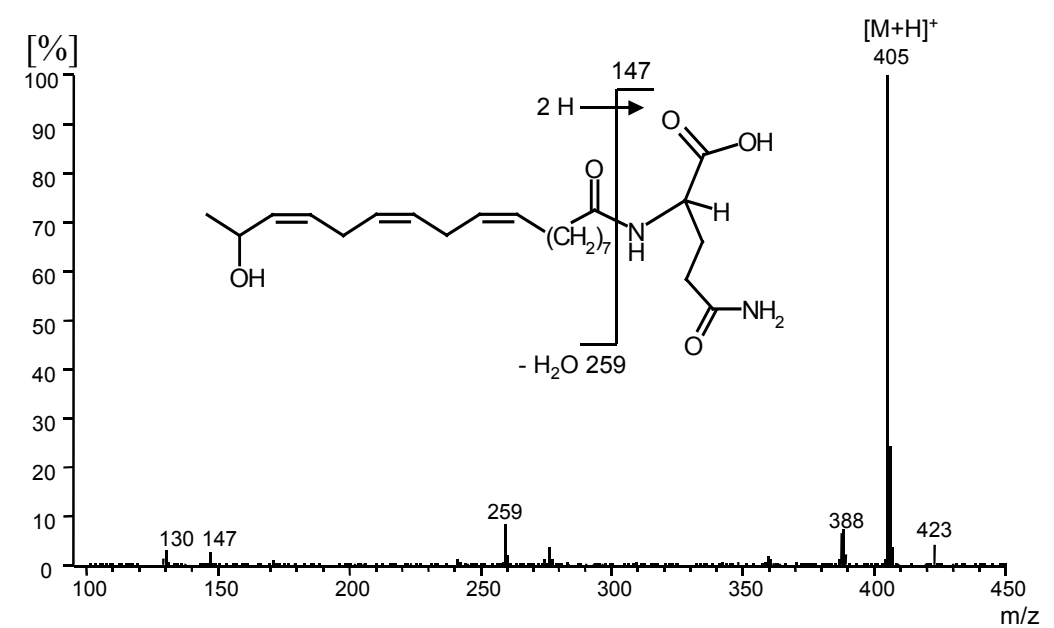

Abb. 44: APCI-MS Spektrum des Volicitins aus dem Regurgitat von Spodoptera littoralis-Larven. 
Die Struktur von Verbindung 1 konnte bisher nicht aufgeklärt werden. Trotz der sehr ähnlichen APCI-Massenspektren scheint keine enge Verwandtschaft zu Acylglutaminkonjugaten vorzuliegen, da MS/MS-Experimente (Micromass Quattro II) eher auf eine Dimerisierung von einem Molekül mit $[\mathrm{M}+\mathrm{H}]^{+} 276 \mathrm{zu} 551$ hindeuten.

\subsubsection{Elektrophysiologische Untersuchungen zur Membranaktivität}

Die Emission bestimmter Duftstoffkomponenten konnte bei Phaseolus lunatus durch Alamethicin induziert werden (ENGELBerTh et al. 2000). Dieses Peptaibol ist in der Lage, $\mathrm{H}^{+}$-selektive Ionenkanäle zu bilden, die zu einer Duftinduktion führen. Da die Duftinduktion bei der Schwarzerle durch Herbivorenfraß von A. alni induziert werden kann, sollte in In-vitro-Studien mit der Technik der „black lipid membranes“ untersucht werden, ob dem Regurgitat der Larven membran-verändernde Eigenschaften zugesprochen werden können.

Nach Zugabe des Larvenregurgitats von $A$. alni in die Elektrolytlösung veränderte sich die Leitfähigkeitseigenschaft der Membran (Abb. 45). Dabei konnten zehn Minuten nach Zugabe des Regurgitats ca. einige zehntel Sekunden lang Veränderungen in der Leitfähigkeit gemessen werden, die auf Öffnungsereignisse von Ionenkanälen hindeuteten (Abb. 45b). Mit fortschreitender Inkubationszeit veränderte sich die Leitfähigkeitseigenschaft der Membran so, daß keine Öffnungsereignisse mehr erkannt werden konnten (Abb. 45c). Nach 20-minütiger Inkubation wurde die Membran zerstört, weil die Leitfähigkeit einen so hohen Wert erreicht hatte. Dieses Verhalten des Larvenregurgitats von $A$. alni an der künstlichen Membran bestätigte sich in mehreren Versuchswiederholungen. 

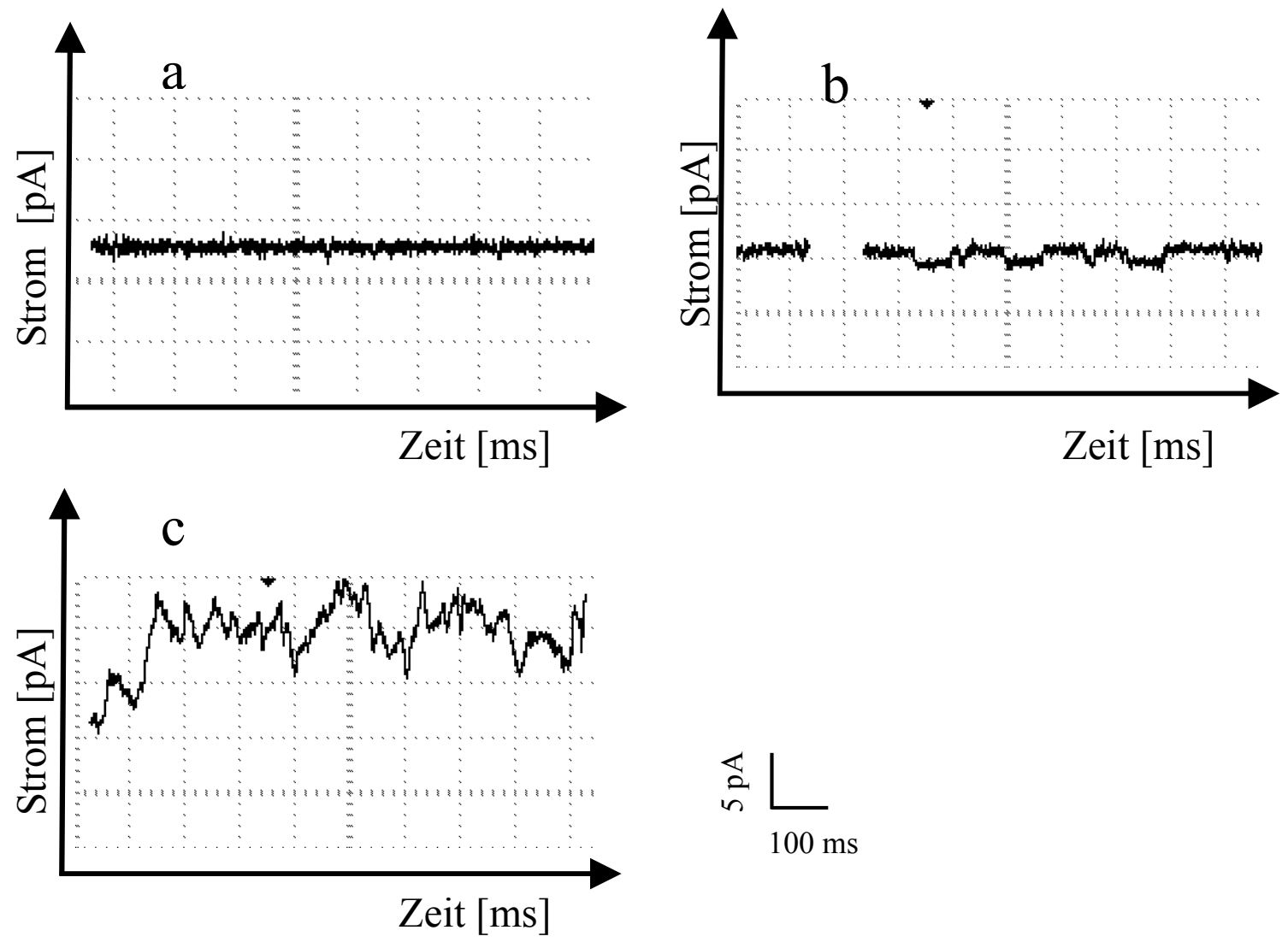

Abb. 45: Einfluß des Agelastica alni-Regurgitats (nach Fraß auf Alnus glutinosa-Blättern) auf die biophysikalischen Eigenschaften der künstlichen bimolekularen Membran. - a) Stromfluktuationsspur vor der Zugabe der Regurgitats. - b) Stromfluktuationsspur nach Zugabe der Regurgitats, $\mathrm{t}=10 \mathrm{~min}$. - c) Stromfluktuationsspur nach Zugabe der Regurgitats, $\mathrm{t}=20 \mathrm{~min}$. Die resultierenden Stromfluktuationsspuren wurden bei einem angelegten Membranpotential von $+50 \mathrm{mV}$ aufgezeichnet. Das Regurgitat wurde jeweils dem trans-Kompartiment der Meßküvette zugesetzt. Anschließend wurde die Elektrolytlösung 1 min gerührt. Elektrolytlösung: 100 mM KCl, 20 mM Hepes, pH 7,0. 


\subsubsection{Fraßpräferenz von Agelastica alni}

Um die Auswirkungen physiologischer Veränderungen im Blattgewebe von A. glutinosa, induziert durch die Applikation verschiedener Signalstoffe wie Jasmonsäure, Salicylsäure, Ethylen, Methyljasmonat, Methylsalicylat auf den Herbivoren A. alni zu testen, wurden Fraßwahlversuche durchgeführt. In den Fraßwahlversuchen wurde den Larven von A. alni jeweils ein Blattstück von unbehandelten (= Kontrolle) und von behandelten Testblättern angeboten (Übersicht Tab. 4, Kap. 4.4.7). Als Versuchsergebnis wurde das Trockengewicht der konsumierten Blattmenge bestimmt (Kap. 4.3.4.3).

Versuch 1: „Kontrolle 1“ vs. „Kontrolle 2“

In der ersten Versuchsvariante, einem Vorversuch zur Überprüfung des Biotestsystems, wurden den Larven von $A$. alni zwei Blattstücke von unbehandelten Blättern „Kontrolle $1^{\text {“ }}$ sowie „Kontrolle $2^{\text {“ }}$ angeboten. In ihrem Fraßverhalten zeigten die Larven keine Präferenz zwischen den Blattstückchen (Abb. 46a). Sie konsumierten von beiden angebotenen Blattstücken eine ähnliche Blattmenge von 2,13 \pm 0,33 mg DW („Kontrolle 1“) und 2,89 \pm 0,35 mg DW (,Kontrolle 2“). Ein signifikanter Unterschied in der gefressenen Menge wurde nicht ermittelt (,Kontrolle $1^{\prime \prime} v s$. „Kontrolle $2^{\prime}, \mathrm{t}=-1,68, \mathrm{p}=0,103$, $\mathrm{n}=60)$.

Versuche 2 und 3: „Kontrolle“ vs. „JA“

In der zweiten Versuchsvariante wurde den Larven ein Stück eines unbehandelten Blattes „Kontrolle“ und das Stück eines mit Jasmonsäure inkubierten Blattes ( $\mathrm{t}=43 \mathrm{~h}$ ) angeboten. Die ermittelten Trockengewichte der gefressenen Blattmengen sind in Abb. $46 \mathrm{~b}$ grafisch dargestellt. Die Larven fraßen von den mit JA-behandelten Blättern ca. $0,21 \pm 0,04 \mathrm{mg}$ DW und von den unbehandelten Blättern etwa dreimal so viel $(0,65 \pm$ 0,06 mg DW) (,Kontrolle“ vs. ,JA“, $\mathrm{t}=7,66, \mathrm{p}<0,001, \mathrm{n}=40$ ). 

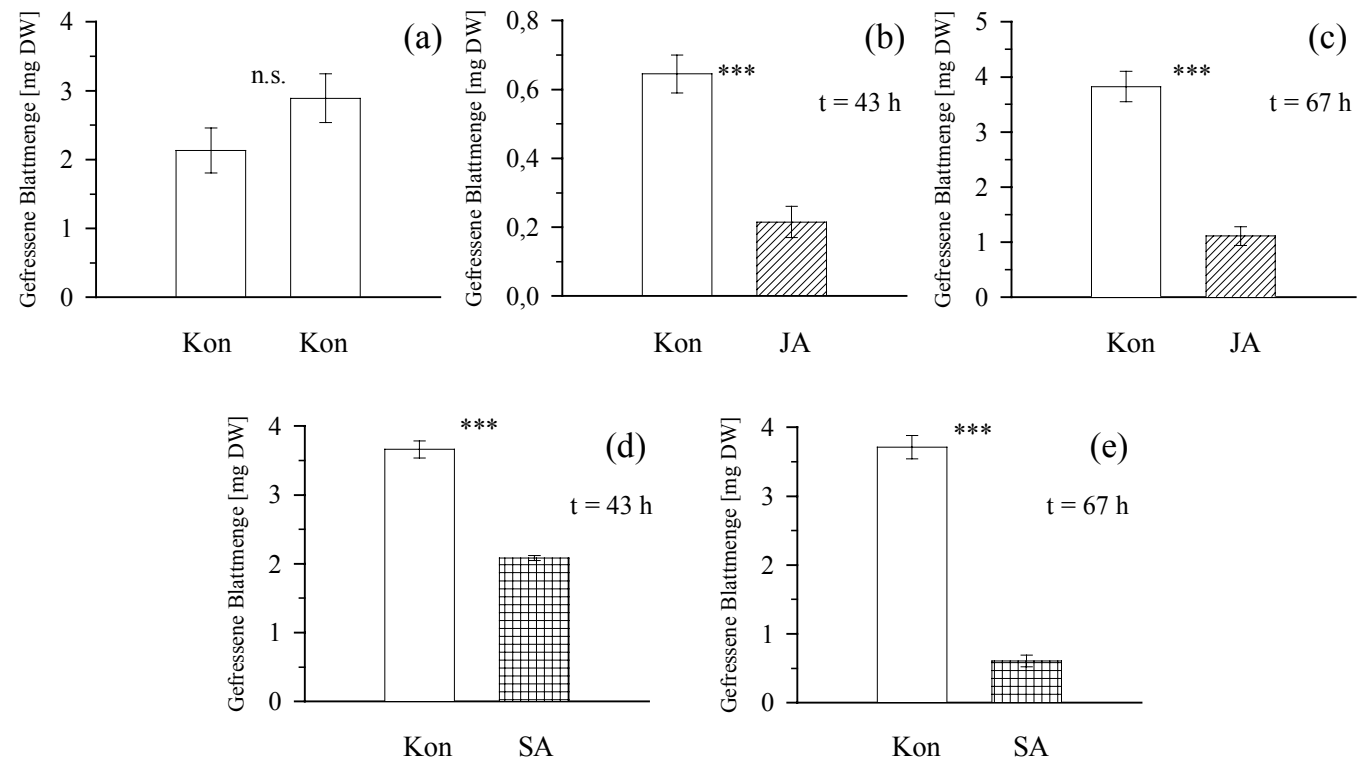

Abb. 46: Fraßwahlversuche mit Agelastica alni-Larven zur Überprüfung der Blattqualität von Alnus glutinosa-Blättern nach Behandlung mit den Induktoren Jasmon- und Salicylsäure. Dargestellt ist das Trockengewicht (DW [mg]) der gefressenen Blattfläche der unbehandelten Erlenblätter (Kon) und der Testblätter nach 18-stündiger Biotestdauer. - a) unbehandelte Erlenblätter nach 48-stündiger Inkubation mit Wasser. - b) behandelte Erlenblätter nach 43-stündiger Inkubation mit Jasmonsäure (JA, $1 \mathrm{mM}$ ). - c) behandelte Erlenblätter nach 67-stündiger Inkubation mit Jasmonsäure (JA, $1 \mathrm{mM})$. - d) behandelte Erlenblätter nach 43-stündiger Inkubation mit Salicylsäure (SA, $1 \mathrm{mM}$ ). - e) behandelte Erlenblätter nach 67-stündiger Inkubation mit Salicylsäure (SA, $1 \mathrm{mM}$ ). Pro Petrischale wurde eine Larve von A. alni eingesetzt. Angegeben sind der Mittelwert und der Standardfehler. Die statistischen Daten des gepaarten t-Tests sind Tab. 14 zu entnehmen. $* * *=\mathrm{p}<0,001$.

Tab. 14: Fraßwahlversuche mit Agelastica alni-Larven zur Überprüfung der Blattqualität von $A l$ nus glutinosa-Blättern nach unterschiedlichen Behandlungen. Vergleich von „Kontrolle“ und „Testblatt“. Die statistischen Werte wurden mit Hilfe des gepaarten t-Tests berechnet.

\begin{tabular}{|c|l|c|c|c|}
\hline Versuch & $\begin{array}{l}\text { Vergleich zwischen Blattstücken unter- } \\
\text { schiedlicher Behandlung }\end{array}$ & $\mathrm{t}$ & $\mathrm{p}$ & $\mathrm{n}$ \\
\hline 1 & Kontrolle $v s$. Kontrolle & $-1,68$ & 0,103 & 60 \\
\hline 2 & Kontrolle $v s$. JA & 7,66 & $<0,001$ & 40 \\
\hline 3 & Kontrolle $v s$. JA & 10,44 & $<0,001$ & 60 \\
\hline 4 & Kontrolle $v s$. SA & 8,31 & $<0,001$ & 60 \\
\hline 5 & Kontrolle $v s$. SA & 15,56 & $<0,001$ & 60 \\
\hline 6 & Kontrolle $v s$. Ethylen & 6,57 & $<0,001$ & 60 \\
\hline 7 & Kontrolle $v s$. MeJA & 7,31 & $<0,001$ & 60 \\
\hline 8 & Kontrolle $v s$. MeSA & 8,79 & $<0,001$ & 60 \\
\hline 10 & Kontrolle und K-Nachbar $v s$. A-Nachbar & 12,18 & $<0,001$ & 105 \\
\hline 11 & Kontrolle und K-Nachbar $v s$. A-Nachbar & 8,28 & $<0,001$ & 105 \\
\hline
\end{tabular}


Für die dritte Versuchsvariante wurde die Inkubationszeit verändert $(t=67 \mathrm{~h})$. Die gefressene Blattmenge der Kontrollblattstücke (3,82 \pm 0,27 mg DW) unterscheidet sich signifikant von der der Jasmonsäureblattstücke (1,11 \pm 0,17 mg DW) (,Kontrolle“ $v s$. „JA“, $\mathrm{t}=10,44, \mathrm{p}<0,001, \mathrm{n}=60)(\mathrm{Abb} .46 \mathrm{c})$. Somit bestätigt sich der schon in Versuch 2 beobachtete Effekt: Jasmonsäure induzierte Veränderungen im pflanzlichen Stoffwechsel, die sich negativ auf das Fraßverhalten von $A$. alni auswirkten.

Versuche 4 und 5: „Kontrolle“ vs. „SA“

Bot man den Larven von $A$. alni im Fraßwahlversuch ein unbehandeltes Blattstück und ein kurzzeitig $(t=43 \mathrm{~h})$ mit Salicylsäure inkubiertes Blattstück an, so fraßen die Tiere signifikant weniger von den behandelten Blättern (Abb. 46d) (,Kontrolle“ vs. „SA“, $\mathrm{t}=$ $8,31, \mathrm{p}<0,001, \mathrm{n}=60)$.

Wurden die Blätter für 67 Stunden mit Salicylsäure inkubiert und anschließend im Fraßwahlversuch den $A$. alni Larven angeboten, so ähnelte das Fraßverhalten dem der vorherigen Versuchsvariante (Abb. 46e). Die Tiere fraßen mit 0,61 \pm 0,09 mg DW gefressener Blattmenge der SA-behandelten Blattstücke deutlich weniger als von den unbehandelten Blattstücken (3,71 \pm 0,17 mg DW) (,Kontrolle“ vs. „SA“, t = 15,56, p < $0,001, \mathrm{n}=60)$.

Versuch 6: „Kontrolle“ vs. „Ethylen“

Dieser Fraßwahlversuch wurde mit Erlenblättern durchgeführt, die 48 Stunden mit Ethylen inkubiert worden waren. Die Laven von A. alni konsumierten deutlich weniger von den mit Ethylen inkubierten Blättern $(0,23 \pm 0,03 \mathrm{mg}$ DW) als von den unbehandelten Blättern (0,67 \pm 0,06 mg DW) (,Kontrolle“ vs. ,Ethylen“, $\mathrm{t}=6,57, \mathrm{p}<0,001, \mathrm{n}=$ 60) (Abb. 47a). Die Inkubation mit Ethylen induzierte Veränderungen im pflanzlichen Stoffwechsel, die sich fraßmindernd auf den Herbivoren auswirkten.

Versuch 7: „Kontrolle“ vs. „MeJA“

Die ermittelten Trockengewichte der gefressenen Blattmengen von Blättern nach 48stündiger Inkubation mit MeJA sind in der Abb. 47b dargestellt. Die Larven von A. alni fraßen von den mit Methyljasmonat behandelten Blättern ca. 0,69 \pm 0,08 mg DW und von den unbehandelten Blättern etwa doppelt so viel (1,58 \pm 0,10 mg DW) (,Kontrolle“ 
vs. ,MeJA“, $\mathrm{t}=7,31, \mathrm{p}<0,001, \mathrm{n}=60$ ). Das flüchtige Methyljasmonat induzierte Veränderungen im pflanzlichen Stoffwechsel, so daß fraßmindernde Auswirkungen auf den Herbivoren zu ermitteln waren.
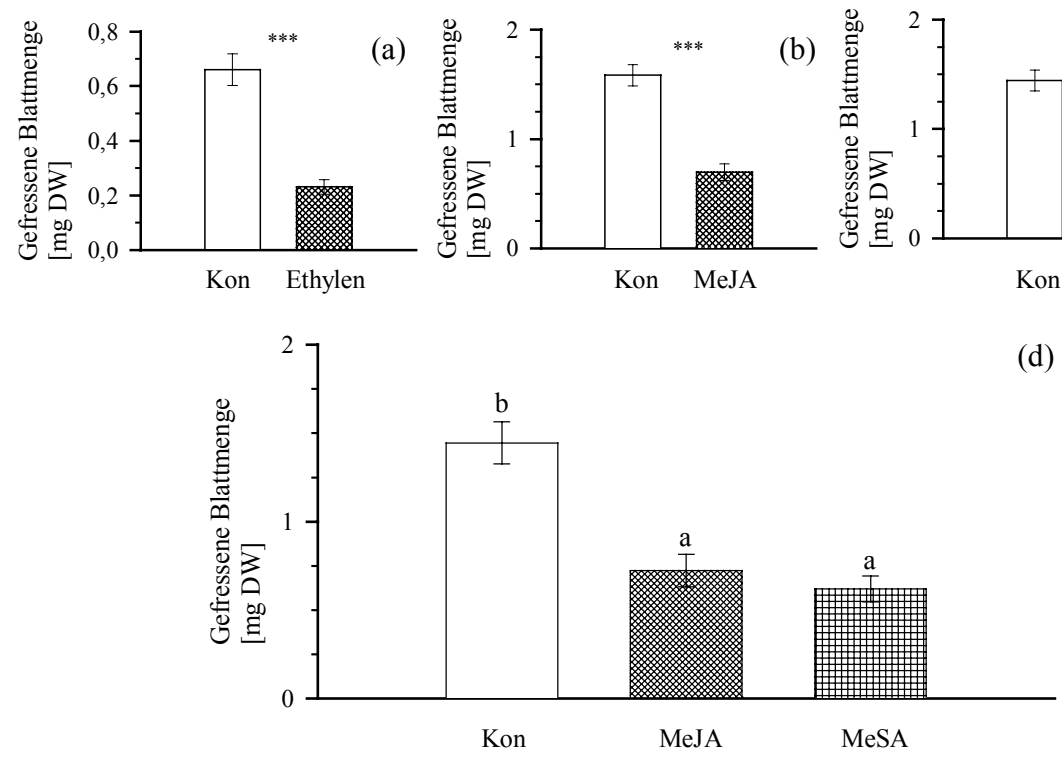

(b)

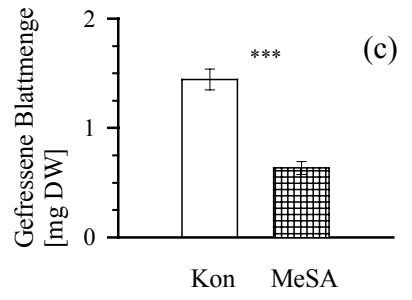

(d)

Abb. 47: Fraßwahlversuche mit Agelastica alni-Larven zur Überprüfung der Blattqualität von Alnus glutinosa-Blättern nach Behandlung mit den flüchtigen Induktoren Ethylen, Methyljasmonat (MeJA) und Methylsalicylat (MeSA). Dargestellt ist das Trockengewicht (DW [mg]) der gefressenen Blattfläche der unbehandelten Erlenblätter (Kon) und der Testblätter nach 18-stündiger Biotestdauer. - a) behandelte Erlenblätter nach 48-stündiger Inkubation mit Ethylen. - b) behandelte Erlenblätter nach 48stündiger Inkubation mit Methyljasmonat (MeJA). - c) behandelte Erlenblätter nach 48-stündiger Inkubation mit Methylsalicylat (MeSA). - d) behandelte Erlenblätter nach 48-stündiger Inkubation mit Methyljasmonat bzw. Methylsalicylat (ANOVA $F=21,69, \mathrm{p}<0,001, \mathrm{n}=72$ ). Verschiedene Buchstaben zeigen signifikante Unterschiede ( $<<0,05$, Newman Keuls-Test) an. Pro Petrischale wurde eine Larve von $A$. alni eingesetzt. Angegeben sind der Mittelwert und der Standardfehler. Die statistischen Daten des t-Tests sind Tab. 14 zu entnehmen. $* * *=p<0,001$.

Versuch 8: „Kontrolle“ vs. „MeSA“

Die zweite flüchtige Komponente, deren Auswirkung auf die Blattqualität der Erlen getestet wurde, war Methylsalicylat. Nach der 48-stündigen Inkubation mit dieser flüchtigen Komponente hatte sich die Qualität der Erlenblätter so verändert, daß die Larven im Fraßwahlversuch von den mit Methylsalicylat behandelten Blättern nur ca. 0,63 $\pm 0,06 \mathrm{mg}$ DW und von den unbehandelten Blättern etwa doppelt so viel fraßen $(1,44 \pm 0,10$ mg DW) (,Kontrolle“ vs. „MeSA“, t = 8,79, $\mathrm{p}<0,001, \mathrm{n}=60)$ (Abb. 47b). 
Das flüchtige Methylsalicylat induzierte Blattveränderungen, die sich nachhaltig auf das Fraßverhalten des Herbivoren A. alni auswirkten.

Versuch 9: „Kontrolle“ vs. „MeJA“ vs. „MeSA“

In einem Fraßwahlversuch wurden den Larven drei Blattstücke unterschiedlicher Qualität angeboten. Getestet wurde ein unbehandeltes, ein mit gasförmigem Methyljasmonat und ein mit gasförmigem Methylsalicylat inkubiertes Blatt. Die ermittelten gefressenen Blattmengen sind in der Grafik (Abb. 47c) dargestellt. Die Larven fraßen von den unbehandelten Blättern ca. 1,44 \pm 0,12 mg DW). Diese gefressene Blattmenge lag signifikant doppelt so hoch wie die der behandelten Blätter, von denen die Larven entweder nur 0,72 \pm 0,10 mg DW (MeJA) oder 0,62 \pm 0,07 mg DW (MeSA) konsumierten (ANOVA: $\mathrm{F}=21,69, \mathrm{p}<0,001, \mathrm{n}=72$ ). Die beiden Signalstoffe verändern die Qualität der Erlenblätter, so daß diese im Fraßwahlversuch einen negativen Einfluß auf das Fraßverhalten der Erlenblattkäferlarven zeigten. Das Fraßverhalten unterschied sich aber nicht zwischen den beiden Versuchsvarianten MeJA und MeSA.

Versuche 10 und 11: „Kon“ vs. „K-Nachbar“ vs. ,A. alni“ vs. „A-Nachbar“ Um die Auswirkungen der Blattveränderungen, hervorgerufen durch Einwirkung fraßinduzierter, flüchtiger Duftstoffe, auf das Fraßverhalten von A. alni-Larven zu testen, wurden die Erlenblätter nach ihrer Inkubation aus Containerversuchen (Kap. 4.4.1.2) den Larven in Fraßwahlversuchen angeboten. In den Fraßwahlversuchen, deren Versuchsanordnung in Abb. 48 (oben) schematisch dargestellt ist, wurde den Larven von $A$. alni jeweils ein Blattstück aus dem ersten Container von der unbehandelten Pflanze „Kontrolle“ und dem benachbarten, unbehandelten Trieb „K-Nachbar“ und aus dem zweiten Container von dem mit Herbivoren geschädigten Blättern „A. alni“ und den benachbarten, nicht befallenen Blättern „A-Nachbar“ angeboten. Die Ergebnisse dieser Fraßwahlversuche sind in Abb. 48 (unten) wiedergegeben. Unter dem Einfluß der fraßinduzierten Duftstoffe eines befressenen Erlentriebes hatte sich die Blattqualität in den benachbarten, nicht befallenen Blättern nach 3-tägiger Inkubation in den Containern so verändert, daß die Larven von $A$. alni von diesen signifikant weniger Blattmenge konsumierten als von unbehandelten Kontrollblattstücken („Kontrolle“ und „K-Nachbar“ vs. „A-Nachbar“, $\mathrm{t}=12,18, \mathrm{p}<0,001, \mathrm{n}=105)$. Dieser Versuch wurde zweimal wiederholt, wobei für die letzte Wiederholung die Inkubation in den Containern vier Tage 
lang erfolgte. Das beobachtete Fraßverhalten der Larven gegenüber Blättern unterschiedlicher Qualität bestätigte sich auch in dieser Wiederholung (,Kontrolle“ und „KNachbar“ vs. ,A-Nachbar“", $\mathrm{t}=8,28, \mathrm{p}<0,001, \mathrm{n}=105)$.
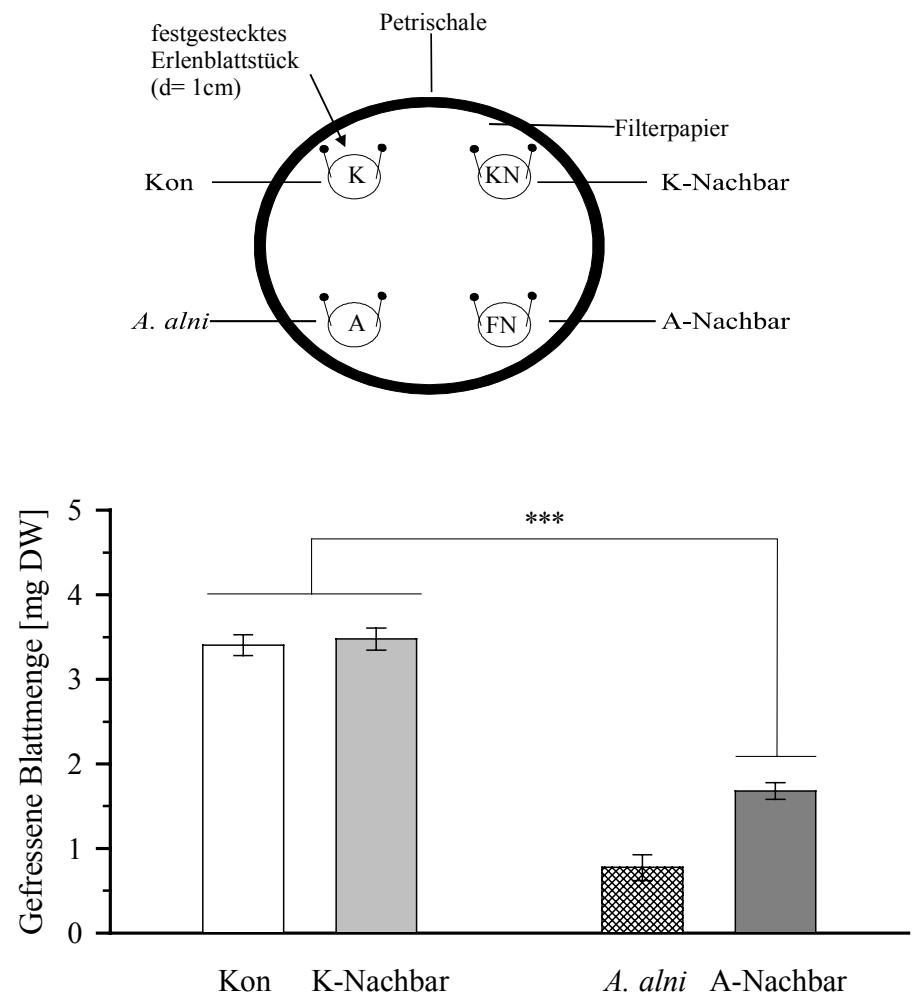

\begin{abstract}
Abb. 48: Schematische Versuchsanordnung der Fraßwahlversuche (oben). Den Larven von Agelastica alni wurden Blattstücke von vier verschiedenen Erlenblättern aus den Containerversuchen angeboten. Unten: Fraßwahlversuche mit $\boldsymbol{A}$. alni Larven zur Überprüfung der Blattqualität von Alnus glutinosa-Blättern nach 72-stündiger Inkubation in geschlossenen Glascontainern. Dargestellt ist das Trockengewicht der gefressenen Blattmenge (DW [mg]) der jeweiligen Blattstücke „Kon“, „KNachbar“, „A. alni“ und „A-Nachbar“ nach 18-stündiger Biotestdauer. Pro Petrischale wurde eine Larve eingesetzt. Angegeben sind der Mittelwert und der Standardfehler. (t-Test: „Kontrolle“ und „K-Nachbar“ vs. „A-Nachbar“, $\mathrm{t}=12,18, \mathrm{p}<0,001, \mathrm{n}=105)$. „Kon“ = Stück eines unbehandelten Blattes, „K-Nachbar“ = Stück eines zur „Kon“ benachbarten, unbehandelten Blattes, „A. alni“ = Stück eines befressenen Blattes, „A- Nachbar“ = Stück eines zu ,A. alni“ benachbarten, nicht befallenen Blattes.
\end{abstract}




\section{Diskussion}

Die vorliegende Arbeit beschäftigt sich mit der Induktion von Abwehrmechanismen bei der Schwarzerle infolge einer Blattschädigung. Es sollte festgestellt werden, ob durch Blattschädigung Veränderungen im pflanzlichen Gewebe induziert werden können und welche Auswirkungen diese spezifischen Blattveränderungen für den Herbivoren A. alni haben. Weiterhin wurden chemische Signalketten, die an der pflanzlichen Abwehr beteiligt sind, analysiert. Die Untersuchungen erstrecken sich zum einen auf die direkte, interspezifische Wechselwirkung zwischen dem Herbivoren und der Pflanze und zum anderen auf einen möglichen intraspezifischen Signaltransfer von fraßgeschädigten Erlenpflanzen auf benachbarte, ungeschädigte Pflanzen. Diesem Phänomen wurde sowohl in Freiland- als auch Laborversuchen näher nachgegangen.

\subsection{Freilandversuche}

\subsubsection{Auswirkungen einer simulierten Herbivorie auf benachbarte, ungeschä- digte Erlenpflanzen: „Reihenversuch“ und ,Topfversuch“"}

Zentraler Punkt der Freilandversuche war die Überprüfung der Hypothese zur Kommunikation zwischen Pflanzen. Dabei wird angenommen, daß geschädigte Pflanzen über Signalstoffe Resistenzen in ungeschädigten Nachbarpflanzen induzieren können. Der Signaltransfer zwischen Pflanzen kann dabei entweder über den Boden- oder den Luftbereich erfolgen. Im Boden können Pflanzen über ihr Wurzelsystem in Kontakt zueinander stehen. Dieser Wurzel-Wurzel-Kontakt kann entweder direkt sein, oder er wird durch Mycorrhiza, Bodenpartikel sowie durch Bodenwasser indirekt vermittelt. Bei dieser Form ist ein Signalaustausch nur über solche Substanzen möglich, die in wasserlöslicher Form vorliegen. Oberirdisch stehen Pflanzen über den Luftbereich in Wechselwirkung: Signale können über die Blätter an die Luft abgegeben werden und per Diffusion oder Wind auf umliegende Blätter (Senderpflanze oder Empfängerpflanze) treffen.

Die erste Möglichkeit des Signaltransfers über den Wurzel-Bodenbereich wurde bei dem Freilandversuch „Topfversuch“ mit A. glutinosa dadurch ausgeschlossen, daß getopfte Pflanzen verwendet wurden. Ferner besaßen die Töpfe keine Löcher im Boden, 
so daß ein Kontakt der Wurzelspitzen mit Bodenpartikeln nicht möglich war. Der zweiten Möglichkeit eines Signaltransfers, der über den Boden-Wurzelbereich und über den Luftbereich vermittelt wird, wurde in dem „Reihenversuch“ mit natürlich wachsenden Erlenbeständen nachgegangen. Die Auswirkungen der simulierten Schädigung wurden auf die unmittelbar benachbarten Bäume und die weiter entfernt stehenden Pflanzen untersucht. Die Ergebnisse dieser Freilandexperimente „Topfversuch“ und „Reihenversuch“ lieferten keine Hinweise bei den analysierten Parametern der relativen Blattschädigung, des spezifischen Blattgewichts, der Blattfestigkeit und der gefressenen Blattmenge im Fraßwahlversuch auf eine induzierte Abwehr bei den unmittelbar benachbarten Bäumen. Ein ähnliches Resultat erzielte auch HATTENDORF (2000). Die Ergebnisse von Dolch (2000), daß der Erlenblattkäfer $A$. alni solche Erlen, die in unmittelbarer Nachbarschaft einer manuell entblätterten Erle standen, deutlich weniger für Fraß annahm als weiter entfernt stehende Bäume, konnten durch die vorliegenden Freilandexperimenten „Reihenversuch“ und „Topfversuch“ nicht bestätigt werden.

Einige Aspekte, die für die Interpretation der Ergebnisse der Freilandversuche in Frage kommen, sollen im folgenden näher erläutert werden. Sie werden in der Tab. 15 kurz für die verschiedenen Freilandarbeiten zusammengefaßt. Bei allen Freilandversuchen handelt es sich um jeweils verschiedene, unabhängige Experimente, die sich in den Punkten wie Versuchsjahr, eingesetztes Pflanzenmaterial, genetische Voraussetzungen, Umweltfaktoren (Temperatur, Feuchtigkeit, Nährstoffhaushalt der Standortböden), Versuchsdesign sowie in Art und Ausmaß der simulierten Herbivorie deutlich voneinander unterscheiden. Sie sind somit unter diesen Gesichtspunkten auch nicht miteinander vergleichbar. Jeder Versuch ist ein eigenständiges, neues Experiment und nicht als Versuchswiederholung anzusehen. Weiterhin sind die genannten Parameter in der Lage, die Wechselwirkung zwischen Pflanze - Herbivor und Pflanze - Pflanze nachhaltig zu beeinflussen.

Um den „Topfversuch“ experimentell durchführen zu können, wurden im Vorfeld des Versuchs Erlenpflanzen von einem Baumschulbetrieb erworben, der die Pflanzen wurzelnackt lieferte. Möglicherweise war die verbleibende Zeitspanne zwischen Eintopfen der Pflanzen im März und Versuchsanfang im Mai für eine vollständige Etablierung der Erlenbäume in den Töpfen zu kurz. 


\begin{tabular}{|c|c|c|c|c|c|c|c|c|c|}
\hline 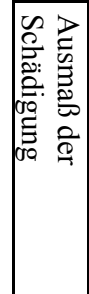 & 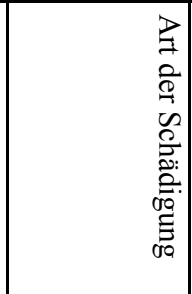 & 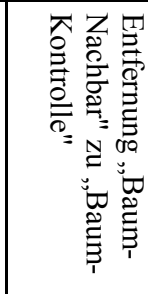 & 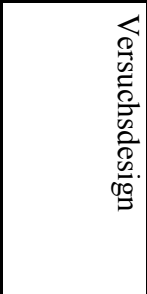 & 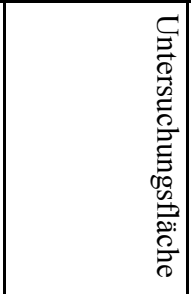 & 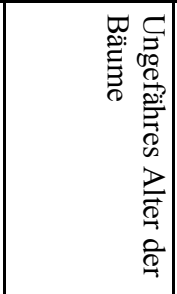 & 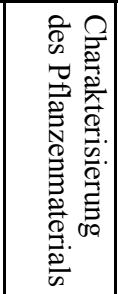 & 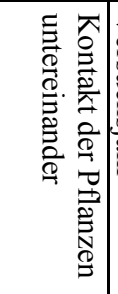 & & \\
\hline 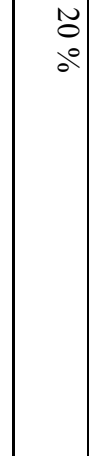 & 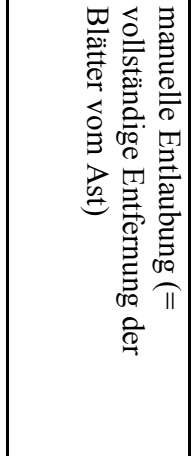 & 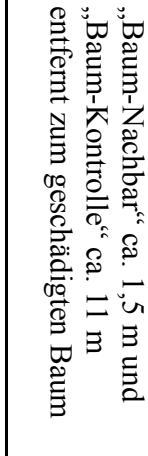 & 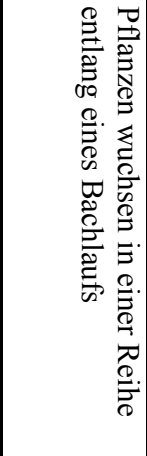 & 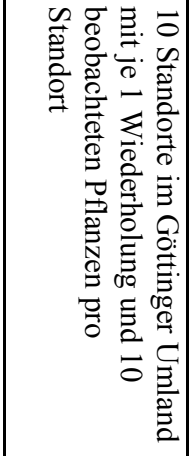 & 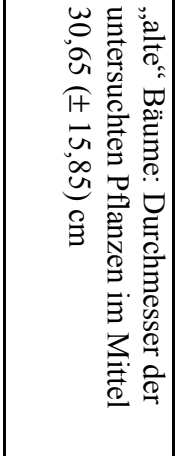 & 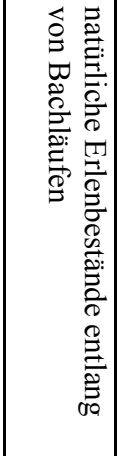 & 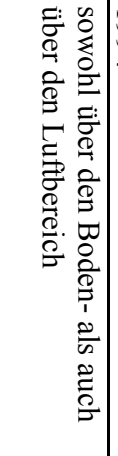 & & 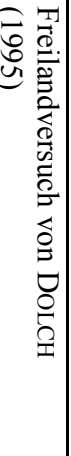 \\
\hline $\begin{array}{l}\text { un } \\
\text { वे }\end{array}$ & 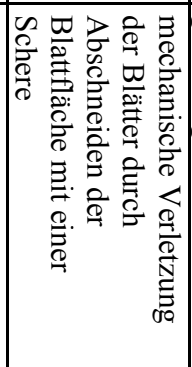 & 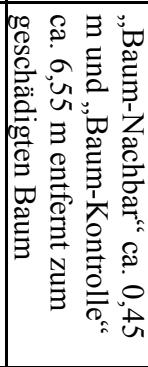 & 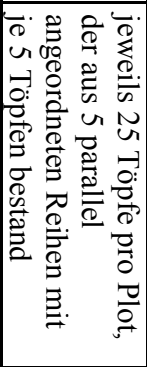 & 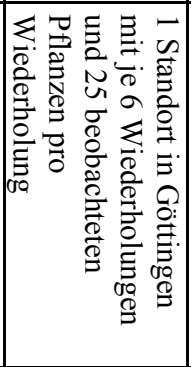 & 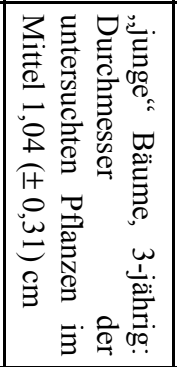 & 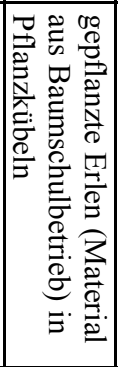 & 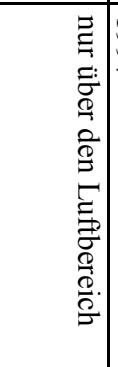 & & 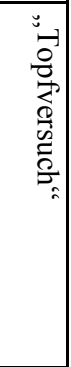 \\
\hline $\begin{array}{l}\text { U. } \\
\text { o }\end{array}$ & 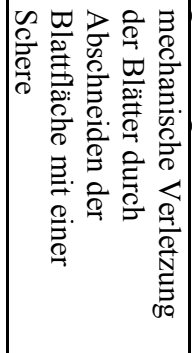 & 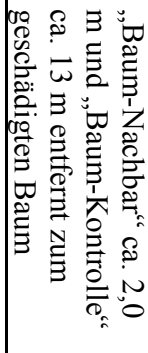 & 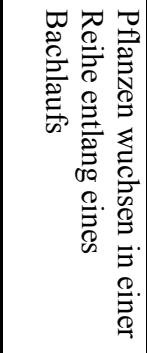 & 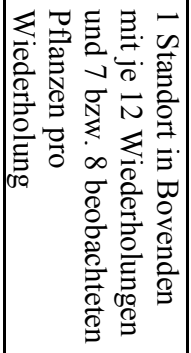 & 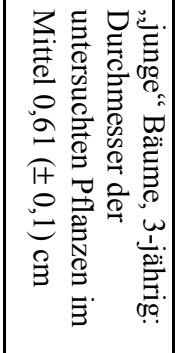 & 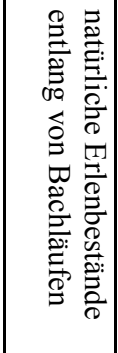 & 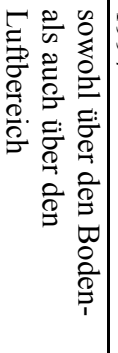 & $\overrightarrow{8}$ & 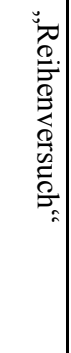 \\
\hline$\vec{a}$ & 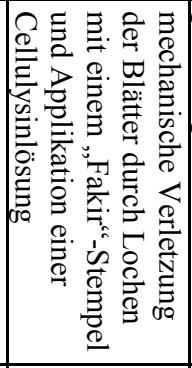 & 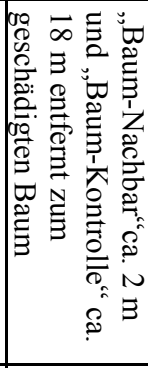 & 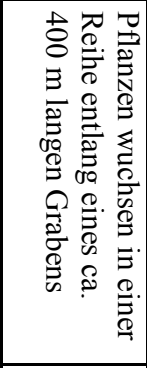 & 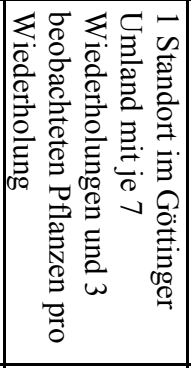 & 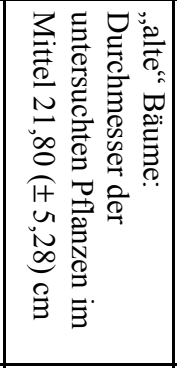 & 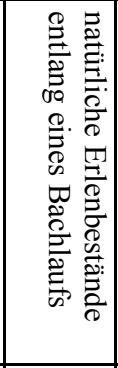 & 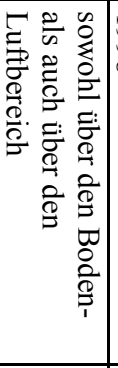 & & 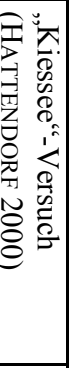 \\
\hline $\begin{array}{l}\overline{8} \\
0^{\circ}\end{array}$ & 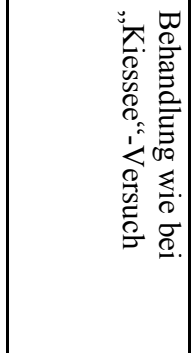 & 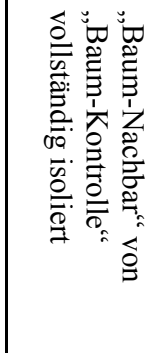 & 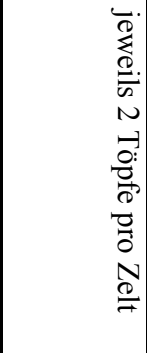 & 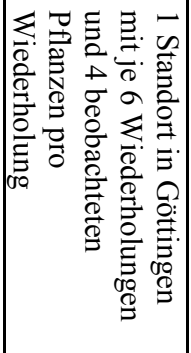 & 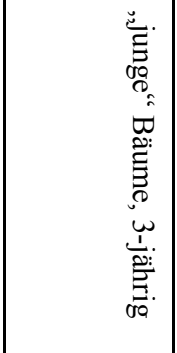 & 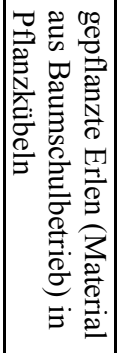 & 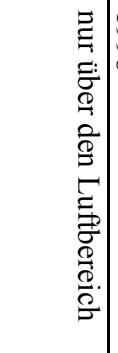 & & 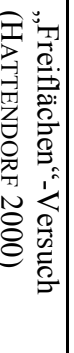 \\
\hline
\end{tabular}


Demgegenüber zeichneten sich die Erlenpflanzen beim Versuchsstart durch einen gesunden Habitus mit vollständig entwickeltem Blattwerk aus. Weiterhin waren auch keine streßbedingten Anzeichen erkenntlich. Über die binnenphysiologischen Vorgänge zu diesem Zeitpunkt kann aber keine Aussage getroffen werden, so daß eventuell vorhandene „Versuchsartefakte“, die beim Eintopfen aufgetreten sein könnten, immerhin in Betracht gezogen werden müssen.

Für den „Topfversuch“ wurden drei Jahre alte Erlen ausgewählt. Um eine bessere Vergleichbarkeit der Freilandversuche untereinander zu erzielen, wurden für den „Reihenversuch“ im Freiland gleichaltrige Erlen ausgewählt. Das Alter der Pflanzen kann einen Einfluß auf induzierte Abwehrmechanismen haben. So nimmt beispielsweise nach Schädigung die Induktion von Proteinaseinhibitoren bei Tomatenpflanzen mit zunehmendem Alter ab (WOLFSON \& MURDOCK 1990). Weiterhin belegen Untersuchungen von OLEKSYN et al. (1998), daß junge, 4 Jahre alte Erlen nach Fraß höhere Phenolgehalte aufwiesen als 40 Jahre alte Erlen gegenüber ungeschädigten Blättern. Da die Erlen der „Topf“- und „Reihenversuche“ ähnlich alt waren wie die von OLEKSYN et al. (1998) verwendeten Pflanzen, ist ein negativer Einfluß des Pflanzenalters bei den eigenen Versuchen wenig wahrscheinlich.

Das Erlenmaterial aus dem Baumschulbetrieb zeichnete sich auch durch eine genetische Homogenität aus. Nach Auskunft des Baumschulbetriebes sind die Pflanzen zwar aus frei abgeblühten Sämlingen aus Samenplantagen hervorgegangen, aber anzunehmen sind identische Eltern. Eine weitgehende genetische Homogenität des Erlenmaterials könnte auch für die Erlen vom „Reihenversuch“ angenommen werden. Die Pflanzen wurden von der Gemeinde in einer Pflanzaktion gesetzt, so daß es wahrscheinlich ist, daß die Erlen auch aus einem einzigen Baumschulbetrieb stammen. Dagegen spricht bei der Erlenstichprobe von Dolch (2000) mit der Beprobung von Erlenpflanzen an zehn verschiedenen Standorten für eine genetisch heterogene Zusammensetzung. Nicht auszuschließen ist, daß sich in diesem Fall genetische Voraussetzungen nachhaltig auf das Versuchsergebnis der Freilandversuche ausgewirkt haben. Daß eine Resistenzausprägung abhängig von dem vorhandenen Genotyp einer Pflanze sein kann, belegen die Untersuchungen von ROBISON \& RAFFA (1994), SHEN \& BACH (1997) und HAVILL \& RAFFA (1999). 
Einen entscheidenden Einfluß auf die induzierte Pflanzenantwort haben auch die Art und das Ausmaß der experimentellen Schädigung. In der vorliegenden Untersuchung konnte sowohl mit dem „Topfversuch“ als auch mit dem „Reihenversuch“ gezeigt werden, daß eine manuelle mechanische Schädigung nicht ausreichte, um deutliche Resistenzeffekte in benachbarten Erlenbäumen zu induzieren. Diese Art der experimentellen Schädigung bietet bei Freilanduntersuchungen generell den Vorteil, daß sie eine einfache Methode darstellt, um starken Herbivorenfraßschaden an zufällig ausgewählten Bäumen zu simulieren. DolCH (2000) konnte mit einer modifizierten Variante, einer künstlichen Entblätterung, signifikante Auswirkungen auf benachbarte Erlen feststellen, die in unmittelbarer Nähe zu einer geschädigten Pflanze standen. Bei seinen Versuchen stellte die Art der Behandlung ein geeignetes Signal zur Resistenzinduktion dar. Basierend auf diesen Ergebnissen wurde deshalb für den „Topf“- und „Reihenversuch“ die mechanische Verletzung zur experimentellen Schädigungsvariante gewählt. Ferner war im Vorfeld der eigenen Versuche davon ausgegangen worden, daß die Erlenpflanzen noch charakteristischer auf diese Form der Behandlung reagieren als bei einer Entblätterung. Nachdem die Blätter an den Blattflächen mit einer Schere mechanisch verletzt worden waren, blieben sie weiterhin an der Pflanze zurück. Diese ,großflächige“ Verletzung stellt einen größeren Stimulus zur Aktivierung pflanzlicher Abwehr dar als die teilweise Entfernung von Blättern. Dafür spricht auch, daß MATTSON \& PALMER (1988) im Rahmen eines Freilandexperiments nachweisen konnten, daß mechanisch verletzte Blätter am Baumast hängenbleiben müssen, um in benachbarten Blattregionen chemische Veränderungen zu induzieren. Wurden die Äste nur teilweise entlaubt, so ließen sich keine induzierten Veränderungen im Blattgewebe benachbarter, nicht entlaubter Astregionen analysieren. Die Autoren folgerten, daß verletzte Blätter am Baum zurückbleiben müssen, damit ein Verwundungssignal über das Gefäßsystem der Pflanze auf nicht geschädigte Blattregionen und somit auf die ganze Pflanze vermittelt werden kann, damit es zur Aktivierung pflanzlicher Abwehr kommen kann. Eventuell wären die pflanzliche Antworten sowie die induzierten Veränderungen bei den Erlenpflanzen der „Topf“- und „Reihenversuche“ noch ausgeprägter gewesen, wenn zusätzlich zu der künstlichen mechanischen Verwundung ,herbivore Faktoren“ wie Regurgitat oder Kot aufgetragen worden wären. Zum Beispiel applizierten HAUKIOJA et al. (1985) zusätzlich Schmetterlingskot auf manuell entlaubte Bäume. Derart behandelte Pflanzen zeigten 
anschließend eine stärkere Resistenz gegenüber Schmetterlingsraupen als wenn man sich nur auf die Entblätterung allein beschränkt hätte. Weitere biochemische und physiologische Untersuchungen belegen den Tatbestand, daß mechanische Verletzung eher eine unspezifische Form der Schädigung ist, die nicht dem Herbivorenfraß entspricht (DYer \& BOKHARI 1976; CAPINERA \& ROLTSCH 1980; TURLINGS et al. 1990; HARTLEY \& LaWton 1991; TOMLin \& Sears 1992; Stout et al. 1994). Nur durch das Einbringen von herbivoren Elicitoren konnte annäherungsweise Herbivorenfraß simuliert werden (TURLINGS et al. 1990; DiCKE et al. 1993; KORTH \& DiXON 1997).

\subsubsection{Auswirkungen einer JA-Applikation auf benachbarte, ungeschädigte Er- lenpflanzen: „JA-Versuch“6}

Da die beiden Freilandversuche „Reihenversuch“ und „Topfversuch“ keinen ausreichenden Hinweis auf die Pflanze-Pflanze-Kommunikation lieferten, wurde im dritten Freilandexperiment Herbivorenfraß statt durch mechanische Schädigung durch exogene Applikation von Jasmonsäure simuliert, weil im Labor über detaillierte physiologische Untersuchungen folgende Kenntnisse gewonnen worden waren.

Die Blattfraßschädigung des Herbivoren A. alni führte zu einer deutlichen Induktion der Jasmonsäurebiosynthese im befressenen Erlenblattgewebe (Kap. 5.2.4), so daß diesem Signalstoff eine Beteiligung an der pflanzlichen Abwehr gegenüber Herbivorie zugesprochen werden kann. Weiterhin zeigte exogen applizierte Jasmonsäure einen induzierenden Effekt auf direkte physiologische Veränderungen im Erlenblattgewebe, die denen nach Herbivorenfraß ähnelten. Jasmonsäure vermehrte den Phenolgehalt der Erlenblätter (Kap. 5.2.1.1), führte zu einer Aktivitätssteigerung von oxidativen Enzymen (Kap. 5.2.1.2.1) sowie von Proteinaseinhibitoren (Kap. 5.2.1.3) aber auch zu einer Induktion der Freisetzung von flüchtigen Blattinhaltsstoffen (Kap. 5.2.3.2).

Die Ergebnisse des „JA-Versuchs“ zeigen, daß Jasmonsäure die direkte pflanzliche Abwehr bei den behandelten Schwarzerlen induzierte und daß diese ,induzierten“ Erlenpflanzen Signalstoffe abgaben, die von den benachbarten, ungeschädigten Erlenpflanzen erkannt wurden. Nach der Wechselwirkung mit diesen Signalstoffen wurden die pflanzlichen Abwehrreaktionen bei den nicht geschädigten Erlenpflanzen so aktiviert, daß es zu einem deutlichen Anstieg im Blattphenolgehalt kam. Eine indirekte In- 
duktion phenolischer Verbindungen in ungeschädigtem Blattgewebe von Populus euroamericana und Acer saccharum über flüchtige Duftstoffe wurde auch von BALDWIN \& SCHULTZ (1983) beobachtet. Ferner verringerten sich die relative Blattschädigung im Freiland und die konsumierte Blattmenge im Fraßwahlversuch. Das bedeutet, daß sich unter dem Einfluß einer Jasmonsäure-behandelten Erlenpflanze die Blattqualität in den benachbarten Blättern des Baumes „Baumnachbar-JA“ so verändert haben müßte, daß die Herbivoren von diesem Baum signifikant weniger Blattmenge konsumierten als von Blättern der Kontrollvariante „Baumnachbar-Kon“. Innerhalb des Untersuchungszeitraums konnten hingegen bei den Baumnachbarn „Baumnachbar-JA“ keine Hinweise auf indirekte Veränderungen im Blattwassergehalt und im spezifischen Blattgewicht ermittelt werden. Diesen morphologisch-mechanischen Barrieren dürften daher keine wesentliche Bedeutung für die induzierte pflanzliche Abwehr bei Alnus zukommen, obwohl es einige Hinweise gibt, daß sie zu direkten, induzierbaren Veränderungen der Blattmorphologie gezählt werden können (FEENY 1970). Die Ausbildung von Blatthaaren als einer weiteren Form einer induzierten - mechanisch-morphologisch ausgeprägten - Abwehr, wäre denkbar gewesen, da BAUR et al. (1991) bei Experimenten mit dreijährigen Grauerlen eine erhöhte Trichomdichte auf neu austreibenden Blättern nach Fraßschädigung von $A$. alni feststellten.

Die Induktion der ermittelten physiologischen Veränderungen kann nur über gasförmige Stoffe erfolgt sein, denn für den Signaltransfer zwischen induzierten Erlenpflanzen und benachbarten, unbehandelten Pflanzen kommt nur der Luftraum in Frage. Aufgrund der Verwendung von getopften Erlenpflanzen kann ein Kontakt über den Wurzelraum ausgeschlossen werden. Weiterhin waren die Erlenbäume so positioniert, daß ein Kontakt über die Blattflächen untereinander nicht gegeben war, so daß ein Jasmonsäuretransfer vom behandelten Baum auf den Baumnachbarn nicht vorstellbar ist. Weiterhin können mögliche Behandlungsartefakte für diese Ergebnisse ausgeschlossen werden. Die mittig angeordneten Erlenpflanzen „JA“ bzw. „K“ wurden an einer geschützten Stelle einer Gewächshausanlage, die weit entfernt von der Versuchsfläche lag, behandelt (Kap. 4.3.3). Eine „Mitbehandlung“ von benachbarten Erlenpflanzen ist damit ausgeschlossen. Weiterhin blieben die Pflanzen hier solange stehen, bis die besprühten Blattflächen abgetrocknet waren. Damit wurde in der Gasphase über der Blattoberfläche verflüchtigte Jasmonsäure ausgeschlossen. Momentan können keine Aussagen darüber 
gemacht werden, wie groß die Mengen an Jasmonsäure waren, die den pflanzlichen Stoffwechsel erreicht haben. Bislang erwies sich eine Sprühbehandlung mit einer 1mM Jasmonsäurelösung als geeignete Methode mit einer sinnvollen Konzentration, die zu keinen toxischen Effekten im pflanzlichen Stoffwechsel geführt hat (THALER 1999; OMER et al. 2000, OMER et al. 2001). Es ist eventuell möglich, daß durch die Sprühbehandlung so hohe Jasmonsäurekonzentrationen in der Pflanze erreicht wurden, daß der flüchtige Methylester der Jasmonsäure in die Gasphase emittiert wurde, da Untersuchungen an Phaseolus lunatus eine Konzentrationsabhängigkeit der Methyljasmonatabgabe in die Gasphase vom endogenen Jasmonsäuregehalt erbrachten (KoCH et al. 1997). Diese Ergebnisse sind aber nicht unmittelbar auf Erlenpflanzen zu übertragen, da bei den Bohnenpflanzen die JA-Applikation über den Transpirationssog erfolgte und im vorliegenden JA-Versuch Jasmonsäure auf die Blätter gesprüht wurde. Weiterhin konnte Methyljasmonat auch nicht im Duftspektrum von Erlenblättern, die im Labor mit Jasmonsäure behandelt worden waren, nachgewiesen werden (Kap. 5.2.3.2). Um die im Labor gewonnenen Erkenntnisse unmittelbar auf das Freiland zu übertragen, müßte man unter Freilandbedingungen an einem Erlenbaum nach der JA-Sprühapplikation den umgebenden Luftraum chemisch analysieren.

Neben dieser Spezifität für die Induktion pflanzlicher Abwehrreaktionen bietet die Verwendung von Jasmonsäure zur Simulierung von Herbivorie noch weitere Vorteile: Weder der direkte Kontakt mit Jasmonsäure oder Methyljasmonat noch die orale Aufnahme über die Nahrung zeigten toxische Effekte auf die Herbivoren: Wurden die Jasmonate in eine künstliche Diät gemischt und in Fraßversuchen Larven von Trichoplusia ni und Manduca sexta angeboten, beeinflußten sie weder das Verhalten noch die Performance der Larven (AVDIUSHKO et al. 1997). Diese Eigenschaften wurden weiterhin von Agrawal (1999) und THALER et al. (2001) bestätigt. Ein zweiter Vorteil exogener JA-Applikation besteht darin, daß „Behandlungsartefakte“ wie sie bei der herkömmlichen Simulierung von Herbivorie auftreten könnten, reduziert bzw. ausgeschlossen werden. Beispielsweise entsteht bei einer Entlaubung großer Blattmassenverlust, oder bei einer mechanischen Verletzung treten großflächige Wundränder auf, über die eine Pathogenbesiedlung erfolgen könnte. 


\subsection{Auswirkungen von Herbivorenfraß und Elicitierung auf die Physiologie von Alnus glutinosa}

In dem Kapitel sollen die für die Wechselwirkung zwischen Schwarzerle und Herbivor bzw. Schwarzerle - Schwarzerle aus den Laborversuchen gewonnenen Erkenntnisse nachfolgend dargelegt werden. Damit sollen alle an der induzierten Abwehr und an der Resistenzinduktion beteiligten Prozesse sowohl in den geschädigten als auch in den benachbarten Erlenpflanzen detaillierter angesprochen werden.

\subsubsection{Durch Herbivorenfraß induzierte Veränderungen im Blattgewebe von Alnus glutinosa}

\subsubsection{Beteiligung endogener Phytohormone}

Der Fraß von $A$. alni führte im Laborexperiment zu einer deutlicher Induktion der Jasmonsäurebiosynthese in den befressenen Erlenblättern (Kap. 5.2.4). Das bedeutet, daß der Herbivor-bedingte Fraßschaden von der Schwarzerle erkannt wird, wahrscheinlich über die Verwundung mit zusätzlicher Erkennung spezifischer Verbindungen aus dem Regurgitat des Herbivoren. Mit Aufnahme der Fraßaktivität des Herbivoren begann auch eine Zunahme des Jasmonsäuregehalts, der sich mit fortschreitender Fraßzeit steigerte. Der Octadecanoidweg wird also infolge Herbivorie deutlich induziert. Er stellt somit über viele Stunden große Mengen Jasmonsäure zur Verfügung und vermittelt dadurch die Signaltransduktion zur Genexpression. Dieser Signalweg von der Schädigung der Pflanze durch Herbivore bis zur Abwehrreaktion unter Beteiligung von Jasmonsäure sowie die molekularen Grundlagen dieser verwundungsinduzierten Signalkette wurden in Kap. 2 detailliert besprochen und schematisch dargestellt (Abb. 3). Zahlreiche Beispiele belegen, welche spezifischen pflanzlichen Abwehrreaktionen über den Octadecansäureweg ausgelöst werden (Kap. 2). Auch bei der Schwarzerle wurden einige Möglichkeiten der chemischen Abwehr untersucht, und eine Beteiligung von Jasmonsäure ist wohl auch für einzelne Substanzklassen gegeben. Auf Herbivorenfraß reagierten Erlenblätter mit der Produktion von Ethylen (Kap. 5.2.3.1) und weiteren flüchtigen Duftverbindungen (Kap. 5.2.3.2). Damit vergleichbar sind die Untersuchungen von PIEL et al. (1997), die Jasmonsäure als Signalüberträger bei der pflanzlichen Duftproduktion bei Bohnenpflanzen ergaben. $\mathrm{Zu}$ weiteren fraßinduzierten Abwehrreaktionen bei der 
Schwarzerle zählen die Enzyme Polyphenoloxidase, Peroxidase und Lipoxygenase (Kap. 5.2.1.2). Von diesen Proteinen ist bekannt, daß ihre Genaktivierung über Jasmonsäure erfolgt (Bell \& Mullet 1991; Tranbarger et al. 1991; Melan et al. 1993; REINBOTHE et al. 1994). Der erhöhte Jasmonsäuregehalt nach Herbivorenfraß dürfte bei der Schwarzerle auch die Gene dieser oxidativen Enzyme aktivieren, deren erhöhte Aktivitäten nach Herbivorenfraß festgestellt werden konnten. Zusätzlich reagierten Blätter der Schwarzerle auf Fraßverletzung der Blattoberfläche mit einer erhöhten Aktivität von Proteinaseinhibitoren (Kap. 5.2.1.3). Dazu stellen sich die Beobachtungen bei Tomatenpflanzen, bei denen über die Biosynthese von Jasmonsäure die Expression der Gene von Proteinaseinhibitoren aktiviert wird (GREEN \& RYAN 1972; BERGEY et al. 1996). In diesem Fall wird die Expression auch noch von Ethylen positiv reguliert (O'DONNELL et al. 1996). Da für die Schwarzerle sowohl die fraßinduzierte Ethylenbiosynthese (Kap. 5.2.3.1) als auch die Bildung von Jasmonsäure auf Herbivorenfraß (Kap. 5.2.4) belegt wurde, kann der Jasmonsäure die Bildung von Proteinaseinhibitoren als Abwehrreaktion gegen Herbivorie zugeschrieben werden. Der Octadecansäureweg mit Jasmonsäure als Signalstoff nimmt bei der Schwarzerle somit eine zentrale Rolle bei der induzierten Abwehr ein.

Für Salicylsäure als Signalstoff konnte kein charakteristischer Verlauf in der Produktion auf Herbivorenfraß belegt werden. Die Beobachtung, daß zu den Zeitpunkten $\mathrm{t}=15 \mathrm{~h}$ und $\mathrm{t}=27 \mathrm{~h}$ Salicylsäuregehalte von hohen Konzentrationen im pflanzlichen Gewebe vorlagen (Abb. 40b, Kap. 5.2.4), muß kritisch gesehen werden. Es erscheint nicht ganz realistisch, daß plötzlich und innerhalb von nur wenigen Stunden solche großen Salicylsäuremengen gebildet werden können. Auch passen die ermittelten Werte der Salicylsäurebestimmung nicht in den Gesamtverlauf aller erhobenen Meßwerte. Somit dürfte es sich bei den beobachteten hohen Salicylsäurewerten zu den beiden Zeitpunkten eher um „Ausreißer“ handeln. Eine mögliche Beteiligung von Salicylsäure als Signalstoff in einer Signaltransduktionskaskade bei der Schwarzerle ist eher unwahrscheinlich. 
6.2.1.2 Chemische Zusammensetzung und Eigenschaften des Regurgitats von Agelastica alni-Larven

Eine Induktion der Jasmonsäurekaskade durch Herbivorenfraß sowie eine spezifische pflanzliche Antwort auf Herbivorie setzen voraus, daß neben der Verwundung, Substanzen eine Rolle spielen müssen, die im Verwundungsbereich zwischen Pflanze und Angreifer freigesetzt und von der Pflanze wahrgenommen werden. Beispielsweise demonstrieren die Phenolquantifzierungen (Kap. 5.2.1.1), die Polyphenoloxidase-Aktivitätsbestimmungen (Kap. 5.2.1.2.1) sowie die Duftuntersuchen (Kap. 5.2.3.2), daß nach reiner Verwundung nicht das Ausmaß pflanzlicher Antwort beobachtet wird wie nach natürlichem Herbivorenfraß. Herbivorie stellte dabei immer einen stärkeren Stimulus zur Aktivierung der Stoffwechselwege dar als eine künstliche mechanische Verletzung.

Generell bedeutet Herbivorenfraß eine besondere Form der mechanischen Blattverletzung dar. Sie ist dadurch gekennzeichnet, daß über den Zeitraum des Fressens kontinuierlich Blattstücke abgerissen werden und dabei das Blatt ständig neu verwundet wird. Der Herbivor A. alni gehört zu den Blattfressern, die je nach Entwicklungsstadium charakteristische Fraßbilder erzeugen: Beim Schabefraß der L1-Larven wird die Blattoberfläche nur unvollständig benagt; beim Fensterfraß der älteren Larvenstadien bleibt die durchscheinende Epidermis der gegenüberliegenden Blattseite erhalten; bei Lochfraß des L3-Stadiums sowie der Imagines weisen die befressenen Blätter unterschiedlich gestaltete Fraßlöcher auf (Abb. 4). Während die Tiere, Larven wie auch Imagines, mit ihren Mundwerkzeugen die Blätter bearbeiten, tritt auch Speichelsekret der Herbivoren in Kontakt mit frisch verletztem Pflanzengewebe. Diese Speichelfaktoren fehlen bei der künstlichen mechanischen Verwundung. Wurde das Regurgitat aber nachträglich auf frisch verwundetes Blattgewebe aufgetragen, so konnte in den vorliegenden Versuchen mit dieser Applikationsvariante die physiologische Antwort induziert werden, die einem Fraß entsprach. Das heißt, daß in dem Regurgitat biotische Verbindungen enthalten sein müssen, die von der Pflanze wahrgenommen werden. Einige Arbeiten bestätigen dies (Turlings et al. 1990; TOMLin \& SEARS 1992; Dicke et al. 1993; STOUT et al. 1994; KorTh \& DiXON 1997). Das Speichelsekret von $A$. alni-Larven erwies sich als eine gelblich-braune Flüssigkeit (Abb. 41). Es handelt sich hier um ein Gemisch aus partiell verdauter pflanzlicher Nahrung mit Verdauungsenzymen, nachdem pflanzliche Nahrungsreste auch lichtmikroskopisch zugeordnet werden konnten. Ferner wies die Regur- 
gitatflüssigkeit eine Farbe auf, die der der Vorder- und Mitteldarmflüssigkeit glich. Bei einigen Schmetterlingsarten, bei denen die Regurgitation eine ursprüngliche Abwehrverhaltensweise darstellt, wird das Erbrochene noch mit Material aus exokrinen Drüsen wie Mandibel- oder Speicheldrüsen vermengt (DETTNER 1999). Evt. trifft dieser Vorgang auch für $A$. alni zu.

Eine chemische Charakterisierung des Regurgitats von $A$. alni-Larven ergab, daß keine Fettsäurederivate wie das Volicitin enthalten waren (Abb. 42, Kap. 5.2.5.1). Diese Verbindung zählt zu den bekanntesten Elicitoren herbivorer Herkunft. Sie wurde aus dem Speichelsekret von S. exigua isoliert und induziert die Duftemission an Maispflanzen (ALBORN et al. 1997). Der Elicitor aktiviert gezielt die Genexpression bestimmter an der Indol- oder Terpenbiosynthese beteiligter Enzyme (FREY et al. 2000; SHEN et al. 2000). Da bei Fraß von $A$. alni-Larven an Blättern von A. glutinosa auch die Emission von Duftstoffen belegt ist (Abb. 38, Kap. 5.2.3.2), kann man folgern, daß Acylglutamine kein allgemeines Prinzip für die Auslösung pflanzlicher Abwehr darstellen. Somit sind andere Komponenten für die Induktion von Abwehrreaktionen verantwortlich. Bestätigt wird diese Hypothese durch eigene Beobachtungen, daß Fraß von $A$. alni-Larven an Blättern von Phaseolus lunatus ein Spektrum mit verschiedenen Duftstoffkomponenten induzierte. Diese fraßinduzierten Duftstoffe entsprachen dabei den Komponenten, die auch durch S. littoralis-Fraß von der Bohne an die Gasphase freigesetzt wurden. Das heißt ein Herbivor wie A. alni ohne Acylglutamine im Speichel konnte an der Bohne die Duftbiosynthese induzieren. Weiterhin werden $\beta$-Glucosidasen als Elicitoren aus Insektenspeichel beschrieben (MATTIACCI et al. 1995), die in der Lage sind, die pflanzliche Abwehr in Form der Duftemission zu induzieren (HOPKE et al. 1994). Der Nachweis für diesen Elicitortyp wurde bei A. alni nicht geführt, so daß sein Vorkommen nicht ausgeschlossen werden kann. Schließlich gibt es aus Pilzen stammende Peptaibole, die für die Duftinduktion verantwortlich sind (ENGELBERTH et al. 2001). Zum Beispiel wird die Biosynthese der Duftstoffkomponenten DMNT, TMTT und Methylsalicylat bei Phaseolus lunatus selektiv durch membrandepolarisierende Substanzen durch Alamethicin sowie von verwandten ionophoren Strukturen induziert (ENGELBERTH et al. 2001). Da sich unter den fraßinduzierten Duftstoffen bei der Schwarzerle die Verbindungen DMNT, TMTT und Methylsalicylat befinden (Abb. 38, Kap. 5.2.3.2), liegt die Vermutung nahe, daß diese Eigenschaften auch dem Regurgitat 
von $A$. alni zugesprochen werden müssen. Die elektrophysiologischen In-vitroUntersuchungen an planaren Lipiddoppelschichten, den „,black lipid membranes“ ließen diese Eigenschaften für das Regurgitat von A. alni erkennen. Das Larvenregurgitat von A. alni veränderte nämlich die Leitfähigkeitseigenschaften der künstlichen Membran. Dabei wurden auftretende Öffnungsereignisse, die Ähnlichkeiten mit Ionenkanälen aufweisen, innerhalb von einigen Zehntelsekunden erkannt (Abb. 45, Kap. 5.2.5.2). Somit stellt Herbivorenfraß bzw. das Regurgitat von $A$. alni ein wichtiges Element zur Reizerkennung dar, das von der Pflanze als spezifisches Signal der Schädigung erkannt wird. Durch diese Wechselwirkung mit der Membran kann es zu veränderten Ionenflüssen von z.B. $\mathrm{Na}^{+}, \mathrm{K}^{+}$, oder $\mathrm{Cl}^{-}$und somit zu Membranpotentialveränderungen kommen. Diese sind in der Literatur als erste Antwort auf die Wechselwirkung mit Hormonen (BLATT \& THIEL 1993; BARBIER-BRYGOO et al. 1991), Elicitoren (MATHIEU et al. 1991; NÜRNBERGER et al. 1994) oder Verwundung (WILDON et al. 1992; HERDE et al. 1997) belegt. Die Veränderungen werden dann über Signalkaskaden zur spezifischen pflanzlichen Antwort wie z.B. der Duftemission (ENGELBERTH et al. 2001) oder der Induktion von Proteinaseinhibitoren (SCHALLER \& FRASSON 2001) umgesetzt.

\subsubsection{Phenolgehalte}

Sowohl nach Fraß der Larven von $A$. alni als auch nach Lepidopterenfraß von S. littoralis nahm der Blattphenolgehalt in den geschädigten Erlenblättern zu (Abb. 25, Kap. 5.2.1.1). Eine Beteiligung von Pflanzenphenolen bei der Antwort der Schwarzerle auf biotische Einflüsse ist somit gegeben. Sie wird auch bei verschiedenen anderen Pflanzenspezies beschrieben (Übersicht bei KARBAN \& BALDWIN 1997; MATTSON et al. 1988). Die Untersuchungen zeigten nicht nur, daß Herbivorenfraß deutlich den Blattphenolgehalt vermehrte, sondern auch, daß je nach Art des Herbivoren das Ausmaß der Zunahme von Phenolen unterschiedlich war: Der Fraß von $A$. alni hatte einen größeren Effekt (Faktor 3,8) als die Fraßschädigung durch S. littoralis (Faktor 2,2). Für diese Beobachtung könnte es folgende Erklärungen geben: Beide herbivoren Organismen unterscheiden sich in der chemischen Zusammensetzung ihres Regurgitats (Kap. 5.2.5.1). Diese Tatsache könnte für eine Wechselwirkung mit der Pflanze hinsichtlich einer spezifischen Erkennung von Bedeutung sein. Weiterhin könnten die Unterschiede zwischen beiden Herbivoren auch in dem Ausmaß der konsumierten Blattfläche liegen. 
Während des Versuches wurde beiden Herbivoren die Möglichkeit gegeben, ungehindert auf den vorhandenen Blättern zu fressen. Jedoch war es schwierig, den Schädigungsgrad zu kontrollieren. Es ergaben sich nämlich zwischen verschiedenen Pflanzen und den Versuchswiederholungen Differenzen bezüglich der konsumierten Blattmenge, die eventuell stärker den Blattphenolgehalt beeinflußten als die Unterschiede im Regurgitat.

Obwohl mit der Folin-Denis-Methode (SWAIN \& HILLIS 1959, modifiziert nach MARTIN \& MARTIN (1982)) nur eine quantitative Phenolbestimmung möglich ist und dabei die ökologisch bedeutsame Verteilung einzelner Komponenten unbekannt bleibt, sollen drei Möglichkeiten mit ihrer biologischen Bedeutung für die Schwarzerle und den Herbivoren diskutiert werden. Nach Verletzung oder Pathogenbefall werden in Bezug auf Veränderungen im Phenolstoffwechsel verschiedene Reaktionswege unterschieden.

$\underline{\text { Oxidation vorhandener Phenole }}$<smiles>[R]c1ccc(O)c(O)c1Oc1cccc(C(C)C)c1O</smiles>

Abb. 49: Durch Phenolase katalysierte Oxidation von Phenolen.

Der wichtigste Enzymkomplex zur Katalyse der Oxidation von Phenolen ist der Phenolase (= Polyphenoloxidase)-Komplex (MASON 1955). Im Zuge der Reaktion werden Monophenole zu Dihydroxybenzolderivaten hydroxyliert und diese zu o-Chinonen oxidiert (Abb. 49), die im weiteren Reaktionsverlauf nicht-enzymatisch polymerisieren oder an nucleophile Gruppen von Proteinen addieren (KosUGE 1969). Die polymeren Produkte sind u.a. für die Dunkelfärbung von verletztem Pflanzengewebe mitverantwortlich (RHOdes \& WoOLTORTON 1978). Da die von A. alni verursachten Fraßstellen braune Ränder aufwiesen, ist diese Reaktion offenbar auch bei der Schwarzerle relevant. Diesen polymeren Produkten werden ähnliche antimikrobielle und proteinfällende Wirkungen wie den Tanninen zugeschrieben (RHODES \& WOOLTORTON 1978), die u.a. als pflanzliche Abwehrstoffe gegen Fraßinsekten bekannt sind. Somit könnten sich auch Schwarzerlen durch Verringerung ihres Nährwertes vor $A$. alni-Fraß schützen. 


\section{Bildung von Wundlignin}

In Pflanzen wurde die Bildung von Wundlignin an der Oberfläche von mechanisch verletzten (RHODES \& WoOLTORTON 1978) oder mit Pilzen infizierten Pflanzenteilen (VANCE et al. 1980; RIDE 1975) beobachtet. Konsequenzen dieser Lignifizierung (RIDE 1978) sind stabilere Zellwände und damit mechanische Barrieren gegen das Eindringen von Pilzhyphen oder Toxinen sowie Schutz gegen die Aktivität der Enzyme des Pathogens oder des Herbivoren (Millet et al. 1975; RIDE \& PEARCE 1979). Im Speichelsekret befinden sich Enzyme oder andere für den Herbivoren typische Verbindungen, denen membranverändernde Eigenschaften zugesprochen werden können. Da beim Fraß von $A$. alni wahrscheinlich Speichelsekret auf die verletzten Wundränder des Blattes gelangt, stellt die Bildung von Wundlignin einen sinnvollen Schutzmechanismus dar. Denkbar wäre auch noch ein Schutz vor Mikroorganismen, deren Vorkommen im Speichelsekret von A. alni belegt werden konnte (Abb. 41, Kap. 5.2.5.1).

\section{$\underline{\text { Synthese niedermolekularer Phenole }}$}

Schließlich führt Streß bei Pflanzen zu einer generell erhöhten Syntheserate einfacher Phenole. Bevorzugt werden dabei Kaffeesäure und Chlorogensäure angereichert (RHODES \& WoOLTORTON 1978) (Abb. 50).<smiles>O=C(O)/C=C/c1ccc(O)c(O)c1</smiles>

(a)<smiles>O=C(/C=C/c1ccc(O)c(O)c1)OC1CC(O)(C(=O)O)CC(O)C1O</smiles>

Abb. 50: Bekannte Sekundärstoffe der Schwarzerle Alnus glutinosa. - a) Kaffeesäure.

- b) Chlorogensäure.

Diese Phenolcarbonsäuren gehören auch zu den bekannten Sekundärstoffen der Erle (HEGNAUER 1964), so daß induzierte quantitative Veränderungen für diese einfachen Phenole bei der Schwarzerle vorstellbar sind. Die Rolle dieser Substanzen ist jedoch unklar, zumal die Toxizität der monomeren Verbindungen niedriger ist als die ihrer oxidierten und polymerisierten Produkte (DESHPANDE et al. 1984). Dennoch konnten für die phenolische Verbindung Chlorogensäure (Abb. 50b) negative Auswirkungen auf das Fraßverhalten (IKONEN et al. 2001) sowie auf das Larvenwachstum herbivorer Insekten 
(ISMAN \& DUfFEY 1982) festgestellt werden. Dieses einfache Phenol könnte somit auch als fraßhemmende Substanz sowie als wirksamer Inhibitor des Larvenwachstums gegen Agelastica alni wirken.

6.2.1.4 Enzymaktivitäten von Polyphenoloxidase, Lipoxygenase, Peroxidase und Katalase

Eng verbunden mit dem Phenolmetabolismus sind die an der Phenolbiosynthese und Modifikation beteiligten Enzyme Polyphenoloxidasen und Peroxidasen. In unbehandelten Erlenblättern konnte eine Grundaktivität der Polyphenoloxidase und Peroxidase ermittelt werden, die durch Herbivorenfraß deutlich vergrößert wurde. Dabei war die Aktivitätserhöhung durch Herbivorenfraßschädigung von $A$. alni erkennbar stärker als die durch S. littoralis-Fraß (Abb. 26, Kap. 5.2.1.2.1). Die Induktion der Polyphenoloxidaseaktivität durch herbivore Insekten wurde z.B. bei krautigen Pflanzen wie Tomaten beobachtet (DUfFEY \& FELTON 1991). Werden Phenolasen durch Fraßverletzung im pflanzlichen Gewebe freigesetzt, katalysieren sie die Oxidation von phenolischen Verbindungen zu Chinonen, die als reaktive Moleküle essentielle Aminosäuren der pflanzlichen Nahrung alkylieren, so daß diese Proteine für die Insekten unbrauchbar werden (DufFey \& FELTON 1991; Felton et al. 1992). Die enzymatischen Versuche machen auch deutlich, daß - ähnlich wie bei den Phenolen - das Ausmaß der Aktivitätssteigerung je nach Herbivorenart und Art der Schädigung verschieden ist. Fraß von A. alni zeigte einen stärkeren Effekt als der Fraß durch S. littoralis. Dafür in Frage kommende Gründe wurden schon bei den Phenolen angesprochen und dürften auch für die Polyphenoloxidasen gelten. Die Beobachtung, daß die durch mechanische Verwundung entstehende PPO-Aktivität nicht der Aktivität entspricht, die durch Herbivorenfraßschädigung induziert wird, bestätigen die Ergebnisse von CONSTABEL et al. (2000).

Neben den Phenolasen sind auch Peroxidasen u.a. am Phenolstoffwechsel beteiligt. Die Enzyme nehmen eine wichtige Rolle während des Lignifizierungsprozesses wahr, da über sie der Weg der radikalischen Vorstufen führt, die sich zu den komplexen Ligninmolekülen zusammenlagern (Abb. 51) (Freudenberg 1965; CHEN 1991; Polle et al. 1994; Milosevic \& SLuSARENKo 1996; WhetTEn et al. 1998) (siehe auch „Bildung von Wundlignin“"). 
<smiles>[R]c1cc(/C=C/CO)cc([R])c1O</smiles>

Zimtalkohol

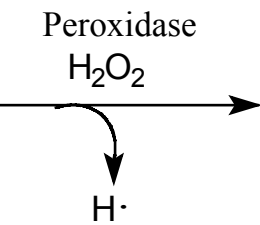<smiles>[R]c1cc(/C=C/CO)cc([R])c1[O-]</smiles>

Aroxyl-Radikal

$$
\uparrow
$$<smiles>[R]C1=CC(=CCCO)C=C([R])C1=O</smiles><smiles>[R]C1=CC(/C=C/CO)C=C([R])C1=O</smiles>

mesomere Radikale

Abb. 51: Polymerisation von Lignin-Vorstufen. An den freien Alkoholen, den Monolignolen, greift eine Peroxidase an und erzeugt durch Abspaltung eines $\mathrm{H}^{*}$-Radikals bzw. durch Elektronenentzug vom phenolischen Anion mesomere Monolignol-Radikale, welche dann spontan in vielfältiger Weise miteinander reagieren.

Aufgrund der Vielzahl möglicher Elektronendonatoren für die durch Peroxidasen katalysierte Reduktion von $\mathrm{H}_{2} \mathrm{O}_{2} \mathrm{zu} \mathrm{H}_{2} \mathrm{O}$ ist eine direkte Lokalisation im Stoffwechsel aber nicht möglich, so daß auch noch andere Funktionen diskutiert werden. Hierher gehören die Mitwirkung bei der Cutinisierung von Zellwänden, Oxidation von Indolessigsäure oder Ethylenbildung.

Zu weiteren Enzymen, deren Aktivität bei den Erlenblättern durch Herbivorenfraß signifikant gesteigert werden konnte, zählen Lipoxygenasen (Abb. 27, Kap. 5.2.1.2.2). Generell stehen sie als Indikator für „Streßsituationen“ (AXELROD 1974). Lipoxygenasen katalysieren die enzymatische Lipidperoxidation. Bei dieser Reaktion wird im ersten Schritt ein H-Radikal aus einem cis,cis-1,4-Pentadienyl-System einer polyungesättigten Fettsäure abstrahiert, und durch nachfolgende Anlagerung von molekularem Sauerstoff entsteht ein Fettsäurehydroperoxid (VICK \& ZIMMERMANN 1984; GARDNER 
1991; Siedow 1991; Bell \& Mullet 1991; Tranbarger et al. 1991; Melan et al. 1993). Fettsäurehydroperoxide stellen ein wichtiges Intermediat für verschiedene Synthesewege dar. Bei den Folgereaktionen muß dann zwischen gezielten enzymatischen Synthesen (z.B. über Allenoxidsynthasen (HAMBERG \& FAHLSTADiUs 1990; HARMS et al. 1995)) von regulatorischen Molekülen wie Jasmonsäure, die als Signalüberträger bei Verwundung und Pathogenbefall angesehen wird (CREELMAN et al. 1992; CREELMAN \& MULLET 1997; FARMER et al. 1992) oder Traumatinsäure und radikalischen Reaktionen, die beim Zerfall von Fettsäurehydroperoxide ablaufen, differenziert werden (DIXON \& LAMP 1990) (Abb. 52).

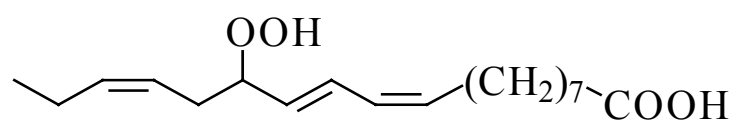

13-Hydroperoxylinolensäure
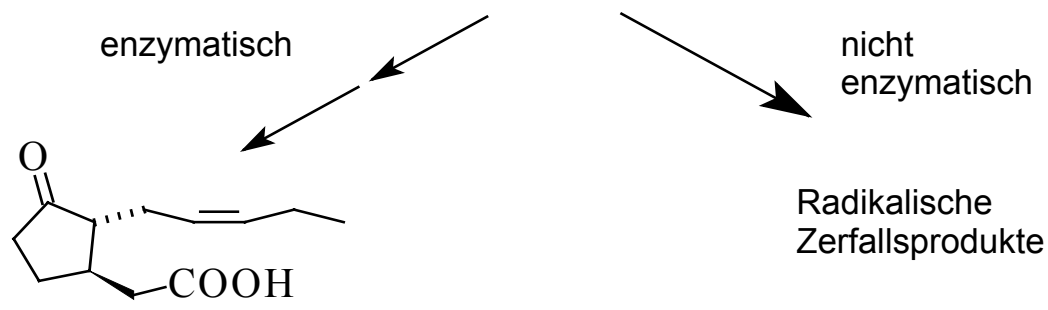

Jasmonsäure

Abb. 52: Folgeprodukte der 13-Hydroperoxylinolensäure.

Für die Schwarzerle konnte die Bildung von Jasmonsäure nach Fraßverletzung durch den Herbivoren A. alni belegt werden (Kap. 5.2.4). Somit ist es naheliegend, daß auch die Enzymaktivität des an der Biosynthese beteiligten Enzyms deutlich erhöht ist. Weiterhin können Fettsäurehydroperoxide über Hydroperoxidlyasen vermittelte Reaktionsschritte zu flüchtigen Aldehyden umgesetzt werden (HATANAKA 1993; MATSUI et al. 1999), die als Bestandteile der green leaf volatiles bekannt sind. Ein wichtiger Vertreter aus dieser Duftstoffklasse, cis-3-Hexenylacetat, wurde ebenfalls im Duftbouquet von $A$. glutinosa nach Fraßschädigung identifiziert (Abb. 38, Kap. 5.2.3.2). Fettsäurehydroperoxide fungieren auch als Substrat für Peroxidasen, so daß sie auch an der Cutinisierung beteiligt sein können (BLÈE \& SCHUBER 1993). Für die Schwarzerle könnte dies gleichermaßen zutreffen, zumal erhöhte Peroxidase-Aktitvitäten und erhöhte Phenolgehalte nach Fraßschädigung ermittelt wurden. Diese verschiedenen Bei- 
spiele demonstrieren, welche wichtige Bedeutung die Lipoxygenase-Aktivitätssteigerung bei den Erlenblättern durch Herbivorenfraß zugesprochen werden kann.

Eng verbunden mit der Aktivität von oxidativen Enzymen als Folge von Herbivorenschädigung im pflanzlichen Gewebe ist auch die Aktivität von Katalasen (BI \& FELTON 1995), die Wasserstoffperoxid in Wasser und Sauerstoff umsetzt und somit der Entgiftung der Zellen dient. Die Aktivität dieses Enzyms konnte nach Herbivorenfraß von A. alni im Blattgewebe nicht signifikant verändert werden (Abb. 29, Kap. 5.2.1.2.4), so daß eine Beteiligung von Katalase als induzierte Veränderung vorläufig ausgeschlossen werden muß.

\subsubsection{Proteinaseinhibitoraktivitäten}

Eine weitere Möglichkeit der induzierten chemischen Abwehr, die Bildung von Proteinaseinhibitoren, gegen den Herbivoren $A$. alni konnte aufgezeigt werden: In unmittelbar befressenem Gewebe vergrößerte sich die Proteinaseinhibitoraktivität um das 5,5-fache. Dabei wurde nicht nur eine direkte Induktion ermittelt, sondern auch eine systemische Induktion der PI-Aktivitäten in noch nicht geschädigten Blättern desselben Erlentriebes (Abb. 30, Kap. 5.2.1.3). Von zahlreichen Pflanzen ist bekannt, daß sie auf Fraßverletzung der Blattoberfläche mit der Biosynthese von Proteinaseinhibitoren reagieren (BROWN \& RyAN 1984; GREEN \& RYAN 1972; RYAN 1990). Die Expression der Proteine erfolgt nicht lokal nur an der Fraßstelle, sondern zeitlich versetzt auch in anderen Teilen der Pflanze, z.B. in unversehrten Blättern (RYAN 1979). Diese Inhibitoren hemmen die proteinhydrolisierenden Enzyme. Wenn das Insekt sie mit der Nahrung aufnimmt, wirken sie daher nachteilig auf seine Fähigkeit aus, das pflanzliche Protein zu nutzen, so daß sich auf diese Weise das Wachstum und die Entwicklung der Fraßschädlinge verzögern (HILDER et al. 1987; JOHNSON et al. 1989). Für die Grauerle (Alnus incana) konnte die biologische Bedeutung von Proteinaseinhibitoren deutlich gemacht werden: Auf Herbivorenfraß des Blattkäfers Galerucella lineola reagierten Grauerlenpflanzen mit der Bildung von Proteinaseinhibitoren, die sich nachhaltig auf die „Performance“ des Herbivoren auswirkten (SELDAL et al. 1994). Die Bildung von Proteinaseinhibitoren bei Fraßverletzung von A. alni im Pflanzengewebe von A. glutinosa könnte sich spezifisch gegen Fraß richten. Inwieweit Proteinaseinhibitoren wirksam bei 
der Abwehr von $A$. alni sind, ist ungeklärt, da manche Insekten Schutzmechanismen entwickelt haben. Durch diese werden die pflanzlichen Proteinaseinhibitoren unwirksam gemacht, so daß die Tiere das pflanzliche Gewebe als Nahrungsquelle nutzen können (JoNGSMA et al. 1995).

\subsubsection{Emission von Duftstoffen}

Fraß von $A$. alni führte an $A$. glutinosa-Blättern zu einer Freisetzung von zahlreichen Duftkomponenten, die von ungeschädigten Erlenblättern nicht abgegeben wurden (Kap. 5.2.3). Zu diesen emittierten Duftstoffen gehörten Ethylen, Terpene, aliphatische Verbindungen und aromatische Verbindungen (Übersicht Abb. 53). Für viele Verbindungen aus dem emittierten Duft von A. glutinosa konnten keine exakte Identifizierungen vorgenommen werden, so daß noch mehr Verbindungen emittiert werden als hier dargelegt. Die Terpene stellen aber die wichtigste Duftstoffklasse dar.

Generell fällt bei der Zuordnung der Komponenten aus dem Duftprofil von Alnus glutinosa auf, daß es sich bei einer Vielzahl der nachgewiesenen Verbindungen um Duftmoleküle handelt, die bereits von krautigen und holzigen Pflanzenspezies als Blattund Blütenduftbestandteile bekannt sind (Übersicht in AREY et al. 1991; KNUDSEN et al. 1993; TOLLSTEN \& MÜLLER 1996). Beispielsweise befinden sich unter den emittierten Duftstoffen Hexenylacetat oder Decanal, die zu den sogenannten green leaf volatiles (VISSER et al. 1979) gehören. Das Vorkommen dieser $\mathrm{C}_{6}$-Verbindungen wird als ubiquitär beschrieben (HATANAKA 1996). Sie verleihen verletztem Blattgewebe den typischen fruchtig-grünen Geruch, der sehr schnell infolge einer unspezifischen Blattschädigung eintritt (HATANAKA et al. 1987; TuRLINGS et al. 1995). Daher ist es nicht überraschend, daß auch bei der Schwarzerle infolge $A$. alni-Fraßschädigung sowie mechanischer Verletzung Hexenylacetat als Marker für Blattverletzung im Duft nachgewiesen wurde. Die Freisetzung von green leaf volatiles sowohl nach mechanischer Verletzung als auch nach Herbivorenfraß wird von zahlreichen Arbeiten belegt (DICKE et al. 1990, TURLings et al. 1990; LOUGHRin et al. 1995; MATTIACCI et al. 1995). Die Unspezifität sowie die rasche Freisetzung lassen sich auf den Biosyntheseweg dieser Verbindungen zurückführen. Wird pflanzliches Gewebe verletzt, kommt es entweder zu einer Autoxidation von Blattmembranlipiden oder zum enzymatischem Abbau von Li- 
nolsäure. Eine De-novo-Biosynthese konnte bei der Baumwolle nach Herbivorenfraß ausgeschlossen werden (PARE \& TUMLINSON 1997a). Zu weiteren, eher allgemeinen Duftstoffkomponenten dürfte auch Methylanthranilat zählen. Diese Verbindung wurde als Blüten- und Blattduft bei vielen Pflanzenspezies beschrieben (STERN et al. 1967; FUJIMORI et al. 1978; KNUDSEN et al. 1993).

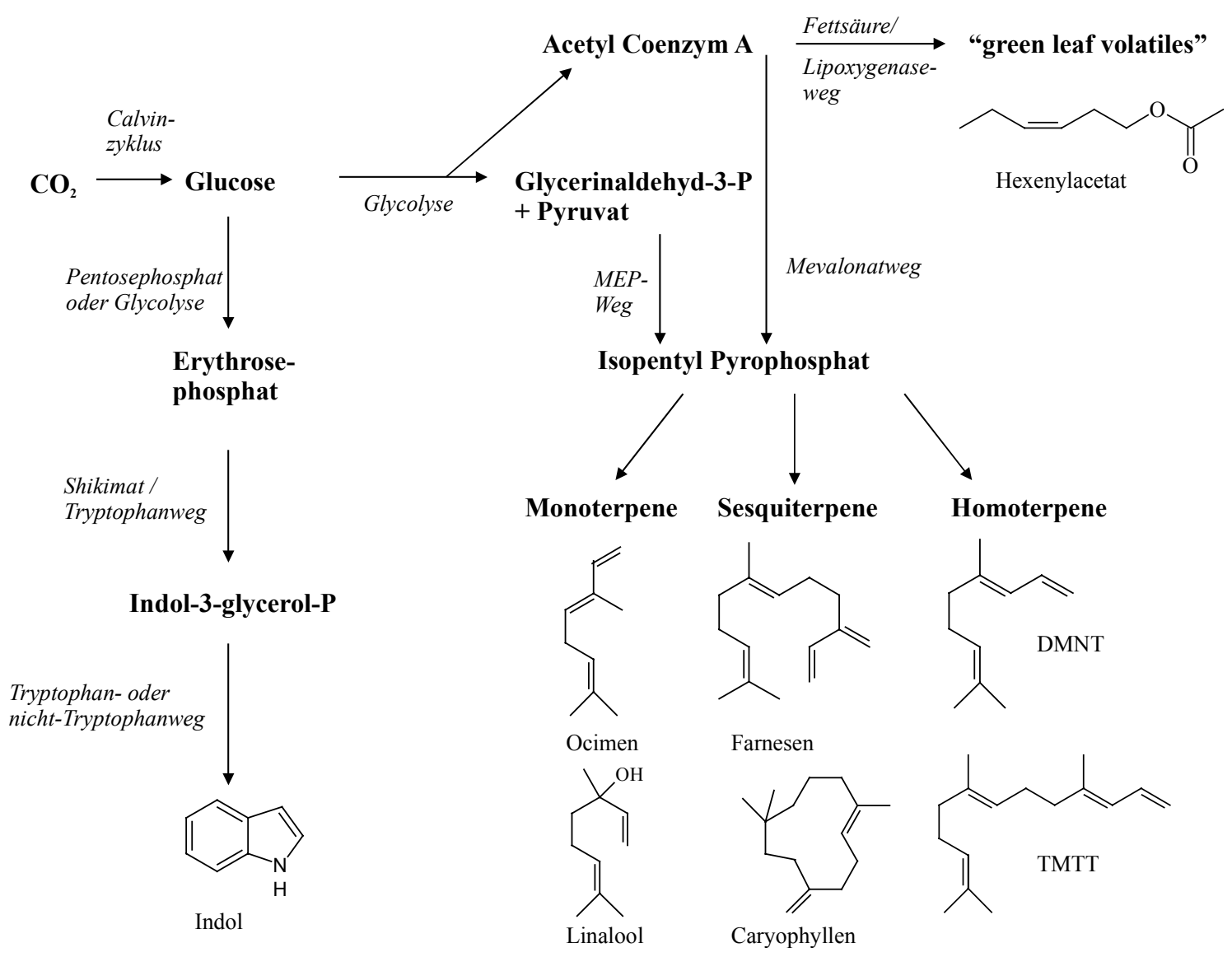

Abb. 53: Biosynthesewege zu einigen der emittierten Duftstoffe von Alnus glutinosa. MEP $=2$-CMethyl-D-erythritolphosphat.

Unter den fraßinduzierten Duftstoffen befinden sich weiterhin solche Verbindungen, die typisch für Herbivorenfraßschädigung sind. Dabei nehmen die Terpene qualitativ und quantitativ den größten Anteil ein: z.B. die Monoterpene Linalool oder Ocimen, die Sesquiterpene Caryophyllen, Farnesen oder Humulen und die beiden Homoterpene DMNT und TMTT. Auch bei anderen Pflanzen-Herbivor-Systemen konnten diese Komponenten nach einer Fraßverletzung nachgewiesen werden (TURLINGS et al. 1990; TURLINGS et al. 1992; LOUGHRIN et al. 1994, 1997; RÖESE et al. 1996). Einen besonderen Stellenwert nehmen die beiden Homoterpene DMNT und TMTT ein. Sie sind nicht 
nur als Blütenduftbestandteile bekannt (KAISER 1991; AZUMA et al. 1997), sondern auch als Marker für Herbivorenfraßschädigung (TuRLINGS et al. 1992; BOLAND et al. 1992; Dicke 1994; MCCALL et al. 1994; LOUGHRIN et al. 1997; SCUTAREANU et al. 1997). Sie werden infolge Herbivorie De-novo synthetisiert (PARE \& TUMLINSON 1997a, b). Weiterhin liegen für diese Homoterpene nähere Kenntnisse vor, über welche Regulationsmechanismen ihre Biosynthese sowie Freisetzung erfolgt (BOLAND \& GÄBLER 1989; GÄBler et al. 1991; DONATH \& BOLAND 1994; BOUWMEESTER et al. 1999; DEGENHARDT \& GERSHENZON 2000).

Die fraßinduzierte Duftemission war charakteristisch für den Herbivoren A. alni und konnte nicht durch mechanische Verletzung des Gewebes simuliert werden. Daß ein Duftprofil nach Einritzen oder Lochen von Blattgewebe nicht dem von Herbivorenfraß entspricht, bestätigen zahlreiche Arbeiten (TURLINGS et al. 1995; TAKABAYASHI \& DiCKE 1995). Nur über die Applikation von Regurgitat auf frisch verletztes Pflanzengewebe oder in Puffer gelöst, konnte ein Duftspektrum induziert werden, das dem nach Herbivorenfraß ähnelte (TURLINGS et al. 1993; MATTIACCI et al. 1995; ALBORN et al. 1997).

Eigene Untersuchungen an der Schwarzerle sowie weitere Versuche an anderen krautigen und holzigen Pflanzenarten belegen eine Beteilung von Jasmonsäure an der Duftproduktion (BOLAND et al. 1995; MEINERS \& HiLKER 2000; HopKE et al. 1994). Dabei ähnelte die Zusammensetzung nach Jasmonsäureapplikation aber nicht vollständig dem Bouquet, das nach A. alni-Fraß abgegeben wurde. Bestimmte Komponenten wie z.B. Methylsalicylat, DMNT oder TMNT, die auch nach Herbivorenfraß nachweisbar waren, konnten entweder nur in Spuren oder gar nicht nachgewiesen werden. Bestätigt wird diese Beobachtung auch von anderen Arbeiten (BOLAND et al. 1999; DiCKE et al. 1999; Gols et al. 1999). Da die Induktion der Duftproduktion, besonders die der Terpene, über die Octadecanoidkaskade vermittelt wird (HOPKE et al. 1994; BOLAND et al. 1995, 1999; KOCH et al. 1999; DiCKE et al. 1999; GOLS et al. 1999), läßt sich damit der induzierende Effekt von Jasmonsäure auf flüchtige Blattinhaltsstoffe erklären.

Der Nachweis bestimmter Komponenten im Duft von Alnus erwies sich nicht nur charakteristisch für die Art der Schädigung, sondern unterlag auch einer Rhythmik (Abb. 39, Kap. 5.2.3.2). Ein diurnaler Verlauf in der Duftabgabe ist sowohl bei Blüten (MAtile \& Altenburger 1988; LOUGHRin et al. 1991) als auch bei Blättern nach Her- 
bivorenfraß für andere Pflanzenarten wie Mais (TURLINGS et al. 1998), Wein (LoUGHRIN et al. 1997) oder Baumwolle (MCCALL et al. 1994; LOUGHRIN et al. 1994; TURLINGS et al. 1995) belegt. Der zeitliche Verlauf der Duftabgabe bei Alnus sowie die Ergebnisse der gerade zitierten Arbeiten (LOUGHRIN et al. 1994: TURLINGS et al. 1995) lassen vermuten, daß die induzierte Emission stark von der Lichtperiode kontrolliert wird. Häufig folgen physiologische Rhythmen physikalischen Rhythmen wie z.B. dem tagesrhythmischen Lichtwechsel (Übersicht SOMERS 1999; MCCLUNG 2001). Um die endogene Tagesrhythmik der Duftproduktion nach Herbivorenfraß bei Alnus zu belegen, müßte man Erlenkeimlinge, die schon als Samen unter konstanten Bedingungen mit Dauerdunkel aufgezogen wurden, mit einzelnen Lichtsignalen als „Zeitgeber“ dazu anstoßen können, die Duftkomponenten dann mit ihrer artspezifischen Periode zu emittieren. Es könnte aber auch sein, daß die beobachtete Duftrhythmik anderen Taktgebern unterliegt. Da die Produktion der Duftstoffe eng an die Photoassimilation gebunden ist z.B. konnte bei der Baumwolle über ${ }^{13} \mathrm{C}$-Fütterungsexperimente ein Einbau der markierten Vorstufen in induzierte Duftkomponenten nachgewiesen werden (PARE \& TUMLINSON 1997a, b) - ist die rhythmische Abgabe der Duftstoffe eng an den Verlauf der Photosynthese gebunden. Als weiteres Indiz an eine enge Bindung der rhythmischen Duftemission an die Photosynthese und somit auch an die Lichtintensität gibt auch der Ort der Terpenbiosynthese. Bei den Terpenen, die durch Herbivorenfraß induziert werden, scheint es so zu sein, daß die Monoterpene hauptsächlich über einen alternativen Biosyntheseweg (MEP-Weg), der unabhängig vom Mevalonat-Weg ist (ROHMER et al. 1993; LiCHTENTHALER 1999), ausschließlich in den Plastiden synthetisiert werden. Die Sesquiterpene konnten über beide Routen (Mevalonat-Weg und MEP-Weg) sowohl in den Plastiden also auch im Cytosol hergestellt werden (PIEL et al. 1998; BOLAND et al. 1999) (Abb. 53). Weiterhin wäre eine Regulation der Duftstoffabgabe bei Alnus über die Spaltöffnungsbreite der Stomata denkbar. Die Bewegungsöffnung von photoaktiven Stomata wird durch Licht induziert. Dieses wirkt vorwiegend dadurch spaltöffnend, daß es unter Einschaltung der Photosynthese den $\mathrm{CO}_{2}$-Partialdruck in den Intercellularen erniedrigt, wobei $\mathrm{CO}_{2}$ das beherrschende Regulativ der Stomata darstellt (RICHTER 1988). Genau diesen Regulationsmechanismus könnte man nutzen, um bei Alnus zu überprüfen, ob die Duftemission an den Öffnungsgrad der Stomata gebunden ist. Tagsüber, wenn der $\mathrm{CO}_{2}$-Partialdruck erniedrigt ist und die Stomata geöffnet sind, könnte 
man durch eine kurzzeitige $\mathrm{CO}_{2}$-Begasung eine gezielte Schließbewegung der Stomata einleiten. Entweder zeigt die Duftemission in diesem Moment einen starken Abfall in der Emissionsrate, was für diese Hypothese sprechen würde, oder der Emissionsverlauf bleibt unbeeinflußt, so daß eine Regulation über die Stomata unwahrscheinlich ist.

Über die Abgabe von Duftstoffen können Pflanzen sich ihrer Umwelt mitteilen und ihren physiologischen Zustand anzeigen. Werden sie von Herbivoren befallen, so emittieren sie flüchtige Komponenten als Zeichen ihres Herbivorenbefalls (Übersicht in KARBAN \& BALDWIN 1997; BALdWIN \& PRESTON 1999; VeT 1999). Diese freigesetzten flüchtigen Duftstoffe spielen eine wichtige Rolle in der tritrophischen Wechselwirkung zwischen Pflanze, Herbivor und Parasitoid oder Prädator (DickE \& SABELIS 1988; Turlings et al. 1990; TuRLings \& TUMLINSON 1992; Vet \& DiCKE 1992; DiCKE 1994; DicKe \& VAN LOON 2000). In dem von der Schwarzerle A. glutinosa sezernierten Duftbouquet nach Fraßschädigung durch den Erlenblattkäfer $A$. alni befanden sich auch Verbindungen wie DMNT, TMTT, Linalool sowie Ocimen, deren ökologische Bedeutung bei anderen Pflanzen-Herbivor-Systemen bekannt ist (PARÈ \& TUMLINSON 1997a; TAKABAYASHI \& DiCKE 1995; MATTIACCI et al. 1995). Eine ähnliche Bedeutung könnte den Terpenen auch im System Schwarzerle-Erlenblattkäfer zukommen. Als natürlich vorkommende Feinde kommen dafür sowohl Baumwanzen (Pentatomidae), Blumenwanzen (Anthocoridae) als auch Schwebfliegen (Syrphidae) in Frage (Übersicht in RANK et al. 1996; KöPF et al. 1997). Ergebnisse von DoLCH (2000) deuten aber eher darauf hin, daß die Gegenspieler ihren Beutetieren folgen und nicht gezielt von flüchtigen Synomonen angelockt werden. Die Artenzahl nahm nach der Entlaubung auf den weit entfernten Erlen zu.

Eine weitere Bedeutung kommt den Duftstoffen in der chemischen Kommunikation zwischen Pflanzen zu. Geschädigte Pflanzen können über flüchtige Verbindungen mit ihren ungeschädigten Nachbarn in Wechselwirkung treten und hier Abwehrmechanismen aktivieren, die dazu beitragen, den drohenden Herbivorenangriff abzuwehren. Auf diese Bedeutung von Duftstoffen in der Resistenzinduktion in ungeschädigten Erlenblättern wird im folgenden Kapitel näher eingegangen. 


\subsubsection{Duftinduzierte Veränderungen im Blattgewebe von Alnus glutinosa}

\subsubsection{Auswirkungen von Ethylen, Methyljasmonat, Methylsalicylat}

Um potentielle Signalstoffe in der Kommunikation der Erlen zu identifizieren, wurden wichtige Duftkomponenten, die in engem Zusammenhang mit Herbivorie stehen, über die Gasphase an Erlenblätter appliziert. Es ergaben sich die in Tab. 16 eingetragenen Veränderungen im Gewebe der Erlenblätter.

Tab. 16: Zusammenfassende Darstellung der Auswirkungen verschiedener Behandlungsweisen auf physiologische Veränderungen im Stoffwechsel von Alnus glutinosa im Labor. $\Uparrow$ : signifikante Erhöhung um das x-fache, : signifikante Reduzierung um das x-fache, $\bullet$ : gemessen, aber ohne signifikanten Effekt. Leeres Kästchen: keine Bestimmung.

\begin{tabular}{|c|c|c|c|c|c|}
\hline $\begin{array}{l}\text { Stoffwechselveränderungen von } \\
\text { A. glutinosa: }\end{array}$ & 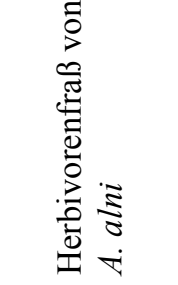 & 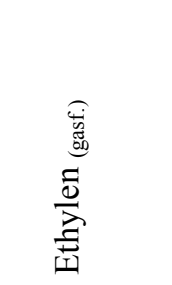 & 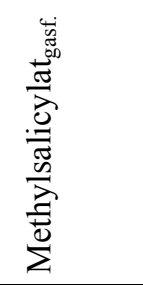 & 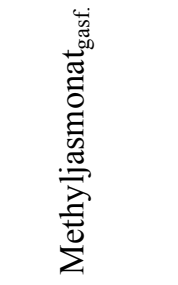 & 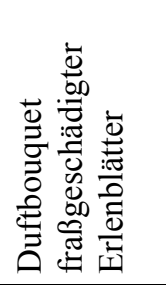 \\
\hline Phenolgehalt & $\Uparrow 2,2$-fach & $\Uparrow 2,6$-fach & $\bullet$ & $\bullet$ & $\Uparrow 1,5$-fach \\
\hline Polyphenoloxidaseaktivität & $\Uparrow 3,1$-fach & $\bullet$ & $\bullet$ & $\bullet$ & $\Uparrow 3,2$-fach \\
\hline Lipoxygenaseaktivität & $\Uparrow 2,7$-fach & $\bullet$ & $\bullet$ & $\bullet$ & $\Uparrow 2,6$-fach \\
\hline Peroxidaseaktivität & $\Uparrow 13,7$-fach & $\bullet$ & $\bullet$ & $\bullet$ & $\Uparrow 4,7$-fach \\
\hline Katalaseaktivität & $\bullet$ & $\bullet$ & $\bullet$ & $\Uparrow 2,1-$ fach & \\
\hline Aktivität von Proteinaseinhibitoren & $\Uparrow 5,5$-fach & $\Uparrow 4,3$-fach & $\bullet$ & $\Uparrow 3,7-f a c h$ & $\Uparrow 1,9$-fach \\
\hline $\begin{array}{l}\text { Konsumierte Blattmenge im } \\
\text { Fraßwahlversuch mit } A \text {. alni- } \\
\text { Larven }\end{array}$ & 4,4-fach & 2,9-fach & 2,3-fach & 2,0 -fach & 2,1-fach \\
\hline
\end{tabular}

Für Ethylen konnte eine induzierende Wirkung auf den Stoffwechsel der Erle mit Veränderungen im Phenolgehalt (Abb. 25, Kap. 5.2.1.1) sowie eine Aktivitätssteigerung von Proteinaseinhibitoren (Abb. 30, Kap. 5.2.1.3) nachgewiesen werden. Diese läßt sich damit erklären, daß Ethylen für die Initiation der Jasmonsäure-vermittelten Wundantwort essentiell ist, infolge der es zu einer verstärkten Expression von Proteinaseinhibitoren kommen kann (PENA CORTES et al. 1988). Das flüchtige Derivat der Jasmonsäure, Methyljasmonat, scheint bei der Schwarzerle auch eine wichtige Rolle einzunehmen, 
denn es induzierte die Katalase-Aktivität und die Proteinaseinhibitoraktivitäten (Abb. 30, Kap. 5.2.1.3). Der induzierende Effekt auf diese Form der pflanzlichen Abwehrreaktionen wurde auch schon von FARMER \& RYAN (1990) beobachtet. Weitere induzierende Wirkungen des Methyljasmonats z.B. auf die Enzymaktivitäten konnten nicht festgestellt werden. Dies war überraschend, denn in anderen Pflanzensystemen konnte dieser Verbindung eine Schlüsselrolle bei der induzierten Abwehr zugesprochen werden, in dem es u.a. die Induktion der Polyphenoloxidase-Aktivität vermittelte (CONSTABEL \& RYAN 1998; CONSTABEL et al. 2000). Weiterhin wurde eine Induktion über den Duft geschädigter Pflanzen, bei dem MeJA die Hauptkomponente darstellte, auf die PPO-Aktivität in ungeschädigten Pflanzen von KARBAN et al. (2000) beschrieben.

Für die Substanz Methylsalicylat kann eine vorläufige Funktion als Signalstoff für die Erle ausgeschlossen werden, denn die Verbindung induzierte weder Veränderungen bei den Phenolen noch bei den Enzymen und Proteinaseinhibitoren (Tab. 16). Methylsalicylat ist zwar als Signalsubstanz zwischen Nicotiana-Pflanzen, die mit dem Tobacco mosaic virus inokuliert worden waren, und befallsfreien Pflanzen, bei denen es eine SAR ausgelöst hatte (SHULAEV et al. 1997), beschrieben, aber eventuell kommt MeSA eher eine Signalfunktion in der Pathogenabwehr als in der Herbivorenabwehr zu. Folglich könnte über die Duftsignale Ethylen und Methyljasmonat ein Signaltransfer zwischen geschädigter und benachbarter, gesunder Erle stattfinden, der in der unbefallenen Pflanze physiologische Veränderungen bewirkt und somit für die Ausbildung einer Resistenz verantwortlich sein könnte. Die Beteiligung von Methyljasmonat an dem Signaltransfer muß dabei aber sehr kritisch angesehen werden, weil dieses Molekül nicht zu den fraßinduzierten Duftstoffen gehörte und auch nicht von Erlenpflanzen nach exogener Jasmonsäureapplikation emittiert wurde. Andererseits konnte belegt werden, daß Jasmonsäure als Signalsubstanz an der endogenen Signalkaskade der Abwehrreaktionen bei der Erle beteiligt ist. Somit könnte Methyljasmonat als flüchtiger Signaltransducer über den Gasraum die Abwehrreaktion bei gesunden Pflanzen induzieren. 


\subsubsection{Auswirkungen fraßinduzierter Duftstoffe}

Unter kontrollierten Bedingungen im Labor wurde dem Mechanismus des Signaltransfers über die Gasphase und der induzierten Veränderungen detaillierter nachgegangen. Die „Containerversuche“, bei denen ungeschädigte Erlenblätter unter dem Einfluß fraßinduzierter Duftstoffe standen, ergaben Veränderungen sowohl in den Phenolen als auch in der Aktivität der oxidativen Enzyme und Proteinaseinhibitoren in benachbarten, ungeschädigten Pflanzen (Tab. 16). Die Induktion der ermittelten physiologischen Veränderungen kann dabei nur über gasförmige Stoffe erfolgt sein, denn für den Signaltransfer zwischen induzierten Blättern und benachbarten, unbehandelten Blättern kommt nur der Luftraum in Frage. Die Erlentriebe standen jeweils einzeln in Schnappdeckelgläschen, so daß kein Kontakt untereinander über die Inkubationslösung gegeben war. Weiterhin waren die Erlentriebe so positioniert, daß ein Kontakt untereinander über die Blattflächen nicht möglich war. Ferner wurde durch einen Gazekäfig, der die befressenen Erlenblättern mit den $A$. alni-Larven umschloß, verhindert, daß die Larven zu den benachbarten Erlentrieben wandern konnten. Es kann zwar nicht ausgeschlossen werden, daß es in den Containern zu einer geringfügigen $\mathrm{CO}_{2}$-Anreicherung durch die Respiration $\operatorname{der} A$. alni-Larven gekommen ist, die die PI-Aktivität beeinflußt hat, aber Versuche an Eucalyptus-Blättern belegen, daß hohe $\mathrm{CO}_{2}$-Konzentrationen erforderlich sind, um den Metabolismus signifikant zu beeinflussen (LAWLER et al. 1997; MCDONALD et al. 1999). Die „Containerexperimente“ bestätigen den im „JA-Versuch“ aufgezeigten Hinweis des intraspezifischen Signaltransfers über den Gasraum zwischen Erlenpflanzen.

Betrachtet man den zeitlichen Verlauf der induzierten Veränderungen in den benachbarten, ungeschädigten Blättern, so scheint eine Aktivierung der Abwehrmechanismen hier nicht sofort zu erfolgen. Die erhöhte Synthese von Phenolen in den benachbarten, ungeschädigten Blättern trat relativ spät ein (Abb. 33, Kap. 5.2.2.1). Erst nach 72 Stunden zeigten die Erlenblätter induzierte Veränderungen an, durch die sie für die fressenden Insekten ungenießbar werden sollten. Im Freiland ergaben sich nach fünf Tagen signifikante Unterschiede im Phenolgehalt der Erlen der verschiedenen Baumpositionen, wobei nach zwölf Tagen die größten Unterschiede ermittelt wurden. Anscheinend gehören Veränderungen im Phenolmetabolismus zu den pflanzlichen Antworten der Erle, die nicht innerhalb von wenigen Stunden, sondern erst nach einigen Tagen erreicht 
werden. Zu den schnell induzierbaren Abwehrmechanismen dürften eher Veränderungen bei den oxidativen Enzymen und Proteinaseinhibitoren zählen. Bereits nach 48 Stunden wurden gravierende Aktivitätssteigerungen im Gewebe von Blättern benachbarter, ungeschädigter Erlentriebe ermittelt. Eine Induktion der oxidativen Enzyme durch fraßinduzierte Duftstoffe erscheint überraschend, denn über die Inkubation mit den einzelnen Duftkomponenten Ethylen, Methylsalicylat und Methyljasmonat konnte dieser Effekt nicht erzielt werden. Zur Erklärung gibt es folgende Möglichkeiten:

a) Die in den Inkubationsversuchen eingesetzten Konzentrationen lagen für Enzyminduktion nicht im physiologischen Bereich, so daß die Blätter nicht reagierten.

b) Die Komponenten wirken nicht auf den pflanzlichen Stoffwechsel, wenn sie einzeln appliziert werden, sondern nur dann, wenn sie im Gemisch angeboten werden.

c) In dem fraßinduzierten Duftstoffspektrum sind zusätzliche Signalstoffe enthalten, die eine induzierende Wirkung auf den Metabolismus der Pflanze haben.

Die Inkubationsversuche mit weiteren flüchtigen Komponenten bestätigen diese Möglichkeit der Abwehrinduktion in ungeschädigten Erlenblättern. Aus dem fraßinduziertem Duftstoffspektrum der Erle zeigten einige Komponenten einen positiven Effekt auf die Aktivität der Proteinaseinhibitoren. Dazu gehörten cis-Jasmon, Ocimen, DMNT und TMTT. Die übrigen Verbindungen zeigten keinen Einfluß auf die Proteinaseinhibitoraktivitäten. Die physiologisch nicht wirksamen Eigenschaften der Moleküle Methylanthranilat, Linalool und Caryophyllen in der Aktivierung von Proteinaseinhibitoren können damit erklärt werden, daß sie eher zu allgemeinen Blüten- und Duftbestandteilen (STERN et al. 1967; FUJIMORI et al. 1978; KNUDSEN et al. 1993) zählen und aufgrund ihrer Biosynthese oder Struktur in keiner engen Verwandtschaft zu Phytohormonen oder anderen Signalstoffen stehen. Beispielsweise ist Methylanthranilat ein flüchtiges Derivat von Anthranilat, das als Intermediat während der Tryptophanbiosynthese fungiert (RÖMPP 1997). Cis-3-Hexenylacetat zeigte auch keinen nachteiligen Effekt auf die Proteinaseinhibitoraktivitäten. Dies erscheint etwas überraschend, denn einige Vertreter der green leaf volatiles wurden als Signalsubstanzen beschrieben, die in der Lage sind, unbefallene Pflanzen vor nachfolgendem Pathogenbefall zu schützen (BATE \& RothSTEIN 1998; Zeringue 1992; HAMILTON-KeMP et al. 1992; Croft et al. 1993). Eine Funktion als Signalsubstanz zwischen herbivorgeschädigten und ungeschädigten Erlenpflanzen kann für cis-3-Hexenylacetat deshalb nicht bestätigt werden. Cis- 
Jasmon steigerte die Aktivität der Proteinaseinhibitoren um den Faktor 14,1-fach und zeigte damit den größten Einfluß. Dieser Effekt läßt sich vermutlich damit erklären, daß cis-Jasmon ein flüchtiger Metabolit von Jasmonsäure ist (KOCH et al. 1997), deren Genexpressionswirkung auf PI-Gene bekannt ist. Das Monoterpen Ocimen wie auch die beiden Homoterpene DMNT und TMTT konnten etwas gleich stark die Aktivitäten der Proteinaseinhibitoren vergrößern, wobei der Effekt vom TMTT etwas schwächer war. Eine Abwehrinduktion in ungeschädigten Erlenblättern kann also nicht nur über die bislang bekannten Signalstoffe Ethylen und Methyljasmonat vermittelt werden, sondern durchaus auch über terpenoide Verbindungen wie Ocimen, DMNT und TMTT. Mit den von ARIMURA et al. (2000) durchgeführten Versuchen an der Limabohne konnte gezeigt werden, daß in unbefallenen Pflanzen, die im Windstrom von durch Spinnmilben befallenen Pflanzen standen, die Expression von fünf verteidigungsspezifischen Genen aktiviert wurde. Durch weiterführende Versuche mit einzelnen, synthetischen Verbindungen aus diesem emittierten Duftstoffgemisch der fraßinduzierten Bohnenpflanzen, konnte für die Komponenten DMNT, TMTT und Ocimen eine induzierende Wirkung auf die Expression von PR-Genen nachgewiesen werden (ARIMURA et al. 2000). Diese Stoffe waren wahrscheinlich für den Pflanze-Pflanze-Signaltranfer verantwortlich, dessen Effekt schon 1992 von BRUIN et al. (1992) beschrieben worden war: Bohnenpflanzen, die den Duftstoffen Spinnmilben-infizierter Artgenossen ausgesetzt waren, zeigten sich geschützt gegen nachfolgenden Spinnmilbenbefall. Somit könnten sowohl die beiden Homoterpene als auch das Monoterpen an dem Signaltransfer zwischen einer geschädigten und einer ungeschädigten Erle beteiligt sein.

Die Ergebnisse der Inkubations- und Containerversuche machen auch deutlich, daß die intraspezifische Signaltransduktion zwischen geschädigten und ungeschädigten Erlenpflanzen nicht durch einzelne Substanzen, sondern durch ein Gemisch zahlreicher flüchtiger Substanzen erfolgt, dessen aktive Komponenten noch nicht vollständig identifiziert sind. Vorstellbar wäre beispielsweise, daß die Hauptkomponente Ethylen zwar aktiv ist, aber es bedarf zusätzlich in Spurenkonzentrationen vorhandene Nebenkomponenten (wie Ocimen, DMNT oder TMTT), um die volle Wirksamkeit des Signals zu erreichen. 
Für die Untersuchung des Signaltransfers zwischen Pflanzen ist es nicht nur interessant, welche Komponenten von geschädigten Pflanzen abgegeben werden und welche physiologischen Veränderungen sie in ungeschädigten Pflanzen induzieren, sondern auch, wie sie von der ungeschädigten Pflanze wahrgenommen werden. Denkbar wären für die Duftsignale zwei verschiedene Erkennungsmechanismen, durch die es zu physiologischen Veränderungen im pflanzlichen Stoffwechsel kommen könnte:

a) Die Duftsignale wirken direkt über eine unmittelbare Wechselwirkung mit der Blattoberfläche. Eventuell könnte man diese Signale einer intraspezifischen Verständigung dann auch als „Phytopheromone“ bezeichnen, wenn sie folgendermaßen definiert werden: Signale, die von Pflanzen als Geruchsstoffe abgegeben werden und bei Artgenossen spezifische physiologische Prozesse regulieren.

b) Die Duftsignale könnten auch indirekt wahrgenommen werden. Beispielsweise wäre eine Adsorption über die Blattoberfläche möglich, infolge derer sie in das pflanzliche Gewebe übergehen und sich von hier aus über das Gefäßsystem über die ganze Pflanze verteilen. Denkbar wäre diese Möglichkeit für Verbindungen wie Methyljasmonat oder Methylsalicylat, da ihre Hydrolyse im wäßrigen Milieu zu den entsprechenden Säuren Jasmon- bzw. Salicylsäure möglich wäre. Für andere Verbindungen, wie z.B. cis-Jasmon oder Terpene, wäre dieser Mechanismus undenkbar, so daß dann die erste Möglichkeit wahrscheinlicher ist.

In Zusammenarbeit mit Prof. Dr. Massimo Maffei von der Universität Turin wurden erste experimentelle Ansätze zu dieser Erkennungsmöglichkeit an der Erle durchgeführt. Eine einzelne Zelle aus dem Blattparenchym wurde mit einer Elektrode angestochen, und die resultierenden Transmembranveränderungen wurden nach Zugabe verschiedener Testlösungen, die das Gewebe umspülten, gemessen (Abb. 54). In diesen Testlösungen wurden einzelne Duftstoffe aus dem induzierten Duftstoffspektrum gelöst, z.B. Ocimen, und ihre Wirkung auf die pflanzliche Membran getestet. Für die Erlenblattzellen konnte ein Ruhepotential von $-52 \mathrm{mV}$ ermittelt werden. Erreichte die gelöste terpenoide Substanz Ocimen (100 ppm) den Zellverband, so veränderte sich schlagartig das Membranpotential auf $-138 \mathrm{mV}$. Das heißt, daß nur über die Wechselwirkung zwischen Molekül und Membran können charakteristische Veränderungen hervorgerufen werden. Die Moleküle scheinen dabei nicht in den hydrophoben Bereich der Membran einzudringen, weil nach dem Waschen mit Pufferlösung das Membranpoten- 
tial der Ausgangssituation erreicht wurde. Ähnliche membranverändernde Eigenschaften werden von GRIFFIN et al. (2000) beschrieben.

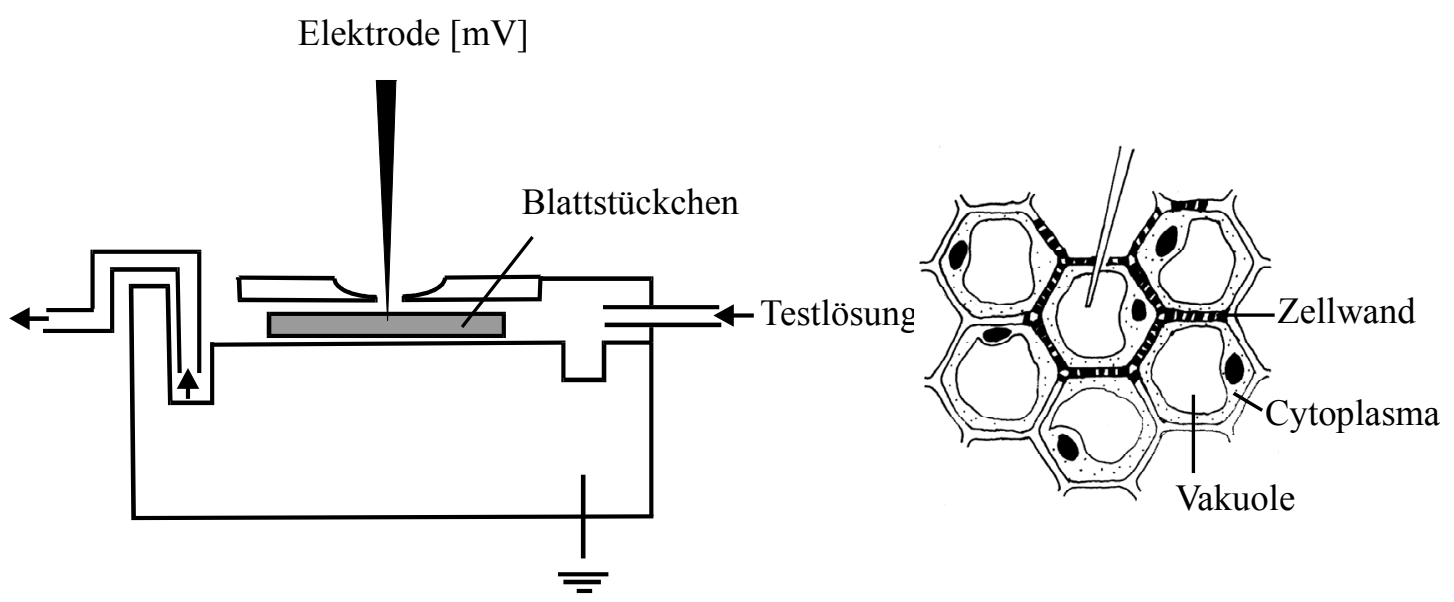

Abb. 54: Schematische Darstellung des Versuchsaufbaus zur Messung von Membranpotentialen an Blattparenchymzellen.

Durch diese Wechselwirkung der Duftmoleküle mit der Membran kann es zu veränderten Ionenflüssen und somit zu Membranpotential-Veränderungen kommen, von denen bekannt ist, daß sie als Signalweg an der Signaltransduktion bei der pflanzlichen Abwehr wirken (WhITE 2000; BLUME et al. 2000). Diese experimentellen Ansätze können für zukünftige Experimente zur Untersuchungen eines Signaltransfers zwischen Pflanzen eine interessante Grundlage darstellen. 


\subsubsection{Auswirkungen induzierter Veränderungen auf den Herbivoren Agelastica alni}

Pflanzen von A. glutinosa reagierten auf Herbivorenfraß sowie auf flüchtige Signale wie Ethylen, Methyljasmonat, ß-Ocimen, 4,8-Dimethylnona-1,3,7-trien, 4,8,12-Trimethyltrideca-1,3,7,11-tetraen, fraßinduzierte Duftstoffe aber auch auf Signalsubstanzen wie Jasmon- oder Salicylsäure mit unterschiedlichen Formen physiologischer Veränderungen. Begleitend zu den chemischen und physikalischen Analysen wurden mit Fraßwahlversuchen die Auswirkungen der simulierten Herbivorie bzw. induzierter Blattveränderungen auf die Herbivoren A. alni bestimmt.

Das Verhalten phytophager Insekten wird durch zahlreiche Faktoren gesteuert: primäre Pflanzeninhaltsstoffe (MCNeILL \& SouthWOOD 1978; MATTSON 1980; SCRIBER \& Slansky 1981; DenNo 1983), Blattwassergehalt (SCRIBER \& FEENy 1979; Fowler 1983), Blattfestigkeit (FEeny 1970; COLEY 1983; RAupP 1985), Trichome (BAUR et al. 1991) oder sekundäre Pflanzeninhaltsstoffe wie Phenole, Proteinaseinhibitoren. Diese Parameter können jeweils einzeln, aber auch additiv zusammenwirken. Welche Bedeutung den einzelnen Parametern bei der Nahrungspräferenz zukommt, variiert vermutlich von Insekt zu Insekt.

\section{Chemische Blatteigenschaften}

Da keine Hinweise auf indirekte Veränderungen im Blattwassergehalt oder im spezifischen Blattgewicht ermittelt wurden (Abb. 24, Kap. 5.1.3.3), können somit auch keine Aussagen darüber getroffen werden, ob sie die Nahrungspräferenz des Erlenblattkäfers beeinflussen. Der steuernde Faktor für das Fraßverhalten von A. alni dürften daher sekundäre Pflanzeninhaltsstoffe sein. So lagen die Gehalte der Blattphenole bei den Baumnachbarn höher als bei den Kontrollpflanzen des „JA-Versuchs“, so daß sie das Fraßverhalten der Herbivoren beeinflußt haben (Abb. 24, Kap. 5.1.3). Zusätzlich bestätigen die Ergebnisse der Containerversuche (Kap. 5.2.2), daß unter dem Einfluß fraßgeschädigter Erlen sich die Phenolgehalte, die Aktivitäten der oxidativen Enzyme und die der Proteinaseinhibitoren in ungeschädigten, benachbarten Erlen signifikant erhöhten.

Diese physiologische Zusammensetzung der Erlenblätter wirkte sich so nachhaltig auf 
die Larven von $A$. alni aus, daß sie von den behandelten Blättern deutlich weniger Blattmasse fraßen.

Sowohl Jasmon- als auch Salicylsäure und ebenso die flüchtigen Duftstoffe Ethylen, Methyljasmonat und Methylsalicylat veränderten die direkte Zusammensetzung der Erlenblätter so, daß die Larven von $A$. alni von den behandelten Blättern deutlich weniger Blattmasse fraßen. Betrachtet man die physiologischen Veränderungen (Tab. 16), die nach unterschiedlichen Inkubationsvarianten ermittelt wurden, mit den Ergebnissen der Fraßwahlversuche, so spiegelt sich die erhöhte Anreicherung sekundärer Pflanzeninhaltsstoffe auch in dem Fraßverhalten von $A$. alni wider: Larven von $A$. alni konsumierten deutlich weniger Blattmasse von den Blättern, die sich durch hohe Phenolgehalte, erhöhte Aktivität oxidativer Enzyme und Proteinaseinhibitoren auszeichneten. Durch die Produktion dieser Vielzahl von Sekundärmetaboliten kann die Schwarzerle somit einen wirkungsvollen Schutz gegen Fraß von $A$. alni aufbauen. Welche einzelnen Komponenten der induzierten Verbindungen letztendlich das Fraßverhalten der Larven beeinflußt haben, konnte in diesem Rahmen nicht näher untersucht werden. Denkbar ist aber, daß die Mischung aus Blattphenolen, oxidativen Enzymen und Proteinaseinhibitoren additiv wirken. 


\subsubsection{Bedeutung der Pflanze-Pflanze-Kommunikation für das System Schwarzerle-Blauer Erlenblattkäfer}

Die Erkenntnisse zur Beschreibung der Pflanze-Pflanze-Kommunikation für das System Schwarzerle-Blauer Erlenblattkäfer werden in der Abb. 55 zusammengefaßt.
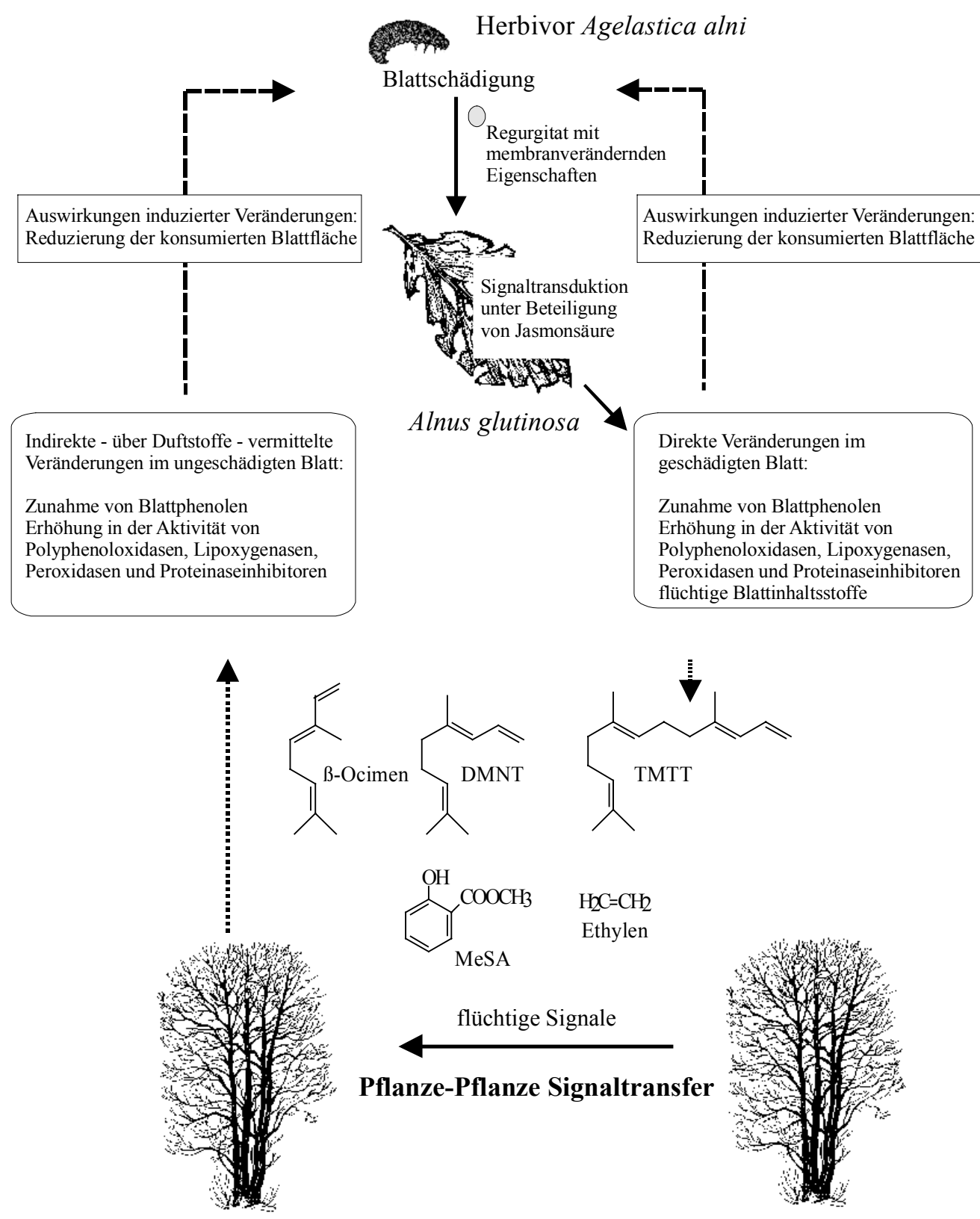

Abb. 55: Schematische Darstellung der durch chemische Signale induzierten Veränderungen sowie zum Signaltransfer zwischen Erlenpflanzen. 
Nach Herbivorenfraß von A. alni emittieren die Schwarzerlen flüchtige Duftstoffe insbesondere Ethylen, Methylsalicylat (MeSA), 4,8-Dimethylnona-1,3,7-trien (DMNT), 4,8,12-Trimethyltrideca-1,3,7,11-tetraen (TMTT) und $\beta$-Ocimen, die als flüchtige Signalstoffe für die Resistenzinduktion in ungeschädigten Pflanzen in Frage kommen. Regurgitat von $A$. alni-Larven zeigt membranverändernde Eigenschaften, so daß vermutlich herbivoreneigene Elicitoren für die Induktion der Abwehr erforderlich sind. Die Signaltransduktion erfolgt über den octadecanoiden Signalstoff Jasmonsäure. Erlenpflanzen reagierten auf Herbivorenfraß mit der Biosynthese von Phenolen und einer Veränderung in der Aktivität von Polyphenoloxidasen, Lipoxygenasen, Peroxidasen und Proteinaseinhibitoren. Diese Verbindungen haben eine bedeutende Rolle als pflanzliche Verteidigungsstrategie gegen den Herbivoren A. alni, da Erlenblätter, die sich durch einen erhöhten Phenolgehalt sowie eine erhöhte Aktivität oxidativer Enzyme und Proteinaseinhibitoren auszeichneten, deutlich weniger befressen wurden als nicht verändertes Erlenblattmaterial. Induzierte Veränderungen bestimmen nicht nur die räumliche und zeitliche Verteilung der Insekten auf der Wirtspflanze (FEENY 1970; RHOADES 1983) sowie das Ausmaß der Blattschädigung (RAUSHER 1981; RAUPP 1985), sondern sie wirken sich auch auf das Überleben, Wachstum und die Entwicklung der Fressenden aus. So können einem Herbivorenangriff ausgesetzte Schwarzerlen nicht nur sich selbst, sondern durch Kommunikation bei ihren benachbarten Artgenossen über die Ausbildung von Resistenzen eine Unattraktivität gegenüber Herbivoren erzielen und gewissermaßen so einen Puffergürtel unattraktiv gewordener Bäume bilden, der sie gegenüber nachfolgenden Herbivoren „,maskierten“. 


\subsubsection{Schlußbemerkung}

Bereits einige Autoren fanden Hinweise für eine Kommunikation unter Pflanzen, doch die Mechanismen bzw. welche Stoffe an dem Signaltransfer beteiligt waren, blieben bei den ersten Freilandarbeiten unentdeckt (RHOADES 1983, 1985; BALDWIN \& SCHULTZ 1983). Weiterhin gab es experimentelle Ansätze im Labor, die die Kommunikation wahrscheinlich machten. Doch sie zeichneten sich entweder dadurch aus, daß es reine „Begasungsversuche“ mit einzelnen Duftsubstanzen (vorwiegend Methyljasmonat) waren oder daß der interspezifische Signaltransfer zwischen zwei verschiedenen Pflanzenarten in gasdichten Inkubationsgefäßen untersucht wurde. Dabei wurden Artemisia als Senderpflanze und Lysopersicon als Empfängerpflanze eingesetzt (FARMER \& RYAN 1990; FARMER et al. 1998; MCCONN et al. 1997). Dieses Versuchsdesign ist weit von natürlichen Bedingungen entfernt und daher ökologisch wenig relevant, da beispielsweise Artemisia und Lysopersicon nicht am selben Standort wachsen. Versuche im Freiland unter Berücksichtigung des Signaltransfermechanismus und des potentiellen Signalüberträgerstoffes liegen von KARBAN et al. (2000) vor. Die Untersuchungen zielen auf einen interspezifischen Signaltransfer zwischen Artemisia als Senderpflanze und Nicotiana als Empfängerpflanze. Bei der Auswahl der Pflanzen wurde berücksichtigt, daß beide Pflanzenarten am selben Standort wuchsen und somit eine Wechselwirkung auch unter natürlichen Bedingungen gegeben war.

Die Besonderheit der vorliegenden Untersuchungen an A. glutinosa ist, daß der intraspezifische Signaltransfer zwischen Schwarzerlen im Freiland unter natürlichen Bedingungen gezeigt werden konnte und daß modellhafte Containerversuche im Labor den Effekt sanktionierten. Die chemischen Analysen belegen zusätzlich, daß induzierte Veränderungen bei den benachbarten, unverletzten Erlenblättern vorkommen. Es konnten der Mechanismus und die beteiligten Signalsubstanzen näher charakterisiert werden. Auch wenn die Übertragbarkeit von Laborversuchen auf das Freiland ein Problem ist (Verwendung von abgeschnittenen Erlentrieben und Glascontainern), stellen sie eine notwendige Ergänzung zum Freilandversuch dar. Unter natürlichen Bedingungen können viele Faktoren die Pflanze-Pflanze-Beziehung beeinflussen, so daß es schwierig wird, die genauen Mechanismen zu identifizieren. Dies kann nur über Laborversuche unter kontrollierten Bedingungen erreicht werden. Ein zukunftsorientierter 
experimenteller Ansatz zur weiteren Untersuchung des Signaltransfers unter Erlenpflanzen im Freiland könnte über molekularbiologische Arbeiten erfolgen, zumal erste Ergebnisse zur Genexpression bei gestreßten Pflanzen zeigen, mit welchen Veränderungen bei fraßinduzierten Duftstoffen zu rechnen ist (ARIMURA et al. 2000). Die in Laborversuchen etablierten molekularbiologischen Methoden müßten im nächsten Schritt auch im Freiland angewandt werden, um die Resultate zur Existenz von Kommunikation zwischen den Schwarzerlen zu manifestieren. 


\section{$7 \quad$ Zusammenfassung}

In dieser Arbeit wurde die Hypothese getestet, ob es eine chemische Kommunikation zwischen Pflanzen geben kann. Danach sollen geschädigte Pflanzen über flüchtige Signalstoffe Abwehrreaktionen in ungeschädigten Nachbarpflanzen induzieren und damit nicht nur sich, sondern auch ihre benachbarten Artgenossen vor nachfolgendem Fraß schützen. Diesem Signaltransfer wurde bei der Schwarzerle (Alnus glutinosa) und dem Blauen Erlenblattkäfer (Agelastica alni) als Schadinsekt nachgegangen. Die Untersuchungen gliederten sich in folgende Bereiche: (I.) Direkte Auswirkungen von Herbivorenfraß und Elicitierung auf die Physiologie von A. glutinosa sowie die Beteiligung endogener Phytohormone an der pflanzlichen Abwehr. (II.) Untersuchung einer Resistenzinduktion von ungeschädigten Bäumen in der Nachbarschaft geschädigter Bäume. (III.) Duftinduzierte Veränderungen im Blattgewebe von $A$. glutinosa.

I. Es wird die Induktion von Abwehrmechanismen bei der Schwarzerle infolge des Befalls durch den Herbivoren A. alni beschrieben. In Freiland- und Laborversuchen wurden spezifische Blattveränderungen anhand physiologischer Parameter (Phenolgehalt, Enzymaktivitäten von Polyphenoloxidase, Peroxidase, Lipoxygenase und Katalase, Proteinaseinhibitoraktivität) festgestellt, die ihre Qualität als Nahrung für den Herbivoren reduzieren und die daher im Zusammenhang mit der pflanzlichen Abwehr stehen sollten.

- Fraß von A. alni vermehrte den Blattphenolgehalt und steigerte die Aktivität von oxidativen Enzymen (Polyphenoloxidase, Lipoxygenase, Peroxidase) und Proteinaseinhibitoren.

- In Fraßwahlversuchen konsumierten die Larven von $A$. alni deutlich weniger Blattmasse von induzierten Erlenblättern als von nicht induzierten Blättern, da sich erstere durch hohe Phenolgehalte und erhöhte Aktivitäten von Polyphenoloxidasen, Lipoxygenasen, Peroxidasen, Katalasen und Proteinaseinhibitoren auszeichneten. Diese induzierten Blatteigenschaften sollten zu wirkungsvollen Mechanismen pflanzlicher Abwehr bei der Schwarzerle zählen. 
- Natürlicher Herbivorenfraß konnte durch Regurgitatapplikation auf mechanisch verletztes Erlenblattgewebe imitiert werden, wodurch sich der Blattphenolgehalt und die Polyphenoloxidase-Aktivität erhöhten. Mechanische Verletzung allein erwies sich für die Induktion der beschriebenen Reaktionen als unzureichend.

- Das Regurgitat der $A$. alni-Larven wurde mittels LC-MS untersucht, wobei $N$ Acylaminosäurekonjugate wie Volicitin nicht nachgewiesen werden konnte, denen eine duftinduzierende Wirkung bei anderen Pflanzen (z.B. Zea mays) zugesprochen wird. Allerdings ergaben elektrophysiologische Untersuchungen an einer künstlichen Bilayermembran Hinweise auf Inhaltsstoffe mit porenbildenden Eigenschaften, die möglicherweise für die Induktion der Abwehr bei befressenen Blättern verantwortlich sind.

- Fraß von $A$. alni induzierte die Freisetzung von Duftstoffen an geschädigten Erlenblättern. Dabei konnte mittels photoakustischer Spektroskopie Ethylen quantifiziert werden. Zu weiteren, flüchtigen Verbindungen, die mittels Closed Loop Stripping-Analyse angereichert und per GC-MS bestimmt wurden, zählten Terpene, aromatische und aliphatische Substanzen. Die Art der Schädigung war charakteristisch für die Zusammensetzung des Duftspektrums. Die Emission der fraßinduzierten flüchtigen Sekundärmetaboliten erwies sich als zeitabhängig und unterlag einer circadianen Rhythmik mit Emissionsmaxima am Tag, die von der Photoperiode kontrolliert wurde.

Weiterhin wurde die chemische Signalkette, die an der pflanzlichen Abwehr vermittelt, analysiert.

- Herbivorenfraß von A. alni führte zu einer deutlichen aber transienten Induktion der endogenen Jasmonsäurebiosynthese im befressenen Blattgewebe. Demnach ist Jasmonsäure an der pflanzlichen Abwehr gegenüber Herbivorie beteiligt. Weiterhin übte exogen applizierte Jasmonsäure einen induzierenden Effekt auf den Phenolgehalt; Enzymaktivitäten von Polyphenoloxidase, Peroxidase und Lipoxygenase; Proteinaseinhibitoraktivitäten sowie auf die Produktion flüchtiger Blattinhaltsstoffe aus.

II. Der Resistenzinduktion ungeschädigter Nachbarn von geschädigten Bäumen, die ausschließlich über den Luftbereich mittels Duftstoffen vermittelt werden könnte, wurde in dem „Topfversuch“ (mit getopften Erlenpflanzen) nachgegangen. Einer 
alternativen Resistenzinduktion ungeschädigter Nachbarpflanzen, die auch über den Boden-Wurzelbereich vermittelt werden könnte, erfolgte an natürlichen Erlenbeständen im „Reihenversuch“. Starke Herbivorie wurde durch mechanische Blattverletzung simuliert. Bei beiden Versuchen traten bei den ungeschädigten Nachbar-Erlenbäumen keine Veränderungen in den Parametern Blattwassergehalt, spezifisches Blattgewicht, Blattfestigkeit, quantitativer Blattphenolgehalt auf. Darüber hinaus ergaben die Blattschädigung an den Freilandbäumen als auch die Fraßwahlversuche keine Hinweise auf eine Fraßpräferenz für nichtinduziertes Blattmaterial.

Weiterhin wurde Herbivorenfraß in einem Freilandexperiment durch exogene Applikation von Jasmonsäure simuliert (,JA-Versuch“), weil im Laborversuch die elicitierende Wirkung von Jasmonsäure belegt worden war.

Die JA-Behandlung einer mittig angeordneten Erlenpflanze führte bei den benachbarten Bäumen zu einer signifikanten Zunahme im Phenolgehalt der Blätter. Das spezifische Blattgewicht und die Blattfestigkeit blieben unverändert. Ferner zeigte sich im Freiland eine verminderte Blattschädigung an den benachbarten Bäume. Auch im Biotest wiesen die Herbivoren für induzierte Blätter eine deutlich geringere Fraßpräferenz als für nicht induzierte Blätter auf. Somit dürfte die exogene Jasmonsäureapplikation in den behandelten Erlen eine direkte Abwehr induziert haben, in deren Folge flüchtige Signale freigesetzt wurden. Da die Erlenpflanzen im „JA-Versuch“ miteinander nicht über den Wurzelraum in Verbindung standen, muß der Signaltransfer über den Luftraum stattgefunden haben.

III. Die Laborversuche lieferten erste Informationen über die Natur der flüchtigen Signalstoffe, die für die Ausbildung einer Resistenz bei der unbefallenen Pflanze vor nachfolgendem Herbivorenschaden verantwortlich sein könnten.

- Um einen Signaltransfer zwischen einem geschädigten und einem benachbarten, ungeschädigten Erlentrieb modellhaft nachzustellen, wurden „Container“-Versuche durchgeführt. Um einen fraßinduzierten Trieb wurde eine befallsfreie Pflanze plaziert, so daß emittierte Duftstoffe ungehindert über den Gasraum zu den ungeschädigten Blättern gelangen konnten. Unter dem Einfluß des Duftbouquets fraßinduzierter Erlenblätter traten bei ungeschädigten Erlenblättern die gleichen Blattveränderungen bezüglich des Phenolgehalts und der Aktivität von oxidativen Enzymen sowie von 
Proteinaseinhibitoren auf wie bei befallenen Blättern. Ferner wirkten sich diese Veränderungen in den benachbarten, ungeschädigten Blättern nachhaltig auf das Fraßverhalten von $A$. alni aus, womit ein Beweis für die Übertragung der Resistenz vom befallenen auf den benachbarten, unbefallenen Erlentrieb erbracht wurde.

- Die exogene Applikation einzelner Duftbestandteile wie Ethylen und Methyljasmonat konnte im Experiment zwar einzelne Abwehrreaktionen induzieren, aber das gesamte Spektrum der Abwehrreaktionen konnte nur durch das komplexe Duftbouquet der mit Herbivoren befallenen Blätter aktiviert werden. Ethylenbehandlung vergrößerte lediglich den Phenolgehalt und die Aktivität von Proteinaseinhibitoren, die auch von Methyljasmonat positiv beeinflußt wurde.

- $\mathrm{Zu}$ weiteren Komponenten des fraßinduzierten Duftstoffspektrums mit Signalübertragungsfunktion zählten $\beta$-Ocimen, 4,8-Dimethylnona-1,3,7-trien und 4,8,12-Trimethyltrideca-1,3,7,11-tetraen, die in bei Begasungsversuchen einen deutlichen Effekt auf die Aktivität von Proteinaseinhibitoren zeigten.

Die Ergebnisse des „JA-Freilandversuchs“ mit getopften Erlen sowie der Containerversuch, belegen, daß geschädigte Erlenpflanzen über Duftstoffe in benachbarten, befallsfreien Erlenpflanzen prinzipiell eine Abwehr auslösen und somit eine Resistenz gegen Herbivore ausbilden können. Die eingangs gestellte Frage, ob eine Kommunikation zwischen befallenen Erlenpflanzen und befallsfreien Nachbarn stattfinden kann, ist somit grundsätzlich positiv zu beantworten. Die intraspezifische Signaltransduktion zwischen geschädigten und ungeschädigten Erlenpflanzen erfolgt dabei nicht durch einzelne Substanzen, sondern durch ein Gemisch zahlreicher flüchtiger Substanzen, dessen aktive Komponenten noch nicht vollständig identifiziert sind. Um aber diese im Labor gewonnenen Erkenntnisse unmittelbar auf die Freilandsituation übertragen zu können, müssen noch die unmittelbar als Reaktion auf die simulierte Herbivorie emittierten Duftstoffe Ethylen sowie die anderen flüchtigen Duftkomponenten quantitativ unter natürlichen Bedingungen analysiert werden. 


\section{$8 \quad$ Literatur}

Abeles FB, Morgan PW, Saltveit ME (1992) Ethylene in plant biology. Academic Press, New York

Agrawal A (1999) Induced responses to herbivory in wild radish: effects on several herbivories and plant fitness. Ecology 80:1713-1723

Aichele D, Schweigler HW (1994) Die Blütenpflanzen Mitteleuropas. FranckhKosmos Verlag, Stuttgart:288-293

Alborn T, Turlings TCJ, Jones TH, Stenhagen G, Loughrin JH, Tumlinson JH (1997) An elicitor of plant volatiles from beet armyworm oral secretion. Science 276:945-949

Arey J, Winer AM, Atkinson R, Aschmann SM, Long WD, Morrison CL (1991) The emission of (Z)-3-hexen-1-ol, (Z)-3-hexenylacetate and other oxygenated hydrocarbons from agricultural plant-species. Atmospheric Environment Part aGeneral Topics 25:1063-1075

Arimura G, Ozawa R, Shimoda T, Nishioka T, Boland W, Takabyashi J (2000) Herbivory-induced volatiles elicit defence genes in lima bean leaves. Nature 406:512-515

Avdiushko SA, Brown GC, Dahlman DL, Hildebrand DF (1997) Methyl jasmonate exposure induces insect resistance in cabbage and tobacco. Environmental Entomology 26:642-654

Axelrod B (1974) Lipoxygenases. Advances in Chemistry Series 136:324-348

Azuma H, Thien LB, Toyota M, Asakawa Y, Kawano S (1997) Distribution and differential expression of (E)-4,8-dimethyl-1,3,7-nonatriene in leaf and floral volatiles of magnolia and liriodendron taxa. Journal of Chemical Ecology 23:24672478

Baldwin IT (1996) Methyl jasmonate-induced nicotine production in Nicotiana attenuata: inducing defenses in the field without wounding. Entomologia Experimentalis et Applicata 80:213-220

Baldwin IT, Preston CA (1999) The eco-physiological complexity of plant responses to insect herbivores. Planta 208:137-145

Baldwin IT, Schultz JC (1983) Rapid changes in tree leaf chemistry induced by damage - evidence for communication between plants. Science 221:277-279

Baldwin IT, Zhang ZP, Diab N, Ohnmeiss TE, McCloud ES, Lynds GY, Schmelz EA (1997) Quantification, correlations and manipulations of wound-induced changes in jasmonic acid and nicotine in Nicotiana sylvestris. Planta 201:397-404

Barbier-Brygoo H, Ephritikhine G, Klambt D, Maurel C, Palme K, Schell J, Guern J (1991) Perception of the auxin signal at the plasma-membrane of tobacco mesophyll protoplasts. Plant Journal 1:83-93 
Bate NJ, Rothstein SJ (1998) $\mathrm{C}_{6}$-volatiles derived from the lipoxygenase pathway induce a subset of defense-related genes. Plant Journal 16:561-569

Baur R, Benz G (1983) Verschlechterte Nahrungsqualität der Grauerle Alnus incana nach Kahlfraß durch den Erlenblattkäfer Agelastica alni (Coleoptera, Chrysomelidae) und negative Rückkoppelung auf dessen Reproduktion. Mitteilungen der Schweizerischen Entomologischen Gesellschaft 56:245-250

Baur R, Binder S, Benz G (1991) Nonglandular leaf trichomes as short-term inducible defense of the grey alder, Alnus incana (L.), against the chrysomelid beetle, Agelastica alni (L.) Oecologia 87:219-226

Bell E, Mullet JE (1991) Lipoxygenase gene-expression is modulated in plants by water deficit, wounding, and methyl jasmonate. Molecular \& General Genetics 230:456-462

Bergey DR, Hoi GA, Ryan CA (1996) Polypeptide signaling for plant defensive genes exhibits analogies to defense signaling in animals. Proceedings of the National Academy of Sciences of the United States of America 93:12053-12058

Bergomaz R, Boppre M (1986) A simple instant diet for rearing arctiidae and other moths. Journal of the Lepidopterist Society 40:131-137

Bi JL, Felton GW (1995) Foliar oxidative stress and insect herbivory - primary compounds, secondary metabolites, and reactive oxygen species as components of induced resistance. Journal of Chemical Ecology 21:1511-1530

Blatt MR, Thiel G (1993) Hormonal-control of ion-channel gating. Annual Review of Plant Physiology and Plant Molecular Biology 44:543-567

Blee E, Schuber F (1993) Biosynthesis of cutin monomers: involvement of a lipoxygenase/peroxygenase pathway. The Plant Journal 4:113-123

Blume B, Nürnberger T, Nass N, Scheel D (2000) Receptor-mediated increase in cytoplasmic free calcium required for activation of pathogen defense in parsley. Plant Cell 12:1425-1440

Boland W, Gäbler A (1989) Biosynthesis of homoterpenes in higher plants. Helvetica Chimica Acta 72:247-253

Boland W, Feng Z, Donath J, Gäbler A (1992) Are acyclic $\mathrm{C}_{11}$ and $\mathrm{C}_{16}$ homoterpenes plant volatiles indicating herbivory. Naturwissenschaften 79:368-371

Boland W, Gäbler A, Gilbert M, Feng ZF (1998) Biosynthesis of $\mathrm{C}_{11^{-}}$and $\mathrm{C}_{16^{-}}$ homoterpenes in higher plants; stereochemistry of the C-C-bond cleavage reaction. Tetrahedron 54:14725-14736

Boland W, Hopke J, Donath J, Nüske J, Bublitz F (1995) Jasmonic acid and coronatin induce odor production in plants. Angewandte Chemie-International Edition in English 34:1600-1602

Boland W, Koch T, Krumm T, Piel J, Jux A (1999) Induced biosynthesis of insect semiochemicals in plants. In: D. J. Chadwick \& J. Goode (eds), Insect-plant interactions and induced plant defence. Wiley, Chicester (Novartis Foundation Symposium 223):110-123 
Bonello P, McNee WR, Storer AJ, Wood DL, Gordon TR (2001) The role of olfactory stimuli in the location of weakened hosts by twig-infesting Pityophthoros spp. Ecological Entomology 26:8-15

Bouwmeester HJ, Verstappen FWA, Posthumus MA, Dicke M (1999) Spider miteinduced (3s)-(E)-nerolidol synthase activity in cucumber and lima bean. The first dedicated step in acyclic $\mathrm{C}_{11}$-homoterpene biosynthesis. Plant Physiology 121:173180

Bradford MM (1976) Rapid and sensitive method for quantitation of microgram quantities of protein utilizing principle of protein-dye binding. Analytical Biochemistry 72:248-254

Brown WE, Ryan CA (1984) Isolation and characterization of a wound-induced trypsin- inhibitor from alfalfa leaves. Biochemistry 23:3418-3422

Bruin J, Dicke M, Sabelis MW (1992) Plants are better protected against spider-mites after exposure to volatiles from infested conspecifics. Experientia 48:525-529

Bünnige M, Hilker M (1999) Larval exocrine glands in the galerucine Agelastica alni L. (Coleoptera: Chrysomelidae): their morphology and possible functions. Chemoecology 9:55-62

Capinera JL, Roltsch WJ (1980) Response of wheat seedlings to actual and simulated migratory grasshopper (Orthoptera, Acrididae) defoliation. Journal of Economic Entomology 73:258-261

Chen, C-L (1991) Lignin: occurrence in woody tissues, isolation, reactions, and structure. New York, Dekker:183-261

Cohen Y, Gisi U, Niderman T (1993) Local and systemic protection against Phytophthora infestans induced in potato and tomato plants by jasmonic acid and jasmonic methylester. Phytopathology 83:1054-1062

Coley PD (1983) Herbivory and defensive characteristics of tree species in a lowland tropical forest. Ecological Monographs 53:209-233

Constabel CP, Ryan CA (1998) A survey of wound- and methyl jasmonate-induced leaf polyphenol oxidase in crop plants. Phytochemistry 47:507-511

Constabel CP, Yip L, Patton JJ, Christopher ME (2000) Polyphenol oxidase from hybrid poplar. Cloning and expression in response to wounding and herbivory. Plant Physiology 124:285-295

Creelman RA, Mullet JE (1997) Biosynthesis and action of jasmonates in plants. Annual Review of Plant Physiology and Plant Molecular Biology 48:355-381

Creelman RA, Tierney ML, Mullet JE (1992) Jasmonic acid methyl jasmonate accumulate in wounded soybean hypocotyls and modulate wound gene-expression. Proceedings of the National Academy of Sciences of the United States of America 89:4938-4941

Croft KPC, Juttner F, Slusarenko AJ (1993) Volatile products of the lipoxygenase pathway evolved from Phaseolus vulgaris (L) leaves inoculated with Pseudomonas syringae pv-phaseolicola. Plant Physiology 101:13-24 
Dahms KG (1996) Das kleine Holzlexikon. Wegra Verlag GmbH, 7. Auflage, Tamm

Degenhardt $\mathbf{J}$, Gershenzon $\mathbf{J}$ (2000) Demonstration and characterization of (E)nerolidol synthase from maize: a herbivore-inducible terpene synthase participating in (3e)-4,8-dimethyl-1,3,7-nonatriene biosynthesis. Planta 210:815-822

Dempsey DA, Shah J, Klessig DF (1999) Salicylic acid and disease resistance in plants. Critical Reviews in Plant Sciences 18:547-575

Denno RF (1983) Tracking variable host plants in space and time. In: R.F. Denno \& M.S. McClure (eds), Variable Plants and Herbivores in Natural and Managed Systems. Academic Press, New York

Deroe C, Pasteels JM (1982) Distribution of adult defense glands in chrysomelids (Coleoptera: Chrysomelidae) and its significance in the evolution of defensemechanisms within the family. Journal of Chemical Ecology 8:67-82

Deshpande SS, Sathe SK, Salunkhe DK (1984) Chemistry and safety of plant polyphenols. Advances in Experimental Medicine and Biology 177:457-495

Dettner K (1999) Insekten als Nahrungsquelle, Abwehrmechanismen. In: K. Dettner \& K. Peters (eds), Lehrbuch der Entomologie. Gustav Fischer, Stuttgart Jena:569-613

Dicke M (1994) Local and systemic production of volatile herbivore-induced terpenoids - their role in plant-carnivore mutualism. Journal of Plant Physiology 143:465-472

Dicke M, Sabelis MW (1988) How plants obtain predatory mites as bodyguards. Netherlands Journal of Zoology 38:148-165

Dicke M, Van Loon JJA (2000) Multitrophic effects of herbivore-induced plant volatiles in an evolutionary context. Entomologia Experimentalis et Applicata 97:237-249

Dicke M, Gols R, Ludeking D, Posthumus MA (1999) Jasmonic acid and herbivory differentially induce carnivore- attracting plant volatiles in lima bean plants. Journal of Chemical Ecology 25:1907-1922

Dicke M, Sabelis MW, Takabayashi J, Bruin J, Posthumus MA (1990) Plant strategies of manipulating predator-prey interactions through allelochemicals: Prospects for application in pest control. Journal of Chemical Ecology 16:30913118

Dicke M, VanBaarlen P, Wessels R, Dijkman H (1993) Herbivory induces systemic prduction of plant volatiles that attract predators of the herbivore: Extraction of endogenous elicitor. Journal of Chemical Ecology 19:581-599

Dixon RA, Lamb CJ (1990) Molecular communication in interactions between plants and microbial pathogens. Annual Review of Plant Physiology and Plant Molecular Biology 41:339-367

Doares SH, Syrovets T, Weiler EW, Ryan CA (1995) Oligogalacturonides and chitosan active plant defensive genes through the octadecanoid pathway. Proceedings of the National Academy of Sciences of the United States of America 92:4095-4098 
Dolch R (1995) Wechselwirkungen zwischen Schwarzerle und Erlenblattkäfer (Agelastica alni): Herbivorie, induzierte Resistenz und „sprechende Bäume". Diplomarbeit, Zoologisches Institut, Universität Karlsruhe

Dolch R, Tscharntke T (2000) Defoliation of alders (Alnus glutinosa) affects herbivory by leaf beetles on undamaged neighbours. Oecologia 125:504-511

Donath J, Boland W (1994) Biosynthesis of acyclic homoterpenes in higher-plants parallels steroid-hormone metabolism. Journal of Plant Physiology 143:473-478

Duffey SS, Felton GW (1991) Enzymatic antinutritive defenses of the tomato plant against insects. Acs Symposium Series 449:166-197

Durner J, Shah J, Klessig DF (1997) Salicylic acid and disease resistance in plants. Trends in Plant Science 2:266-274

Dyer MI, Bokhari UG (1976) Plant-animal interactions - studies of effects of grasshopper grazing on blue grama grass. Ecology 57:762-772

Engelberth J, Koch T, Kühnemann F, Boland W (2000) Channel-forming peptaibols are potent elicitors of plant secondary metabolism and tendril coiling. Angewandte Chemie-International Edition 39:1860-1862

Engelberth J, Koch T, Schüler G, Bachmann N, Rechtenbach J, Boland W (2001) Ion channel-forming alamethicin is a potent elicitor of volatile biosynthesis and tendril coiling. Cross talk between jasmonate and salicylate signaling in lima bean. Plant Physiology 125:369-377

Enyedi AJ, Yalpani N, Silverman P, Raskin I (1992) Signal molecules in systemic plant-resistance to pathogens and pests. Cell 70:879-886

Eschenbach C (1995) Zur Physiologie und Ökologie der Schwarzerle (Alnus glutinosa). Dissertation, Botanisches Institut der Christian-Albrechts-Universität zu Kiel

Faccioli G (1979) Relation of peroxidase, catalase and polyphenoloxidase to acquiredresistance in plants of Chenopodium amaranticolor locally infected by tobacco necrosis virus. Phytopathologische Zeitschrift-Journal of Phytopathology 95:237249

Farmer EE, Ryan CA (1990) Interplant communication - airborne methyl jasmonate induces synthesis of proteinase-inhibitors in plant-leaves. Proceedings of the National Academy of Sciences of the United States of America 87:7713-7716

Farmer EE, Ryan CA (1992) Octadecanoid precursors of jasmonic acid activate the synthesis of wound-inducible proteinase-inhibitors. Plant Cell 4:129-134

Farmer EE, Johnson RR, Ryan CA (1992) Regulation of expression of proteinaseinhibitor genes by methyl jasmonate and jasmonic acid. Plant Physiology 98:9951002

Farmer EE, Weber H, Vollenweider S (1998) Fatty acid signaling in Arabidopsis. Planta 206:167-174

Feeny $\mathbf{P}$ (1970) Seasonal changes in oak leaf tannins and nutrients as a cause of spring feeding by winter moth caterpillars. Ecology 51:565-581 
Felton GW, Donato KK, Broadway RM, Duffey SS (1992) Impact of oxidized plant phenolics on the nutritional quality of dietary-protein to a noctuid herbivore, Spodoptera exigua. Journal of Insect Physiology 38:277-285

Fowler SV (1983) The foliage feeding insects on birch: plant fitness loss, apparency and the levels of anti-herbivore defences. PhD Thesis University of York

Fowler SV, Lawton JH (1985) Rapidly induced defenses and talking trees - the devils advocate position. American Naturalist 126:181-195

Freudenberg K (1965) Lignin - its constitution and formation from p-hydroxycinnamyl alcohols. Science 148:595-\&

Frey M, Stettner C, Pare PW, Schmelz EA, Tumlinson JH, Gierl A (2000) An herbivore elicitor activates the gene for indole emission in maize. Proceedings of the National Academy of Sciences of the United States of America 97:14801-14806

Fujimori T, Kasuga R, Kaneko H, Noguchi M (1978) Neutral volatile components of burley tobacco. Beiträge zur Tabakforschung International 9:317-325

Gäbler A, Boland W, Preiss U, Simon H (1991) Stereochemical studies on homoterpene biosynthesis in higher plants - mechanistic, phylogenetic, and ecological aspects. Helvetica Chimica Acta 74:1773-1789

Gardner HW (1991) Recent investigations into the lipoxygenase pathway of plants. Biochimica et Biophysica Acta 1084:221-239

Gill CJ (1975) Ecological significance of adventitious rooting as a response to flooding in woody species, with special reference to Alnus glutinosa (L.) Gaertn. Flora 164:85-97

Gols R, Posthumus MA, Dicke M (1999) Jasmonic acid induces the production of gerbera volatiles that attract the biological control agent Phytoseiulus persimilis. Entomologia Experimentalis et Applicata 93:77-86

Green TR, Ryan CA (1972) Wound-induced proteinase inhibitor in plant leaves possible defense mechanism against insects. Science 175:776-\&

Greenberg J (1997) Programmed cell death in plant-pathogen interactions. Annual Review of Plant Physiology and Plant Molecular Biology 48:525-545

Griffin SG, Markham JL, Dennis G, Wyllie SG (2000) Using atomic force microscopy to view the effects of terpenoids on the stability and packing of phosphatidlcholine supported lipid bilayers. International Symposium on Essential Oils, Hamburg. Posterbeitrag

Grosse W, Schröder P (1984) Oxygen-supply of roots by gas-transport in alder-trees. Zeitschrift für Naturforschung C-a Journal of Biosciences 39:1186-1188

Grosse W, Schröder P (1985) Aeration of the roots and chloroplast-free tissues of trees. Berichte der Deutschen Botanischen Gesellschaft 98:311-318

Hamberg M, Fahlstadius P (1990) Allene oxide cyclase: a new enzyme in plant lipid metabolism. Archives of Biochemistry and Biophysics 276:518-526

Hamilton-Kemp TR, McCracken CT, Loughrin JH, Andersen RA, Hildebrand DF (1992) Effects of some natural volatile compounds on the pathogenic fungi 
Alternaria alternata and Botrytis cinerea. Journal of Chemical Ecology 18:10831091

Harms H, Atzorn R, Brash A, Kuhn H, Wasternack C, Willmitzer L, Pena-Cortes H (1995) Expression of a flax allene oxide synthase cDNA leads to increased endogenous jasmonic acid (JA) levels in transgenic potato plants but not to a corresponding activation of JA-responding genes. The Plant Cell 7:1645-1654

Hartley, SE, Lawton JH (1991) Biochemical aspects and significance of rapidly induced accumulation of phenolics in birch foliage. In: D.W. Tallamy \& M.J. Raupp (eds), Phytochemical induction by herbivores. John Wiley \& Sons, New York:105-132

Hatanaka A (1993) The biogeneration of green odour by green leaves. Phytochemistry 34:1201-1208

Hatanaka A (1996) The fresh green odor emitted by plants. Food Reviews International 12:303-350

Hatanaka A, Kajiwara T, Sekiya J (1987) Biosynthetic pathway for $C_{6}$ aldehyde formation from linolenic acid in green leaves. Chem. Phys. Lipids 44:341-361

Hattendorf J (2000) Induzierte Resistenz und ,sprechende Bäume”: Experimente mit Schwarzerlen und Erlenblattkäfern. Diplomarbeit im wissenschaftlichen Studiengang Agrarwissenschaften an der Universität Göttingen, Fachbereich Agrarwissenschaften

Haukioja E, Suomela J, Neuvonen S (1985) Long-term inducible resistance in birch foliage: triggering cues and efficacy on a defoliator. Oecologia 65: 363-369

Havill NP, Raffa KF (1999) Effects of elicitation treatment and genotypic variation on induced resistance in populus: impacts on gypsy moth (Lepidoptera: Lymantriidae): development and feeding behavior. Oecologia 120:295-303

Hegi G (1981) Illustrierte Flora von Mitteleuropa, Bd. 3, Teil 1. Verlag Paul Parey, Berlin und Hamburg:173-179

Hegnauer R (1964) Chemotaxonomie der Pflanzen, Bd. 3. Birkhäuser Verlag, Basel und Stuttgart

Herde O, Pena-Cortes H, Willmitzer L, Fisahn J (1997) Stomatal responses to jasmonic acid, linolenic acid and abscisic acid in wild-type and aba-deficient tomato plants. Plant Cell and Environment 20:136-141

Hildebrand DF, Hymowitz T (1982) Carotene and chlorophyll bleaching by soybeans with and without seed lipoxygenase-1. Journal of Agricultural and Food Chemistry 30:705-708

Hilder VA, Gatehouse AMR, Sheerman SE, Barker RF, Boulter D (1987) A novel mechanism of insect resistance engineered into tobacco. Nature 330:160-163

Hopke J, Donath J, Blechert S, Boland W (1994) Herbivore-induced volatiles - the emission of acyclic homoterpenes from leaves of Phaseolus lunatus and Zea mays can be triggered by a beta-glucosidase and jasmonic acid. Febs Letters 352:146-150 
Howe HF, Westley LC (1993) Anpassung und Ausbeutung - Wechselbeziehungen zwischen Pflanzen und Tieren. Spektrum Akademischer Verlag, Heidelberg

Ikonen A, Tahvanainen J, Roininen $\mathbf{H}$ (2001) Chlorogenic acid as an antiherbivore defence of willows against leaf beetles. Entomologia Experimentalis et Applicata 99:47-54

Isman MB, Duffey SS (1982) Toxicity of tomato phenolic compounds to the fruitworm Heliothis zea. Entomologia Experimentalis et Applicata 31:370-376

Jeker TB (1981) Durch Insektenfraß induzierte, resistenzähnliche Phänomene bei Pflanzen. Wechselwirkungen zwischen Grauerle, Alnus incana (L.) und den Erlenblattkäfern Agelastica alni und Melasoma aenea (L.) sowie zwischen Stumpfblättrigem Ampfer, Rumex obtusifolius (L.) und Ampferblattkäfer Gastrophysa viridula (Deg.). Ph.D. Thesis Nr. 6895 ETH Zürich

Johnson R, Narvaez J, An G, Ryan CA (1989) Expression of proteinase inhibitors I and II in transgenic tobacco plants: effects on natural defense against Manduca sexta larvae. Proceedings of the National Academy of Sciences of the United States of America 86:9871-9875

Jolivet P, Petitpierre E, Hsiao TH (1988) Biology of chrysomelidae. Kluwer Academic Publishers, Dordrecht, S. XXIII-XXIV

Jongsma MA, Bakker PL, Stiekema WJ (1993) Quantitative-determination of serine proteinase-inhibitor activity using a radial diffusion assay. Analytical Biochemistry 212:79-84

Jongsma MA, Bakker PL, Peters J, Bosch D, Stiekema WJ (1995) Adaptation of Spodoptera exigua larvae to plant proteinase- inhibitors by induction of gut proteinase activity insensitive to inhibition. Proceedings of the National Academy of Sciences of the United States of America 92:8041-8045

Jongsma MA, Bakker PL, Visser B, Stiekema WJ (1994) Trypsin-inhibitor activity in mature tobacco and tomato plants is mainly induced locally in response to insect attack, wounding and virus-infection. Planta 195:29-35

Josefsson LG, Rask L (1997) Cloning of a putative G-protein coupled receptor from Arabidopsis thaliana. Eureopean Journal of Biochemistry 249:415-420

Kahl J, Siemens DH, Aerts RJ, Gäbler R, Kühnemann F, Preston CA, Baldwin IT (2000) Herbivore-induced ethylene suppresses a direct defense but not a putative indirect defense against an adapted herbivore. Planta 210:336-342

Kaiser R (1991) Trapping, investigation and reconstruction of flower scents. In: Müller DM, Lamparsky D (eds) Perfumes: art, science and technology. Elsevier Applied Science, London New York: 213-250

Karban R, Baldwin I (1997) Induced responses to herbivory. The University of Chicago Press, Chicago, Illinois

Karban R, Myers JH (1989) Induced plant-responses to herbivory. Annual Review of Ecology and Systematics 20:331-348 
Karban R, Baldwin IT, Baxter KJ, Laue G, Felton GW (2000) Communication between plants: induced resistance in wild tobacco plants following clipping of neighboring sagebrush. Oecologia 125:66-71

Knudsen JT, Tollsten L, Bergstrom LG (1993) Floral scents - a checklist of volatile compounds isolated by headspace techniques. Phytochemistry 33:253-280

Koch K (1992) Die Käfer Mitteleuropas - Ökologie, Bd. E3. Goecke \& Krefeld Verlag, Krefeld

Koch T, Bandemer K, Boland W (1997) Biosynthesis of cis-jasmone: a pathway for the inactivation and the disposal of the plant stress hormone jasmonic acid to the gas phase? Helvetica Chimica Acta 80:838-850

Koch T, Krumm T, Jung V, Engelberth J, Boland W (1999) Differential induction of plant volatile biosynthesis in the lima bean by early and late intermediates of the octadecanoid- signaling pathway. Plant Physiology 121:153-162

Köpf A, Rank NE, Roininen H, Tahvanainen J (1997) Defensive larval secretions of leaf beetles attract a specialist predator Parasyrphus nigritarsis. Ecological Entomology 22:176-183

Korth KL, Dixon RA (1997) Evidence for chewing insect-specific molecular events distinct from a general wound response in leaves. Plant Physiology 115:1299-1305

Kosuge T (1969) Role of phenolics in host response to infection. Annual Review of Phytopathology 7:195-\&

Lamb C, Dixon A (1997) The oxidative burst in plant disease resistance. Annual Review of Plant Physiology and Plant Molecular Biology 48:251-275

Lawler IR, Foley WJ, Woodrow IE (1997) The effects of elevated $\mathrm{CO}_{2}$ atmospheres on the nutritional quality of Eucalyptus foliage and its interaction with soil nutrient and light availability. Oecologia 109:59-68.

Lichtenthaler HK (1999) The 1-deoxy-D-xylulose-5-phosphate pathway of isoprenoid biosynthesis in plants. Annual Review of Plant Physiology 50:47-65

Loughrin JH, Manukian A, Heath RR, Tumlinson JH (1995) Volatiles emitted by different cotton varieties damaged by feeding beet armyworm larvae. Journal of Chemical Ecology 21:1217-1227

Loughrin JH, Potter DA, Hamiltonkemp TR, Byers ME (1997) Diurnal emission of volatile compounds by japanese beetle- damaged grape leaves. Phytochemistry 45:919-923

Loughrin JH, Hamilton-Kemp TR, Andersen RA, Hildebrand DF (1991) Circadian-rhythm of volatile emission from flowers of Nicotiana sylvestris and N. suaveolens. Physiologia Plantarum 83:492-496

Loughrin JH, Manukian A, Heath RR, Turlings TCJ, Tumlinson JH (1994) Diurnal cycle of emission of induced volatile terpenoids herbivore-injured cotton plants. Proceedings of the National Academy of Sciences of the United States of America 91:11836-11840 
Maisner N (1974) Chrysomelidae. In: W. Schwenke (eds), Die Forstschädlinge Europas, Bd. 2. Verlag Paul Parey, Hamburg und Berlin:202-236

Martin JS, Martin MM (1982) Tannin assays in ecological-studies - lack of correlation between phenolics, proanthocyanidins and protein-precipitating constituents in mature foliage of 6 oak species. Oecologia 54:205-211

Mason HS (1955) Comparative biochemistry of the phenolase complex. Advances in Enzymology and Related Subjects of Biochemistry 16:105-\&

Mathieu Y, Kurkdjian A, Xia H, Guern J, Koller A, Spiro MD, O’Neill M, Albersheim P, Darvill A (1991) Membrane responses induced by oligogalacturonides in suspension-cultured tobacco cells. Plant Journal 1:333-343

Matile P, Altenburger R (1988) Rhythms of fragrance emission in flowers. Planta 174:242-247

Matsui K, Wilkinson J, Hiatt B, Knauf V, Kajiwara T (1999) Molecular cloning and expression of Arabidopsis fatty acid hydroperoxide lyase. Plant Cell Physiology 40:477-481

Mattiacci L, Dicke M, Posthumus MA (1995) Beta-glucosidase - an elicitor of herbivore-induced plant odor that attracts host-searching parasitic wasps. Proceedings of the National Academy of Sciences of the United States of America 92:2036-2040

Mattoo AK, Suttle JC (1991) The plant hormone ethylene. CRC Press, Boca Raton

Mattson WJ (1980) Herbivory in relation to plant nitrogen-content. Annual Review of Ecology and Systematics 11:119-161

Mattson WJ, Palmer SR (1988) Changes in levels of foliar minerals and phenolics in trembling aspen, Populus tremuloides, in response to artificial defoliation. In: W.J. Mattson, J. Levieux, C. Bernard-Dagan (eds), Mechanisms of woody plant defenses against insects. Springer Verlag, New York:154-169

Mattson WJ, Levieux J, Bernard-Dagan C (1988) Mechanisms of woody plant defenses against insects. Springer Verlag, New York

McCall PJ, Turlings TCJ, Loughrin J, Proveaux AT, Tumlinson JH (1994) Herbivore-induced volatile emissions from cotton (Gossypium hirsutum L) seedlings. Journal of Chemical Ecology 20:3039-3050

McCloud ES, Baldwin IT (1997) Herbivory and caterpillar regurgitants amplify the wound- induced increases in jasmonic acid but not nicotine in Nicotiana sylvestris. Planta 203:430-435

McClung CR (2001) Circadian rhythms in plants. Annual Review of Plant Physiology 52:139-162

McConn M, Creelman RA, Bell E, Mullet JE, Browse J (1997) Jasmonate is essential for insect defense Arabidopsis. Proceedings of the National Academy of Sciences of the United States of America 94:5473-5477

McDonald EP, Agrell J, Lindroth RL (1999) $\mathrm{CO}_{2}$ and light effects on deciduous trees: growth, foliar chemistry, and insect performance. Oecologia 119:389-399 
McNeill S, Southwood TRE (1978) Role of nitrogen in the development of insect-plant relationships. In: J.B. Harborne (eds), Biochemical aspects of plant and animal coevolution. Academic Press, New York:77-98

Meiners T, Hilker $M$ (2000) Induction of plant synomones by oviposition of a phytophagous insect. Journal of Chemical Ecology 26:221-232

Melan MA, Dong XN, Endara ME, Davis KR, Ausubel FM, Peterman TK (1993) An Arabidopsis thaliana lipoxygenase gene can be induced by pathogens, abscisicacid, and methyl jasmonate. Plant Physiology 101:441-450

Millett MA, Baker AJ, Satter LD (1975) Pretreatments to enhance chemical, enzymatic, and microbiological attack of cellulosic materials. Biotechnology and Bioengineering193-219

Milosevic N, Slusarenko AJ (1996) Active oxygen metabolism and lignification in the hypersensitive response in bean. Physiological and Molecular Plant Pathology 49:143-158

Miyazaki JH, Yang SF (1987) The methionine salvage pathway in relation to ethylene and polyamine biosynthesis. Physiologia Plantarum 69:366-370

Mohr KH (1966) Chrysomelidae. In: H. Freude, K. W. Harde \& G. A. Lohse (eds), Die Käfer Mitteleuropas, Bd. 9. Goecke \& Evers Verlag, Krefeld:95-280

Mooney HA, Gulmon SL (1982) Constraints of leaf structure and function in reference to herbivory. Bioscience 32:198-206

Müller MJ, Brodschelm W, Spannagl E, Zenk MH (1993) Signaling in the elicitation process is mediated through the octadecanoid pathway leading to jasmonic acid. Proceedings of the National Academy of Sciences of the United States of America 90:7490-7494

Müller P, Rudin DO, Tien HAT, Wescott WC (1962) Reconstitution of cell membrane structure in vitro and it's transformation in vitro and it's transformation into an excitable System. Nature 194:979-980

Nebel M (1993) Betulaceae, Birkengewächse. In: O. Sebald, G. Siegmund \& G. Philippi (eds), Die Farn- und Blütenpflanzen Baden-Württembergs, Bd. 1, Ulmer, Stuttgart:342-355

Novac V, Hrozinka F, Stary B (1976) Atlas of insects harmful to forest trees. Elsevier, Amsterdam

Nürnberger T, Nennstiel D, Jabs T, Sacks WR, Hahlbrock K, Scheel D (1994) High-affinity binding of a fungal oligopeptide elicitor to parsley plasma-membranes triggers multiple defense responses. Cell 78:449-460

O'Donnell PJ, Calvert C, Atzorn R, Wasternack C, Leyser HMO, Bowles DJ (1996) Ethylene as a signal mediating the wound response of tomato plants. Science 274:1914-1917

Oleksyn J, Karolewski P, Giertych MJ, Zytkowiak R, Reich PB, Tjoelker MG (1998) Primary and secondary host plants differ in leaf-level photosynthetic 
response to herbivory: evidence from Alnus and Betula grazed by the alder beetle, Agelastica alni. New Phytologist 140:239-249

Omer AD, Granett J, Karban R, Villa EM (2001) Chemically-induced resistance against multiple pests in cotton. International Journal of Pest Management 47:49-54

Omer AD, Thaler JS, Granett J, Karban R (2000) Jasmonic acid induced resistance in grapes to a root and leaf feeder. Journal of Economic Entomology 93: 840-845

Pare PW, Tumlinson JH (1997a) De novo biosynthesis of volatiles induced by insect herbivory in cotton plants. Plant Physiology 114:1161-1167

Pare PW, Tumlinson JH (1997b) Induced synthesis of plant volatiles. Nature 385:3031

Pena Cortes H, Sanchez Serrano J, Rocha Sosa M, Willmitzer L (1988) Systemic induction of proteinase inhibitor-II gene expression in potato plants by wounding. Planta 174:84-89

Piel J, Atzorn R, Gabler R, Kühnemann F, Boland W (1997) Cellulysin from the plant parasitic fungus Trichoderma viride elicits volatile biosynthesis in higher plants via the octadecanoid signalling cascade. Febs Letters 416:143-148

Piel J, Donath J, Bandemer K, Boland W (1998) Mevalonate-independent biosynthesis of terpenoid volatiles in plants: induced and constitutive emission of volatiles. Angewandte Chemie-International Edition 37:2478-2481

Pieterse CMJ, Van Loon, LC (1999) Salicylic acid-independent plant defence pathways. Trends in Plant Science 4:52-58

Polle A, Otter T, Seifert F (1994) Apoplastic peroxidases and lignification in needles of norway spruce (Picea abies (L.)). Plant Physiology 106:53-60

Rank N, Smiley J, Köpf A (1996) Natural enemies and host plant relationships for Chrysomeline leaf beetles feeding on saliaceae. In: P. H. A. Jolivet \& M. L. Cox (eds), Chrysomelidae Biology, Ecological Studies, Academic Publishing, Amsterdam 2:147-171

Raupp MJ (1985) Effects of leaf toughness on mandibular wear of the leaf beetle, Plagiodera versicolora. Ecological Entomology 10:73-79

Rausher MD (1981) Host plant-selection by Battus philenor butterflies - the roles of predation, nutrition, and plant chemistry. Ecological Monographs 51:1-20

Reinbothe S, Mollenhauer B, Reinbothe C (1994) JIP's and RIP's - the regulation of plant gene-expression by jasmonates in response to environmental cues and pathogens. Plant Cell 6:1197-1209

Rhoades DF (1983) Responses of alder and willow to attack by tent caterpillars and webworms - evidence for pheromonal sensitivity of willows. In: P. Hedin (eds), Plant resistance to insects. American Chemical Society, Washington, D.C. 208:5568

Rhoades, DF (1985) Pheromonal communication between plants. Recent Advances in Phytochemistry:195-218 
Rhodes MJC, Wooltorton, LSC (1978) The biochemistry of wounded plant tissues. Walter de Gryter, Berlin: 243

Richter G (1988) Stoffwechselphysiologie der Pflanzen. 5. Auflage. Thieme Verlag, Stuttgart, New York

Ride JP (1975) Lignification in wounded wheat leaves in response to fungi and it's possible role in resistance. Physiological Plant Pathology 5:125-134

Ride JP (1978) Role of cell-wall alterations in resistance to fungi. Annals of Applied Biology 89:302-306

Ride JP, Pearce RB (1979) Lignification and papilla formation at sites of attempted penetration of wheat leaves by non-pathogenic fungi. Physiological Plant Pathology $15: 79-\&$

Ridge I, Osborne DJ (1970) Hydroxyproline and peroxidases in cell walls of Pisum sativum - regulation by ethylene. Journal of Experimental Botany 21:843-\&

Rieske LK, Raffa KF (1995) Ethylene emission by a deciduous Tree, Tilia americana, in response to feeding by introduced basswood thrips, Thrips calcaratus. Journal of Chemical Ecology 21:187-197

Robison DJ, Raffa KF (1994) Characterization of hybrid poplar clones for resistance to the forest tent caterpillar. Forest Science 40:686-714

Rohmer M, Knani P, Simonin P, Sutter P, Sahm H (1993) Isoprenoid synthesis in bacteria - a novel pathway for early steps leading to isopentenyl diphosphate. Biochemical Journal 295:517-524

Römpp (1997) Römpp Lexikon Naturstoffe. Georg Thieme Verlag, Stuttgart, New York

Roos W, Dordschbal J, Steighardt M, Hieke M, Weiss D, Saalbach G (1999) A redox-dependent, G-protein-coupled phospholipase A of the plasma membrane is involved in the elicitation of alkaloid biosynthesis in Eschscholtzia californica. Biochimica et Biophysica Acta 1448:390-402

Röse USR, Manukian A, Heath RR, Tumlinson JH (1996) Volatile semiochemicals released from undamaged cotton leaves - a systemic response of living plants to caterpillar damage. Plant Physiology 111:487-495

Ryan CA (1979) Proteinase inhibitors. In: G. A. Rosenthal \& D. H. Janzen (eds), Herbivores: their interaction with secondary plant metabolites. Academic Press, New York:599-618

Ryan CA (1990) Protease inhibitors in plants - genes for improving defenses against insects and pathogens. Annual Review of Phytopathology 28:425-449

Sachs L (1992) Angewandte Statistik. Springer Verlag, Berlin

Schaller A, Frasson D (2001) Induction of wound response gene expression in tomato leaves by ionophores. Planta 212:431-435

Schaller A, Ryan CA (1996) Systemin - a polypeptide defense signal in plants. Bioessays 18:27-33 
Scheiwiller M (1991) Wechselwirkungen zwischen der Grauerle Alnus incana und dem Erlenblattkäfer Agelastica alni und ihre Beeinflussung durch Pflanzenwuchs und Hemmstoffe. Dissertation Nr. 7715, ETH Zürich

Schröder P (1989) Characterization of a thermo-osmotic gas transport mechanism in Alnus glutinosa (L.) Gaertn. Trees 3:38-44

Scriber JM, Feeny P (1979) Growth of herbivorous caterpillars in relation to feeding specialization and to the growth form of their food plants. Ecology 60:829-850

Scriber JM, Slansky F (1981) The nutritional ecology of immature insects. Annual Review of Entomology 26:183-211

Scutareanu P, Drukker B, Bruin J, Posthumus MA, Sabelis MW (1997) Volatiles from Psylla-infested pear trees and their possible involvement in attraction of anthocorid predators. Journal of Chemical Ecology 23:2241-2260

Seldal T, Dybwad E, Andersen KJ, Hogstedt G (1994) Wound-induced proteinaseinhibitors in grey alder (Alnus incana) - a defense-mechanism against attacking insects. Oikos 71:239-245

Sembdner G, Parthier B (1993) The biochemistry and the physiological and molecular actions of jasmonates. Annual Review of Plant Physiology and Plant Molecular Biology 44:569-589

Shen BZ, Zheng ZW, Dooner HK (2000) A maize sesquiterpene cyclase gene induced by insect herbivory and volicitin: characterization of wild-type and mutant alleles. Proceedings of the National Academy of Sciences of the United States of America 97:14807-14812

Shen CS, Bach CE (1997) Genetic variation in resistance and tolerance to insect herbivory in Salix cordata. Ecological Entomology 22:335-342

Sherman TD, Vaughn KC, Duke SO (1991) A limited survey of the phylogenetic distribution of polyphenol oxidase. Phytochemistry 30:2499-2506

Shonle I, Bergelson J (1995) Interplant communication revisted. Ecology 76:26602663

Shulaev V, Silverman P, Raskin I (1997) Airborne signalling by methyl salicylate in plant pathogen resistance. Nature 385:718-721

Siedow JN (1991) Plant lipoxygenase - structure and function. Annual Review of Plant Physiology and Plant Molecular Biology 42:145-188

Somers DE (1999) The physiology and molecular bases of the plant circadian clock. Plant Physiology 121:9-19

Staswick PE, Lehman CC (1999) Jasmonic acid-signaled responses in plants. In: A. A: Agrawal, S. Tuzun \& L. Bent (eds), Inducible plant defenses against pathogens and herbivores: Biochemistry, ecology, and agriculture. Phytopathological Society Press, St. Paul, Minnesota:117-136

StatSoft (1996) Statistica for windows version 5.1. Reference Manual. StatSoft, Inc., Tulsa 
Stern DJ, Lee A, McFadden WH, Stevens KL (1967) Volatile from grapes identification of volatiles from concord essence. Journal of Agricultural and Food Chemistry 15:1100-\&

Sticher L, Mauchmani B, Metraux JP (1997) Systemic acquired resistance. Annual Review of Phytopathology 35:235-270

Stout MJ, Workman J, Duffey SS (1994) Differential induction of tomato foliar proteins by arthropod herbivores. Journal of Chemical Ecology 20:2575-2594

Swain T, Hillis WE (1959) The phenolic contituents of Prunus domestica. I The quantitative analysis of phenolic constituents. Journal of Agricultural and Food Chemistry 10:63-68

Takabayashi J, Dicke M (1995) Plant-carnivore mutualism through herbivore-induced carnivore attractants. Trends in Plant Science 1:109-113

Tallamy DW, Raupp MJ (1991) Phytochemical induction by herbivores. John Wily, New York

Thaler JS (1999) Induced resistance in agricultural crops: effects of jasmonic acid on herbivory and yield in tomato plants. Environmental Entomology 28:30-37

Thaler JS, Stout MJ, Karban R, Duffey SS (1996) Exogenous jasmonates simulate insect wounding in tomato plants (Lycopersicon esculentum) in the laboratory and field. Journal of Chemical Ecology 22:1767-1781

Thaler JS, Stout MJ, Karban R, Duffey SS (2001) Jasmonate-mediated induced plant resistance affects a community of herbivores. Ecological Entomology 26:312-324

Tischler W (1977) Kontinuität des Biosystems Erle (Alnus) - Erlenblattkäfer (Agelastica alni). Zeitschrift für angewandte Zoologie 64:70-92

Tollsten L, Müller PM (1996) Volatile organic compounds emitted from beech leaves. Phytochemistry 43:759-762

Tomlin ES, Sears MK (1992) Effects of Colorado potato beetle and potato leafhopper on amino acid profile of potato foliage. Journal of Chemical Ecology 18:481-488

Torii KU (2000) Receptor kinase activation and signal transduction in plants: an emerging picture. Current Opinion in Plant Biology 3:361-367

Tranbarger TJ, Franceschi VR, Hildebrand DF, Grimes HD (1991) The soybean 94-kilodalton vegetative storage protein is a lipoxygenase that is localized in paravenous mesophyll cell vacuoles. Plant Cell 3:973-987

Turlings TCJ, Tumlinson JH (1992) Systemic release of chemical signals by herbivore-injured corn. Proceedings of the National Academy of Sciences of the United States of America 89:8399-8402

Turlings TCJ, Tumlinson JH, Lewis WJ (1990) Exploitation of herbivore-induced plant odors by host-seeking parasitic wasps. Science250:1251-1253

Turlings TCJ, Lengwiler UB, Bernasconi ML, Wechsler D (1998) Timing of induced volatile emissions in maize seedlings. Planta 207:146-152

Turlings TCJ, Loughrin JH, McCall PJ, Rose USR, Lewis WJ, Tumlinson JH (1995) How caterpillar-damaged plants protect themselves by attracting parasitic 
wasps. Proceedings of the National Academy of Sciences of the United States of America 92:4169-4174

Turlings TCJ, McCall PJ, Alborn HT, Tumlinson JH (1993) An elicitor in caterpillar oral secretions that induces corn seedlings to emit chemical signals attractive to parasitic wasps. Journal of Chemical Ecology 19:411-425

Urban W (1995) Physics and spectroscopic application of carbon monoxide lasers, a review. Infrared Physical Technology 36:465-473

Van Gestelen P, Ledeganck P, Wynant I, Caubergs RJ, Asard H (1998) The cantharidin-induced oxidative burst in tobacco BY-2 cell suspension cultures. Protoplasma 205:83-92

Vance CP, Kirk TK, Sherwood RT (1980) Lignification as a mechanism of disease resistance. Annual Review of Phytopathology 18:259-288

Vet LEM (1999) From chemical to population ecology: infochemical use in an evolutionary context. Journal of Chemical Ecology 25:31-49

Vet LEM, Dicke M (1992) Ecology of infochemical use by natural enemies in a tritrophic context. Annual Review of Entomology 37:141-172

Vick BA, Zimmerman DC (1984) Biosynthesis of jasmonic acid by several plantspecies. Plant Physiology 75:458-461

Visser JH, Vanstraten S, Maarse H (1979) Isolation and identification of volatiles in the foliage of potato, Solanum tuberosum, a host plant of the colorado beetle, Leptinotarsa decemlineata. Journal of Chemical Ecology 5:13-25

Walling LL (2000) The myriad plant responses to herbivores. Journal of Plant Growth Regulation 19:195-216

Wasternack C, Parthier B (1997) Jasmonate signalled plant gene expression. Trends in Plant Science 2:302-307

Whetten RW, Mackay JJ, Sederoff RR (1998) Recent advances in understanding lignin biosynthesis. Annual Review of Plant Physiology and Plant Molecular Biology 49:585-609

White PJ (2000) Calcium channels in higher plants. Biochimica et Biophysica Acta 1465:171-189

Wildon DC, Thain JF, Minchin PEH, Gubb IR, Reilly AJ, Skipper YD, Doherty HM, Odonnell PJ, Bowles DJ (1992) Electrical signaling and systemic proteinaseinhibitor induction in the wounded plant. Nature 360:62-65

Wilmanns O (1984) Ökologische Pflanzensoziologie. 3. Auflage, Quelle und Meyer, Heidelberg

Wolfson JL, Murdock LL (1990) Growth of Manduca sexta on wounded tomato plants - role of induced proteinase-inhibitors. Entomologia Experimentalis et Applicata 54:257-264

Yang SF, Hoffman NE (1984) Ethylene biosynthesis and its regulation in higher plants. Annual Review of Plant Physiology and Plant Molecular Biology 35:155189 
Yu LM (1995) Elicitins from Phytophthora and basic resistance in tobacco. Proceedings of the National Academy of Sciences of the United States of America 92:4088-4094

Zeringue HJ (1992) Effects of $\mathrm{C}_{6}-\mathrm{C}_{10}$ alkenals and alkanals on eliciting a defense response in the developing cotton boll. Phytochemistry 31:2305-2308

Zucht G (1934) Zur Biologie von Agelastica alni (L.). Deutsche Entomologische Zeitschrift 3/4:145-218 


\section{Anhang}

\section{A Warendeklaration der Blumenerde CAPRIFLOR-Premium}

Blumenerde für Zimmerpflanzen Premium Qualität, Torfprodukt DIN 11540-F20 mit folgender Zusammensetzung:

Typenbezeichnung: Kultursubstrat

Art: $\quad$ Torfkultursubstrat

Zersetzungsgrad: Gemisch aus wenig bis mäßig und stark zersetztem

Hochmoortorf (H2 - H5 und H6 - H8)

Zusammensetzung: $\quad 90 \%$ Hochmoortorf, $10 \%$ Grünkompost und alle

für das Pflanzenwachstum erforderlichen Nährstoffe:

150 - $300 \mathrm{mg} / \mathrm{l} \mathrm{N}-$ Stickstoff

150 - $300 \mathrm{mg} / 1 \mathrm{P}_{2} 0_{5}$-Phosphat

250 - $400 \mathrm{mg} / 1 \mathrm{~K}_{2} 0-$ Kaliumoxid

100 - 200 mg/l MgO-Magnesiumoxid

Salzgehalt $1,5 \mathrm{~g} / 1$

pH-Wert $\left(\mathrm{CaCl}_{2}\right): \quad 5,0-6,0$

Herkunft: $\quad$ Vehnemoor GmbH, 26683 Saterland-Sedelsberg,

Germany

\section{B Aufzucht von Lepidopteren-Raupen}

Eier von Spodoptera littoralis wurden zum Aufbau einer eigenen Zucht von Prof. Dr. P. Proksch (Universität Würzburg) zur Verfügung gestellt. Die Art wurde entweder auf einer Bohnenbrei-Diät (BERGOMAZ \& BOPPRE 1986) oder auf frischen Bohnenpflanzen (Phaseolus lunatus) gehalten. Alle Entwicklungsstadien von S. littoralis wurden, soweit nicht anders erwähnt, bei einer Temperatur von $23-25{ }^{\circ} \mathrm{C}$ mit einer $16 \mathrm{~h}: 8 \mathrm{~h}$, Licht : Dunkelheit, aufbewahrt.

\section{Freilandversuche}

In den folgenden Tabellen (Tab. C-1 bis Tab. C-20) werden für die Variablen Blattwassergehalt, spezifisches Blattgewicht, Blattfestigkeit, Phenolgehalt und konsumierte Blattmenge im Fraßwahlversuch der jeweiligen Freilandversuche die Baummittelwerte angegeben. 
Tab. C-1: Baumparameter der untersuchten Alnus glutinosa-Pflanzen am Versuchsstandort

Botanischer Garten Göttingen „Topfversuch“ in der Freilandsaison 1997. Angegeben ist der Stammdurchmesser [cm], gemessen in $1 \mathrm{~m}$ Höhe über dem Erdboden, der Bäume „Baum-X“, „BaumNachbar“ (Baum-N), „Baum 2“, „Baum 3“ und „Baum-Kontrolle“ (Baum-K). Angegeben sind der Mittelwert und der Standardfehler des Stammdurchmessers. Weiterhin ist der Abstand [m] der Bäume der Position „Baum-Nachbar“ (Baum-N) bis „Baum-Kontrolle“ (Baum-K) zum geschädigten Baum „Baum$\mathrm{X}^{\text {" }}$ angegeben.

\begin{tabular}{|c|c|c|c|c|c|c|}
\hline Plot-Nr. & Baumreihe-Nr. & Baum-X & Baum-N & Baum 2 & Baum 3 & Baum-K \\
\hline 1 & 1 & 0,53 & 0,59 & 0,97 & 0,79 & 0,97 \\
\hline 1 & 2 & 0,72 & 0,96 & 0,78 & 0,81 & 0,82 \\
\hline 1 & 3 & 0,30 & 0,79 & 0,72 & 0,74 & 0,94 \\
\hline 1 & 4 & 0,80 & 0.94 & 0,78 & 0,88 & 0,68 \\
\hline \multirow[t]{2}{*}{1} & 5 & 0,50 & 0,84 & 1,01 & 0,82 & 0,90 \\
\hline & Mittelwert \pm Stdf & $0,57 \pm 0,09$ & $0,82 \pm 0,07$ & $0,85 \pm 0,06$ & $0,80 \pm 0,02$ & $0,86 \pm 0,05$ \\
\hline 2 & 1 & 1,44 & 1,47 & 1,08 & 1,54 & 1,39 \\
\hline 2 & 2 & 1,60 & 1,38 & 1,01 & 0,98 & 1,21 \\
\hline 2 & 3 & 1,46 & 1,12 & 1,53 & 1,07 & 1,49 \\
\hline 2 & 4 & 1,46 & 1,34 & 1,09 & 0,52 & 1,26 \\
\hline \multirow[t]{2}{*}{2} & 5 & 1,47 & 1,32 & 1,13 & 1,16 & 1,57 \\
\hline & Mittelwert \pm Stdf & $1,48 \pm 0,03$ & $1,32 \pm 0,06$ & $1,16 \pm 0,09$ & $1,05 \pm 0,16$ & $1,38 \pm 0,07$ \\
\hline 3 & 1 & 0,97 & 0,84 & 0,95 & 0,79 & 0,77 \\
\hline 3 & 2 & 0,84 & 1,12 & 0,72 & 0,89 & 1,13 \\
\hline 3 & 3 & 0,69 & 0,87 & 0,75 & 0,88 & 0,90 \\
\hline 3 & 4 & 0,90 & 0,96 & 1,24 & 1,13 & 0,66 \\
\hline \multirow[t]{2}{*}{3} & 5 & 0,88 & 0,72 & 1,22 & 0,71 & 0,81 \\
\hline & Mittelwert \pm Stdf & $0,85 \pm 0,05$ & $0,90 \pm 0,06$ & $0,97 \pm 0,11$ & $\mathbf{0 , 8 8} \pm \mathbf{0 , 0 7}$ & $0,85 \pm 0,08$ \\
\hline 4 & 1 & 0,98 & 1,64 & 0,92 & 1,12 & 1,10 \\
\hline 4 & 2 & 1,38 & 0,61 & 1,02 & 1,09 & 1,57 \\
\hline 4 & 3 & 0,95 & 1,5 & 1,05 & 1,07 & 1,53 \\
\hline 4 & 4 & 1,39 & 1,32 & 1,16 & 1,24 & 1,37 \\
\hline \multirow[t]{2}{*}{4} & 5 & 1,12 & 1,5 & 1,13 & 1,43 & 1,42 \\
\hline & Mittelwert \pm Stdf & $1,16 \pm 0,09$ & $1,31 \pm 0,183$ & $1,06 \pm 0,04$ & $1,19 \pm 0,07$ & $1,39 \pm 0,08$ \\
\hline 5 & 1 & 0,77 & 0,90 & 0,56 & 0,97 & 0,86 \\
\hline 5 & 2 & 0,91 & 0,92 & 0,80 & 0,89 & 0,94 \\
\hline 5 & 3 & 0,80 & 0,59 & 0,99 & 0,71 & 0,86 \\
\hline 5 & 4 & 0,85 & 0,65 & 0,74 & 0,76 & 0,91 \\
\hline \multirow[t]{2}{*}{5} & 5 & 0,86 & 0,79 & 0,70 & 0,78 & 0,81 \\
\hline & Mittelwert \pm Stdf & $0,84 \pm 0,02$ & $0,77 \pm 0,06$ & $0,76 \pm 0,07$ & $0,82 \pm 0,05$ & $0,88 \pm 0,02$ \\
\hline 6 & 1 & 1,17 & 1,40 & 1,77 & 1,17 & 1,43 \\
\hline 6 & 2 & 1,06 & 1,24 & 1,50 & 1,31 & 1,58 \\
\hline 6 & 3 & 1,84 & 1,1 & 1,12 & 0,84 & 1,17 \\
\hline 6 & 4 & 0,98 & 1,54 & 0,78 & 1,32 & 1,54 \\
\hline \multirow[t]{3}{*}{6} & 5 & 1,54 & 0,80 & 1,34 & 0,52 & 1,56 \\
\hline & Mittelwert \pm Stdf & $1,31 \pm 0,16$ & $1,21 \pm 0,13$ & $1,3 \pm 0,17$ & $1,03 \pm 0,15$ & $1,45 \pm 0,08$ \\
\hline & $\begin{array}{l}\text { Abstand zum } \\
\text { Baum-X [m] }\end{array}$ & & 0,45 & $\mathbf{0 , 9 0}$ & 1,35 & 6,55 \\
\hline
\end{tabular}




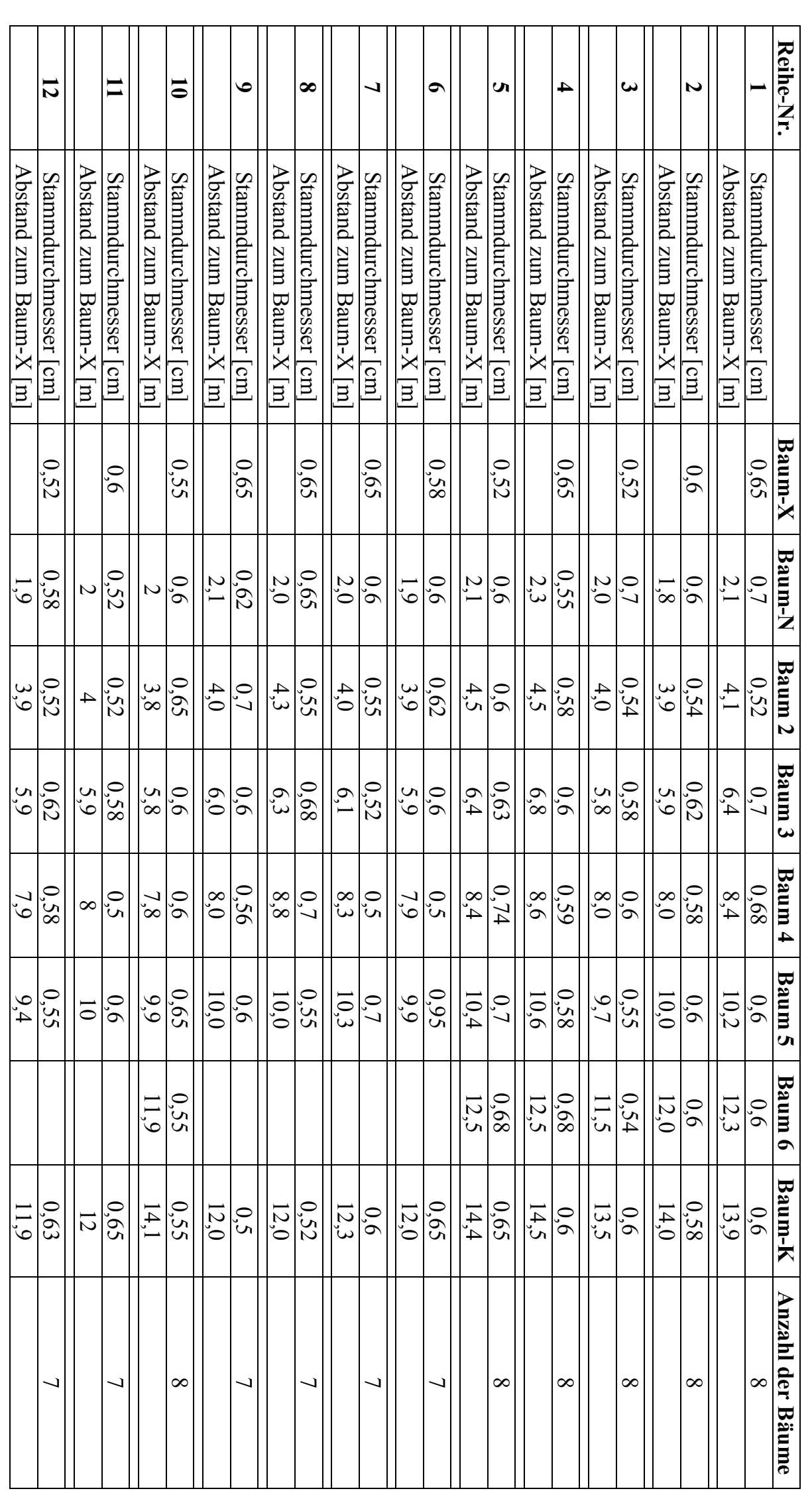

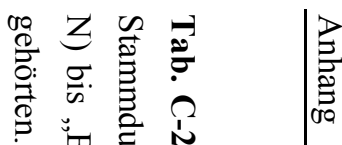

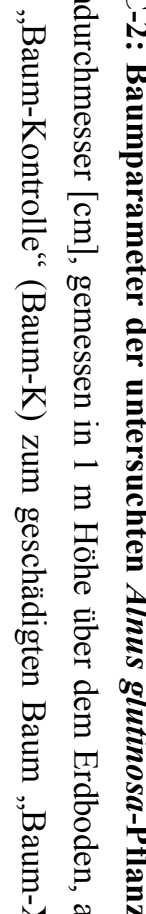

范

ఫ)

密

胥

के

象

害言

哭 空

$\approx$ 要

乡.

ธ. $\Xi$

क क्ष

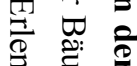

帝志

क्ष

จิ 응

可

$\stackrel{9}{=}$

觉密

$<$ 욤

है

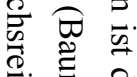

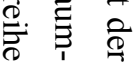


Tab. C-3: Baumparameter der untersuchten Alnus glutinosa-Pflanzen am Versuchsstandort Botanischer Garten Göttingen „JA-Versuch“ in der Freilandsaison 1998. Angegeben ist der Stammdurchmesser [cm], gemessen in 1 m Höhe über dem Erdboden, der Bäume „Baum-JA“, „BaumK“, „Baum-Nachbar 1“ (Baum-N 1), „Baum-Nachbar 2“ (Baum-N 2), „Baum-Nachbar 3“ (Baum-N 3) und „Baum-Nachbar 4“ (Baum-N 4).

\begin{tabular}{|c|c|c|c|c|c|}
\hline Topfgruppe-Nr. & Baum-JA & Baum-N 1 & Baum-N 2 & Baum-N 3 & Baum-N 4 \\
\hline $\mathbf{1}$ & 2,1 & 1,98 & 2,05 & 2,0 & 1,74 \\
\hline $\mathbf{2}$ & 1,95 & 0,87 & 1,77 & 1,82 & 1,69 \\
\hline $\mathbf{3}$ & 1,42 & 2,11 & 2,07 & 1,65 & 1,24 \\
\hline $\mathbf{4}$ & 1,87 & 1,74 & 2,07 & 1,57 & 1,06 \\
\hline $\mathbf{5}$ & 1,9 & 2,07 & 2,12 & 1,96 & 1,94 \\
\hline $\mathbf{6}$ & 1,56 & 0,77 & 2,0 & 1,89 & 1,92 \\
\hline \multicolumn{7}{|l|}{} \\
\hline $\mathbf{7}$ & Baum-K & Baum-N 1 & Baum-N 2 & Baum-N 3 & Baum-N 4 \\
\hline $\mathbf{7}$ & 1,26 & 2,15 & 1,9 & 1,78 & 1,74 \\
\hline $\mathbf{8}$ & 1,73 & 1,52 & 1,63 & 1,56 & 1,6 \\
\hline $\mathbf{1 0}$ & 1,96 & 2,0 & 2,3 & 1,83 & 2,04 \\
\hline $\mathbf{1 1}$ & 1,8 & 2,03 & 1,91 & 2,16 & 1,88 \\
\hline $\mathbf{1 2}$ & 1,44 & 1,92 & 1,7 & 1,69 & 1,95 \\
\hline
\end{tabular}

Tab. C-4: „Topfversuch“. Angegeben ist die relative Blattschädigung [\%] an den Bäumen von Alnus glutinosa der Position „Baum-X“, „Baum-Nachbar“ (Baum-N), „Baum 2", „Baum 3" und „Baum-Kontrolle“ (Baum-K) zu den jeweiligen Beobachtungszeitpunkten. leeres Kästchen = keine Beobachtung

\begin{tabular}{|c|c|c|c|c|c|c|c|}
\hline & & \multicolumn{7}{|c|}{ Beobachtungszeitpunkte in der Freilandsaison 1997 } \\
\hline Plot-Nr. & Baumposition & $\mathbf{1 8 . 0 5}$. & $\mathbf{2 1 . 0 5 .}$ & $\mathbf{2 8 . 0 5 .}$ & $\mathbf{1 1 . 0 6 .}$ & $\mathbf{0 2 . 0 7 .}$ & $\mathbf{0 5 . 0 9 .}$ \\
\hline $\mathbf{1}$ & Baum-X & 5,20 & 8,60 & & & & 77,00 \\
\hline $\mathbf{2}$ & Baum-X & 2,80 & 8,00 & & & & 96,20 \\
\hline $\mathbf{3}$ & Baum-X & 2,80 & 16,40 & & & & 89,00 \\
\hline $\mathbf{4}$ & Baum-X & 4,00 & 12,40 & & & & 70,00 \\
\hline $\mathbf{5}$ & Baum-X & 6,20 & 25,60 & & & & 95,20 \\
\hline $\mathbf{6}$ & Baum-X & 1,40 & 2,40 & & & & 84,00 \\
\hline $\mathbf{1}$ & Baum-N & 5,60 & 5,40 & 12,20 & 40,40 & 32,40 & 49,40 \\
\hline $\mathbf{2}$ & Baum-N & 3,40 & 6,20 & 13,40 & 12,00 & 32,00 & 93,60 \\
\hline $\mathbf{3}$ & Baum-N & 3,80 & 30,00 & 55,20 & 37,40 & 27,00 & 87,00 \\
\hline $\mathbf{4}$ & Baum-N & 4,00 & 4,60 & 13,00 & 8,40 & 17,70 & 91,60 \\
\hline $\mathbf{5}$ & Baum-N & 4,00 & 20,60 & 45,00 & 38,50 & 45,00 & 86,50 \\
\hline $\mathbf{6}$ & Baum-N & 0,60 & 4,20 & 1,80 & 1,80 & 2,60 & 81,00 \\
\hline $\mathbf{1}$ & Baum 2 & 3,60 & 1,80 & 8,50 & 11,60 & 10,40 & 69,00 \\
\hline $\mathbf{2}$ & Baum 2 & 1,20 & 15,20 & 26,80 & 15,00 & 8,00 & 95,20 \\
\hline $\mathbf{3}$ & Baum 2 & 3,20 & 19,20 & 36,00 & 18,80 & 22,40 & 86,00 \\
\hline $\mathbf{4}$ & Baum 2 & 4,40 & 17,00 & 35,00 & 24,00 & 19,50 & 79,00 \\
\hline $\mathbf{5}$ & Baum 2 & 3,20 & 14,00 & 33,80 & 28,00 & 42,00 & 82,00 \\
\hline $\mathbf{6}$ & Baum 2 & 0,20 & 3,00 & 8,40 & 1,40 & 1,00 & 72,00 \\
\hline $\mathbf{1}$ & Baum 3 & 1,60 & 19,20 & 43,00 & 44,70 & 48,00 & 80,00 \\
\hline $\mathbf{2}$ & Baum 3 & 2,00 & 4,20 & 15,20 & 17,40 & 12,50 & 93,00 \\
\hline $\mathbf{3}$ & Baum 3 & 7,00 & 8,80 & 18,20 & 25,20 & 31,00 & 87,00 \\
\hline $\mathbf{4}$ & Baum 3 & 0,00 & 4,40 & 12,40 & 5,40 & 15,60 & 88,00 \\
\hline
\end{tabular}


Fortsetzung Tab. C-4

\begin{tabular}{|c|c|c|c|c|c|c|c|}
\hline & & \multicolumn{5}{|c|}{ Beobachtungszeitpunkte in der Freilandsaison 1997 } \\
\hline Plot-Nr. & Baumposition & $\mathbf{1 8 . 0 5 .}$ & $\mathbf{2 1 . 0 5 .}$ & $\mathbf{2 8 . 0 5 .}$ & $\mathbf{1 1 . 0 6 .}$ & $\mathbf{0 2 . 0 7 .}$ & $\mathbf{0 5 . 0 9 .}$ \\
\hline $\mathbf{5}$ & Baum 3 & 4,60 & 25,00 & 45,00 & 33,00 & 34,50 & 94,00 \\
\hline $\mathbf{6}$ & Baum 3 & 0,40 & 5,60 & 9,40 & 1,80 & 2,20 & 68,00 \\
\hline $\mathbf{1}$ & Baum-K & 4,80 & 15,00 & 23,20 & 20,40 & 21,40 & 89,00 \\
\hline $\mathbf{2}$ & Baum-K & 4,20 & 12,00 & 20,40 & 22,00 & 27,00 & 96,60 \\
\hline $\mathbf{3}$ & Baum-K & 2,80 & 9,20 & 22,00 & 17,40 & 27,00 & 96,20 \\
\hline $\mathbf{4}$ & Baum-K & 1,00 & 4,00 & 12,80 & 6,00 & 6,40 & 78,60 \\
\hline $\mathbf{5}$ & Baum-K & 3,20 & 17,00 & 34,00 & 18,50 & 12,40 & 71,00 \\
\hline $\mathbf{6}$ & Baum-K & 1,20 & 4,40 & 5,20 & 2,60 & 2,20 & 56,00 \\
\hline
\end{tabular}

Tab. C-5: „Topfversuch“. Angegeben ist der prozentuale Blattwassergehalt [\%] von Alnus glutinosa-Blättern einer unmittelbar benachbarten, unverletzten Erle „Baum-Nachbar“ und einer

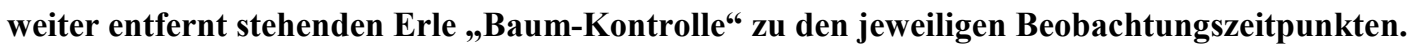

\begin{tabular}{|c|c|c|c|c|c|c|c|}
\hline & & \multicolumn{5}{|c|}{ Beobachtungszeitpunkte in der Freilandsaison 1997 } \\
\hline Plot-Nr. & Baumposition & $\mathbf{1 8 . 0 5 .}$ & $\mathbf{2 1 . 0 5 .}$ & $\mathbf{2 8 . 0 5 .}$ & $\mathbf{1 1 . 0 6 .}$ & $\mathbf{0 2 . 0 7 .}$ & $\mathbf{0 5 . 0 9 .}$ \\
\hline $\mathbf{1}$ & Baum-Nachbar & 72,34 & 70,39 & 69,22 & 64,86 & 59,75 & 70,06 \\
\hline $\mathbf{1}$ & Baum-Kontrolle & 73,48 & 68,81 & 71,23 & 65,36 & 62,37 & 68,08 \\
\hline $\mathbf{2}$ & Baum-Nachbar & 70,24 & 69,37 & 71,63 & 66,66 & 64,58 & 67,52 \\
\hline $\mathbf{2}$ & Baum-Kontrolle & 72,37 & 70,30 & 70,67 & 64,17 & 62,15 & 65,50 \\
\hline $\mathbf{3}$ & Baum-Nachbar & 71,48 & 69,23 & 72,91 & 68,16 & 66,13 & 63,90 \\
\hline $\mathbf{3}$ & Baum-Kontrolle & 70,94 & 70,17 & 71,32 & 63,96 & 61,65 & 66,79 \\
\hline $\mathbf{4}$ & Baum-Nachbar & 71,31 & 69,38 & 70,72 & 52,98 & 62,69 & 66,92 \\
\hline $\mathbf{4}$ & Baum-Kontrolle & 68,10 & 68,67 & 70,03 & 62,49 & 66,90 & 69,42 \\
\hline $\mathbf{5}$ & Baum-Nachbar & 68,85 & 69,21 & 71,54 & 64,00 & 61,65 & 66,32 \\
\hline $\mathbf{5}$ & Baum-Kontrolle & 69,35 & 68,68 & 70,67 & 63,62 & 60,35 & 66,92 \\
\hline $\mathbf{6}$ & Baum-Nachbar & 69,22 & 69,74 & 71,35 & 65,79 & 67,30 & 69,00 \\
\hline $\mathbf{6}$ & Baum-Kontrolle & 66,94 & 66,57 & 70,54 & 64,20 & 62,25 & 68,88 \\
\hline
\end{tabular}

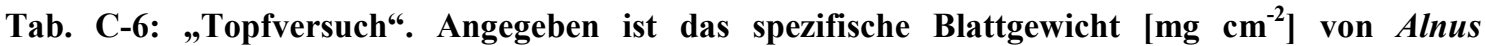
glutinosa-Blättern einer unmittelbar benachbarten, unverletzten Erle „Baum-Nachbar“6 und einer weiter entfernt liegenden Erle „Baum-Kontrolle“ zu den jeweiligen Beobachtungszeitpunkten.

\begin{tabular}{|c|c|c|c|c|c|c|c|}
\hline & & \multicolumn{5}{|c|}{ Beobachtungszeitpunkte in der Freilandsaison 1997 } \\
\hline Plot-Nr. & Baumposition & $\mathbf{1 8 . 0 5}$. & $\mathbf{2 1 . 0 5 .}$ & $\mathbf{2 8 . 0 5 .}$ & $\mathbf{1 1 . 0 6 .}$ & $\mathbf{0 2 . 0 7 .}$ & $\mathbf{0 5 . 0 9 .}$ \\
\hline $\mathbf{1}$ & Baum-Nachbar & 4,58 & 5,91 & 6,04 & 7,29 & 7,28 & 5,18 \\
\hline $\mathbf{1}$ & Baum-Kontrolle & 5,07 & 5,12 & 4,97 & 7,78 & 6,70 & 4,99 \\
\hline $\mathbf{2}$ & Baum-Nachbar & 4,89 & 5,78 & 5,01 & 5,52 & 6,26 & 4,79 \\
\hline $\mathbf{2}$ & Baum-Kontrolle & 4,79 & 6,42 & 4,79 & 6,36 & 6,45 & 5,38 \\
\hline $\mathbf{3}$ & Baum-Nachbar & 5,01 & 5,08 & 4,90 & 5,64 & 5,84 & 5,53 \\
\hline $\mathbf{3}$ & Baum-Kontrolle & 5,46 & 6,51 & 4,81 & 6,63 & 6,78 & 5,46 \\
\hline $\mathbf{4}$ & Baum-Nachbar & 5,72 & 5,64 & 5,25 & 8,03 & 6,56 & 5,73 \\
\hline $\mathbf{4}$ & Baum-Kontrolle & 6,11 & 5,60 & 5,86 & 7,18 & 6,38 & 5,38 \\
\hline $\mathbf{5}$ & Baum-Nachbar & 5,74 & 6,41 & 5,24 & 6,56 & 8,01 & 6,18 \\
\hline $\mathbf{5}$ & Baum-Kontrolle & 5,43 & 5,25 & 5,26 & 7,16 & 7,57 & 5,14 \\
\hline $\mathbf{6}$ & Baum-Nachbar & 5,58 & 5,21 & 4,00 & 5,16 & 5,26 & 3,99 \\
\hline $\mathbf{6}$ & Baum-Kontrolle & 5,64 & 6,76 & 5,23 & 6,15 & 6,56 & 5,00 \\
\hline
\end{tabular}


Tab. C-7: „Topfversuch“. Angegeben ist die Blattfestigkeit $\left[\mathrm{mg} \mathrm{cm}^{-2}\right]$ von Alnus glutinosa-Blättern einer unmittelbar benachbarten, unverletzten Erle „Baum-Nachbar“ und einer weiter entfernt liegenden Erle „Baum-Kontrolle“ zu den jeweiligen Beobachtungszeitpunkten.

\begin{tabular}{|c|c|c|c|c|c|c|c|}
\hline & & \multicolumn{5}{|c|}{ Beobachtungszeitpunkte in der Freilandsaison 1997 } \\
\hline Plot-Nr. & Baumposition & $\mathbf{1 8 . 0 5}$. & $\mathbf{2 1 . 0 5 .}$ & $\mathbf{2 8 . 0 5 .}$ & $\mathbf{1 1 . 0 6 .}$ & $\mathbf{0 2 . 0 7 .}$ & $\mathbf{0 5 . 0 9 .}$ \\
\hline $\mathbf{1}$ & Baum-Nachbar & 778,23 & 850,76 & 917,07 & 960,93 & 977,45 & 994,70 \\
\hline $\mathbf{1}$ & Baum-Kontrolle & 703,16 & 911,22 & 951,71 & 1065,84 & 990,42 & 824,97 \\
\hline $\mathbf{2}$ & Baum-Nachbar & 821,70 & 836,81 & 838,35 & 1094,69 & 1063,01 & 992,61 \\
\hline $\mathbf{2}$ & Baum-Kontrolle & 721,14 & 779,93 & 1013,98 & 1041,56 & 1005,08 & 970,81 \\
\hline $\mathbf{3}$ & Baum-Nachbar & 881,83 & 853,79 & 957,63 & 787,56 & 965,21 & 1029,74 \\
\hline $\mathbf{3}$ & Baum-Kontrolle & 706,45 & 721,36 & 778,12 & 1014,09 & 1011,80 & 1074,54 \\
\hline $\mathbf{4}$ & Baum-Nachbar & 888,68 & 896,50 & 1029,22 & 891,56 & 1182,72 & 935,67 \\
\hline $\mathbf{4}$ & Baum-Kontrolle & 1041,30 & 790,41 & 931,05 & 953,80 & 1114,60 & 928,61 \\
\hline $\mathbf{5}$ & Baum-Nachbar & 826,22 & 778,63 & 1033,66 & 949,83 & 1025,85 & 884,21 \\
\hline $\mathbf{5}$ & Baum-Kontrolle & 718,35 & 814,64 & 998,89 & 1080,65 & 1014,38 & 914,09 \\
\hline $\mathbf{6}$ & Baum-Nachbar & 803,34 & 860,02 & 837,85 & 1014,60 & 1100,09 & 873,72 \\
\hline $\mathbf{6}$ & Baum-Kontrolle & 972,32 & 850,18 & 913,08 & 917,66 & 1076,08 & 888,97 \\
\hline
\end{tabular}

Tab. C-8: „Topfversuch“. Angegeben ist der Phenolgehalt $\mathrm{DW}^{-1}\left[\mathrm{mg} \mathrm{g}^{-1}\right]$ von Alnus glutinosaBlättern einer unmittelbar benachbarten, unverletzten Erle „Baum-Nachbar“ und einer weiter entfernt stehenden Erle „Baum-Kontrolle“ zu den jeweiligen Beobachtungszeitpunkten.

\begin{tabular}{|c|c|c|c|c|c|c|c|}
\hline & & \multicolumn{5}{|c|}{ Beobachtungszeitpunkte in der Freilandsaison 1997 } \\
\hline Plot-Nr. & Baumposition & $\mathbf{1 8 . 0 5 .}$ & $\mathbf{2 1 . 0 5 .}$ & $\mathbf{2 8 . 0 5 .}$ & $\mathbf{1 1 . 0 6 .}$ & $\mathbf{0 2 . 0 7 .}$ & $\mathbf{0 5 . 0 9 .}$ \\
\hline $\mathbf{1}$ & Baum-Nachbar & 4,94 & 16,54 & 10,31 & 18,90 & 13,30 & 13,87 \\
\hline $\mathbf{1}$ & Baum-Kontrolle & 6,18 & 19,04 & 9,10 & 11,82 & 9,52 & 12,92 \\
\hline $\mathbf{2}$ & Baum-Nachbar & 7,91 & 42,49 & 2,80 & 4,18 & 3,29 & 4,13 \\
\hline $\mathbf{2}$ & Baum-Kontrolle & 7,20 & 15,73 & 2,45 & 4,95 & 5,40 & 3,61 \\
\hline $\mathbf{3}$ & Baum-Nachbar & 2,41 & 4,82 & 8,55 & 5,18 & 13,86 & 5,84 \\
\hline $\mathbf{3}$ & Baum-Kontrolle & 5,23 & 21,13 & 3,46 & 5,02 & 11,34 & 5,18 \\
\hline $\mathbf{4}$ & Baum-Nachbar & 4,53 & 12,39 & 5,18 & 6,67 & 6,18 & 15,76 \\
\hline $\mathbf{4}$ & Baum-Kontrolle & 3,35 & 6,71 & 6,53 & 6,25 & 7,40 & 14,97 \\
\hline $\mathbf{5}$ & Baum-Nachbar & 2,12 & 4,23 & 6,78 & 5,17 & 17,64 & 15,03 \\
\hline $\mathbf{5}$ & Baum-Kontrolle & 4,56 & 19,12 & 5,68 & 8,62 & 15,90 & 14,69 \\
\hline $\mathbf{6}$ & Baum-Nachbar & 7,09 & 34,18 & 5,88 & 4,48 & 6,59 & 7,33 \\
\hline $\mathbf{6}$ & Baum-Kontrolle & 7,49 & 14,98 & 6,75 & 5,84 & 6,12 & 10,43 \\
\hline
\end{tabular}

Tab. C-9: „Topfversuch". Angegeben ist die gefressene Blattmenge [mg DW] durch Agelastica alni-Imagines bzw. Larven (L) im Fraßwahlversuch. Den Imagines wurden Blattstücke von Alnus glutinosa-Blättern einer unmittelbar benachbarten, unverletzten Erle „Baum-Nachbar“ und einer weiter entfernt stehenden Erle „Baum-Kontrolle“ angeboten.

\begin{tabular}{|c|c|c|c|c|c|c|c|c|c|}
\hline & & \multicolumn{8}{|c|}{ Beobachtungszeitpunkte in der Freilandsaison 1997 } \\
\hline Plot-Nr. & Baumposition & $\mathbf{1 8 . 0 5}$ & $\mathbf{2 1 . 0 5}$. & $\mathbf{2 8 . 0 5}$. & $\mathbf{1 1 . 0 6}$ & $\mathbf{1 1 . 0 6 .}(\mathbf{L})$ & $\mathbf{0 2 . 0 7}$ & $\mathbf{0 2 . 0 7 .}(\mathbf{L})$ & $\mathbf{0 5 . 0 9}$ \\
\hline $\mathbf{1}$ & Baum-Nachbar & 2,88 & 2,57 & 6,84 & 0,21 & 0,83 & 0,21 & 1,78 & 2,31 \\
\hline $\mathbf{1}$ & Baum-Kontrolle & 5,26 & 1,53 & 5,76 & 1,65 & 3,17 & 3,32 & 1,22 & 1,94 \\
\hline $\mathbf{2}$ & Baum-Nachbar & 3,05 & 4,73 & 4,10 & 3,67 & 1,30 & 2,23 & 2,09 & 2,30 \\
\hline $\mathbf{2}$ & Baum-Kontrolle & 4,74 & 1,28 & 5,68 & 4,44 & 2,26 & 3,87 & 2,69 & 3,45 \\
\hline
\end{tabular}


Fortsetzung Tab. C-9

\begin{tabular}{|c|c|c|c|c|c|c|c|c|c|}
\hline & & \multicolumn{8}{|c|}{ Beobachtungszeitpunkte in der Freilandsaison 1997 } \\
\hline Plot-Nr. & Baumposition & $\mathbf{1 8 . 0 5}$ & $\mathbf{2 1 . 0 5}$. & $\mathbf{2 8 . 0 5}$ & $\mathbf{1 1 . 0 6}$. & $\mathbf{1 1 . 0 6 .}(\mathbf{L})$ & $\mathbf{0 2 . 0 7}$ & $\mathbf{0 2 . 0 7 . (} \mathbf{( L )}$ & $\mathbf{0 5 . 0 9 .}$ \\
\hline $\mathbf{3}$ & Baum-Nachbar & 3,54 & 3,57 & 3,99 & 3,44 & 1,17 & 1,33 & 0,91 & 3,64 \\
\hline $\mathbf{3}$ & Baum-Kontrolle & 2,03 & 5,35 & 4,27 & 1,73 & 0,26 & 1,05 & 1,29 & 4,69 \\
\hline $\mathbf{4}$ & Baum-Nachbar & 5,47 & 2,56 & 4,92 & 2,15 & 1,96 & 1,73 & 1,31 & 4,94 \\
\hline $\mathbf{4}$ & Baum-Kontrolle & 1,09 & 2,76 & 5,17 & 2,62 & 0,52 & 0,99 & 1,30 & 2,93 \\
\hline $\mathbf{5}$ & Baum-Nachbar & 2,97 & 3,25 & 4,71 & 4,00 & 1,74 & 2,23 & 0,44 & 3,13 \\
\hline $\mathbf{5}$ & Baum-Kontrolle & 1,86 & 4,37 & 3,06 & 1,32 & 1,75 & 1,33 & 1,83 & 3,16 \\
\hline $\mathbf{6}$ & Baum-Nachbar & 1,95 & 4,37 & 1,40 & 5,61 & 1,83 & 4,40 & 2,05 & 3,90 \\
\hline $\mathbf{6}$ & Baum-Kontrolle & 4,85 & 2,04 & 1,42 & 1,35 & 2,90 & 6,87 & 2,89 & 2,52 \\
\hline
\end{tabular}

Tab. C-10: „Reihenversuch“. Angegeben ist die relative Blattschädigung [\%] an den Bäumen von Alnus glutinosa der Position „Baum-X“, „Baum-Nachbar“ (Baum-N), „Baum 2“, „Baum 3“, „Baum 4“, „Baum 5“, „Baum 6“ und „Baum-Kontrolle“ (Baum-K) an den jeweiligen Beobachtungszeitpunkten. Leeres Kästchen: keine Datenaufnahme.

\begin{tabular}{|c|c|c|c|c|c|c|c|}
\hline & & \multicolumn{7}{|c|}{ Beobachtungszeitpunkte in der Freilandsaison 1997 } \\
\hline Reihe & Baumposition & $\mathbf{1 9 . 0 5}$ & $\mathbf{2 2 . 0 5}$ & $\mathbf{2 9 . 0 5}$ & $\mathbf{1 2 . 0 6 .}$ & $\mathbf{0 4 . 0 7 .}$ & $\mathbf{0 4 . 0 9}$ \\
\hline $\mathbf{1}$ & Baum-X & 25 & 30 & & & & 98 \\
\hline $\mathbf{2}$ & Baum-X & 15 & 10 & & & & 90 \\
\hline $\mathbf{3}$ & Baum-X & 25 & 25 & & & & 80 \\
\hline $\mathbf{4}$ & Baum-X & 10 & 15 & & & & 98 \\
\hline $\mathbf{5}$ & Baum-X & 5 & 10 & & & & 95 \\
\hline $\mathbf{6}$ & Baum-X & 10 & 15 & & & & 90 \\
\hline $\mathbf{7}$ & Baum-X & 10 & 10 & & & & 98 \\
\hline $\mathbf{8}$ & Baum-X & 5 & 10 & & & & 95 \\
\hline $\mathbf{9}$ & Baum-X & 10 & 10 & & & & 90 \\
\hline $\mathbf{1 0}$ & Baum-X & 10 & 15 & & & & 95 \\
\hline $\mathbf{1 1}$ & Baum-X & 10 & 10 & & & & 98 \\
\hline $\mathbf{1 2}$ & Baum-X & 10 & 20 & & & & 90 \\
\hline & & & & & & & \\
\hline $\mathbf{1}$ & Baum-N & 25 & 30 & 50 & 35 & 80 & 98 \\
\hline $\mathbf{2}$ & Baum-N & 15 & 10 & 30 & 25 & 60 & 98 \\
\hline $\mathbf{3}$ & Baum-N & 20 & 30 & 40 & 45 & 75 & 95 \\
\hline $\mathbf{4}$ & Baum-N & 10 & 10 & 25 & 40 & 90 & 85 \\
\hline $\mathbf{5}$ & Baum-N & 5 & 5 & 25 & 30 & 80 & 98 \\
\hline $\mathbf{6}$ & Baum-N & 10 & 15 & 30 & 50 & 50 & 90 \\
\hline $\mathbf{7}$ & Baum-N & 10 & 5 & 35 & 40 & 55 & 95 \\
\hline $\mathbf{8}$ & Baum-N & 5 & 15 & 40 & 50 & 80 & 100 \\
\hline $\mathbf{9}$ & Baum-N & 5 & 5 & 25 & 30 & 60 & 85 \\
\hline $\mathbf{1 0}$ & Baum-N & 10 & 15 & 25 & 30 & 65 & 95 \\
\hline $\mathbf{1 1}$ & Baum-N & 10 & 10 & 20 & 35 & 60 & 95 \\
\hline $\mathbf{1 2}$ & Baum-N & 10 & 20 & 20 & 45 & 75 & 90 \\
\hline & & & & & & & \\
\hline $\mathbf{1}$ & Baum 2 & 25 & 30 & 60 & 40 & 85 & 100 \\
\hline $\mathbf{2}$ & Baum 2 & 15 & 15 & 45 & 30 & 80 & 95 \\
\hline $\mathbf{3}$ & Baum 2 & 20 & 20 & 50 & 55 & 70 & 95 \\
\hline $\mathbf{4}$ & Baum 2 & 5 & 5 & 30 & 50 & 80 & 85 \\
\hline $\mathbf{5}$ & Baum 2 & 10 & 15 & 20 & 35 & 75 & 98 \\
\hline
\end{tabular}


Fortsetzung Tab. C-10

\begin{tabular}{|c|c|c|c|c|c|c|c|}
\hline & & \multicolumn{6}{|c|}{ Beobachtungszeitpunkte in der Freilandsaison 1997} \\
\hline Reihe & Baumposition & 19.05 . & 22.05 . & 29.05 . & 12.06. & 04.07. & 04.09. \\
\hline 6 & Baum 2 & 15 & 20 & 35 & 50 & 75 & 85 \\
\hline 7 & Baum 2 & 3 & 3 & 30 & 7 & 60 & 98 \\
\hline 8 & Baum 2 & 5 & 10 & 30 & 40 & 50 & 95 \\
\hline 9 & Baum 2 & 5 & 10 & 30 & 45 & 70 & 90 \\
\hline 10 & Baum 2 & 20 & 30 & 40 & 40 & 80 & 97 \\
\hline 11 & Baum 2 & 10 & 15 & 25 & 25 & 60 & 98 \\
\hline 12 & Baum 2 & 15 & 20 & 10 & 35 & 80 & 90 \\
\hline 1 & Baum 3 & 20 & 30 & 55 & 50 & 85 & 90 \\
\hline 2 & Baum 3 & 15 & 15 & 30 & 30 & 80 & 85 \\
\hline 3 & Baum 3 & 25 & 30 & 45 & 60 & 90 & 96 \\
\hline 4 & Baum 3 & 5 & 5 & 15 & 30 & 75 & 100 \\
\hline 5 & Baum 3 & 5 & 5 & 30 & 15 & 75 & 95 \\
\hline 6 & Baum 3 & 20 & 20 & 30 & 30 & 55 & 90 \\
\hline 7 & Baum 3 & 5 & 10 & 30 & 60 & 80 & 98 \\
\hline 8 & Baum 3 & 10 & 10 & 40 & 40 & 80 & 100 \\
\hline 9 & Baum 3 & 10 & 10 & 30 & 30 & 50 & 98 \\
\hline 10 & Baum 3 & 10 & 15 & 40 & 50 & 70 & 100 \\
\hline 11 & Baum 3 & 10 & 15 & 30 & 20 & 75 & 100 \\
\hline 12 & Baum 3 & 10 & 20 & 35 & 40 & 77 & 95 \\
\hline 1 & Baum 4 & 20 & 20 & 50 & 55 & 85 & 100 \\
\hline 2 & Baum 4 & 20 & 20 & 30 & 40 & 60 & 90 \\
\hline 3 & Baum 4 & 10 & 10 & 45 & 55 & 55 & 90 \\
\hline 4 & Baum 4 & 10 & 15 & 25 & 40 & 80 & 90 \\
\hline 5 & Baum 4 & 5 & 5 & 25 & 30 & 80 & 98 \\
\hline 6 & Baum 4 & 10 & 15 & 25 & 30 & 60 & 90 \\
\hline 7 & Baum 4 & 5 & 10 & 35 & 10 & 75 & 98 \\
\hline 8 & Baum 4 & 5 & 10 & 30 & 30 & 60 & 98 \\
\hline 9 & Baum 4 & 10 & 15 & 40 & 10 & 70 & 98 \\
\hline 10 & Baum 4 & 20 & 25 & 40 & 40 & 40 & 97 \\
\hline 11 & Baum 4 & 10 & 15 & 15 & 20 & 80 & 100 \\
\hline 12 & Baum 4 & 15 & 20 & 30 & 75 & 77 & 90 \\
\hline 1 & Baum 5 & 30 & 30 & 60 & 55 & 90 & 98 \\
\hline 2 & Baum 5 & 20 & 20 & 40 & 30 & 70 & 100 \\
\hline 3 & Baum 5 & 30 & 30 & 45 & 40 & 60 & 97 \\
\hline 4 & Baum 5 & 15 & 20 & 25 & 40 & 90 & 100 \\
\hline 5 & Baum 5 & 10 & 20 & 30 & 40 & 85 & 95 \\
\hline 6 & Baum 5 & 10 & 15 & 30 & 15 & 60 & 80 \\
\hline 7 & Baum 5 & 10 & 15 & 35 & 30 & 80 & 90 \\
\hline 8 & Baum 5 & 5 & 20 & 20 & 40 & 80 & 98 \\
\hline 9 & Baum 5 & 5 & 5 & 50 & 60 & 60 & 90 \\
\hline 10 & Baum 5 & 20 & 25 & 20 & 60 & 75 & 95 \\
\hline 11 & Baum 5 & 5 & 5 & 10 & 40 & 70 & 95 \\
\hline 12 & Baum 5 & 5 & 10 & 30 & 50 & 60 & 95 \\
\hline 1 & Baum 6 & 25 & 30 & 60 & 45 & 80 & 100 \\
\hline 2 & Baum 6 & 10 & 10 & 50 & 20 & 60 & 80 \\
\hline 3 & Baum 6 & 25 & 25 & 30 & 40 & 50 & 90 \\
\hline
\end{tabular}


Fortsetzung Tab. C-10

\begin{tabular}{|c|c|c|c|c|c|c|c|}
\hline & & \multicolumn{6}{|c|}{ Beobachtungszeitpunkte in der Freilandsaison 1997 } \\
\hline Reihe & Baumposition & $\mathbf{1 9 . 0 5 .}$ & $\mathbf{2 2 . 0 5}$ & $\mathbf{2 9 . 0 5 .}$ & $\mathbf{1 2 . 0 6 .}$ & $\mathbf{0 4 . 0 7 .}$ & $\mathbf{0 4 . 0 9 .}$ \\
\hline $\mathbf{4}$ & Baum 6 & 20 & 25 & 30 & 30 & 95 & 95 \\
\hline $\mathbf{5}$ & Baum 6 & 20 & 25 & 30 & 50 & 85 & 98 \\
\hline $\mathbf{6}$ & Baum 6 & 5 & 10 & 20 & 35 & 80 & 90 \\
\hline & & & & & & & \\
\hline $\mathbf{1}$ & Baum-K & 20 & 25 & 50 & 40 & 90 & 90 \\
\hline $\mathbf{2}$ & Baum-K & 15 & 15 & 35 & 30 & 60 & 90 \\
\hline $\mathbf{3}$ & Baum-K & 25 & 25 & 30 & 40 & 75 & 98 \\
\hline $\mathbf{4}$ & Baum-K & 10 & 15 & 20 & 20 & 85 & 98 \\
\hline $\mathbf{5}$ & Baum-K & 5 & 5 & 35 & 10 & 75 & 98 \\
\hline $\mathbf{6}$ & Baum-K & 5 & 10 & 30 & 55 & 50 & 90 \\
\hline $\mathbf{7}$ & Baum-K & 5 & 10 & 40 & 45 & 50 & 98 \\
\hline $\mathbf{8}$ & Baum-K & 5 & 10 & 45 & 45 & 80 & 100 \\
\hline $\mathbf{9}$ & Baum-K & 5 & 10 & 20 & 35 & 55 & 98 \\
\hline $\mathbf{1 0}$ & Baum-K & 10 & 10 & 20 & 35 & 70 & 98 \\
\hline $\mathbf{1 1}$ & Baum-K & 5 & 5 & 25 & 30 & 65 & 98 \\
\hline $\mathbf{1 2}$ & Baum-K & 5 & 10 & 30 & 30 & 70 & 95 \\
\hline
\end{tabular}

Tab. C-11: „Reihenversuch“. Angegeben ist der prozentuale Blattwassergehalt [\%] von Alnus glutinosa-Blättern einer unmittelbar benachbarten, unverletzten Erle „Baum-Nachbar“ und einer weiter entfernt stehenden Erle „Baum-Kontrolle“ zu den jeweiligen Beobachtungszeitpunkten.

\begin{tabular}{|c|c|c|c|c|c|c|c|}
\hline & & \multicolumn{6}{|c|}{ Beobachtungszeitpunkte in der Freilandsaison 1997 } \\
\hline Reihe & Baumposition & $\mathbf{1 9 . 0 5 .}$ & $\mathbf{2 2 . 0 5 .}$ & $\mathbf{2 9 . 0 5 .}$ & $\mathbf{1 2 . 0 6 .}$ & $\mathbf{0 4 . 0 7 .}$ & $\mathbf{0 4 . 0 9 .}$ \\
\hline $\mathbf{1}$ & Baum-Kontrolle & 71,74 & 72,99 & 69,45 & 65,12 & 63,79 & 62,08 \\
\hline $\mathbf{1}$ & Baum-Nachbar & 70,62 & 70,74 & 66,61 & 61,97 & 67,20 & 61,64 \\
\hline $\mathbf{2}$ & Baum-Kontrolle & 70,07 & 64,37 & 63,54 & 61,94 & 65,53 & 61,67 \\
\hline $\mathbf{2}$ & Baum-Nachbar & 71,95 & 70,47 & 65,82 & 66,04 & 62,30 & 62,41 \\
\hline $\mathbf{3}$ & Baum-Kontrolle & 72,46 & 69,33 & 67,86 & 63,24 & 62,30 & 64,19 \\
\hline $\mathbf{3}$ & Baum-Nachbar & 71,57 & 73,41 & 69,67 & 63,80 & 66,93 & 64,07 \\
\hline $\mathbf{4}$ & Baum-Kontrolle & 72,53 & 71,04 & 69,45 & 67,13 & 68,62 & 65,64 \\
\hline $\mathbf{4}$ & Baum-Nachbar & 71,12 & 70,43 & 68,49 & 64,09 & 65,18 & 62,65 \\
\hline $\mathbf{5}$ & Baum-Kontrolle & 71,43 & 71,56 & 69,50 & 64,96 & 67,87 & 62,40 \\
\hline $\mathbf{5}$ & Baum-Nachbar & 68,79 & 70,47 & 67,39 & 64,29 & 64,07 & 61,02 \\
\hline $\mathbf{6}$ & Baum-Kontrolle & 69,44 & 71,51 & 67,27 & 67,72 & 65,50 & 63,88 \\
\hline $\mathbf{6}$ & Baum-Nachbar & 69,92 & 68,52 & 64,17 & 62,58 & 68,71 & 63,41 \\
\hline $\mathbf{7}$ & Baum-Kontrolle & 70,60 & 71,94 & 68,76 & 64,71 & 59,70 & 61,96 \\
\hline $\mathbf{7}$ & Baum-Nachbar & 70,57 & 70,45 & 68,83 & 68,19 & 64,82 & 60,93 \\
\hline $\mathbf{8}$ & Baum-Kontrolle & 71,88 & 73,58 & 69,79 & 66,90 & 66,72 & 62,76 \\
\hline $\mathbf{8}$ & Baum-Nachbar & 71,23 & 70,98 & 68,04 & 62,99 & 65,88 & 60,51 \\
\hline $\mathbf{9}$ & Baum-Kontrolle & 71,88 & 73,58 & 69,79 & 66,90 & 66,72 & 62,76 \\
\hline $\mathbf{9}$ & Baum-Nachbar & 72,47 & 68,41 & 67,54 & 65,70 & 68,54 & 61,70 \\
\hline $\mathbf{1 0}$ & Baum-Kontrolle & 71,52 & 69,73 & 65,91 & 62,58 & 66,97 & 60,12 \\
\hline $\mathbf{1 0}$ & Baum-Nachbar & 71,69 & 71,42 & 70,41 & 65,86 & 67,19 & 64,57 \\
\hline $\mathbf{1 1}$ & Baum-Kontrolle & 64,77 & 71,93 & 71,28 & 68,05 & 67,24 & 61,78 \\
\hline $\mathbf{1 1}$ & Baum-Nachbar & 67,31 & 70,59 & 68,34 & 64,45 & 67,58 & 62,36 \\
\hline $\mathbf{1 2}$ & Baum-Kontrolle & 68,29 & 70,72 & 66,90 & 63,28 & 62,80 & 60,88 \\
\hline $\mathbf{1 2}$ & Baum-Nachbar & 64,67 & 72,98 & 69,80 & 65,45 & 69,01 & 64,90 \\
\hline
\end{tabular}


Tab. C-12: „Reihenversuch“. Angegeben ist das spezifische Blattgewicht $\left[\mathrm{mg} \mathrm{cm}^{-2}\right]$ von Alnus glutinosa-Blättern einer unmittelbar benachbarten, unverletzten Erle „Baum-Nachbar“ und einer weiter entfernt stehenden Erle „Baum-Kontrolle“ ${ }^{6 u}$ den jeweiligen Beobachtungszeitpunkten.

\begin{tabular}{|c|c|c|c|c|c|c|c|}
\hline & & \multicolumn{7}{|c|}{ Beobachtungszeitpunkte in der Freilandsaison 1997 } \\
\hline Reihe & Baumposition & $\mathbf{1 9 . 0 5 .}$ & $\mathbf{2 2 . 0 5 .}$ & $\mathbf{2 9 . 0 5 .}$ & $\mathbf{1 2 . 0 6 .}$ & $\mathbf{0 4 . 0 7 .}$ & $\mathbf{0 4 . 0 9 .}$ \\
\hline $\mathbf{1}$ & Baum-Kontrolle & 7,86 & 4,38 & 5,57 & 5,59 & 5,74 & 2,44 \\
\hline $\mathbf{1}$ & Baum-Nachbar & 6,40 & 6,20 & 6,59 & 4,96 & 5,31 & 4,01 \\
\hline $\mathbf{2}$ & Baum-Kontrolle & 7,45 & 4,72 & 6,47 & 5,71 & 5,21 & 3,44 \\
\hline $\mathbf{2}$ & Baum-Nachbar & 6,98 & 4,28 & 7,04 & 5,50 & 4,96 & 4,03 \\
\hline $\mathbf{3}$ & Baum-Kontrolle & 5,26 & 2,48 & 4,68 & 5,57 & 4,08 & 4,14 \\
\hline $\mathbf{3}$ & Baum-Nachbar & 7,43 & 5,69 & 5,29 & 4,67 & 4,42 & 4,21 \\
\hline $\mathbf{4}$ & Baum-Kontrolle & 7,42 & 5,58 & 5,11 & 4,20 & 2,92 & 3,99 \\
\hline $\mathbf{4}$ & Baum-Nachbar & 5,59 & 6,41 & 6,15 & 5,65 & 3,85 & 5,02 \\
\hline $\mathbf{5}$ & Baum-Kontrolle & 6,51 & 5,66 & 6,43 & 5,92 & 5,84 & 5,05 \\
\hline $\mathbf{5}$ & Baum-Nachbar & 5,27 & 3,57 & 5,31 & 5,66 & 4,27 & 3,91 \\
\hline $\mathbf{6}$ & Baum-Kontrolle & 6,64 & 5,61 & 5,78 & 5,50 & 5,63 & 4,79 \\
\hline $\mathbf{6}$ & Baum-Nachbar & 6,18 & 3,91 & 6,11 & 5,71 & 4,49 & 4,12 \\
\hline $\mathbf{7}$ & Baum-Kontrolle & 5,38 & 7,33 & 5,58 & 6,21 & 4,86 & 4,60 \\
\hline $\mathbf{7}$ & Baum-Nachbar & 5,64 & 5,93 & 5,59 & 4,89 & 4,37 & 5,28 \\
\hline $\mathbf{8}$ & Baum-Kontrolle & 5,27 & 4,87 & 7,02 & 5,30 & 4,20 & 5,02 \\
\hline $\mathbf{8}$ & Baum-Nachbar & 4,14 & 6,87 & 5,06 & 4,87 & 4,42 & 4,11 \\
\hline $\mathbf{9}$ & Baum-Kontrolle & 6,71 & 3,63 & 6,61 & 4,56 & 3,98 & 4,13 \\
\hline $\mathbf{9}$ & Baum-Nachbar & 5,72 & 7,89 & 6,55 & 5,64 & 5,22 & 3,62 \\
\hline $\mathbf{1 0}$ & Baum-Kontrolle & 5,85 & 4,23 & 5,72 & 4,30 & 4,53 & 3,68 \\
\hline $\mathbf{1 0}$ & Baum-Nachbar & 6,84 & 4,10 & 5,41 & 4,87 & 4,64 & 4,34 \\
\hline $\mathbf{1 1}$ & Baum-Kontrolle & 6,44 & 5,58 & 5,16 & 4,12 & 2,65 & 2,97 \\
\hline $\mathbf{1 1}$ & Baum-Nachbar & 6,58 & 2,96 & 6,16 & 5,53 & 2,91 & 3,21 \\
\hline $\mathbf{1 2}$ & Baum-Kontrolle & 7,28 & 5,77 & 5,42 & 4,39 & 2,48 & 3,10 \\
\hline $\mathbf{1 2}$ & Baum-Nachbar & 8,02 & 5,35 & 4,94 & 5,83 & 3,91 & 3,24 \\
\hline
\end{tabular}

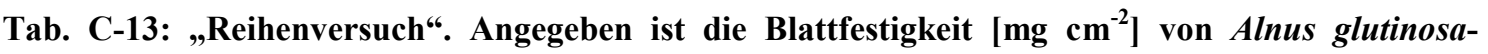
Blättern einer unmittelbar benachbarten, unverletzten Erle „Baum-Nachbar“6 und einer weiter entfernt stehenden Erle „Baum-Kontrolle“ zu den jeweiligen Beobachtungszeitpunkten.

\begin{tabular}{|c|c|c|c|c|c|c|c|}
\hline & & \multicolumn{5}{|c|}{ Beobachtungszeitpunkte in der Freilandsaison 1997 } \\
\hline Reihe & Baumposition & $\mathbf{1 9 . 0 5 .}$ & $\mathbf{2 2 . 0 5 .}$ & $\mathbf{2 9 . 0 5 .}$ & $\mathbf{1 2 . 0 6 .}$ & $\mathbf{0 4 . 0 7 .}$ & $\mathbf{0 4 . 0 9 .}$ \\
\hline $\mathbf{1}$ & Baum-Kontrolle & 998,15 & 961,40 & 1126,39 & 1126,72 & 863,32 & 984,11 \\
\hline $\mathbf{1}$ & Baum-Nachbar & 992,37 & 907,20 & 1181,88 & 1180,39 & 846,41 & 1187,54 \\
\hline $\mathbf{2}$ & Baum-Kontrolle & 1021,82 & 1075,48 & 1235,09 & 1151,60 & 873,93 & 1259,74 \\
\hline $\mathbf{2}$ & Baum-Nachbar & 1066,62 & 866,59 & 1157,78 & 1024,88 & 934,52 & 1130,76 \\
\hline $\mathbf{3}$ & Baum-Kontrolle & 1012,90 & 1180,06 & 1280,95 & 1324,88 & 983,40 & 1205,90 \\
\hline $\mathbf{3}$ & Baum-Nachbar & 992,04 & 935,76 & 841,37 & 985,22 & 995,92 & 922,51 \\
\hline $\mathbf{4}$ & Baum-Kontrolle & 1133,76 & 1074,39 & 1226,35 & 1023,10 & 780,43 & 1171,34 \\
\hline $\mathbf{4}$ & Baum-Nachbar & 997,66 & 973,44 & 1267,22 & 1073,66 & 986,88 & 1292,36 \\
\hline $\mathbf{5}$ & Baum-Kontrolle & 1127,57 & 1091,89 & 950,60 & 1075,99 & 908,85 & 1095,93 \\
\hline $\mathbf{5}$ & Baum-Nachbar & 1110,19 & 948,84 & 998,58 & 1007,33 & 858,08 & 1084,95 \\
\hline $\mathbf{6}$ & Baum-Kontrolle & 1078,62 & 996,28 & 1158,81 & 1176,05 & 993,60 & 1364,18 \\
\hline $\mathbf{6}$ & Baum-Nachbar & 1085,72 & 1012,53 & 1497,19 & 1390,54 & 892,41 & 1211,39 \\
\hline $\mathbf{7}$ & Baum-Kontrolle & 862,71 & 1139,14 & 1079,72 & 1078,46 & 1083,50 & 1021,38 \\
\hline $\mathbf{7}$ & Baum-Nachbar & 793,69 & 1144,35 & 1016,22 & 1121,04 & 990,48 & 1079,30 \\
\hline
\end{tabular}


Fortsetzung Tab. C-13

\begin{tabular}{|c|c|c|c|c|c|c|c|}
\hline & & \multicolumn{6}{|c|}{ Beobachtungszeitpunkte in der Freilandsaison 1997 } \\
\hline Reihe & Baumposition & $\mathbf{1 9 . 0 5 .}$ & $\mathbf{2 2 . 0 5 .}$ & $\mathbf{2 9 . 0 5 .}$ & $\mathbf{1 2 . 0 6 .}$ & $\mathbf{0 4 . 0 7 .}$ & $\mathbf{0 4 . 0 9}$. \\
\hline $\mathbf{8}$ & Baum-Kontrolle & 771,15 & 1123,81 & 1093,37 & 1279,00 & 1120,58 & 1264,44 \\
\hline $\mathbf{8}$ & Baum-Nachbar & 855,48 & 964,88 & 1424,40 & 1067,97 & 980,23 & 1289,04 \\
\hline $\mathbf{9}$ & Baum-Kontrolle & 988,98 & 826,82 & 1083,08 & 1012,60 & 1037,62 & 1146,95 \\
\hline $\mathbf{9}$ & Baum-Nachbar & 981,33 & 859,18 & 1179,72 & 1334,95 & 960,05 & 937,28 \\
\hline $\mathbf{1 0}$ & Baum-Kontrolle & 974,14 & 1081,25 & 1294,91 & 1168,10 & 956,30 & 1194,42 \\
\hline $\mathbf{1 0}$ & Baum-Nachbar & 991,83 & 1117,64 & 1157,23 & 1139,34 & 958,03 & 1048,83 \\
\hline $\mathbf{1 1}$ & Baum-Kontrolle & 1041,77 & 934,52 & 1033,96 & 1019,69 & 1043,46 & 1139,71 \\
\hline $\mathbf{1 1}$ & Baum-Nachbar & 946,96 & 921,14 & 1257,42 & 1147,21 & 1161,48 & 1180,85 \\
\hline $\mathbf{1 2}$ & Baum-Kontrolle & 872,29 & 944,67 & 1257,83 & 1131,55 & 1119,79 & 1084,09 \\
\hline $\mathbf{1 2}$ & Baum-Nachbar & 925,78 & 1070,77 & 1226,98 & 1017,77 & 1047,96 & 1143,93 \\
\hline
\end{tabular}

Tab. C-14: „Reihenversuch“. Angegeben ist die gefressene Blattmenge [mg DW] durch Agelastica alni-Imagines bzw. Larven (L) im Fraßwahlversuch. Den Imagines wurden Blattstücke von Alnus glutinosa-Blättern einer unmittelbar benachbarten, unverletzten Erle „Baum-Nachbar“ und einer weiter entfernt stehenden Erle „Baum-Kontrolle“ angeboten.

\begin{tabular}{|c|c|c|c|c|c|c|c|c|c|c|}
\hline & & \multicolumn{9}{|c|}{ Beobachtungszeitpunkte in der Freilandsaison 1997 } \\
\hline Reihe & Baumposition & $\mathbf{1 9 . 0 5}$. & $\mathbf{2 2 . 0 5 .}$ & $\mathbf{2 9 . 0 5 .}$ & $\mathbf{1 2 . 0 6 .}$ & $\mathbf{1 2 . 0 6 .}(\mathbf{L})$ & $\mathbf{0 4 . 0 7 .}$ & $\mathbf{0 4 . 0 7 . (} \mathbf{( L )}$ & $\mathbf{0 4 . 0 9 .}$ \\
\hline $\mathbf{1}$ & Baum-Kontrolle & 4,76 & 3,16 & 3,49 & 2,92 & 3,05 & 3,45 & 4,24 & 1,51 \\
\hline $\mathbf{1}$ & Baum-Nachbar & 4,11 & 1,80 & 1,33 & 3,87 & 1,18 & 3,08 & 2,54 & 1,53 \\
\hline $\mathbf{2}$ & Baum-Kontrolle & 3,96 & 3,72 & 1,50 & 5,39 & 3,17 & 4,45 & 2,01 & 1,30 \\
\hline $\mathbf{2}$ & Baum-Nachbar & 4,19 & 3,47 & 4,17 & 2,89 & 0,61 & 2,57 & 1,60 & 5,03 \\
\hline $\mathbf{3}$ & Baum-Kontrolle & 4,20 & 2,39 & 2,93 & 2,64 & 5,53 & 2,47 & 1,63 & 2,86 \\
\hline $\mathbf{3}$ & Baum-Nachbar & 4,00 & 2,02 & 4,15 & 3,11 & 2,43 & 4,18 & 1,18 & 4,32 \\
\hline $\mathbf{4}$ & Baum-Kontrolle & 4,10 & 4,63 & 4,98 & 4,40 & 2,89 & 2,88 & 2,15 & 2,44 \\
\hline $\mathbf{4}$ & Baum-Nachbar & 4,48 & 4,60 & 1,85 & 3,40 & 3,16 & 3,39 & 4,79 & 4,38 \\
\hline $\mathbf{5}$ & Baum-Kontrolle & 4,38 & 3,47 & 5,87 & 4,54 & 0,35 & 2,54 & 1,32 & 0,76 \\
\hline $\mathbf{5}$ & Baum-Nachbar & 7,97 & 2,86 & 6,69 & 6,49 & 2,12 & 5,20 & 2,22 & 4,32 \\
\hline $\mathbf{6}$ & Baum-Kontrolle & 4,30 & 1,79 & 8,60 & 5,06 & 2,49 & 2,95 & 1,53 & 2,38 \\
\hline $\mathbf{6}$ & Baum-Nachbar & 6,81 & 3,00 & 7,76 & 3,61 & 3,53 & 4,29 & 3,18 & 0,30 \\
\hline $\mathbf{7}$ & Baum-Kontrolle & 3,27 & 1,12 & 2,43 & 2,65 & 1,42 & 3,20 & 1,90 & 5,88 \\
\hline $\mathbf{7}$ & Baum-Nachbar & 3,21 & 2,67 & 1,29 & 1,94 & 3,19 & 3,41 & 2,53 & 4,95 \\
\hline $\mathbf{8}$ & Baum-Kontrolle & 3,54 & 3,58 & 2,66 & 2,01 & 1,80 & 4,44 & 6,06 & 2,24 \\
\hline $\mathbf{8}$ & Baum-Nachbar & 6,69 & 3,25 & 2,18 & 3,49 & 0,81 & 4,90 & 3,17 & 1,39 \\
\hline $\mathbf{9}$ & Baum-Kontrolle & 2,99 & 2,82 & 5,10 & 3,93 & 2,69 & 3,11 & 2,99 & 0,04 \\
\hline $\mathbf{9}$ & Baum-Nachbar & 4,83 & 2,83 & 1,62 & 1,51 & 2,50 & 3,46 & 2,32 & 2,67 \\
\hline $\mathbf{1 0}$ & Baum-Kontrolle & 2,62 & 2,66 & 4,97 & 2,86 & 0,49 & 1,47 & 2,23 & 1,77 \\
\hline $\mathbf{1 0}$ & Baum-Nachbar & 2,62 & 1,07 & 7,19 & 2,37 & 3,84 & 2,91 & 2,53 & 1,59 \\
\hline $\mathbf{1 1}$ & Baum-Kontrolle & 4,02 & 3,93 & 5,77 & 2,51 & & 6,08 & 2,42 & 1,83 \\
\hline $\mathbf{1 1}$ & Baum-Nachbar & 5,05 & 4,55 & 6,80 & 3,78 & & 3,83 & 2,50 & 0,22 \\
\hline $\mathbf{1 2}$ & Baum-Kontrolle & 5,60 & 2,52 & 6,44 & 1,81 & & 3,28 & 5,35 & 1,40 \\
\hline $\mathbf{1 2}$ & Baum-Nachbar & 4,32 & 4,83 & 6,49 & 3,88 & & 6,80 & 2,68 & 4,47 \\
\hline
\end{tabular}


Tab. C-15: „JA-Versuch“. Angegeben ist die relative Blattschädigung [\%] von Alnus glutinosaBlättern der Erlenpflanzen „Baumnachbar-Kon“ und „Baumnachbar-JA“ zu den jeweiligen Beobachtungszeitpunkten.

\begin{tabular}{|c|c|c|c|c|c|c|c|c|}
\hline & & \multicolumn{6}{|c|}{ Beobachtungszeitpunkte in der Freilandsaison 1998 } \\
\hline Plot-Nr. & Baumposition & $\mathbf{0 6 . 0 5 .}$ & $\mathbf{1 2 . 0 5 .}$ & $\mathbf{1 9 . 0 5 .}$ & $\mathbf{0 9 . 0 6 .}$ & $\mathbf{1 7 . 0 7 .}$ & $\mathbf{2 4 . 0 7 .}$ & $\mathbf{1 5 . 0 8 .}$ \\
\hline $\mathbf{1}$ & Baumnachbar-Kon & 7,24 & 13,27 & 23,37 & 32,50 & 58,34 & 66,71 & 61,25 \\
\hline $\mathbf{1}$ & Baumnachbar-JA & 4,03 & 2,94 & 4,79 & 21,25 & 22,71 & 23,96 & 30,13 \\
\hline $\mathbf{2}$ & Baumnachbar-Kon & 1,41 & 11,90 & 18,30 & 28,96 & 40,83 & 43,37 & 56,00 \\
\hline $\mathbf{2}$ & Baumnachbar-JA & 3,81 & 5,78 & 3,35 & 15,71 & 26,67 & 25,77 & 31,25 \\
\hline $\mathbf{3}$ & Baumnachbar-Kon & 7,39 & 13,99 & 16,37 & 37,50 & 41,70 & 41,67 & 51,50 \\
\hline $\mathbf{3}$ & Baumnachbar-JA & 0,90 & 1,61 & 1,31 & 12,07 & 26,64 & 11,22 & 32,50 \\
\hline $\mathbf{4}$ & Baumnachbar-Kon & 2,94 & 12,33 & 13,36 & 26,46 & 42,08 & 40,00 & 50,25 \\
\hline $\mathbf{4}$ & Baumnachbar-JA & 1,47 & 1,62 & 2,30 & 12,32 & 17,08 & 26,22 & 30,25 \\
\hline $\mathbf{5}$ & Baumnachbar-Kon & 1,71 & 12,54 & 12,89 & 31,90 & 42,09 & 42,29 & 49,90 \\
\hline $\mathbf{5}$ & Baumnachbar-JA & 0,91 & 0,94 & 0,48 & 12,66 & 28,33 & 30,41 & 30,13 \\
\hline $\mathbf{6}$ & Baumnachbar-Kon & 3,41 & 14,09 & 14,96 & 40,83 & 42,08 & 39,16 & 66,65 \\
\hline $\mathbf{6}$ & Baumnachbar-JA & 4,80 & 4,04 & 3,09 & 21,67 & 22,11 & 26,66 & 32,45 \\
\hline
\end{tabular}

Tab. C-16: „JA-Versuch“. Angegeben ist der prozentuale Blattwassergehalt [\%] von Alnus glutinosa-Blättern der Erlenpflanzen „Baumnachbar-Kon“ und „Baumnachbar-JA“ zu den jeweiligen Beobachtungszeitpunkten.

\begin{tabular}{|c|c|c|c|c|c|c|c|c|}
\hline & & \multicolumn{6}{|c|}{ Beobachtungszeitpunkte in der Freilandsaison 1998 } \\
\hline Plot-Nr. & Baumposition & $\mathbf{0 6 . 0 5}$ & $\mathbf{1 2 . 0 5}$ & $\mathbf{1 9 . 0 5 .}$ & $\mathbf{0 9 . 0 6 .}$ & $\mathbf{1 7 . 0 7 .}$ & $\mathbf{2 4 . 0 7 .}$ & $\mathbf{1 5 . 0 8 .}$ \\
\hline $\mathbf{1}$ & Baumnachbar-Kon & 72,01 & 66,49 & 64,25 & 62,57 & 65,59 & 65,45 & 60,95 \\
\hline $\mathbf{1}$ & Baumnachbar-JA & 70,56 & 64,71 & 61,36 & 63,77 & 65,35 & 66,10 & 65,68 \\
\hline $\mathbf{2}$ & Baumnachbar-Kon & 71,99 & 65,30 & 62,47 & 61,90 & 65,10 & 66,95 & 66,87 \\
\hline $\mathbf{2}$ & Baumnachbar-JA & 70,91 & 66,97 & 65,48 & 62,35 & 66,26 & 66,18 & 64,56 \\
\hline $\mathbf{3}$ & Baumnachbar-Kon & 71,41 & 64,96 & 63,41 & 64,47 & 63,95 & 64,05 & 63,44 \\
\hline $\mathbf{3}$ & Baumnachbar-JA & 68,08 & 61,47 & 64,04 & 64,21 & 65,35 & 64,77 & 64,31 \\
\hline $\mathbf{4}$ & Baumnachbar-Kon & 68,63 & 66,39 & 62,73 & 62,64 & 65,02 & 65,90 & 65,10 \\
\hline $\mathbf{4}$ & Baumnachbar-JA & 67,80 & 66,82 & 62,15 & 65,58 & 66,28 & 66,99 & 66,60 \\
\hline $\mathbf{5}$ & Baumnachbar-Kon & 70,91 & 67,45 & 62,24 & 62,97 & 64,31 & 65,37 & 60,47 \\
\hline $\mathbf{5}$ & Baumnachbar-JA & 70,92 & 66,69 & 62,60 & 63,61 & 65,57 & 66,15 & 69,22 \\
\hline $\mathbf{6}$ & Baumnachbar-Kon & 68,98 & 66,59 & 63,80 & 62,29 & 66,10 & 66,12 & 54,06 \\
\hline $\mathbf{6}$ & Baumnachbar-JA & 71,86 & 67,46 & 64,56 & 62,91 & 64,74 & 68,20 & 66,27 \\
\hline
\end{tabular}

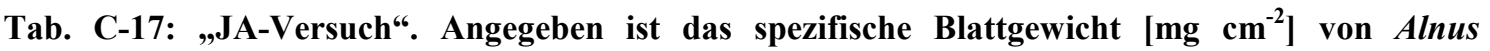
glutinosa-Blättern der Erlenpflanzen „Baumnachbar-Kon“ und „Baumnachbar-JA“ zu den jeweiligen Beobachtungszeitpunkten.

\begin{tabular}{|c|c|c|c|c|c|c|c|c|}
\hline & & \multicolumn{6}{|c|}{ Beobachtungszeitpunkte in der Freilandsaison 1998 } \\
\hline Plot-Nr. & Baumposition & $\mathbf{0 6 . 0 5 .}$ & $\mathbf{1 2 . 0 5 .}$ & $\mathbf{1 9 . 0 5 .}$ & $\mathbf{0 9 . 0 6 .}$ & $\mathbf{1 7 . 0 7 .}$ & $\mathbf{2 4 . 0 7 .}$ & $\mathbf{1 5 . 0 8 .}$ \\
\hline $\mathbf{1}$ & Baumnachbar-Kon & 4,80 & 7,29 & 7,05 & 6,92 & 6,80 & 6,54 & 7,23 \\
\hline $\mathbf{1}$ & Baumnachbar-JA & 5,63 & 6,84 & 7,77 & 7,24 & 6,78 & 6,67 & 6,77 \\
\hline $\mathbf{2}$ & Baumnachbar-Kon & 5,14 & 6,68 & 6,89 & 7,32 & 6,51 & 6,02 & 6,64 \\
\hline $\mathbf{2}$ & Baumnachbar-JA & 5,16 & 6,28 & 6,49 & 7,01 & 6,12 & 6,34 & 6,38 \\
\hline $\mathbf{3}$ & Baumnachbar-Kon & 5,49 & 7,35 & 7,18 & 7,09 & 7,12 & 6,62 & 6,47 \\
\hline $\mathbf{3}$ & Baumnachbar-JA & 6,45 & 8,24 & 6,94 & 6,86 & 7,09 & 6,51 & 6,50 \\
\hline
\end{tabular}


Fortsetzung Tab. C-17

\begin{tabular}{|c|c|c|c|c|c|c|c|c|}
\hline & & \multicolumn{7}{|c|}{ Beobachtungszeitpunkte in der Freilandsaison 1998 } \\
\hline Plot-Nr. & Baumposition & $\mathbf{0 6 . 0 5 .}$ & $\mathbf{1 2 . 0 5 .}$ & $\mathbf{1 9 . 0 5}$ & $\mathbf{0 9 . 0 6}$ & $\mathbf{1 7 . 0 7 .}$ & $\mathbf{2 4 . 0 7 .}$ & $\mathbf{1 5 . 0 8 .}$ \\
\hline $\mathbf{4}$ & Baumnachbar-Kon & 5,89 & 5,84 & 6,92 & 7,30 & 6,50 & 5,97 & 6,40 \\
\hline $\mathbf{4}$ & Baumnachbar-JA & 6,01 & 6,37 & 7,20 & 6,43 & 6,21 & 6,03 & 6,01 \\
\hline $\mathbf{5}$ & Baumnachbar-Kon & 5,21 & 6,61 & 6,64 & 6,90 & 7,25 & 6,13 & 6,93 \\
\hline $\mathbf{5}$ & Baumnachbar-JA & 5,18 & 5,71 & 6,81 & 6,71 & 6,59 & 5,48 & 5,35 \\
\hline $\mathbf{6}$ & Baumnachbar-Kon & 5,61 & 6,00 & 6,88 & 6,67 & 6,25 & 5,69 & 8,03 \\
\hline $\mathbf{6}$ & Baumnachbar-JA & 4,84 & 5,54 & 6,29 & 7,06 & 7,16 & 6,26 & 6,65 \\
\hline
\end{tabular}

Tab. C-18: „JA-Versuch“. Angegeben ist die Blattfestigkeit $\left[\mathrm{mg} \mathrm{cm}^{-2}\right]$ von Alnus glutinosa-Blättern der Erlenpflanzen „Baumnachbar-Kon“ und „Baumnachbar-JA“ zu den jeweiligen Beobachtungszeitpunkten.

\begin{tabular}{|c|c|c|c|c|c|c|c|c|}
\hline & & \multicolumn{7}{|c|}{ Beobachtungszeitpunkte in der Freilandsaison 1998 } \\
\hline Plot-Nr. & Baumposition & $\mathbf{0 6 . 0 5 .}$ & $\mathbf{1 2 . 0 5}$ & $\mathbf{1 9 . 0 5}$ & $\mathbf{0 9 . 0 6 .}$ & $\mathbf{1 7 . 0 7 .}$ & $\mathbf{2 4 . 0 7 .}$ & $\mathbf{1 5 . 0 8 .}$ \\
\hline $\mathbf{1}$ & Baumnachbar-Kon & 839,01 & 1129,05 & 1757,30 & 2151,55 & 911,04 & 1281,46 & 1142,95 \\
\hline $\mathbf{1}$ & Baumnachbar-JA & 819,92 & 1954,17 & 1319,73 & 1241,24 & 1016,79 & 922,03 & 740,48 \\
\hline $\mathbf{2}$ & Baumnachbar-Kon & 849,80 & 1046,12 & 1348,07 & 985,12 & 1055,32 & 865,91 & 1131,99 \\
\hline $\mathbf{2}$ & Baumnachbar-JA & 724,32 & 935,12 & 1140,67 & 1288,18 & 1299,44 & 1069,46 & 1119,61 \\
\hline $\mathbf{3}$ & Baumnachbar-Kon & 756,33 & 1370,93 & 1114,25 & 1663,13 & 970,87 & 989,29 & 1313,77 \\
\hline $\mathbf{3}$ & Baumnachbar-JA & 1338,16 & 1638,97 & 1707,05 & 1973,11 & 1794,16 & 1518,21 & 1225,40 \\
\hline $\mathbf{4}$ & Baumnachbar-Kon & 937,42 & 973,44 & 1111,52 & 1002,75 & 1019,91 & 1284,95 & 1006,71 \\
\hline $\mathbf{4}$ & Baumnachbar-JA & 884,08 & 1035,99 & 1478,69 & 1061,95 & 1171,28 & 912,86 & 765,96 \\
\hline $\mathbf{5}$ & Baumnachbar-Kon & 846,90 & 1542,31 & 1452,26 & 1155,47 & 1446,30 & 891,19 & 973,13 \\
\hline $\mathbf{5}$ & Baumnachbar-JA & 926,69 & 1171,70 & 1236,53 & 1982,19 & 1110,88 & 1274,59 & 1122,62 \\
\hline $\mathbf{6}$ & Baumnachbar-Kon & 962,99 & 1113,42 & 1607,74 & 963,38 & 1306,95 & 804,79 & 1149,92 \\
\hline $\mathbf{6}$ & Baumnachbar-JA & 786,01 & 918,71 & 1041,14 & 1848,42 & 1183,04 & 1119,84 & 1112,97 \\
\hline
\end{tabular}

Tab. C-19: „JA-Versuch“. Angegeben ist der Phenolgehalt $\mathrm{DW}^{-1}\left[\mathrm{mg} \mathrm{g}^{-1}\right]$ von Alnus glutinosaBlättern der Erlenpflanzen „Baumnachbar-Kon“ und „Baumnachbar-JA“ zu den jeweiligen Beobachtungszeitpunkten.

\begin{tabular}{|c|c|c|c|c|c|c|c|c|}
\hline & & \multicolumn{7}{|c|}{ Beobachtungszeitpunkte in der Freilandsaison 1998 } \\
\hline Plot-Nr. & Baumposition & $\mathbf{0 6 . 0 5 .}$ & $\mathbf{1 2 . 0 5}$ & $\mathbf{1 9 . 0 5 .}$ & $\mathbf{0 9 . 0 6 .}$ & $\mathbf{1 7 . 0 7 .}$ & $\mathbf{2 4 . 0 7 .}$ & $\mathbf{1 5 . 0 8 .}$ \\
\hline $\mathbf{1}$ & Baumnachbar-Kon & 2,60 & 2,35 & 3,82 & 20,32 & 14,91 & 17,98 & 14,28 \\
\hline $\mathbf{1}$ & Baumnachbar-JA & 8,57 & 16,66 & 17,25 & 30,31 & 24,00 & 34,87 & 22,96 \\
\hline $\mathbf{2}$ & Baumnachbar-Kon & 12,92 & 8,63 & 18,41 & 13,42 & 14,79 & 16,30 & 10,76 \\
\hline $\mathbf{2}$ & Baumnachbar-JA & 2,57 & 11,57 & 15,87 & 31,14 & 37,76 & 40,77 & 33,72 \\
\hline $\mathbf{3}$ & Baumnachbar-Kon & 1,33 & 8,83 & 11,05 & 18,75 & 13,32 & 20,28 & 9,86 \\
\hline $\mathbf{3}$ & Baumnachbar-JA & 9,00 & 12,83 & 28,79 & 16,72 & 32,77 & 33,92 & 14,26 \\
\hline $\mathbf{4}$ & Baumnachbar-Kon & 2,55 & 4,28 & 14,36 & 10,43 & 16,95 & 16,26 & 11,15 \\
\hline $\mathbf{4}$ & Baumnachbar-JA & 12,65 & 13,24 & 29,72 & 26,25 & 25,09 & 18,76 & 20,46 \\
\hline $\mathbf{5}$ & Baumnachbar-Kon & 1,23 & 4,98 & 5,18 & 8,56 & 18,80 & 18,29 & 6,50 \\
\hline $\mathbf{5}$ & Baumnachbar-JA & 5,48 & 15,09 & 13,77 & 23,35 & 26,41 & 29,95 & 28,23 \\
\hline $\mathbf{6}$ & Baumnachbar-Kon & 13,09 & 9,09 & 9,07 & 9,78 & 26,77 & 27,99 & 28,30 \\
\hline $\mathbf{6}$ & Baumnachbar-JA & 5,65 & 19,28 & 32,78 & 18,99 & 34,31 & 64,32 & 41,68 \\
\hline
\end{tabular}


Tab. C-20: „JA-Versuch“. Angegeben ist die gefressene Blattmenge [mg DW] durch Agelastica alni-Imagines im Fraßwahlversuch. Den Imagines wurden Blattstücke von Alnus glutinosa-Blättern einer Erlenpflanze der Behandlungsvariante „Baumnachbar-Kon“ und „Baumnachbar-JA“ zu den jeweiligen Beobachtungszeitpunkten angeboten.

\begin{tabular}{|c|c|c|c|c|c|c|c|c|}
\hline & & \multicolumn{6}{|c|}{ Beobachtungszeitpunkte in der Freilandsaison 1998 } \\
\hline Plot-Nr. & Baumposition & $\mathbf{0 6 . 0 5 .}$ & $\mathbf{1 2 . 0 5 .}$ & $\mathbf{1 9 . 0 5 .}$ & $\mathbf{0 9 . 0 6 .}$ & $\mathbf{1 7 . 0 7 .}$ & $\mathbf{2 4 . 0 7 .}$ & $\mathbf{1 5 . 0 8 .}$ \\
\hline $\mathbf{1}$ & Baumnachbar-Kon & 2,75 & 4,37 & 4,89 & 3,66 & 1,43 & 2,99 & 0,96 \\
\hline $\mathbf{1}$ & Baumnachbar-JA & 3,01 & 1,37 & 0,65 & 0,63 & 0,73 & 0,38 & 0,46 \\
\hline $\mathbf{2}$ & Baumnachbar-Kon & 1,36 & 3,15 & 2,96 & 3,10 & 2,40 & 2,15 & 1,22 \\
\hline $\mathbf{2}$ & Baumnachbar-JA & 2,77 & 3,70 & 1,11 & 0,87 & 0,52 & 1,28 & 0,39 \\
\hline $\mathbf{3}$ & Baumnachbar-Kon & 3,53 & 3,12 & 3,87 & 2,29 & 1,61 & 2,27 & 1,46 \\
\hline $\mathbf{3}$ & Baumnachbar-JA & 2,85 & 1,87 & 0,79 & 1,59 & 1,36 & 0,44 & 0,36 \\
\hline $\mathbf{4}$ & Baumnachbar-Kon & 3,26 & 5,84 & 5,32 & 3,08 & 2,29 & 4,22 & 2,03 \\
\hline $\mathbf{4}$ & Baumnachbar-JA & 3,25 & 2,65 & 1,04 & 1,10 & 0,48 & 0,82 & 0,62 \\
\hline $\mathbf{5}$ & Baumnachbar-Kon & 3,21 & 3,61 & 3,99 & 3,48 & 3,09 & 2,60 & 1,66 \\
\hline $\mathbf{5}$ & Baumnachbar-JA & 2,31 & 1,36 & 1,58 & 1,05 & 0,59 & 0,79 & 0,53 \\
\hline $\mathbf{6}$ & Baumnachbar-Kon & 2,44 & 3,99 & 3,64 & 3,14 & 1,49 & 0,91 & 2,12 \\
\hline $\mathbf{6}$ & Baumnachbar-JA & 2,42 & 0,64 & 1,34 & 1,12 & 1,22 & 0,85 & 0,80 \\
\hline
\end{tabular}


D Lösungen zur quantitativen Bestimmung der ProteinaseinhibitorenAktivitäten

I. Puffer zur Extraktion des Pflanzenmaterials

Proteinextraktionspuffer $(\mathrm{V}=11$, mit $\mathrm{pH} 7,6)$ :

50 g Polyvinypolypyrrolidon (PVPP, Sigma); 2 g Phenylthioharnstoff (Sigma); $5 \mathrm{~g}$ Diethyldithiocarbamat (Sigma); 18,6 g Na 2 EDTA (Sigma), auf 11 mit 0,1 M Tris-HCl auffüllen.

II. Zusammensetzung des Agarmediums für jeweils eine Petrischale $(12 \times 12 \mathrm{~cm}$, Greiner):

0, $9 \mathrm{~g}$ Agar in $50 \mathrm{ml} \mathrm{0,1} \mathrm{M} \mathrm{Tris-Puffer}(\mathrm{pH} 7,6)$ lösen und aufkochen.

Nach dem Abkühlen des Agarmediums auf ca. $50{ }^{\circ} \mathrm{C}$ wurden $50 \mu$ Proteinaselösung (Trypsin $1 \mathrm{mg} \mathrm{ml}^{-1}$,Typ III, Fluka) zu der Agarlösung gegeben, gut durchmischt und anschließend in die Petrischale gegossen.

III. Eichreihe zur Bestimmung der PI-Aktivität

Es wurde eine STI-Eichlösung (Proteinase Inhibitor aus Sojabohne (Boehringer Mannheim)) in folgenden Konzentrationen hergestellt:

\begin{tabular}{|c|c|c|}
\hline Bezeichnung & STI-Konzentration [mg/ml] & PI Molarität \\
\hline PI 1 & 0,30 & $4,59 \mu \mathrm{M}$ \\
\hline PI 2 & 0,15 & $2,3 \mu \mathrm{M}$ \\
\hline PI 3 & 0,075 & $1,15 \mu \mathrm{M}$ \\
\hline PI 4 & 0,0375 & $0,57 \mu \mathrm{M}$ \\
\hline PI 5 & 0,0187 & $0,29 \mu \mathrm{M}$ \\
\hline
\end{tabular}

IV. Anfärbung der Agarplatte

Für die Anfärbung einer Agarplatten wurden $25 \mathrm{ml}$ einer frisch zubereiteten Färbelösung folgender Zusammensetzung benötigt:

Teil A: 12 mg Fast Blue (Serva) in 0,125 ml Aqua dest. lösen

Teil B: 6 mg APNE ( $N$-Acetyl-phenylalanin- 3 -naphtylester, Bachem) in $5 \mathrm{ml}$ Dimetylsulfoxid (DMSO (Sigma)) lösen

Teil A und Teil B wurden vereint und in $20 \mathrm{ml} \mathrm{0,1} \mathrm{M} \mathrm{Tris-HCl,} \mathrm{pH} \mathrm{7,6} \mathrm{gelöst}$ 


\section{E Labordaten}

Tab. E-1: Ermittelte Phenolgehalte $\mathrm{DW}^{-1}\left[\mathrm{mg} \mathrm{g}^{-1}\right]$ nach 72-stündiger Inkubation (Phenolassay 1). Angegeben sind die Phenolgehalte verschiedener Versuchsbehandlungen der einzelnen Versuchswiederholungen (n).

\begin{tabular}{|c|c|c|c|c|c|c|}
\hline & \multicolumn{7}{|c|}{ Versuchsbehandlungen } \\
\hline $\mathbf{n}$ & Kontrolle & A. alni & S. littoralis & mechanisch & $\begin{array}{c}\text { Regurgitat \& } \\
\text { mechanisch }\end{array}$ & $\begin{array}{c}\text { Regurgitat \& } \\
\text { gelöst }\end{array}$ \\
\hline $\mathbf{1}$ & 4,72 & 16,36 & 9,92 & 6,76 & 9,45 & 7,65 \\
\hline $\mathbf{2}$ & 4,98 & 11,69 & 10,85 & 7,89 & 8,54 & 8,38 \\
\hline $\mathbf{3}$ & 5,02 & 19,38 & 12,65 & 6,42 & 10,83 & 7,47 \\
\hline $\mathbf{4}$ & 5,20 & 22,59 & 9,63 & 6,93 & 9,97 & 8,62 \\
\hline $\mathbf{5}$ & 5,46 & 24,57 & 17,22 & 7,58 & 9,00 & 7,70 \\
\hline $\mathbf{6}$ & 6,37 & 28,48 & 19,07 & 7,63 & 9,07 & 7,01 \\
\hline $\mathbf{7}$ & 6,57 & 30,08 & 11,32 & 7,31 & 9,36 & 7,33 \\
\hline $\mathbf{8}$ & 7,11 & 30,55 & 17,41 & 6,96 & 9,56 & 7,45 \\
\hline $\mathbf{9}$ & 7,64 & 33,02 & 8,01 & 7,52 & 9,68 & 7,44 \\
\hline $\mathbf{1 0}$ & 6,58 & 11,02 & 14,75 & 8,24 & 11,10 & 8,10 \\
\hline
\end{tabular}

Tab. E-2: Ermittelte Phenolgehalte $\mathrm{DW}^{-1}\left[\mathrm{mg} \mathrm{g}^{-1}\right]$ nach 72-stündiger Inkubation (Phenolassay 2). Angegeben sind die Phenolgehalte verschiedener Versuchsbehandlungen der einzelnen Versuchswiederholungen (n).

\begin{tabular}{|c|c|c|c|c|c|c|c|}
\hline & \multicolumn{7}{|c|}{ Versuchsbehandlungen } \\
\hline $\mathbf{n}$ & Kontrolle & $\boldsymbol{A} \cdot \mathbf{a l n i}$ & $\mathbf{J A}$ & $\mathbf{S A}$ & Ethylen & MeJA & MeSA \\
\hline $\mathbf{1}$ & 4,98 & 7,31 & 11,10 & 7,20 & 11,04 & 5,88 & 6,07 \\
\hline $\mathbf{2}$ & 5,46 & 11,69 & 11,75 & 6,30 & 15,55 & 5,29 & 5,40 \\
\hline $\mathbf{3}$ & 5,02 & 9,68 & 10,23 & 6,31 & 10,52 & 7,64 & 4,29 \\
\hline $\mathbf{4}$ & 6,57 & 8,00 & 10,19 & 6,83 & 14,03 & 5,97 & 3,83 \\
\hline $\mathbf{5}$ & 5,60 & 7,42 & 11,13 & 6,46 & 17,28 & 6,35 & 7,93 \\
\hline $\mathbf{6}$ & 4,08 & 6,89 & 10,84 & 6,28 & 14,88 & 7,11 & 6,91 \\
\hline $\mathbf{7}$ & 4,98 & 6,36 & 15,45 & 6,57 & 11,25 & 4,08 & 4,76 \\
\hline $\mathbf{8}$ & 5,02 & 11,69 & 13,26 & 6,97 & 13,02 & 6,30 & 5,62 \\
\hline $\mathbf{9}$ & 5,20 & 19,38 & 12,44 & 7,21 & 10,49 & 6,53 & 6,35 \\
\hline $\mathbf{1 0}$ & 5,46 & 22,59 & 11,43 & 7,40 & 16,49 & 5,60 & 6,44 \\
\hline
\end{tabular}


Tab. E-3: Ermittelte PPO-Aktivitäten $\left[\Delta \mathrm{E}_{490} \mathrm{~min}^{-1} \mathrm{mg}^{-1}\right.$ Protein] nach 48-stündiger Inkubation (Enzymassay 1). Angegeben sind die PPO-Aktivitäten verschiedener Versuchsbehandlungen der einzelnen Versuchswiederholungen (n).

\begin{tabular}{|c|c|c|c|c|c|}
\hline $\mathbf{n}$ & Kontr. & $\boldsymbol{A} \cdot \boldsymbol{a l n i}$ & Ethylen & MeJA & MeSA \\
\hline $\mathbf{1}$ & 59,71 & 113,59 & 2,48 & 11,74 & 57,27 \\
\hline $\mathbf{2}$ & 60,99 & 167,99 & 25,63 & 33,17 & 38,43 \\
\hline $\mathbf{3}$ & 37,64 & 183,49 & 20,08 & 18,24 & 47,73 \\
\hline $\mathbf{4}$ & 58,09 & 192,70 & 36,03 & 58,87 & 32,75 \\
\hline $\mathbf{5}$ & 32,19 & 120,76 & 4,35 & 47,77 & 69,93 \\
\hline
\end{tabular}

Tab. E-4: Ermittelte PPO-Aktivitäten $\left[\Delta \mathrm{E}_{490} \mathrm{~min}^{-1} \mathrm{mg}^{-1}\right.$ Protein] nach 72-stündiger Inkubation (Enzymassay 2). Angegeben sind die PPO-Aktivitäten verschiedener Versuchsbehandlungen der einzelnen Versuchswiederholungen (n).

\begin{tabular}{|c|c|c|c|c|c|c|c|c|c|c|c|}
\hline & \multicolumn{10}{|c|}{ Versuchsbehandlungen } \\
\hline $\mathbf{n}$ & Kontr. & A. alni & S. & littoralis & mech. & \multicolumn{2}{c|}{ Regurgitat } \\
mech. & JA & SA & Ethylen & MeJA & MeSA \\
\hline $\mathbf{1}$ & 42,65 & 210,32 & 173,00 & 79,79 & 63,61 & 61,44 & 93,14 & 48,88 & 46,62 & 59,24 & 47,73 \\
\hline $\mathbf{2}$ & 61,24 & 162,92 & 120,66 & 88,13 & 89,79 & 56,49 & 87,07 & 48,96 & 57,82 & 60,69 & 47,95 \\
\hline $\mathbf{3}$ & 47,58 & 168,54 & 123,52 & 59,23 & 89,24 & 59,73 & 81,49 & 51,50 & 59,49 & 63,37 & 48,91 \\
\hline $\mathbf{4}$ & 58,53 & 181,79 & 166,92 & 63,61 & 71,96 & 57,71 & 91,90 & 56,63 & 60,25 & 63,86 & 56,36 \\
\hline $\mathbf{5}$ & 56,63 & 183,19 & 168,25 & 64,25 & 83,37 & 58,94 & 83,37 & 58,44 & 63,37 & 67,49 & 58,26 \\
\hline $\mathbf{6}$ & 57,82 & 192,40 & 150,41 & 68,53 & 82,19 & 59,11 & 70,69 & 59,66 & 69,69 & 68,86 & 59,41 \\
\hline $\mathbf{7}$ & 59,47 & 192,71 & 162,11 & 57,58 & 78,58 & 57,57 & 87,70 & 59,43 & 73,61 & 69,79 & 63,70 \\
\hline $\mathbf{8}$ & 53,61 & 113,40 & 123,94 & 60,32 & 75,87 & 43,73 & 104,60 & 59,47 & 75,87 & 76,63 & 69,93 \\
\hline $\mathbf{9}$ & 69,79 & 191,71 & 123,60 & 63,17 & 77,82 & 69,67 & 123,18 & 63,37 & 83,63 & 87,70 & 78,58 \\
\hline $\mathbf{1 0}$ & 43,86 & 120,76 & 130,57 & 76,63 & 81,94 & 88,65 & 78,58 & 63,86 & 87,30 & 88,69 & 82,06 \\
\hline
\end{tabular}

Tab. E-5: Ermittelte LOX-Aktivitäten $\left[\Delta \mathrm{E}_{234} \mathrm{~min}^{-1} \mathrm{mg}^{-1}\right.$ Protein] nach 48-stündiger Inkubation (Enzymassay 3). Angegeben sind die LOX-Aktivitäten verschiedener Versuchsbehandlungen der einzelnen Versuchswiederholungen (n).

\begin{tabular}{|c|c|c|c|c|c|}
\hline $\mathbf{n}$ & Kontr. & $\boldsymbol{A} \cdot \boldsymbol{a l n i}$ & Ethylen & MeJA & MeSA \\
\hline $\mathbf{1}$ & 352,42 & 1727,67 & 487,03 & 796,00 & 773,38 \\
\hline $\mathbf{2}$ & 578,71 & 759,99 & 647,01 & 909,19 & 652,17 \\
\hline $\mathbf{3}$ & 458,17 & 1288,99 & 720,37 & 626,76 & 6076,23 \\
\hline $\mathbf{4}$ & 553,17 & 5711,44 & 720,73 & 833,89 & 108,02 \\
\hline $\mathbf{5}$ & 231,63 & 3020,33 & 918,29 & 915,72 & 1090,61 \\
\hline
\end{tabular}


Tab. E-6: Ermittelte LOX-Aktivitäten $\left[\Delta \mathbf{E}_{234} \mathrm{~min}^{-1} \mathrm{mg}^{-1}\right.$ Protein] nach 72-stündiger Inkubation (Enzymassay 4). Angegeben sind die LOX-Aktivitäten verschiedener Versuchsbehandlungen der einzelnen Versuchswiederholungen (n).

\begin{tabular}{|c|c|c|c|c|c|c|c|}
\hline & \multicolumn{7}{|c|}{ Versuchsbehandlungen } \\
\hline $\mathbf{n}$ & Kontrolle & $\boldsymbol{A} \cdot \boldsymbol{a l n i}$ & $\mathbf{J A}$ & $\mathbf{S A}$ & Ethylen & MeJA & MeSA \\
\hline $\mathbf{1}$ & 358,52 & 620,64 & 604,42 & 430,17 & 546,65 & 568,62 & 446,37 \\
\hline $\mathbf{2}$ & 553,17 & 1726,07 & 957,67 & 578,17 & 869,89 & 795,94 & 673,94 \\
\hline $\mathbf{3}$ & 467,04 & 1510,91 & 831,57 & 541,17 & 719,43 & 752,34 & 646,41 \\
\hline $\mathbf{4}$ & 458,17 & 832,60 & 730,84 & 535,82 & 646,10 & 726,79 & 606,23 \\
\hline $\mathbf{5}$ & 394,62 & 752,51 & 652,49 & 496,70 & 611,91 & 646,69 & 467,39 \\
\hline $\mathbf{6}$ & 465,75 & 1300,12 & 823,61 & 536,56 & 718,27 & 733,89 & 620,43 \\
\hline $\mathbf{7}$ & 481,83 & 1684,52 & 852,67 & 553,17 & 720,37 & 752,51 & 652,52 \\
\hline $\mathbf{8}$ & 446,14 & 759,99 & 719,86 & 511,17 & 616,34 & 709,11 & 552,49 \\
\hline $\mathbf{9}$ & 358,84 & 646,69 & 630,19 & 481,83 & 578,97 & 631,56 & 465,40 \\
\hline $\mathbf{1 0}$ & 578,17 & 2291,19 & 968,98 & 582,90 & 889,92 & 932,60 & 732,60 \\
\hline
\end{tabular}

Tab. E-7: Ermittelte POD-Aktivitäten $\left[\Delta \mathbf{E}_{470} \mathrm{~min}^{-1} \mathrm{mg}^{-1}\right.$ Protein] nach 48-stündiger Inkubation (Enzymassay 5). Angegeben sind die POD-Aktivitäten verschiedener Versuchsbehandlungen der einzelnen Versuchswiederholungen (n).

\begin{tabular}{|c|c|c|c|c|c|}
\hline $\mathbf{n}$ & Kontr. & $\boldsymbol{A} \cdot \boldsymbol{a l n i}$ & Ethylen & MeJA & MeSA \\
\hline $\mathbf{1}$ & 5,11 & 105,02 & 0,51 & 1,98 & 1,80 \\
\hline $\mathbf{2}$ & 11,20 & 130,21 & 0,74 & 1,76 & 0,56 \\
\hline $\mathbf{3}$ & 2,79 & 75,03 & 1,09 & 1,50 & 20,8 \\
\hline $\mathbf{4}$ & 4,92 & 76,26 & 2,74 & 2,97 & 6,46 \\
\hline $\mathbf{5}$ & 7,78 & 52,20 & 1,78 & 0,99 & 7,61 \\
\hline
\end{tabular}

Tab. E-8: Ermittelte POD-Aktivitäten $\left[\Delta \mathbf{E}_{470} \mathrm{~min}^{-1} \mathrm{mg}^{-1}\right.$ Protein] nach 72-stündiger Inkubation (Enzymassay 6). Angegeben sind die POD-Aktivitäten verschiedener Versuchsbehandlungen der einzelnen Versuchswiederholungen (n).

\begin{tabular}{|c|c|c|c|c|c|c|c|}
\hline & \multicolumn{7}{|c|}{ Versuchsbehandlungen } \\
\hline $\mathbf{n}$ & Kontrolle & $\boldsymbol{A} \cdot \boldsymbol{a l n i}$ & $\mathbf{J A}$ & $\mathbf{S A}$ & Ethylen & MeJA & MeSA \\
\hline $\mathbf{1}$ & 9,20 & 130,02 & 13,41 & 5,21 & 7,41 & 8,13 & 10,14 \\
\hline $\mathbf{2}$ & 7,11 & 105,21 & 20,43 & 9,25 & 10,26 & 9,61 & 15,74 \\
\hline $\mathbf{3}$ & 6,31 & 85,03 & 16,81 & 7,21 & 8,28 & 8,79 & 11,76 \\
\hline $\mathbf{4}$ & 7,80 & 94,44 & 18,38 & 8,25 & 9,34 & 9,11 & 13,79 \\
\hline $\mathbf{5}$ & 7,19 & 88,67 & 17,95 & 7,65 & 9,28 & 8,95 & 12,72 \\
\hline $\mathbf{6}$ & 8,38 & 105,21 & 18,71 & 8,33 & 9,94 & 9,41 & 14,38 \\
\hline $\mathbf{7}$ & 7,79 & 86,26 & 17,64 & 7,26 & 8,34 & 8,11 & 12,51 \\
\hline $\mathbf{8}$ & 3,79 & 105,21 & 22,16 & 11,34 & 10,34 & 9,69 & 15,86 \\
\hline $\mathbf{9}$ & 9,07 & 82,20 & 23,04 & 12,94 & 11,24 & 10,11 & 17,64 \\
\hline $\mathbf{1 0}$ & 3,92 & 85,03 & 13,99 & 6,26 & 8,31 & 8,46 & 11,19 \\
\hline
\end{tabular}


Tab. E-9: Ermittelte KAT-Aktivitäten $\left[\Delta \mathrm{E}_{240} \mathrm{~min}^{-1} \mathrm{mg}^{-1}\right.$ Protein] nach 48-stündiger Inkubation (Enzymassay 7). Angegeben sind die KAT-Aktivitäten verschiedener Versuchsbehandlungen der einzelnen Versuchswiederholungen (n).

\begin{tabular}{|c|c|c|c|c|c|}
\hline $\mathbf{n}$ & Kontr. & $\boldsymbol{A} \cdot \boldsymbol{a l n i}$ & Ethylen & MeJA & MeSA \\
\hline $\mathbf{1}$ & 866,73 & 1496,29 & 1347,84 & 873,27 & 430,60 \\
\hline $\mathbf{2}$ & 576,15 & 644,99 & 890,35 & 1162,16 & 273,03 \\
\hline $\mathbf{3}$ & 359,67 & 714,21 & 850,21 & 2214,61 & 606,51 \\
\hline $\mathbf{4}$ & 691,49 & 1224,97 & 433,71 & 767,69 & 419,01 \\
\hline $\mathbf{5}$ & 490,72 & 602,69 & 408,58 & 1718,56 & 281,66 \\
\hline
\end{tabular}

Tab. E-10: Ermittelte KAT-Aktivitäten $\left[\Delta \mathrm{E}_{240} \mathrm{~min}^{-1} \mathrm{mg}^{-1}\right.$ Protein] nach 72-stündiger Inkubation. (Enzymassay 8). Angegeben sind die KAT-Aktivitäten verschiedener Versuchsbehandlungen der einzelnen Versuchswiederholungen (n).

\begin{tabular}{|c|c|c|c|c|c|c|c|}
\hline & \multicolumn{7}{|c|}{ Versuchsbehandlungen } \\
\hline $\mathbf{n}$ & Kontrolle & A. alni & JA & SA & Ethylen & MeJA & MeSA \\
\hline $\mathbf{1}$ & 547,23 & 1009,15 & 715,68 & 646,44 & 749,12 & 1235,42 & 603,21 \\
\hline $\mathbf{2}$ & 666,73 & 1224,07 & 759,87 & 723,64 & 900,35 & 1694,73 & 630,60 \\
\hline $\mathbf{3}$ & 434,76 & 748,57 & 637,21 & 511,46 & 628,12 & 1047,70 & 553,03 \\
\hline $\mathbf{4}$ & 576,22 & 1127,10 & 719,34 & 673,17 & 758,88 & 1397,37 & 614,42 \\
\hline $\mathbf{5}$ & 576,16 & 1224,28 & 748,95 & 699,34 & 852,21 & 1559,70 & 626,51 \\
\hline $\mathbf{6}$ & 490,72 & 759,09 & 676,44 & 519,74 & 648,37 & 1142,16 & 566,26 \\
\hline $\mathbf{7}$ & 365,73 & 715,97 & 576,85 & 501,23 & 545,89 & 1008,06 & 545,89 \\
\hline $\mathbf{8}$ & 359,67 & 603,22 & 501,97 & 475,67 & 548,87 & 1214,86 & 485,98 \\
\hline $\mathbf{9}$ & 363,55 & 646,45 & 547,68 & 491,87 & 423,71 & 893,27 & 529,03 \\
\hline $\mathbf{1 0}$ & 691,49 & 1495,15 & 866,73 & 784,19 & 1345,84 & 1738,56 & 667,23 \\
\hline
\end{tabular}

Tab. E-11: Ermittelte Aktivitäten der Proteinaseinhibitoren ( $\mu$ g PI $\mathrm{mg}^{-1}$ Protein $\mathrm{g}^{-1} \mathrm{FW}$ ) nach $72-$ stündiger Inkubation (PI-Assay 1).

\begin{tabular}{|c|c|c|c|c|c|c|c|c|}
\hline & \multicolumn{7}{|c|}{ Versuchsbehandlungen } \\
\hline $\mathbf{n}$ & Kontrolle & $\boldsymbol{A .}$ alni & $\boldsymbol{A}$. alni, syst. & JA & SA & Ethylen & MeJA & MeSA \\
\hline $\mathbf{1}$ & 3,55 & 9,95 & 15,34 & 9,10 & 6,99 & 7,88 & 12,00 & 10,23 \\
\hline $\mathbf{2}$ & 3,29 & 19,00 & 14,3 & 8,80 & 3,38 & 15,69 & 13,60 & 7,23 \\
\hline $\mathbf{3}$ & 5,95 & 27,79 & 22,19 & 11,82 & 2,64 & 22,60 & 8,40 & 3,25 \\
\hline $\mathbf{4}$ & 2,77 & 18,46 & 6,96 & 12,55 & 5,90 & 14,99 & 15,10 & 7,23 \\
\hline $\mathbf{5}$ & 3,95 & 17,99 & 9,41 & 10,83 & 4,77 & 12,55 & 11,00 & 8,55 \\
\hline $\mathbf{6}$ & 3,16 & 22,91 & 15,57 & 15,48 & 6,24 & 18,72 & 13,63 & 4,46 \\
\hline $\mathbf{7}$ & 2,64 & 19,35 & 13,23 & 16,32 & 5,64 & 20,02 & 17,41 & 3,72 \\
\hline $\mathbf{8}$ & 4,77 & 29,40 & 12,64 & 18,93 & 7,39 & 16,97 & 20,21 & 1,81 \\
\hline
\end{tabular}


Fortsetzung Tab. E-11 (PI-Assay 1)

\begin{tabular}{|c|c|c|c|c|c|c|c|c|}
\hline & \multicolumn{7}{|c|}{ Versuchsbehandlungen } \\
\hline $\mathbf{n}$ & Anthranilat & $\begin{array}{c}\text { Hexenyl- } \\
\text { acetat }\end{array}$ & cis-Jasmon & Ocimen & Linalool & $\begin{array}{c}\text { Caryo- } \\
\text { phyllen }\end{array}$ & DMNT & TMTT \\
\hline $\mathbf{1}$ & 2,39 & 5,46 & 60,86 & 30,35 & 4,03 & 4,47 & 31,87 & 12,77 \\
\hline $\mathbf{2}$ & 2,35 & 6,02 & 50,31 & 18,39 & 2,67 & 3,27 & 10,20 & 15,51 \\
\hline $\mathbf{3}$ & 5,65 & 7,66 & 68,72 & 44,21 & 4,59 & 5,93 & 25,97 & 15,84 \\
\hline $\mathbf{4}$ & 3,32 & 6,97 & 64,00 & 39,80 & 5,69 & 3,16 & 38,88 & 15,14 \\
\hline $\mathbf{5}$ & 7,35 & 10,20 & 57,82 & 50,14 & 5,89 & 4,57 & 46,02 & 12,36 \\
\hline $\mathbf{6}$ & 2,45 & 8,19 & 40,59 & 35,19 & 2,57 & 3,89 & 29,08 & 19,37 \\
\hline $\mathbf{7}$ & 5,59 & 9,57 & 44,67 & 28,49 & 4,35 & 3,99 & 34,19 & 25,49 \\
\hline $\mathbf{8}$ & 6,89 & 7,94 & 38,49 & 22,36 & 5,36 & 5,46 & 18,17 & 26,40 \\
\hline
\end{tabular}

Tab. E-12: Ermittelte Phenolgehalte $\mathrm{DW}^{-1}\left[\mathrm{mg} \mathrm{g}^{-1}\right]$ nach verschiedenen Inkubationszeiten $\mathrm{t}[\mathrm{h}]$ in Containern (Containerversuch-Phenolassay 1).

\begin{tabular}{|c|c|c|c|c|c|}
\hline \multirow[t]{2}{*}{$\mathrm{n}$} & \multirow[t]{2}{*}{$\mathrm{t}[\mathrm{h}]$} & \multicolumn{2}{|c|}{ Container 1} & \multicolumn{2}{|c|}{ Container 2} \\
\hline & & „Kontrolle” & „Kontrolle-Nachbar“ & ,A. alni-Fraß“ & „A. alni-Nachbar“" \\
\hline 1 & 3 & 3,26 & 2,33 & 3,19 & 3,25 \\
\hline 2 & 3 & 3,65 & 2,45 & 2,74 & 3,28 \\
\hline 3 & 3 & 2,66 & 3,46 & 3,21 & 2,33 \\
\hline 4 & 3 & 2,74 & 3,1 & 3,49 & 2,78 \\
\hline 5 & 3 & 2,75 & 1,83 & 3,28 & 3,23 \\
\hline 6 & 3 & 2,89 & 2,05 & 3,66 & 3,12 \\
\hline 7 & 3 & 2,76 & 2,99 & 2,98 & 2,37 \\
\hline 1 & 6 & 3,45 & 2,47 & 4,61 & 2,84 \\
\hline 2 & 6 & 3,51 & 3,29 & 4,96 & 2,09 \\
\hline 3 & 6 & 2,89 & 2,05 & 3,26 & 4,2 \\
\hline 4 & 6 & 2,15 & 2,73 & 4,81 & 3,57 \\
\hline 5 & 6 & 3,52 & 3,17 & 4,66 & 3,49 \\
\hline 6 & 6 & 3,14 & 3,4 & 3,74 & 3,28 \\
\hline 7 & 6 & 2,56 & 2,93 & 3,47 & 2,94 \\
\hline 1 & 12 & 3,58 & 3,64 & 6,36 & 3,65 \\
\hline 2 & 12 & 4,43 & 4,41 & 5,66 & 3,28 \\
\hline 3 & 12 & 4,74 & 4,525 & 6,79 & 4,42 \\
\hline 4 & 12 & 3,25 & 3,5 & 7,64 & 4,58 \\
\hline 5 & 12 & 4,21 & 3,39 & 7,7 & 4,57 \\
\hline 6 & 12 & 3,39 & 3,16 & 6,43 & 3,99 \\
\hline 7 & 12 & 3,94 & 3,94 & 6,39 & 4,29 \\
\hline 1 & 24 & 4,61 & 4,74 & 8,82 & 4,94 \\
\hline 2 & 24 & 4,99 & 4,16 & 9,35 & 4,84 \\
\hline 3 & 24 & 4,21 & 4,57 & 11,50 & 5,03 \\
\hline 4 & 24 & 4,81 & 4,55 & 8,39 & 5,20 \\
\hline 5 & 24 & 5,55 & 4,70 & 9,82 & 5,37 \\
\hline 6 & 24 & 4,54 & 4,23 & 8,02 & 5,66 \\
\hline 7 & 24 & 4,82 & 5,07 & 10,71 & 5,52 \\
\hline
\end{tabular}


Fortsetzung Tab. E-12 (Containerversuch-Phenolassay 1)

\begin{tabular}{|c|c|c|c|c|c|}
\hline $\mathbf{n}$ & $\mathbf{t}[\mathbf{h}]$ & \multicolumn{2}{|c|}{ Container 1 } & \multicolumn{2}{c|}{ Container 2 } \\
\hline & & „Kontrolle” & „Kontrolle-Nachbar“6 & ,A. alni-Fraß & ,A. alni-Nachbar“6 \\
\hline $\mathbf{1}$ & $\mathbf{4 8}$ & 5,89 & 4,94 & 13,48 & 5,85 \\
\hline $\mathbf{2}$ & 48 & 5,8 & 4,29 & 13,17 & 6,50 \\
\hline $\mathbf{3}$ & 48 & 6,93 & 5,26 & 14,74 & 6,47 \\
\hline $\mathbf{4}$ & 48 & 6,85 & 5,81 & 12,21 & 6,55 \\
\hline $\mathbf{5}$ & 48 & 4,18 & 5,53 & 11,82 & 6,12 \\
\hline $\mathbf{6}$ & 48 & 4,86 & 6,07 & 13,85 & 5,38 \\
\hline $\mathbf{7}$ & 48 & 4,15 & 6,39 & 11,45 & 5,08 \\
\hline & & & & & 10,7 \\
\hline $\mathbf{1}$ & $\mathbf{7 2}$ & 6,85 & 6,28 & 14,91 & 9,18 \\
\hline $\mathbf{2}$ & 72 & 5,6 & 7,6 & 13,02 & 9,47 \\
\hline $\mathbf{3}$ & 72 & 7,75 & 6,4 & 14,07 & 8,55 \\
\hline $\mathbf{4}$ & 72 & 7,58 & 5,37 & 15,23 & 7,12 \\
\hline $\mathbf{5}$ & 72 & 5,84 & 7,16 & 17,33 & 8,83 \\
\hline $\mathbf{6}$ & 72 & 5,48 & 6,62 & 18,3 & 13,84 \\
\hline $\mathbf{7}$ & 72 & 5,85 & 6,91 & 16,51 & \\
\hline
\end{tabular}

Tab. E-13: Ermittelte Enzymaktivitäten nach 72-stündiger Inkubation in Containern. (Containerversuch-Enzymassay 1). Angegeben sind die Aktivitäten der einzelnen Versuchswiederholungen (n).

\begin{tabular}{|c|c|c|c|c|c|}
\hline \multirow[t]{2}{*}{ Enzym } & \multirow[t]{2}{*}{$\mathbf{n}$} & \multicolumn{2}{|c|}{ Container 1} & \multicolumn{2}{|c|}{ Container 2} \\
\hline & & „Kontrolle“6 & „Kontrolle-Nachbar“6 & ,A. alni-Fraß ${ }^{66}$ & ,A. alni-Nachbar“6 \\
\hline PPO & 1 & 2,82 & 3,60 & 57,12 & 22,51 \\
\hline $\mathrm{PPO}$ & 2 & 4,18 & 2,64 & 31,60 & 21,27 \\
\hline $\mathrm{PPO}$ & 3 & 0,52 & 2,13 & 17,05 & 4,16 \\
\hline $\mathrm{PPO}$ & 4 & 5,28 & 3,67 & 98,31 & 11,72 \\
\hline $\mathrm{PPO}$ & 5 & 5,88 & 6,17 & 51,02 & 24,94 \\
\hline PPO & 6 & 22,80 & 8,13 & 28,08 & 7,95 \\
\hline $\mathrm{PPO}$ & 7 & 6,83 & 9,60 & 25,68 & 20,81 \\
\hline $\mathrm{PPO}$ & 8 & 9,19 & 9,80 & 17,96 & 23,98 \\
\hline PPO & 9 & 9,42 & 7,25 & 45,80 & 17,05 \\
\hline POD & 1 & 0,66 & 1,04 & 6,24 & 3,56 \\
\hline POD & 2 & 1,31 & 1,15 & 6,92 & 4,34 \\
\hline POD & 3 & 0,69 & 1,06 & 6,48 & 4,18 \\
\hline POD & 4 & 1,08 & 0,39 & 4,85 & 2,45 \\
\hline POD & 5 & 1,50 & 1,40 & 6,20 & 3,76 \\
\hline POD & 6 & 1,03 & 2,05 & 8,54 & 2,72 \\
\hline POD & 7 & 2,29 & 0,68 & 12,68 & 3,13 \\
\hline POD & 8 & 2,31 & 2,12 & 11,71 & 2,94 \\
\hline POD & 9 & 0,84 & 1,49 & 7,08 & 4,60 \\
\hline LOX & 1 & 67,97 & 24,26 & 787,00 & 354,02 \\
\hline LOX & 2 & 83,17 & 39,73 & 871,59 & 397,98 \\
\hline LOX & 3 & 19,14 & 46,32 & 904,00 & 310,33 \\
\hline
\end{tabular}


Fortsetzung Tab. E-13 (Containerversuch-Enzymassay 1)

\begin{tabular}{|c|c|c|c|c|c|}
\hline Enzym & $\mathbf{n}$ & \multicolumn{2}{|c|}{ Container 1 } & \multicolumn{2}{c|}{ Container 2 } \\
\hline & & ,Kontrolle“6 & „Kontrolle-Nachbar“6 & „A. alni-Fraß & „A. alni-Nachbar“6 \\
\hline LOX & 4 & 25,80 & 55,85 & 998,59 & 389,14 \\
\hline LOX & 5 & 33,66 & 56,13 & 632,30 & 404,51 \\
\hline LOX & 6 & 48,49 & 74,69 & 844,79 & 510,73 \\
\hline LOX & 7 & 134,40 & 91,85 & 578,60 & 302,81 \\
\hline LOX & 8 & 87,94 & 153,57 & 787,43 & 338,66 \\
\hline LOX & 9 & 235,30 & 198,76 & 803,85 & 472,33 \\
\hline
\end{tabular}

Tab. E-14: Ermittelte Aktivitäten der Proteinaseinhibitoren ( $\mu$ g PI $\mathrm{mg}^{-1}$ Protein $\mathrm{g}^{-1} \mathrm{FW}$ ) nach $72-$ stündiger Inkubation in Containern (Containerversuch-PI-Assay 1). Angegeben sind die Aktivitäten der einzelnen Versuchswiederholungen (n).

\begin{tabular}{|c|c|c|c|c|}
\hline $\mathbf{n}$ & \multicolumn{2}{|c|}{ Container 1 } & \multicolumn{2}{c|}{ Container 2 } \\
\hline & „Kontrolle“6 $^{\text {,KKontrolle-Nachbar“6 }}$ & „A. alni-Fraß“6 & „A. alni-Nachbar“6 \\
\hline $\mathbf{1}$ & 5,41 & 5,86 & 9,28 & 5,21 \\
\hline $\mathbf{2}$ & 3,29 & 4,94 & 8,98 & 5,09 \\
\hline $\mathbf{3}$ & 7,98 & 4,72 & 9,29 & 6,04 \\
\hline $\mathbf{4}$ & 1,97 & 1,90 & 15,69 & 8,96 \\
\hline $\mathbf{5}$ & 1,15 & 2,77 & 8,10 & 7,35 \\
\hline $\mathbf{6}$ & 2,31 & 1,75 & 10,63 & 7,41 \\
\hline
\end{tabular}

Tab. E-15: Fraßwahlversuche mit Agelastica alni-Larven zur Überprüfug der Blattqualität von Alnus glutinosa-Blättern nach Behandlung mit verschiedenen Substanzen. Angegeben sind die gefressenen Blattmengen der jeweiligen Versuchsvarianten (Variante).

\begin{tabular}{|c|c|c|c|c|c|c|c|c|c|c|}
\hline $\mathbf{n}$ & \multicolumn{2}{|c|}{ Variante 1 } & \multicolumn{2}{c|}{ Variante 2 } & \multicolumn{2}{c|}{ Variante 3 } & \multicolumn{2}{c|}{ Variante 4 } & \multicolumn{2}{c|}{ Variante 5 } \\
\hline & „Kon““ & „Kon“ & „Kon“ & „JA“ & „Kon““ & „JA“ & „Kon“ & „SA“ & „Kon“ & „SA“ \\
\hline $\mathbf{1}$ & 0,09 & 0,93 & 0,44 & 0,02 & 2,82 & 0,01 & 4,43 & 3,67 & 3,53 & 0,27 \\
\hline $\mathbf{2}$ & 4,56 & 3,35 & 0,26 & 0,13 & 1,32 & 0,27 & 3,61 & 3,39 & 5,34 & 0,40 \\
\hline $\mathbf{3}$ & 1,69 & 5,78 & 0,69 & 0,01 & 2,42 & 0,57 & 4,07 & 3,79 & 3,29 & 1,09 \\
\hline $\mathbf{4}$ & 2,26 & 1,37 & 0,60 & 0,07 & 2,45 & 0,82 & 4,35 & 3,37 & 3,94 & 0,80 \\
\hline $\mathbf{5}$ & 4,37 & 2,02 & 0,38 & 0,01 & 2,09 & 0,11 & 4,71 & 3,48 & 3,74 & 1,58 \\
\hline $\mathbf{6}$ & 0,66 & 3,19 & 0,75 & 0,65 & 4,34 & 0,86 & 2,40 & 1,85 & 3,24 & 1,42 \\
\hline $\mathbf{7}$ & 0,00 & 6,95 & 0,92 & 0,56 & 3,55 & 0,66 & 4,65 & 2,06 & 3,38 & 0,18 \\
\hline $\mathbf{8}$ & 0,03 & 2,46 & 0,59 & 0,06 & 5,58 & 3,48 & 3,84 & 1,18 & 3,55 & 0,50 \\
\hline $\mathbf{9}$ & 2,44 & 3,17 & 0,82 & 0,00 & 4,62 & 1,20 & 4,06 & 1,39 & 1,59 & 0,41 \\
\hline $\mathbf{1 0}$ & 7,09 & 3,43 & 1,07 & 0,19 & 7,03 & 0,86 & 3,25 & 3,21 & 3,24 & 0,52 \\
\hline $\mathbf{1 1}$ & 1,07 & 2,04 & 0,69 & 0,10 & 4,95 & 1,79 & 4,45 & 3,09 & 3,74 & 0,52 \\
\hline $\mathbf{1 2}$ & 1,61 & 0,50 & 0,46 & 0,28 & 4,65 & 0,58 & 4,41 & 2,12 & 4,55 & 0,16 \\
\hline $\mathbf{1 3}$ & 5,57 & 3,34 & 0,35 & 0,14 & 5,07 & 2,30 & 3,65 & 1,85 & 2,72 & 0,03 \\
\hline $\mathbf{1 4}$ & 0,84 & 4,61 & 0,24 & 0,24 & 3,55 & 1,51 & 3,53 & 1,49 & 4,49 & 1,17 \\
\hline $\mathbf{1 5}$ & 0,72 & 5,61 & 0,51 & 0,01 & 3,54 & 2,52 & 3,28 & 2,33 & 3,97 & 0,19 \\
\hline $\mathbf{1 6}$ & 2,34 & 3,71 & 0,93 & 0,29 & 4,81 & 0,74 & 3,61 & 1,34 & 3,59 & 1,16 \\
\hline $\mathbf{1 7}$ & 4,64 & 3,92 & 0,81 & 0,51 & 2,24 & 0,89 & 3,82 & 0,62 & 4,95 & 0,26 \\
\hline $\mathbf{1 8}$ & 2,83 & 5,29 & 0,54 & 0,40 & 4,60 & 2,74 & 1,90 & 1,06 & 4,98 & 0,24 \\
\hline
\end{tabular}


Fortsetzung Tab. E-15

\begin{tabular}{|c|c|c|c|c|c|c|c|c|c|c|}
\hline $\mathbf{n}$ & \multicolumn{2}{|c|}{ Variante 1 } & \multicolumn{2}{c|}{ Variante 2 } & \multicolumn{2}{c|}{ Variante 3 } & \multicolumn{2}{c|}{ Variante 4 } & \multicolumn{2}{c|}{ Variante 5 } \\
\hline & „Kon““ & „Kon“ & „Kon“ & „JA“ & „Kon““ & „JA“ & „Kon“ & „SA“ & „Kon““ & „SA“ \\
\hline $\mathbf{1 9}$ & 4,37 & 1,18 & 1,05 & 0,46 & 6,08 & 2,15 & 3,22 & 1,71 & 4,05 & 0,27 \\
\hline $\mathbf{2 0}$ & 0,74 & 1,55 & 0,81 & 0,16 & 4,77 & 2,96 & 3,63 & 0,98 & 1,81 & 0,50 \\
\hline $\mathbf{2 1}$ & 1,13 & 0,97 & & & 3,96 & 1,93 & 3,72 & 1,47 & 4,71 & 0,57 \\
\hline $\mathbf{2 2}$ & 1,57 & 1,07 & & & 5,70 & 0,50 & 3,87 & 3,40 & 3,58 & 0,45 \\
\hline $\mathbf{2 3}$ & 0,43 & 1,24 & & & 5,28 & 0,20 & 2,79 & 2,46 & 2,61 & 1,13 \\
\hline $\mathbf{2 4}$ & 0,41 & 2,76 & & & 2,85 & 0,50 & 3,50 & 0,08 & 2,50 & 1,36 \\
\hline $\mathbf{2 5}$ & 0,72 & 0,22 & & & 5,31 & 0,00 & 2,30 & 2,39 & 2,95 & 1,01 \\
\hline $\mathbf{2 6}$ & 1,72 & 1,21 & & & 1,78 & 0,63 & 3,75 & 1,62 & 3,69 & 0,18 \\
\hline $\mathbf{2 7}$ & 2,25 & 2,36 & & & 1,61 & 0,50 & 4,18 & 1,67 & 3,75 & 0,11 \\
\hline $\mathbf{2 8}$ & 2,28 & 6,15 & & & 3,30 & 0,78 & 3,05 & 2,11 & 4,04 & 0,27 \\
\hline $\mathbf{2 9}$ & 3,66 & 6,06 & & & 1,67 & 0,75 & 3,76 & 0,48 & 5,23 & 1,42 \\
\hline $\mathbf{3 0}$ & 2,00 & 0,41 & & & 2,79 & 0,69 & 4,25 & 2,93 & 4,60 & 0,05 \\
\hline
\end{tabular}

Fortsetzung Tab. E-15

\begin{tabular}{|c|c|c|c|c|c|c|c|c|c|}
\hline $\mathbf{n}$ & \multicolumn{2}{|c|}{ Variante 6 } & \multicolumn{2}{|c|}{ Variante 7 } & \multicolumn{2}{c|}{ Variante 8 } & \multicolumn{3}{c|}{ Variante 9 } \\
\hline & „Kon” & „Ethylen“ & „Kon“ & „MeJA“ & „Kon“ & „MeSA“ & „Kon“ & „MeJA“ „MeSA“ \\
\hline $\mathbf{1}$ & 0,52 & 0,38 & 0,64 & 0,50 & 0,64 & 0,26 & 0,64 & 0,26 & 0,50 \\
\hline $\mathbf{2}$ & 0,69 & 0,31 & 0,78 & 0,05 & 0,78 & 0,31 & 0,78 & 0,31 & 0,05 \\
\hline $\mathbf{3}$ & 0,28 & 0,09 & 0,75 & 0,36 & 0,75 & 0,23 & 0,75 & 0,23 & 0,36 \\
\hline $\mathbf{4}$ & 0,73 & 0,48 & 1,05 & 0,23 & 1,05 & 0,15 & 1,05 & 0,15 & 0,23 \\
\hline $\mathbf{5}$ & 0,80 & 0,08 & 1,77 & 0,87 & 1,44 & 0,62 & 1,40 & 1,03 & 0,66 \\
\hline $\mathbf{6}$ & 0,44 & 0,13 & 1,38 & 0,66 & 1,40 & 1,01 & 1,13 & 0,70 & 0,82 \\
\hline $\mathbf{7}$ & 0,16 & 0,09 & 1,18 & 0,82 & 1,23 & 0,70 & 1,01 & 0,71 & 0,14 \\
\hline $\mathbf{8}$ & 0,13 & 0,37 & 1,09 & 0,14 & 1,06 & 0,71 & 1,89 & 0,76 & 0,25 \\
\hline $\mathbf{9}$ & 0,27 & 0,17 & 1,68 & 0,25 & 1,99 & 0,76 & 1,07 & 0,85 & 0,78 \\
\hline $\mathbf{1 0}$ & 0,72 & 0,46 & 1,01 & 0,78 & 1,81 & 0,85 & 1,22 & 0,87 & 0,92 \\
\hline $\mathbf{1 1}$ & 1,57 & 0,33 & 1,33 & 0,92 & 1,08 & 0,87 & 1,26 & 1,38 & 1,27 \\
\hline $\mathbf{1 2}$ & 0,68 & 0,12 & 1,61 & 1,27 & 1,06 & 1,38 & 1,26 & 0,50 & 0,75 \\
\hline $\mathbf{1 3}$ & 0,43 & 0,07 & 1,62 & 0,75 & 1,22 & 0,50 & 2,43 & 0,88 & 0,95 \\
\hline $\mathbf{1 4}$ & 0,49 & 0,20 & 1,73 & 0,95 & 2,43 & 0,88 & 2,52 & 1,28 & 0,98 \\
\hline $\mathbf{1 5}$ & 0,70 & 0,27 & 2,13 & 0,98 & 2,52 & 1,22 & 1,48 & 1,09 & 0,68 \\
\hline $\mathbf{1 6}$ & 1,30 & 0,14 & 1,22 & 0,68 & 1,48 & 1,09 & 1,54 & 0,09 & 1,17 \\
\hline $\mathbf{1 7}$ & 0,80 & 0,07 & 1,54 & 1,17 & 1,54 & 0,09 & 1,46 & 0,18 & 1,19 \\
\hline $\mathbf{1 8}$ & 0,41 & 0,39 & 1,64 & 1,19 & 1,46 & 0,18 & 1,68 & 0,43 & 1,76 \\
\hline $\mathbf{1 9}$ & 0,91 & 0,13 & 1,37 & 1,76 & 1,68 & 0,43 & 1,62 & 0,74 & 1,59 \\
\hline $\mathbf{2 0}$ & 0,63 & 0,03 & 1,95 & 1,59 & 1,62 & 0,74 & 1,50 & 0,35 & 0,52 \\
\hline $\mathbf{2 1}$ & 1,16 & 0,04 & 2,05 & 0,52 & 1,50 & 0,35 & 0,95 & 0,52 & 0,68 \\
\hline $\mathbf{2 2}$ & 0,62 & 0,25 & 1,98 & 0,68 & 0,98 & 0,52 & 0,97 & 0,41 & 0,54 \\
\hline $\mathbf{2 3}$ & 0,81 & 0,28 & 1,09 & 0,54 & 0,85 & 0,41 & 2,21 & 0,76 & 0,34 \\
\hline $\mathbf{2 4}$ & 0,67 & 0,44 & 2,65 & 0,34 & 1,99 & 0,76 & 2,87 & 0,38 & 0,21 \\
\hline $\mathbf{2 5}$ & 0,65 & 0,54 & 2,74 & 0,21 & 2,68 & 0,38 & & & \\
\hline $\mathbf{2 6}$ & 1,16 & 0,12 & 2,22 & 0,75 & 1,23 & 0,55 & & & \\
\hline $\mathbf{2 7}$ & 0,72 & 0,21 & 1,25 & 0,81 & 1,34 & 0,75 & & & \\
\hline $\mathbf{2 8}$ & 0,47 & 0,46 & 1,84 & 0,39 & 0,99 & 0,44 & & & \\
\hline $\mathbf{2 9}$ & 0,49 & 0,07 & 2,01 & 0,27 & 1,68 & 0,87 & & & \\
\hline $\mathbf{3 0}$ & 0,56 & 0,22 & 2,25 & 0,41 & 1,86 & 0,97 & & & \\
\hline
\end{tabular}


Fortsetzung Tab. E-15

\begin{tabular}{|c|c|c|c|c|}
\hline \multirow[b]{3}{*}{ n } & \multicolumn{4}{|c|}{ Variante 10} \\
\hline & \multicolumn{2}{|c|}{ Container 1} & \multicolumn{2}{|c|}{ Container 2} \\
\hline & „Kontrolle“6 & „,Kontrolle-Nachbar“ & ,A. alni-Fraß ${ }^{66}$ & ,A. alni-Nachbar \\
\hline 1 & 4,11 & 3,28 & 0,04 & 2,60 \\
\hline 2 & 3,55 & 3,65 & 0,84 & 2,41 \\
\hline 3 & 3,17 & 4,12 & 1,04 & 3,11 \\
\hline 4 & 4,21 & 3,21 & 0,23 & 2,03 \\
\hline 5 & 3,49 & 3,74 & 2,90 & 2,17 \\
\hline 6 & 4,33 & 3,58 & 1,50 & 1,52 \\
\hline 7 & 3,85 & 3,84 & 0,63 & 1,85 \\
\hline 8 & 3,92 & 3,66 & 0,44 & 2,33 \\
\hline 9 & 3,52 & 4,65 & 3,22 & 1,92 \\
\hline 10 & 2,86 & 3,32 & 1,55 & 1,68 \\
\hline 11 & 3,51 & 4,72 & 0,53 & 1,57 \\
\hline 12 & 3,94 & 3,57 & 0,17 & 1,49 \\
\hline 13 & 4,25 & 3,86 & 0,85 & 0,25 \\
\hline 14 & 3,97 & 3,79 & 0,06 & 1,23 \\
\hline 15 & 3,29 & 2,92 & 0,19 & 1,42 \\
\hline 16 & 3,19 & 1,42 & 0,45 & 1,60 \\
\hline 17 & 2,17 & 2,61 & 0,86 & 1,36 \\
\hline 18 & 2,31 & 1,93 & 0,41 & 0,64 \\
\hline 19 & 2,84 & 2,81 & 0,24 & 1,65 \\
\hline 20 & 2,24 & 4,01 & 1,61 & 1,12 \\
\hline 21 & 2,25 & 3,52 & 0,53 & 2,35 \\
\hline 22 & 2,65 & 2,50 & 0,39 & 2,60 \\
\hline 23 & 3,47 & 3,13 & 1,20 & 1,17 \\
\hline 24 & 2,20 & 2,74 & 0,13 & 1,20 \\
\hline 25 & 2,53 & 2,81 & 0,63 & 1,48 \\
\hline 26 & 3,86 & 4,05 & 0,33 & 1,57 \\
\hline 27 & 3,93 & 3,01 & 0,11 & 2,51 \\
\hline 28 & 3,83 & 4,61 & 0,32 & 1,12 \\
\hline 29 & 4,58 & 4,20 & 0,37 & 1,41 \\
\hline 30 & 4,39 & 4,06 & 0,73 & 1,91 \\
\hline 31 & 3,32 & 2,79 & 0,60 & 1,55 \\
\hline 32 & 4,60 & 4,50 & 3,79 & 2,00 \\
\hline 33 & 2,64 & 2,87 & 0,03 & 1,32 \\
\hline 34 & 3,09 & 4,65 & 0,03 & 1,09 \\
\hline 35 & 3,12 & 3,58 & 0,23 & 1,60 \\
\hline
\end{tabular}


Fortsetzung Tab. E-15

\begin{tabular}{|c|c|c|c|c|}
\hline \multirow[b]{3}{*}{$\mathbf{n}$} & \multicolumn{4}{|c|}{ Variante 11} \\
\hline & \multicolumn{2}{|c|}{ Container 1} & \multicolumn{2}{|c|}{ Container 2} \\
\hline & „Kontrolle“6 & „Kontrolle-Nachbar & ,A. alni-Fraß6" & ,A. alni-Nachbar \\
\hline 1 & 4,17 & 4,07 & 0,34 & 1,26 \\
\hline 2 & 3,15 & 4,15 & 0,33 & 1,45 \\
\hline 3 & 3,82 & 2,07 & 0,61 & 1,50 \\
\hline 4 & 3,42 & 2,83 & 1,18 & 1,23 \\
\hline 5 & 2,32 & 2,53 & 0,98 & 1,94 \\
\hline 6 & 2,59 & 2,96 & 0,81 & 1,80 \\
\hline 7 & 2,41 & 2,96 & 0,92 & 1,99 \\
\hline 8 & 2,51 & 2,61 & 0,27 & 1,17 \\
\hline 9 & 2,73 & 2,78 & 0,55 & 2,52 \\
\hline 10 & 3,24 & 3,32 & 0,10 & 2,15 \\
\hline 11 & 3,05 & 4,05 & 0,42 & 2,16 \\
\hline 12 & 2,97 & 2,96 & 0,72 & 2,41 \\
\hline 13 & 4,29 & 4,04 & 1,47 & 2,72 \\
\hline 14 & 3,51 & 2,67 & 0,55 & 1,37 \\
\hline 15 & 2,97 & 3,70 & 1,03 & 3,36 \\
\hline 16 & 3,37 & 2,28 & 0,42 & 1,84 \\
\hline 17 & 2,01 & 2,94 & 0,11 & 1,92 \\
\hline 18 & 3,08 & 4,04 & 0,76 & 1,77 \\
\hline 19 & 2,13 & 2,61 & 0,16 & 0,63 \\
\hline 20 & 3,59 & 2,23 & 1,19 & 2,22 \\
\hline 21 & 2,71 & 3,41 & 0,88 & 2,14 \\
\hline 22 & 2,49 & 2,88 & 0,75 & 2,09 \\
\hline 23 & 2,24 & 2,56 & 1,35 & 2,58 \\
\hline 24 & 2,31 & 2,69 & 0,03 & 1,99 \\
\hline 25 & 2,53 & 2,62 & 0,99 & 1,64 \\
\hline 26 & 2,20 & 2,59 & 1,25 & 2,17 \\
\hline 27 & 2,69 & 3,02 & 1,65 & 2,29 \\
\hline 28 & 2,88 & 2,69 & 1,04 & 2,15 \\
\hline 29 & 2,20 & 2,82 & 0,46 & 1,83 \\
\hline 30 & 3,56 & 3,27 & 1,47 & 1,36 \\
\hline 31 & 3,23 & 3,20 & 0,88 & 0,38 \\
\hline 32 & 2,16 & 1,74 & 0,74 & 1,26 \\
\hline 33 & 1,50 & 1,83 & 1,03 & 1,50 \\
\hline 34 & 2,31 & 2,17 & 0,31 & 0,93 \\
\hline 35 & 2,81 & 2,18 & 0,47 & 0,68 \\
\hline
\end{tabular}


Tab. E-16: Zusammenfassung der Daten der endogenen Jasmon (JA)- und Salicylsäurebestimmung (SA) an Alnus glutinosa-Blättern. Angegeben sind die ermittelten Konzentrationen von JA (ng g $\left.{ }^{-1} \mathrm{FW}\right)$ und SA (ng $\mathrm{g}^{-1} \mathrm{FW}$ ) zu bestimmten Zeitpunkten der mit Herbivoren besetzten Blättern (Agelastica alniFraß) und der unbehandelten Blätter (Kontrolle). FW = Frischgewicht. ,-,,= keine Probennahme. Berechnet wurden der Mittelwert und der Standardfehler des Mittelwerts (Stdf) der einzelnen Versuchswiederholungen $(n=4$, Ausnahme bei Versuchsdauer $t=0$ h: $n=5)$.

\begin{tabular}{|c|c|c|c|c|c|}
\hline \multirow[t]{2}{*}{$\begin{array}{l}\text { Versuchs- } \\
\text { dauer [h] }\end{array}$} & \multirow[t]{2}{*}{ Uhrzeit } & \multicolumn{2}{|c|}{ Kontrolle } & \multicolumn{2}{|c|}{ Herbivorenfraß } \\
\hline & & $\begin{array}{l}\text { SA-Gesamtgehalt } \\
\left(\operatorname{ng~g~}^{-1} \text { FW) }\right.\end{array}$ & $\begin{array}{c}\text { JA-Gesamtgehalt } \\
\text { (ng g }{ }^{-1} \text { FW) }\end{array}$ & $\begin{array}{l}\text { SA-Gesamtgehalt } \\
\left(\mathrm{ng} \mathrm{g}^{-1} \mathrm{FW}\right)\end{array}$ & $\begin{array}{c}\text { JA-Gesamtgehalt } \\
\text { (ng g }{ }^{-1} \text { FW) }\end{array}$ \\
\hline 0 & $9^{\underline{00}}$ & 454,02 & 18,57 & 834,10 & 18,57 \\
\hline 0 & $9 \underline{00}$ & 351,34 & 11,71 & 865,39 & 19,57 \\
\hline 0 & $9^{\underline{00}}$ & 543,93 & 17,40 & 796,52 & 18,41 \\
\hline 0 & $9^{\underline{00}}$ & 703,5 & 11,211 & 879,17 & 16,27 \\
\hline 0 & $9^{\underline{00}}$ & 666,86 & 12,12 & 994,80 & 19,55 \\
\hline \multicolumn{2}{|c|}{ Mittelwert \pm Stdf } & $543,93 \pm 65,47$ & $14,20 \pm 1,56$ & $873,99 \pm 33,38$ & $18,47 \pm 0,61$ \\
\hline 1 & $10^{00}$ & 626,23 & 15,34 & 1003,67 & 39,84 \\
\hline 1 & $10 \stackrel{00}{0}$ & 543,55 & 24,28 & 1115,21 & 26,21 \\
\hline 1 & $10^{00}$ & 706,31 & 10,53 & 1227,67 & 34,25 \\
\hline 1 & $10^{00}$ & 666,86 & 38,023 & 1004,30 & 18,16 \\
\hline \multicolumn{2}{|c|}{ Mittelwert \pm Stdf } & $635,74 \pm 34,80$ & $22,04 \pm 6,04$ & $1087,72 \pm 53,51$ & $29,62 \pm 4,73$ \\
\hline 2 & $11 \underline{00}$ & 444,53 & 76,64 & 810,23 & 99,67 \\
\hline 2 & $11 \frac{00}{1}$ & 402,68 & 86,91 & 665,82 & 87,24 \\
\hline 2 & $11 \underline{00}$ & 454,02 & 80,63 & 786,99 & 82,71 \\
\hline 2 & $11 \underline{00}$ & 413,14 & 64,78 & 742,207 & 89,6 \\
\hline \multicolumn{2}{|c|}{ Mittelwert \pm Stdf } & $454,02 \pm 12,28$ & $86,91 \pm 4,65$ & $810,23 \pm 31,80$ & $98,80 \pm 3,58$ \\
\hline 2,5 & $11 \frac{30}{-}$ & 669,19 & 88,36 & 673,55 & 128,71 \\
\hline 2,5 & $11 \stackrel{30}{\underline{3}}$ & 559,09 & 93,74 & 722,9 & 125,99 \\
\hline 2,5 & $11 \stackrel{30}{-}$ & 544,531 & 94,15 & 669,18 & 103,15 \\
\hline 2,5 & $11 \stackrel{30}{-}$ & 573,64 & 82,71 & 776,61 & 102,71 \\
\hline \multicolumn{2}{|c|}{ Mittelwert \pm Stdf } & $586,61 \pm 28,16$ & $89,74 \pm 2,69$ & $710,56 \pm 25,16$ & $115,14 \pm 7,07$ \\
\hline 3 & $12 \underline{00}$ & 454,02 & 103,74 & 776,45 & 148,55 \\
\hline 3 & $12^{\underline{00}}$ & 669,18 & 94,78 & 828,75 & 162,06 \\
\hline 3 & $12 \underline{00}$ & 776,61 & 93,85 & 730,09 & 132,93 \\
\hline 3 & $12^{\underline{00}}$ & 573,64 & 87,71 & 770,49 & 120,13 \\
\hline \multicolumn{2}{|c|}{ Mittelwert \pm Stdf } & $618,37 \pm 68,69$ & $95,02 \pm 3,30$ & $776,45 \pm 20,24$ & $141,05 \pm 9,23$ \\
\hline 5,5 & $14 \stackrel{30}{30}$ & 981,48 & 83,93 & 1078,12 & 626,20 \\
\hline 5,5 & $14 \stackrel{30}{2}$ & 1174,75 & 95,33 & 1470,45 & 402,29 \\
\hline 5,5 & $14 \stackrel{30}{2}$ & 623,25 & 127,83 & 1181,34 & 572,40 \\
\hline 5,5 & $14^{30}$ & 510,81 & 117,35 & 1293,31 & 638,30 \\
\hline \multicolumn{2}{|c|}{ Mittelwert \pm Stdf } & $822,58 \pm 154,43$ & $106,11 \pm 10,02$ & $1255,81 \pm 83,96$ & $559,80 \pm 54,42$ \\
\hline 6 & $15^{00}$ & - & - & 1379,81 & 826,45 \\
\hline 6 & $15^{00}$ & - & - & 1047,75 & 707,24 \\
\hline 6 & $15^{00}$ & - & - & 1744,86 & 703,15 \\
\hline 6 & $15^{00}$ & - & - & 1644,71 & 776,62 \\
\hline \multicolumn{2}{|c|}{ Mittelwert \pm Stdf } & & & $1454,28 \pm 155,86$ & $753,37 \pm 29,62$ \\
\hline
\end{tabular}


Fortsetzung Tab. E-16

\begin{tabular}{|c|c|c|c|c|c|}
\hline \multirow{2}{*}{$\begin{array}{l}\text { Versuchs- } \\
\text { dauer [h] }\end{array}$} & \multirow[t]{2}{*}{ Uhrzeit } & \multicolumn{2}{|c|}{ Kontrolle } & \multicolumn{2}{|c|}{ Herbivorenfraß } \\
\hline & & $\begin{array}{c}\text { SA-Gesamtgehalt } \\
\text { (ng g }{ }^{-1} \text { FW) }\end{array}$ & $\begin{array}{c}\text { JA-Gesamtgehalt } \\
\text { (ng g }{ }^{-1} \text { FW) }\end{array}$ & $\begin{array}{l}\text { SA-Gesamtgehalt } \\
\left(\text { ng g }^{-1} \mathrm{FW}\right)\end{array}$ & $\begin{array}{c}\text { JA-Gesamtgehalt } \\
\left(\text { ng g }^{-1} \text { FW) }\right.\end{array}$ \\
\hline 7,5 & $16^{30}$ & - & - & 2009,63 & 1349,73 \\
\hline 7,5 & $16^{30}$ & - & - & 2133,11 & 1837,14 \\
\hline 7,5 & $16^{30}$ & - & - & 2256,57 & 1905,03 \\
\hline 7,5 & $16^{\underline{30}}$ & - & - & 1985,64 & 1348,51 \\
\hline \multicolumn{2}{|c|}{ Mittelwert \pm Stdf } & & & $2096,24 \pm 62,44$ & $1610,10 \pm 151,31$ \\
\hline 9 & $18^{\underline{00}}$ & 429,73 & 88,63 & 622,37 & 155,72 \\
\hline 9 & $18^{\underline{00}}$ & 387,88 & 69,99 & 597,16 & 161,75 \\
\hline 9 & $18^{\underline{00}}$ & 322,93 & 94,18 & 793,48 & 115,40 \\
\hline 9 & $18^{\underline{00}}$ & 359,50 & 72,19 & 771,57 & 135,51 \\
\hline \multicolumn{2}{|c|}{ Mittelwert \pm Stdf } & $375,02 \pm 22,56$ & $81,24 \pm 5,99$ & $696,15 \pm 50,33$ & $142,10 \pm 10,52$ \\
\hline 10,5 & $19^{\underline{30}}$ & 1106,02 & 97,25 & 1536,91 & 164,22 \\
\hline 10,5 & $19^{\underline{30}}$ & 808,44 & 69,71 & 1971,82 & 195,33 \\
\hline 10,5 & $19^{30}$ & 589,82 & 54,34 & 1095,82 & 306,80 \\
\hline 10,5 & $19^{\underline{30}}$ & 581,82 & 45,53 & 1212,99 & 556,96 \\
\hline \multicolumn{2}{|c|}{ Mittelwert \pm Stdf } & $771,53 \pm 123,23$ & $66,71 \pm 11,33$ & $1454,39 \pm 196,08$ & $305,83 \pm 89,13$ \\
\hline 12 & $21 \underline{00}$ & 398,84 & 52,97 & 1295,77 & 120,44 \\
\hline 12 & $21 \underline{00}$ & 1008,57 & 66,68 & 1055,19 & 126,61 \\
\hline 12 & $21 \underline{00}$ & 1026,90 & 35,80 & 998,08 & 93,74 \\
\hline 12 & $21 \underline{00}$ & 668,21 & 43,94 & 1075,33 & 153,79 \\
\hline \multicolumn{2}{|c|}{ Mittelwert \pm Stdf } & $775,63 \pm 150,25$ & $64,12 \pm 13,82$ & $1106,09 \pm 65,30$ & $3123,65 \pm 12,32$ \\
\hline 15 & $24 \stackrel{00}{0}$ & 926,12 & 37,61 & 11117,22 & 99,43 \\
\hline 15 & $24 \stackrel{00}{-}$ & 967,35 & 11,60 & 13573,45 & 150,23 \\
\hline 15 & $24 \stackrel{00}{-}$ & 793,84 & 106,29 & 19440,26 & 139,16 \\
\hline 15 & $24 \stackrel{00}{-}$ & 689,73 & 132,74 & 10026,90 & 204,99 \\
\hline \multicolumn{2}{|c|}{ Mittelwert \pm Stdf } & $844,26 \pm 63,42$ & $72,06 \pm 28,42$ & $13539,46 \pm 2102,10$ & $148,45 \pm 21,77$ \\
\hline 18 & 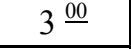 & - & - & 709,80 & 83,76 \\
\hline 18 & $3 \stackrel{00}{2}$ & - & - & 927,11 & 62,76 \\
\hline 18 & $3^{\underline{00}}$ & - & - & 777,99 & 56,88 \\
\hline 18 & $3^{\underline{00}}$ & - & - & 804,30 & 63,25 \\
\hline \multicolumn{2}{|c|}{ Mittelwert \pm Stdf } & & & $804,80 \pm 45,37$ & $66,66 \pm 5,88$ \\
\hline 21 & $6^{\underline{00}}$ & 609,80 & 27,02 & 723,60 & 97,89 \\
\hline 21 & $6^{00}$ & 727,11 & 19,65 & 659,37 & 69,33 \\
\hline 21 & $6^{\underline{00}}$ & 577,99 & 12,37 & 835,00 & 65,57 \\
\hline 21 & $6^{00}$ & 504,30 & 19,68 & 945,98 & 107,50 \\
\hline \multicolumn{2}{|c|}{ Mittelwert \pm Stdf } & $604,80 \pm 46,37$ & $19,68 \pm 2,99$ & $790,99 \pm 63,13$ & $85,07 \pm 10,39$ \\
\hline 24 & $9^{\underline{00}}$ & 876,25 & 1,51 & 1518,93 & 105,54 \\
\hline 24 & $9 \underline{00}$ & 704,88 & 6,99 & 1417,56 & 84,22 \\
\hline 24 & $9^{\underline{00}}$ & 707,97 & 21,59 & 1044,22 & 88,69 \\
\hline 24 & 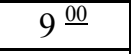 & 674,58 & 12,30 & 1590,28 & 101,30 \\
\hline \multicolumn{2}{|c|}{ Mittelwert \pm Stdf } & $740,92 \pm 45,73$ & $10,60 \pm 4,27$ & $1392,75 \pm 121,45$ & $94,94 \pm 5,05$ \\
\hline
\end{tabular}


Fortsetzung Tab. E-16

\begin{tabular}{|c|c|c|c|c|c|}
\hline \multirow{2}{*}{$\begin{array}{l}\text { Versuchs- } \\
\text { dauer [h] }\end{array}$} & \multirow[t]{2}{*}{ Uhrzeit } & \multicolumn{2}{|c|}{ Kontrolle } & \multicolumn{2}{|c|}{ Herbivorenfraß } \\
\hline & & \begin{tabular}{|c|} 
SA-Gesamtgehalt \\
$\left(\mathrm{ng} \mathrm{g}^{-1}\right.$ FW)
\end{tabular} & $\begin{array}{c}\text { JA-Gesamtgehalt } \\
\left(\text { ng g }^{-1} \text { FW) }\right.\end{array}$ & $\begin{array}{c}\text { SA-Gesamtgehalt } \\
\left(\text { ng g }^{-1} \text { FW) }\right.\end{array}$ & $\begin{array}{c}\text { JA-Gesamtgehalt } \\
\left(\mathrm{ng} \mathrm{g}^{-1} \mathrm{FW}\right)\end{array}$ \\
\hline 27 & $12^{\underline{00}}$ & 1040,03 & 13,55 & 1493,88 & 257,75 \\
\hline 27 & $12^{\frac{00}{2}}$ & 841,36 & 19,69 & 1623,22 & 152,15 \\
\hline 27 & $12 \underline{00}$ & 782,31 & 13,64 & 3616,33 & 167,96 \\
\hline 27 & $12^{\underline{00}}$ & 855,64 & 28,94 & 4980,28 & 272,36 \\
\hline \multicolumn{2}{|c|}{ Mittelwert \pm Stdf } & $879,84 \pm 55,70$ & $18,95 \pm 3,62$ & $2928,43 \pm 838,89$ & $212,55 \pm 30,63$ \\
\hline 30 & $15^{00}$ & - & - & 729,35 & 150,60 \\
\hline 30 & $15^{00}$ & - & - & 579,09 & 167,52 \\
\hline 30 & $15^{\underline{00}}$ & - & - & 709,07 & 138,41 \\
\hline 30 & $15^{00}$ & - & - & 629,58 & 179,88 \\
\hline \multicolumn{2}{|c|}{ Mittelwert \pm Stdf } & & & $661,77 \pm 34,97$ & $159,10 \pm 9,14$ \\
\hline 33 & $18^{\underline{00}}$ & 468,91 & 29,63 & 588,91 & 161,09 \\
\hline 33 & $18^{\underline{00}}$ & 367,84 & 29,47 & 677,84 & 182,48 \\
\hline 33 & $18^{\underline{00}}$ & 478,046 & 15,97 & 791,31 & 117,35 \\
\hline 33 & $18^{00}$ & 519,88 & 18,95 & 812,69 & 132,43 \\
\hline \multicolumn{2}{|c|}{ Mittelwert \pm Stdf } & $45,67 \pm 32,24$ & $23,50 \pm 3,54$ & $776,80 \pm 52,13$ & $148,33 \pm 14,55$ \\
\hline 36 & $21 \underline{00}$ & - & - & 1268,61 & 246,82 \\
\hline 36 & $21 \stackrel{00}{0}$ & - & - & 576,76 & 309,08 \\
\hline 36 & $21 \stackrel{00}{0}$ & - & - & 559,27 & 346,10 \\
\hline 36 & $21 \underline{00}$ & - & - & 764,83 & 122,27 \\
\hline \multicolumn{2}{|c|}{ Mittelwert \pm Stdf } & & & $792,37 \pm 165,42$ & $256,07 \pm 49,07$ \\
\hline 39 & $24 \underline{00}$ & 548,75 & 41,31 & 636,98 & 230,54 \\
\hline 39 & $24 \underline{00}$ & 344,97 & 12,59 & 861,3 & 168,74 \\
\hline 39 & $24 \stackrel{00}{0}$ & 446,86 & 26,95 & 516,49 & 198,80 \\
\hline 39 & $24^{00}$ & 368,78 & 38,67 & 532,94 & 138,70 \\
\hline \multicolumn{2}{|c|}{ Mittelwert \pm Stdf } & $427,34 \pm 45,95$ & $29,88 \pm 6,55$ & $636,93 \pm 79,40$ & $184,19 \pm 19,72$ \\
\hline 45 & $6 \underline{00}$ & - & - & 755,54 & 331,33 \\
\hline 45 & $6^{00}$ & - & - & 655,39 & 362,80 \\
\hline 45 & $6^{\underline{00}}$ & - & - & 651,16 & 452,19 \\
\hline 45 & $6^{\underline{00}}$ & - & - & 818,80 & 299,86 \\
\hline \multicolumn{2}{|c|}{ Mittelwert \pm Stdf } & & & $720,22 \pm 40,76$ & $361,55 \pm 32,83$ \\
\hline 48 & $9^{\underline{00}}$ & 412,71 & 45,19 & 484,64 & 993,40 \\
\hline 48 & $9^{00}$ & 675,33 & 19,05 & 574,19 & 571,43 \\
\hline 48 & $9 \underline{00}$ & 703,59 & 25,27 & 923,05 & 794,01 \\
\hline 48 & $9 \stackrel{00}{-}$ & 510,22 & 33,19 & 594,18 & 353,26 \\
\hline \multicolumn{2}{|c|}{ Mittelwert \pm Stdf } & $575,46 \pm 69,01$ & $30,67 \pm 5,63$ & $644,02 \pm 96,01$ & $678,03 \pm 138,37$ \\
\hline 50 & $11 \underline{00}$ & 655,39 & 18,42 & 2967,89 & 402,85 \\
\hline 50 & $11 \stackrel{00}{-}$ & 451,16 & 10,59 & 1203,16 & 260,02 \\
\hline 50 & $11 \stackrel{00}{\underline{0}}$ & 618,26 & 25,16 & 883,17 & 670,19 \\
\hline 50 & $11 \stackrel{00}{-}$ & 688,98 & 11,98 & 1159,12 & 353,26 \\
\hline \multicolumn{2}{|c|}{ Mittelwert \pm Stdf } & $603,45 \pm 52,77$ & $16,54 \pm 3,34$ & $1553,34 \pm 476,80$ & $421,58 \pm 87,99$ \\
\hline
\end{tabular}




\section{Danksagung}

Herrn Prof. Dr. Teja Tscharntke danke ich für die Anregung und Betreuung meiner Arbeit in Göttingen. Durch seine stete Diskussions- und Hilfsbereitschaft konnten auftretende Probleme schnell geklärt werden.

Ich danke Herrn Prof. Dr. Wilhelm Boland vom Max-Planck-Institut für Chemische Ökologie (Jena) für seine Kooperationsbereitschaft und Unterstützung, ohne die die Anfertigung der Arbeit in diesem Rahmen unmöglich gewesen wäre.

Herrn Prof. Dr. Matthias Schaefer danke ich für die Übernahme des Referats.

Der Hessischen Landesanstalt für Forsteinrichtung, Waldforschung und Waldökologie (Hann. Münden) sage ich Dank für die Bereitstellung des Erlenmaterials.

Mein Dank gilt sowohl den jenensischen Laborkollegen als auch den Mitgliedern des Göttinger Lehrstuhls für das angenehme Arbeitsklima und ihre ständige Hilfsbereitschaft.

Mein besonderer Dank gilt

- Anja Biedermann für ihre Mithilfe bei den Phytohormonbestimmungen und Angelika Berg für die Betreuung der Erlenpflanzen und Erlenblattkäfer

- Dieter Spiteller für seine stete Einsatzbereitschaft, die anregenden Gespräche und die Mithilfe bei den chemischen Untersuchungen des Larvenregurgitats

- Susanne Schiele, Jan Hattendorf und Clemens Ostrowicz für ihre Mithilfe bei verschiedenen Laborversuchen

- PD. Dr. Frank Kühnemann für die PAS-Messungen

- Susan Kutschbach, Karin Mengele, Dr. Thomas Paululat, Dr. Stefan Peter, Dr. Bettina Schmitt, Oliver Wittig für ihre tatkräftige Unterstützung beim Gelingen dieser Arbeit

Schließlich danke ich meinen Eltern und Dr. phil. Gerhard Koß (Weiden i. d. Opf.), die durch ihre großartige ideelle und finanzielle Unterstützung mein Biologiestudium und damit diese Arbeit ermöglicht haben. 


\section{Erklärung}

Hiermit erkläre ich, daß ich die vorliegende Arbeit selbständig verfaßt und keine anderen als die von mir angegebenen Quellen und Hilfsmittel verwendet habe.

Weiterhin erkläre ich, daß ich mich an keiner anderen Universität um einen Doktorgrad beworben habe.

Göttingen, im September 2001

(Sabine Anke Thießen) 


\section{Vorträge und Publikationen}

- Conference: „Chemical Ecology in the Molecular Age” vom 05.04. - 07. 04.1998 in Jena, Posterpräsentation

- Pflanzenschutztagung vom 05.10. - 08.10.1998 in Halle/Saale: Vortrag mit dem Titel: Gibt es „talking trees”? - Charakterisierung flüchtiger Komponenten geschädigter Schwarzerlen

- Thießen, S.; Tscharntke, T.; Boland, W. (1998) Gibt es „talking trees”? Charakterisierung flüchtiger Komponenten geschädigter Schwarzerlen. Mitteilungen an das Biologische Bundesamt, H. 357, p- 336-337.

- GfÖ-Tagung vom 13.09. - 18.09.1999 in Bayreuth: Thießen, S.; Tscharntke, T.; Boland, W. (1999) „Talking trees”? - Die Charakterisierung flüchtiger Komponenten geschädigter Schwarzerlen. Posterpräsentation

- Arbeitstagung der Arbeitskreise Parasitoide und Pflanze/Insekt (DGaaE): Symposium Multitrophische Interaktionen zwischen Pflanzen, Mikroorganismen und Insekten vom 31.01. - 01.04.2000 in Göttingen. Vortrag mit dem Titel: Veränderungen im Stoffwechsel der Schwarzerle Alnus glutinosa nach Herbivorenschädigung und verschiedenen Behandlungen mit chemischen Induktoren.

- Tscharntke, T., Thießen, S., Dolch, R., Boland, W. (2001): Herbivory, induced resistance, and interplant signal transfer in Alnus glutinosa. Biochemical Systematics and Ecology 29:1025-1047. 


\section{Lebenslauf}

Name:

Geburtsdatum:

Eltern:

Schulausbildung

1975 - 1979

$1979-1981$

$1981-1988$

Studium

$1988-1995$

$1997-2001$

Berufstätigkeiten
Sabine Anke Thießen

09.03.1969 in Wilhelmshaven

Lehrer i.R. Uwe Thießen

Lehrerin Rosemarie Thießen, geb. Eich

Grundschule Hafenstraße, Nordenham

Orientierungsstufe-Mitte, Nordenham

Besuch des Gymnasiums Nordenham, Abschluß: Abitur

Studium der Biologie an der Universität Bayreuth. Diplomarbeit bei Prof. Dr. Konrad Dettner (Tierökologie): „Die Bedeutung des Naturstoffes Cantharidin für die Biologie und Ökologie von Notoxus monoceros (L.) (Coleoptera: Anthicidae)“. Abschluß: Dipl. Biologin

Wissenschaftliche Mitarbeiterin am Lehrstuhl Agrarökologie, Universität Göttingen, Prof. Dr. Teja Tscharntke. Anfertigung der Promotionsarbeit. Kooperation und Versuchsdurchführungen am MPI für Chemische Ökologie, Jena, Abteilung Bioorganik bei Prof. Dr. Wilhelm Boland.

Praktikantin in der Obstbauversuchsanstalt Jork (12.08.20.09.1991) (Landwirtschaftskammer Hannover)

Wissenschaftliche Hilfskraft im DFG-Projekt „Ausbreitungsmechanismen“ der Universität Bayreuth im National Reservat „Shimba Hills“, Kenia (04.08.1995 03.02.1996)

Aushilfskraft im Amt für Landwirtschaft und Ernährung, Bayreuth (15.04.-31.07.1996)

Wissenschaftliche Technische Mitarbeiterin in der Abteilung Bioorganik bei Prof. Dr. Wilhelm Boland (MPI für Chemische Ökologie, Jena) (01.05.1999-30.09.1999) 